

Toum Diredor A. Raddatis

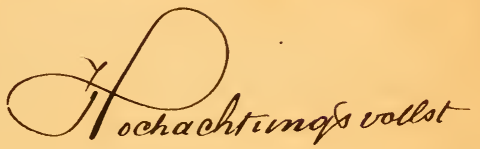

des

cresfawer. 


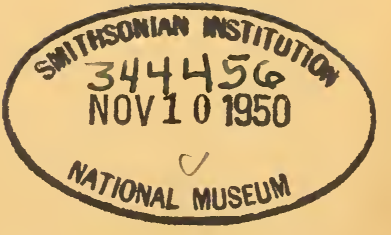




\section{Beschreibung sechs nener Dipteren-Arten.}

Von

\section{Ferdinand $\underset{\% \text {, }}{\text { Kowarz. }}$}

Vorgelegt in der Sitzung vom 6. März 1867. ।

\section{Porphyrops longilamellatus $\mathrm{n} . \mathrm{sp} \cdot \sigma^{\circ}$.}

Dunkelmetallischgriin; am Rückenschilde mit zwei bis hinter die Mitte reichenden dunklen Längsstriemen und einzelnen schwarzen Borsten; Brustseiten grau. Flügel blass gelbbräunlich tingirt, gegen die Spitze der Costalzelle hin etwas intensiver. Schiippchen und Schwinger blassgelblich, ersteres weisslich bewimpert. Hiiften schwarz, weiss bewimpert, ungedornt; Schenkel mit Ausnahme ihrer äussersten Spitzen, welche an den vorderen Paaren gelb, an den hintersten braun sind, schwarz, die vordersten unten auffallender-, die mittleren kürzer weiss bewimpert, an den hintersten aussen an der Spitze ein einzelnes schwarzes Börstchen; Vorderschienen gelb, die hintersten am Wurzeldrittel braun, sonst schwarz, alle aussen mit einer Reihe schwarzer Borsten, die mittleren überdiess auf der Innenseite nahe der Spitze mit einzelnen Borsten; Metatarsen des ersten Paares an der Spitze nach inuen etwas erweitert und so wie die des mittleren Paares gelb, die iibrigen Tarsenglieder verdunkelt, die hintersten ganz schwarz. Hinterleib wie der Rïckenschild gefärbt, mit kurzen schwarzen Haaren sparsam bekleidet, an der Basis und am Bauche weiss bewimpert, die Einschnitte sehr schmal schwarz, die Hintersäume mit kurzen schwarzen Börstchen. Hypopygium glänzend schwarz, beborstet; Analanhänge sehr auffallend gebildet; die äussern gelbbraun, sehr lang, schmal, S-förmig geschwungen und überdiess wahrscheinlich in Folge der Vertrocknung - um ihre Längenachse gedreht, an der Basis schwarz behaart, weiterhin blass - theilweise sehr 
langbewimpert (Fig. $A a$

die seitliche, Fig. $B a$

die obere Ansicht); die inneren Anlänge (Fig. $A b$ ) sind gräuz. schwarz, kiirzer, stärker, schwach gewellt und vorn schief abgeschuitten, an der Spitze mit einem kurzen Börstchen. Untergesicht
A

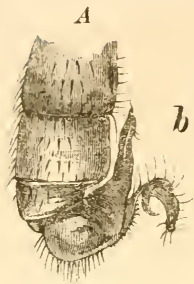

B

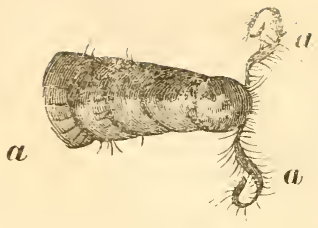

schmal, weiss schimmernd, Stirne breit, metallischblangriin. gegen den Angenrand hin weisslich bereift, am Scheitel schwarz beborstet; Fïhler ganz schwarz, die Basalglieder sehr kurz, das zweite oben mit einem lïingern, unteı mit einem kïrzeren Börstchen, das dritte Flied ziemlich gross, zweimal so lang als an der Basis breit, die endständige Borste am Grunde verdickt, länger als die Fïhler; Backenbart sehr dicht, weiss. Grösse $2 \frac{1}{2}$ ".

Diese durch die Bildung ihrer Genitalien ausgezeichnete Art fing ich im vorigen Jahr Mitte Mai bei Mährisch-Schönberg in einer grasreichen $\mathrm{Au}$ auf Blättern sitzend und hielt sie voreilig ihrer etwas verlängerten Hinterbeine wegen für $P$. crassipes $\mathrm{Mg}$., der an demselben Standorte in ziemlich reichlicher Anzahl vorhanden war.

Diese Geg*end wäre jedem Dipterologen zur sorgfältigsten Durchforschung anzuempfehlen. Während meines nur achttägigen Aufenthaltes dortselbst war ich so glücklich, an Dolichopiden allein, den oberwähuten Porphyrops crassipes M g., den Diaphorus distendens $\mathbf{M}$ g. und den Dolichopus ornatipes $\mathbf{L}$ ö w, diese für unser Faunengebiet bisher fremd gebliebenen Bürger aufzufinden.

\section{Gymnopterus comitialis n. sp. Ђ’.}

Lebhaft metallisch grïn; Rïckenschild ockergelb breit, vor der Iliigelwurzel eine sammtschwarze Makel, Brust- und llinterleibsseiten weissgrau schimmerud; schwanze Borsten stehen am Rücken auf Punktwärzchen in vier Reihen geordnet, eben solche zerstreut oben an den Brustseiten und je eine längere an den Seiten des schwach geraudeten Schildchens, auf der Mitte des Rückenschildes ïberdiess eine enge Doppelreihe sehr zarter Börstchen; die Beborstung an den Ringrsäumen des Hinterleibes ist kürzer und niederliegend. Hypopygium schwarz, weissgrau schimmernd; dic äusseren Analanhänge pflugscharförmig, an der Basis gelb, am kammartig zerschlitzten Aussenrande breit schwarzbraun; die innern Anhänge ganz gelb, kurz trapezförmig. Stime metalliseb grün, ockergelb bereift; Untergesicht goldgelb; Wimperu des hinteren Augen- 
randes gelblich weiss, gegen den Scheitel zu schwarz; Fühler kurz, Basalglieder unten gelb, oben gebräunt, das dritte Glied sclıwarzbraun, breit, stumpfwinkelig zugespitzt, kaum länger als die beiden ersten zusammen, Borste lang und pubescent. Flïgel länglich oval, vom Vorderrand zur Spitze schief gerundet, graulich tingirt, der Vorderrand scheinbar, bisweilen wirklich gelbbräunlich, was durch das Zusammendrängen der schwarzbraunen Längsaderu geschieht; Radial- und Cubitalader sehr stark genähert und fast parallel, letztere vor der Mündung abwärts geschwungen und mit der ähnlich verlaufenden Discoidalader zusammenneigend; Schwinger gelb; Schüppchen schwarz bewimpert. Vorderhüften gelb, weisslichgrau bereift, die hintern Paare von der Farbe der Brustseiten; Beborstung an den Vorderhüften am deutlichsten. Schenkel und Schienen gelb, letztere an den Hinterbeinen gegen die Spitze zu gebräunt, Vorder- und Mitteltarsen mit Ausnahme der Wurzel bräunlich. Hintertarsen schwarzbraun. Die Mittel- und Hinterschenkel tragen vorn vor der Spitze je ein Borstenhaar; die Schienen und besonders die der hintern Paare reichlich beborstet. Grösse $3-3^{1} / 2^{\prime \prime \prime}$.

Die Art steht in Form der Fühler, der Genitalien, des Flügelgeäders und in der allgemeinen Beborstung den G. regalis Löw. am nächsten, unterscheidet sich aber durch gedrungeneren Habitus, mindere Grösse und die verhältnissmässig kürzeren ungeflecktell Flïgel; mit G. ducalis Lw. kann sie der gelben Vorderhüften wegen nicht verwechselt werden.

Bei Losoncz (Tugar-Bad) auf Wasserpflanzen und Schlamm ziemlich häufig.

\section{Rhamphomyia conformis n. sp. ơ $\%$.}

Tä Rekenschild, Schildchen, Hinterrücken, Hüften, sowie der Bauch und die Hinterleibsseiten matt dunkelbläulichgrau, Hinterleibsrücken dunkler, grauschwarz, von hinten besehen mit weisslichgrau schimmernden, sehr schmalen Hinterrandssäumen; Rückenschild mit zwei entferut stehenden vorn und hinten verkürzten schwarzgrauen Striemen, auf welchen schwarze Borstenreihen stehen, zwischen beiden eine Reihe zarter Börstchen, welche wie eine dunkle Mittelstrieme sich darstellen; einzelne Börstchen zerstreut an den Schultern bis zur Flügelwurzel; am Hinterrande des Schildchens vier schwarze Borsten; Hinterleib an den Seiten des ersten und zweiten Ringes ziemlich dicht, an den Hintersäumen der übrigen Ringe nicht aufiallend behaart; die äussern Haltklappen schwärzlich, breit blattartig, einen rundlichen Raum, in welchem das unpaarige, einem starken Faden gleichende mittlere Organ kaum vorragt, umschliessend. Untergesicht und die kurze Stirne weissgrau schimmernd, Hinterkopf von der Farbe des Rückens, die langen Wimpern

Bd. XrII. Ablandl. 
au Augenrande dasellost sclıwarz; Rüssel schwarzbraun, an der Basis glänzend, seukrecht, 11/2mal so lang als der Kopf; Taster schwarz, selır kurz vorstehend, an der Spitze bewimpert; Augen auf der Stime zusammenstossend, nur den Scheitel freilassend, Punktaugen erhaben; Fülıler schwarz, Basalglieder schwarz behart, das zweite Glied fast rund, halb so lang als das erste, das dritte mehr als doppelt so lang als die beiden ersten zusammen, Griffel sehr kurz, oben weisslich schimmerud. Flügel schlank, sehr blassbräunlich tingirt, Adern schwarzbraun, an der Flügelwurzel gelblich; hintere Basalzelle unbedeutend kürzer, als die vordere, die Discoidalzelle auf der Fliigelmitte; Basis der Radialader gelb, sehr sclıwach, vor dem Ursprunge der Costalader aber plötzlich angeschwollen und schwarzbraun; Randmal braun; Schwinger blassgelb. Die schlarken Beine einfaclı, schwarz glänzend, Hüften belıart, Schenkel fast nackt und nur die vordersten, sowie auch alle Schienen bewimpert; die Beborstung der letztern an den vordersten aussen, an den mittleren aussen und innen einfach, an den hintersten nach aussen und hintell doppelt, nach inuen einfach schütter gereiht; Hintertarseu mehr als doppelt so lang, als die Schiene, Metatarsus von halber Schienenlänge.

Das $\$$ gleiclıt dem $\sigma$ in der Färbung des Körpers und Anordnung des Flïgelgeäders; an Hinterleibe sind die weisslich schimmernden Hinterrandssäume deutlicher, die Legeröhre ist kurz, schwarz; die Flügeladerı sind stärker uud verleihen dem Flügel ein dunkleres Ausseheu, die Discoidalzelle ist nicht verlängert, sondern wie beim $\sigma^{\top}$ auf der Flügelmitte. Beine wie beim ơ beschaffen. Stirne bis zum Scheitel, die Angen breit trennend, weissgrau. Grösse $23 / 4-3^{\prime \prime \prime}$.

Die Art ist an der dicken Anschwellung der Radialader, an den einfachen Beinen und an der gleichartigen Bildung der Discoidalzelle in beiden Geschlechtern sehr leicht zu erkennen.

Ich fing diese Art Anfangs April bei Losoncz auf einer Wiese, wo sie, die langen Hinterbeine herabhängend zahlreich in der Luft schwärmte, und auf naheu Büschen ausruhte.

\section{Platypeza superba 11, sp. $\sigma^{\top}$}

Rïckenschild, Schildchen und Hinterleib sammtschwarz, letzterer vom zweiten Ringe an mit schwarzgrau schimmeruden, zienlich breiten, den Seitemrand nicht erreichenden Vorderrandsbindeu, Brustseiteu und Bauch dunkelbraungrau, Afterring schwarzgrau, Rückenschild hinten seitlich vor dem Schildchen, so wie das Schildchen selbst am Rande mit schwarzeu Borsthaaren, die sonstige Behaarung an den Schultern und vor der Flïgelwurzel bïschelig, schwarz und nur an der Afterspitze goldigschimmernd. Untergesicht, Stime und Hinterkopf schwarz, Fülıler braun, Augen und Punktaugeu roth, im Tode gebräunt; Augeuhinterrand 
schwarz bewimpert. Flügel schlank, fast zugespitzt, blassgelb tiugirt, Costalzelle gesättigter; der untere Zweig der Discoidalader erreicht den Flügelrand vollständig, hintere Querader länger als das Randstïck der Posticalader, vordere Basalzelle etwas länger als die hintere, Aualzelle spitz und stark verlängert; Schwinger schwarzbraun. Hüften braun, grau schimmernd, Schenkel schwarzbraun, Schienen etwas lichter, Knie und Tarsen gelb, letztere gegen die Spitze zu etwas dunkler, die drei ersten Glieder der Hintertarsen in abnehmender Grösse erweitert, mit goldigem Tomente dicht bedeckt. Grösse stark 2“".

Ich fing ein oc im September 1866 bei Losoncz (Tugar-Bad) an einer feuchten grasreichen Stelle auf Blättern.

Von Platypeza picta M g., mit der sie im Flügelgeäder und auch in der Grösse übereinstimmt, durch die nur au der Basis gelben Fiihler, durch das schwarze Untergesicht und den ganz ungezeichneten Rückenschild zu unterscheiden.

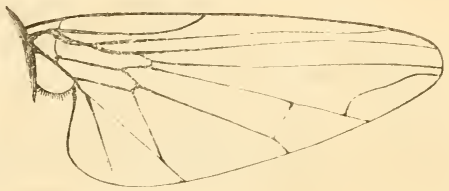

\section{Platypeza barbata ı. sp. $\precsim$.}

Rückenschild, Schildchen und Hinterleih sanmtschwarz, ersterer mit zwei bis über die Mitte reichenden einander genäherten undeutlicheı schwarzgrauen Längsstriemen, letzterer mit ebenso gefärbtem Bauche und After, Brustseiten dunkelbraungrau; die spärlichen Borstenlıaare am hinteren Theile des Rückens und Schildchens, sowie die an den Schulterecken kurz büschelartigen, vor der Flügelwurzel längeren Wimperhaare schwarz, Hinterleib besonders an den Seitell mit ziemlich dichter braunschimmernder Behaarung. Untergesicht, Stirne, Hinterkopf und Füller schwarz, Rüssel schwarzhraun, Augen braunroth, im Tode dunkler, Punktaugen glänzend schwarz; die Bewimperung am hinteren Augenraude wenig auffallend, desto mehr die an Wangen und Backen. Flügel im Umrisse keilförmig, schlank, blass gelbbräunlich tingirt, längs den Adern, sowie die Costalzelle intensiver, wodurch der Vorderrand und die Spitze wie beraucht erscheinen; der untere $\mathrm{Zweig}$ der Discoidalader erreicht den Flügelrand nicht; vordere Basalzelle doppelt so lang als die hintere und unbedeutend kïrzer als die Mediastinalzelle, Discoidalzelle fast bis zum Flügelrande erweitert, Analzelle zugespitzt, nur bis zur lıalben Läıge der Analader reichelld; Schwinger gelb. Hüften, Schenkel und Schienen dunkelbraun, erstere grau schimmernd, Knie, die äusserste Basis der Schienen und die an der Spitze verdunkelten Tarsen der Vorderbeine gelb, die drei ersten Glieder der 
Hintertarsen in abıehmender Grösse erweitert, oben dunkelbraun, unten gelb, mit dichtem goldschimmernden Tomente bedeckt. Grösse '2"“.

Sie gleicht zumeist der vorheschriebenen $P l$. superba, unterscheidet sich jedoch durch die Zeichnung am Ruicken, den Mangel der Querbinden an Hinterleib durch die gelben Schwinger und das verschiedene Flügelgeäder.

Ich entdeckte ein o

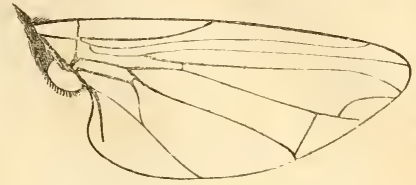
gleichzeitig und an deuselben Standorte mit der vorigen.

\section{Anthrax claripennis n. $\mathrm{sp}$.}

Schwarz, Brust, Schildchen und die vier ersten Hinterleibsringe nit goldgelblicher Behaarung, welche obenauf sehr dïnn, seitlicb dichter ist; die beiden letzten Ringe schwarz und nur der letzte an den Seiten büschelartig rein weiss behaart, der vierte Ring mit einer gelben, auf der Mitte schmalen, gegen den Seitenrand hin wenig erweiterten, aus Schuppenhärchen gebildeten Vorderrandsbinde; die beiden folgenden Ringe mit ebensolchen sehr schmalen und gleichbreiten Hinterrandssäumen. Bauch sehr sparsan behaart und die Ringzeichnungen daselbst wie gepudert, was auch am ersten Ringe wahrzunehmen; die schwarze Behaarung auf den beiden letzten Banchringen wie oben und ebenso die weisse büschelartige Behaarung vorhandell. Flügel ganz rein glashell, stark glänzend. Beine schwarz, die Schenkel und Schienen aussen sparsam, inmen dichter gläuzend, gelblichweis bepudert, die Schenkel auf der Unterseite, so wie alle Schienen mit kurzen schwarzen Dörnchen; Tarsen ohne Haftläppchen. Untergesicht mit dichter, gelber, weisslich glänzender, Stirne, Scheitel mit schwarzer kurz geschorener, nur oberhalb der Fühler - gegen den Augenrand hin gelblich schimmernder Behaarung; hinterer Augenrand silberweiss; Fiihler schwarz, in gewisser Richtung etwas fahlschimmernd; Rüssel schwarz, Taster blass, ziemlich kurz, fadenscheinig und sehr zart bewimpert. Grösse $51 / 2-6$ "“.

Sie gehört in die Gruppe von A. flava, hottentotta.

Im Betragen gleicht sie ganz dem der verwandten Arten. Ich entdeckte sie vor zwei Jahren zuerst an eimer einzigen Stelle bei Miskolcz in Hochsommer auf niederem Gebïsche und auf trockenem Wege; im J. 1866 traf ich sie wiederholt an verschiedenen Stellen unter den obgenannten Verhältnissen bei Losoncz. 


\section{Dipterologische Notizen.}

II.

Fon Ferdinand Kowarz in Losoncz.

(Aus den Verhandlungen d. k. k. zoolog.-botanischen Gesellschaft in Wien [Jahrgang 1868] besonders abgedruckt.)

Vorgelegt in der Sitzung vom 5. Febr. 1868.

1. Plesiastina annulata $\mathrm{Mg} \cdot \sigma$ und apicalis Win $\mathrm{n} . \%$. Winnertz; Verh. d. zool.-bot. Gesellsch. XVII, 670 und 671, 1 und 2.

Anfangs Mai 1867 sammelte ich im Losonczer Walde an einem schattigen Graben auf niederen Viburnumbüschen zwei copulirte Pärchen der $\mathbf{P l}$. annulata ơ mit apicalis $\%$; ein drittes eben solches Pärchen beobachtete ich in der Begattung begriffen; die übrigen nicht copulirten Stïcke gehörten im männlichen Geschlechte zu annulata, die Weibchen dagegen sämmtlich zu apicalis.

Winnertz beschreibt unter apicalis nur das $\$$ (wie wenigstens aus dem Texte hervorgeht, obwohl in der Aufschrift das Zejchen o beigefügt ist), bei annulata dagegen geschieht des $\$$ keine Erwälınung, was in seiner so unübertroffenen Monographie der Pilzmücken fast nirgends vermisst wird, - Aus Obigem folgere ich daher, dass $P$. apicalis und annulata zu ein und derselben Art gehören dürften.

\section{Limnobia pannonica n. sp. $\sigma^{7} \%$.}

Glänzend schwarz. Untergesicht sammt Schnautze, Stirne, Taster und die beiden Fïhlerbasalglieder schwarz, grau bestäubt, Scheitel und Hinterkopf glänzend; die Fühlergeiselglieder gelb, gegen ihr Ende hin verdunkelt; Halsstück verlängert und wie der Rückenschild glänzend schwarz, Brustseiten grauschimmernd, von den Schultern bis zur Flïgelbasis eine erhabene gelbliche Linie; Hinterrücken und Scluildchen gelbbraun, auf der Mitte verdunkelt; letzteres und eine kurze von diesem bis zur Quernaht reichende Strieme weiss schimmernd. Schwinger gelb. Flügel gleichmässig blassgelblich tingirt, schwarzbrauı und grnubraun fast gitterartig gefleckt, - die schwarzbraunen Flecke 
stehen an der Basis der Radialader, an der Mïndungsstelle der Mediastinalader und an der Querader, welche die Subcostal- mit der Radialader verbindet; ebensolche kleine Flecke vor dem dritten grösseren Flecke und an der Mündung der Subcosta; drei weniger intensive graubräunliche Schattentlecke in der vorderen Basalzelle und eben so viele noch, blässere am Flügelhinterrand in den letzten drei Zellen; die Adern melı. weniger braun und gran, die Flügelspitze jedoch schmal aber intensiv braungesäumt; Costal- Mediastinal- und Subcostalader gelb, alle iibrigen braun, die Mediastinalader mündet weit hinter dem Ursprunge der Radialader. Beine gelb, alle Schenkel an der Spitze breit schwarzbraun, die vordersten ïberdies: mit einem noch breiteren ebenso gefärbten Ringe nuf der Mitte; Schienen etwas dunkler gelb, an der Spitze und Basis bräunlich; alle Tarsen nit Ausmahme der äussersten Basis schwarzbraun. Hinterleib auch am Banche glänzend schwarz, mit kurzer spärlicher falılgelber Behaarung, welche den Glanz etwas ermattet. Haltklappen des $\sigma^{\nearrow}$ länglich, verdickt, an der inneren Basis rostgelb, soust schwarz, glänzend, auf der Oberseite mit sammtartiger schwarzer Behaarung, die hornigen Anhänge kurz, zahnartig, schwarz, an der Basis gleichfalls gchb; die obere Platte am Hinterleibsende rostgelb, die untere schwarz; die unparigen Aubänge vorstehend, ungleich lang, der längere gelb, der kürzere schwarz. Grösse $4-41 / \mathbf{z}^{\prime \prime \prime}$.

Das 9 gleicht dem бvollkommen; die Legeröhre mässig dick, an der Basis glänzend rostgelb, sonst schwarz; ihre Haltklappen läuglich, spitz, rostgelb. Grösse $4 \frac{1}{2}-5 “$.

feh sammelte diese Art alljälırlich im Mai im Losonczer Walde auf einer sumpfigen Wiese, wo sie mit der daselbst selı gemeinen Limnobia tripunctata häufig vorkommt.

In der äusseren Erscheinung und besonders in der Form des Flügels und Geäders der L. tripunctata F., in der Zeichnnng des Flïgels aber der L. thavipes F. sehr älınlich, doch von beiden durch die schwarze glänzende Körperfärbung und die mehr schwarzbraunen Flecke an Flïgelvorderrande verschieden.

\section{Sybistroma setosa Seluin. ?.}

Schiller; Fauna austriaca I. 224.

Mir ist erinnerlich, dass das Weibchen dieser nu Losoncz sehr häufigen Art noch nicht genügend bekaunt ist; ich beschrcibe es daher wie folgt:

Untergesicht breit, grau, silberweiss schinmernd; Fühler sehr kurz, auf der Oberseite schwarzlorau, unten rostgelb, das dritte Glied so lang als die beiden Basalglieder, unten rundlich, oben gerade zugeschuitten, wodurch rorne eine kurze Ecke entsteht; die am Grunde verdickte, rinfiche 
Borste deutlich auf der MItte des driften Fühlerglleles elugefügt und meist dem Oberrande aufliegend, was ihre Stellung - jedenfalls oberflächlich apieal erscheimen macht. Legeröhre sammt Lamellen schwarz, unter dem rundlich abgestutzten letzten Hinterleibsring verborgen. Beine einfach. Alles Uebrige - auch der Rïssel und die gelben weisslich schimuernden Taster kaum mehr vorstehend als wie beim $\delta$.

lch erkenne dieses $\mathcal{Q}$ bestimmt und sicher an der Färbuug der Fiihler und an dem schwarzbraunen Fleck auf der Oberseite der hintersten Schenkelspitze.

\section{Dolichopus Braueri Now. Q.}

Nowicki: Verhandl. d. zool.-botan. Gesellsch. XVII. 351 ऽ.

An den Uferbiischen des Schladahaches bei Franzensbad sammelte ich im Juli vorigen Jahres D. Braueri Now. in beiden Geschlechtern. Das Weibchen - bisher unbekannt - gleicht dem $\delta$ und ist an den vorberschend gelben Schienen und weissen Cilien am Augenhinterrande leicht kenntlich. Das Untergesicht ist doppelt so breit, als beim o, und mehr weissgrau; die Fïhler kïrzer; die Flïgel minder rein glashell; die Körperfarbe weniger leblaft, oft zum Olivengriinen neigend; der letzte Hinterleibsring gerade abgestutzt, Legeröhre sammt Lamellen schwarz, kurz vorragend. Alles Uebrige wie beim $\left.\sigma^{*}\right)$.

\section{Gymnopternus ministerialis 11. sp. Ђ̆.}

Metallisch griin. Untergesicht goldgelb; Stirne erzgrïn, über den Fïhlern und am Augenrande dichter gelblichgrau bereift. Fühler kurz, ganz schwarz, das dritte Glied kaum so lang als die beiden Basalglieder, kurzspitzig, mit verhältnissmässig ianger, stark pubescenter nach vorn ahgebogener Fïhlerborste, Cilien gelblichweiss, am Scheitelraude sowie die starken Stirnborsten schwarz; Palpen kurz, vorstehend und mindest an der Spitze gelbschimmerud. - Riickenschild auf der Vorderhälfte und auf den Schultern ockergelblich bestäubt, eine sclimale Mittelstrieme von der Grundfarbe freilassend; der Theil vor dem Schildchen und das gerandete Schildchen selbst kaum bereift; vor der Flïgelwurzel eine striemenartige sammtschwarze Nackel; Brustseiten lichtgraulich, die metallische Grundfarbe fleckenartig durchdringend.

Beborstung des Rückens schwarz und geordnet; an den Seiten des Schiluchens nabe vor dessen Basis je eine starke Borste. Schüppehen schmutziggelb, schwarz bewimpert; Schwinger blassgelb. Fliigel im Umrisse länglich oval, grau tingirt, an der Wurzel heller und fast gelblich; der Vorderrand besonders an der Spitzenhälfte bis zur Cubitalader

*) Es ist sehr wahrschpinlich, Ilass. wie Fe dtse he nko (Verzeichn. d. Dipt, les Muskaner Gouv.) behauptet, diese Art mit Dolichopus tibiellus zusamnenfallt. 
schwärzlichgrau - bei durchfallendem Lichte gelbbraun - gegen die Wurzel hin gelbbräunlich verwaschen; eine ähnliche dunkelgraue Säumung begleitet die Discoidalader, die hintere Querader und zmm Theil auch die Posticalader; die letztere verschwindet vor der etwas ausgekerbten Mündungsstelle am Flïgelhinterrande und ist bis zu diesem als Falte fortgesetzt; die Cubitalader ist von ihrer Mitte an weitbogig zur nicht vollkommen gerade verlaufendeu und vor der Flügelspitze müudenden Discoidalader geneigt und von dieser doppelt so weit abstehend, als von der mit ihr parallelen Radialader. Vorderhüfte im Grunde gelblich, jedoch an der äussersten Basis, Spitze uud Innenseite verwaschen bräunlich gefleckt, durchaus graulich bestäubt und daher - oberflichlich besehen - verdunkelt erscheinend; die Vorderhiiften überdiess mit kurzer, schwarzer Bewimpermng und einigen schwarzen Borsten an der Spitze; die Hinterhïften schwarzbraun, dicht grau bestäubt; Schenkel und Schienen ockergelb, die hintersten Schienen am Spitzenviertel, sowie alle Tarsenglieder mit Ausuahme des gelbbraunen vordersten Metatarsus schwarzbraun; Mittel- und Hinterschenkel vor der Spitze mit einer einzelnen abstehenden Borste; die ïbrige Beborstung an den Schienen, besonders der hinteren Paare ziemlich dicht, stark und schwarz. Die sonstige Beschaffenheit der Beine einfach; die hintersten Tarsenglieder zusammengenommen so lang als die Schiene, der Metatarsus kaum bemerkbar kürzer als das nächste Glied. - Hinterleib wie der Rückenschild gefärbt, besonders an den Seiten gelblichgrau bestäubt, mit einer Rückenlinie von der Grundfarbe und dunklen Einschnitten. Hypopygium schwarz, grau bestäubt, an den Seiten mit dunkel metallisch-grïnem Schimmer; äussere Analanlı̈̈nge spitz dreieckig, an der innern Basis gelbbräunlich, znm Rande hin in sehr ausgedehnter Weise schwarzbraun, der Rand sellsst schwarz, zerschlitzt und schwarz gewimpert; die innern Anhänge kurystumnelig, lamellenartig, gelb, gläızend. Frösse $2^{1} / 2 “$.

\% unbekannt.

Ich sammelte diese $A$ rt bei Losoncs.Tugarbad in einer sumpfigen Au auf Uferbïschen, wo sie mit $G$. reyalis $\mathrm{Mg}$. und $G$. comitialis $\mathrm{m}$. jedoch sehr selten vorkommt.

G. ministerialis steht zwischen diesen beiden genannten Arten und zeigt mit letzterer die meiste Verwandtschaft; von regalis unterscheidet er sich durch geringere Grösse, goldgelbes Untergesicht und weniger intensive Bräunung an der Spitzenhälfte des Flïgelvorderrandes; ron comitalis dagegen durch aufiallendere Flïgelzeichmmng und die Färbung der Beine, welche bei der letztgenannten etwas heller und auf den Vordertarsen und Hinterschienen ausgebreiteter gelb ist; von beiden endlich durch ganz schwarze Fïhler und verdunkelte Vorderhïften. Letztere Eigenschaften erinuern an $G$. ducalis $L$ w., dessen Vorderluiften sind jedoch "bis gegen die Spitze hin schwarzbraun." 


\section{Gymnopternus civilis n. sp. 9 .}

Metallisch grün glänzend. Untergesicht rein weiss; Stirne metallisch grïn oder blaugrïn glänzend; Fühler kurz, gelb, das dritte Glied kurzspitzig, kaum länger als die beiden Basalglieder, an der Spitze etwas gebräunt; die Fühlerborste schwarzbraun, nach vorn abgebogen, deutlich und dicht behaart; Cilien weiss, Stiruborsten schwarz. Rü ckenschild rorne kaum etwas graulich bereift, mit einer bis zum Schildchen reichenden, kupferfarbigen breiten Strieme, vor der Flügelwurzel eine sammtschwarze längliche Makel; Brustseiten grau; Beborstung schwarz, und wie gewöhulich geordnet; vor der Schildchenbasis jederseits eine ansehnliche schwarze Randborste. Schwinger und Schüppchen fablgelb, dieses schwarz gewimpert. Flïgel lïnglich-oval, gelbbräunlich tingirt, die Spitzenhälfte des Vorderrandes bis zur Cubitalader intensiver gelbbraun zur Wurzel hin rerwaschen; die Cubitalader von ihrer Mitte an seicht-bogig zur fast gerade verlaufenden und ror der Flügelspitze mündenden Discoidalader geneigt; der weiteste Abstand dieser beiden Adern doppelt so gross, als der der Radial- von der Cubitalader; der Flïgellinterrand an der Mündung:stelle der Posticalader ausgekerbt; die Discoidal- und hintere Querader undeutlich bräunlich gesäumt. Beine einfach, gelb, nur die hintersten Schienen an der Spitze und alle Tarsen brauı; sämmtliche Hüften weisslich schimmernd, die Mittellïften aussen ausgebreiteter, die hintersten nur an der änssersten Basis lichtgrau; Mittel- und Hinterschenkel vorn vor der Spitze mit einer einzelnen schwarzen absteheuden Borste; die schwarze Beborstung der Schienen an den hinteren Paaren dichter, an den Mittelschienen überdiess auf der Innenseite eine ziemlich deutliche, geordnete, dichte Reihe kurzer Wimperbörstchen, welche zwar auch an den hintersten Schienen rorhanden, jedoch minder auffallend erscheinen. Hinterleib von der Farbe des Rückenschildes, oft mit kupferfarbigem Anfluge, der mindest an den Einschnitten immer vorhanden ist; Basis und Bauch grau bestäubt; Hypopygium schwarz, grau schimmernd; die äusseren Antänge spitz dreieckig, gelb, mit nach innen verwaschenem schmal schwarzbraunem Rande, dieser zerschlitzt und schwarz bewimpert, die inneren kurzlamellig, ganz gelb. Grösse $23 / 4^{\prime \prime \prime}$.

Das $\$$ gleicht dem $\sigma^{7}$; das U'ntergesicht ist jedoch breiter und weniger rein weiss; die Bewimperung an den Mittelschienen kaum angedeutet; Legeröhre sammt Lamellen zurïckgezogelı.

Diese Art befindet sich in der Sammlung des Pester Nationalmuseums und wurde rom Herrn v. Frivaldsky im Pester Stadtwäldchen aufgefunden.

Ihre Aehnlichkeit mit den vorbesprochenen Arten ist auffallend, jedoch die Färbung des U'ntergesichtes, der Fühler, Hïften und besonders 
die mehr als bei irgund cincr ilu mahestehenden $A$ rt anfillende Bewimperung der Mittelschienen sind Merkmale, welche eine Unterscheidung sehr leicht ermöglichen.

\section{Teuchophorus pectinifer $11.5 p .0 \%$}

ơ IT torgesicht weisschimmerid; Stime mctallisch grïn, auf der Mitte schwärzlich; Fiilıler schwarz, schr kurz, mit pubesconter Riickenborste. - Räckenschild, Schildchen und Ilinterleib dunkelerzgriin, etwas gelbgraulich bercift, Beborstumg des Rückens schwarz, liurz und gereiht; Brustseiten grau. Schüppchen schwarz gewimpert und wie die Schwinger gelb; lingel blassgraulich tingirt, metallischblau glänzend, Flïgelschwiele sehr auffallend schwarz. Hïften gelb, die rordersten an der Spitze beborstet; Beine gelb, nur die Tarsen gegen ihr Fnde hin verdunkelt und die hintersten Schenkel oben an der Spitze undeutlich gebrännt; die vordersten Beine nur auf der Unterseite des Metatarsus mit l:urzer aber dichter Beborstung; die Mittelschenkel haben an der Basis nnten meist vier lange, strahlenförmig abstehende, sehr bemerkenswerthe Borsten und wie die Hinterschenkel vor der Spitze je ein zartes Börstchen, die letzteren sind kurz behaart und ungleichartig beborstet; die Mittelschienen haben aussen am ersten Drittel ein Borstenpaar, ein ebensolches innen hinter der Mitte und ein einzelnes an der Spitze, die hintersten Schienen geziert; dieselben sind mit Ausnahme ihrer l3asis rerdickt, auf ihrer lmmenseite vor der Mitte ein wenig ausgekerbt und daselbst mit einem warzenförmigen Kuötchen versehen,

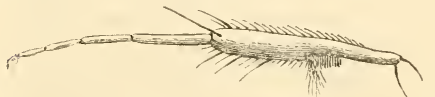

welches ron einer an Grunde desselben befindlichen, längeren, bogigen Borste ïberragt wird bei einiger Vergrösserung löst sich dieses Knötchen in einen von eng an einander gedrängten, lamellenartigen, anfänglich kurzen aber gleichlangen Wimpern gebildeten, winzigen Kamm auf, dessen Zälıne zuı Ende hin allmälig feiner und länger sich als mannigfach geschwungene Wimperhärchen darstellen, deren letzteres besonders lang und durch die nächststehenden wie verstärkt die obbesagte Borste ist - etwa am letzten Drittel dieser Sehiene gleichfalls auf der Innenseite drei einzelne, lang abstehende Borsten nach einander, aussen sind dieselben der ganzen Länge nach mit schütterer, doch nahezu zottig langer, aufstrebender Behaarung bekleidet; hinterste Tarsen länger als die Schienen, Metatarsus etwas länger als das nächste Glied. - Hypopygium eingesenkt, kaum bemerkbar vorstehend, mit kleinen, schwarzbraunen, knötchenförmigeu Anhängen. -.. Grösse $4 / 5 "$ ".

Das $\%$ hat ein etwas breiteres, weissgrames Untergesicht, noch kürzec Fühler, einfache Beine - vorderster Metatarsus und die Mittel- 
schenkel auf der Unterseite nackt, die hintersten Schienen aussen mit einer geordneten Reihe zarter Bürstchen - Flügel ohne Schwiele - mit gelbem durchschimmernden Bauch und nur kurz vorstehencle schwarze Lamellen; alles Cebrige wie beim $\sigma^{7}$.

Ich fing diese Art im Juli 1867 bei Eger unt Franzensbad in Böhmen mit $T$. spinigerellus $Z \mathrm{tt}$. $\sigma$ all Bachufern auf niederen Sumpfpflanzen, wo sie nicht selten zu sein scheint, im Juni desselben Jahres bei Losoncz ein $\sigma$ mit $T$. calcaratus $\mathbf{N}$ eq., der daselbst vorherrschend i.t.

T. pectinifer gleicht beiden genannten Arten, doch im männlichen Geschlechte an der abweichenden Bildung der Hinterschienen leicht zu erkemnen, von $\boldsymbol{T}$. monacanthus $\mathrm{Lw}$. in beiden Geschlechtem durch die Färbung der Beine. Das $\underset{q}{ }$ konnte ich mit spinigerellus $\mathbf{q}$ nicht vergleichen, dem calcarctus ist es aber so ähnlich, dass ich ausser dem Fehlen eines dem letzteren eigenen sehr zarten Borstenhärchens auf der Mitte der Innenseite der hintersten Schienen keinen haltharen Unterschied zwischen beiden zu ermittein vermochte.

\section{Sympycnus elegans Mg. ơ \%.}

Chrysolus eleguns. Meig. System. Beschr. VI. 362. 9. - Gymuoplermus eleyaus. Schin. Fauna austr. V. 21 2. Löw, Dipt. Beitr. VI. 22.

Meigen beschreibt im VI. Theile der „europäischen zweiflügeligen Insekten" einen Chrysotus eleyans, den Löw (Neue dipterolog. Beitr. V. 48 und l. c.) zur Gattung Gymnopternus stellte, wohin auch die bis dahin nur im weiblichen Geschlechte bekannte Art am natürlichsten untergebracht werden musste. Nir ist es gelungen, sie in beiden freschlechtern aufzufinden und sebe ich mich daher veranlasst, das Nothwendigste hieriiber zu ergänzen. - Der Gattung Chrysotus II g. kann hier der dursalen Stellung der Fühlerborste wegelı nicht gedacht werden; das verburgene llypopygium des Männchens geniigt, die Art auch von Gymnopternus Lw. abzutrennen. Diese Eigenschaften, ferner der von der Selte her zusamuntugedrïchte llinterleib und das Fehlen der Flïgelschwiele kennzeichnen hauptsächlich die Gattung Sympycnus L,w., von welcher S. eleylans mit Rücksicht auf die bisher in Oesterreich anfgefundenen Arten durch ungezierte Hintertarsen und zarteren Körperbau abweicht und insoferne nit Medeterus bifasciatus II c q. und Dolichopus bifasciellus Z t t. - welche identisch sein dürften - in nächster Verwandischaft stehen wird.

Untergesicht rein weiss schimmernd, unter den Fühlern am breitesten, zum Mundrande hin allmälig rerschmälert; Stirne dunkelmetallisch, mit ansehulichen schwarzen Scheitelborsten; Cilien undeutlich; Fïhler schwarzbrann, mässig laug, das dritte Glied heller bralu, läng- 
lich đreieckig zugespitzt, dicht kurzharig, mit verläıgerter, an der Basis eingefïgter, mikroskopisch pubescenter Borste; Palpen gelb, weisslich schimmernd, kurz vorragend. Rückenschild erzgrïn, sparsau aber langborstig, am Vorderrand schmal bindenartig schwärzlich, ror der Flügelwurzel mit einer verhältulssuässig grossen, sehr auffallenden, sanmtsrhwarzen rundlirhen Makel; Brustseiten grau, metallisch schimmernd; Schildchen breit gerandet, metallisch blaugrün, mit zwei schwarzen, bogig zusammenneigenden Randborsten vor der Basis. Schwinger hellgelb; Schüppchen gelblich, mit langen blassgelben Wimperharen. Fliigel in I'mrisse länglich eiförmig, blass braungraulich tingirt, am Vorderrande intensiver, die ganze Flügelfläche bläulich irisirend; Adern schwarzbraum, Cubital- und Discoidalader parallel. Beine einfach, sehr sparsam borstlich, gelb, nur die Tarsen gegen das Ende hiu braun werdend; Vorderhüften mit je zwei schwarzen Börstchen an der Spitze, alle Schenkel ebenda mit einer einzelnen abstehenden Borste, welche nur an den hinteren Paaren auffallender ist, auf der Tnterseite der Vorderschenkel eine abstehende Borste, kurz vor der Basis, Hinterschienen mit zerstrenter Beborstung; die hintersten Schienen und Tarsen fast gleicl lang, der linterste Metatarsus jedoch um beinahe ein Fünftel kürzer als das nächste Glied. Ilinterleib doppelfärbig: erster Ring metallisch grün, zweiter und dritter durchscheinend gelb, die folgenden dunkel erzgrün, alle mit schwärzlichen Einschnitten und kurzer Behaarung, welche von einzelnen längeren Borstenhärchen besonders an den Ringräudern ïberragt wird. Нypopygium sammt den äusseren Anhängen braun; ersteres halb verborgen, letztere bewimpert, länglich, verschoben dreieckig mit kurz, jedoch scharf vorstehender Ecke. Grösse 1 $1 / 4^{\prime \prime \prime}$.

\& Das Weibchen hat ein breiteres Untergesicht, mit dunkler Querlinie auf der Mitte, viel kürzere und dunklere Fühler, weiter vorragendem schwarzbraunen Rïssel und diesen in gleicher Länge deckende schwachkeulige Taster; der Hinterleib ist einfärbig metallisch gïı, am Ende gerade abgestutzt. Alles Uebrige wie beim $\sigma^{-}$. - Die Bräunung: der Hinterschenkelspitze kaum angedentet.

Ich sammelte diese Art vom Mai - September in Böhmen, Mähren und Ungarn auf niederen Sumpfpflanzen, wo sie sich - im Allgemeinen selten - mit anderen sympycnus-Arten herumtrieb.

\section{Medeterus chrysotimiformis n. sp. $\%$.}

Untergesicht vor der weisslich schimmernden Querleiste lebhaft metallisch blaugrün glänzend, ober derselben schwärzlichgrau; Stirne grau bestäubt; Fiihler sehr kurz, schwarz, mit verlängerter Endborste; Rüssel glänzendschwarz, sackartig vorstehend; Cilien gelbschimmernd, Stirnborsten schwarz. - Riickenschild, Schildchen und Hinterleib erzgrün; ersterer von gelblichgrauer Bestänbung bedeckt, ohne auffal- 
lende Striemen, mit spärlicher, haarartiger, schwarzer Beborstung; letzterer mit anliegender, sehr kurzer, gelber Behaarung, die Grundfarbe lebhafter durchdringend; Hinterleibsende gerade abgeschnitten. - Brustseiten grau, mit einigen Metallschimmer. Schwinger und Schüppchen blassgelb. Flägel im ITurisse länglichoval, die Spitze daher mehr zugerundet, blassgelblich getrïbt, mit blassgelben Adern; Radialader gerade, Cubitalader seicht bogig, vor der Flïgelspitze mündend, Discoidalader von der hinteren Querader an gerade, zur vorgehenden geneigt, verhältnissmässig weit von dieser abstehend, hinter der Flïgelspitze mündend; hintere Querader gerade, ihr Abstand vom Fliigelrande etwa um 1/4 ihrer eigenen Länge grösser. Alle Hüften schwarzbraun, grau schimmernd. Schenkel, Schienen und alle Tarsen blassgelb. Grösse $3 / 4$ "“.

Herr von Frivaldszky entdeckte diese so ausgezeichnete Art bei Ofen.

Von den verwandten, kleineren, ganz gelbbeinigen Arten besitzen M. plumbellus M g. (H. minutus Z tt.), M. flavipes $\mathrm{Mg}$. und M. gratiosus wemn hieher gehörig - ein grauweisses Untergesicht, die beiden ersteren iiberdiess gelbe Vorderhüften und anders gefärbte Fliigel; $\boldsymbol{H}$ albipes $Z \mathbf{t t}$. endlich, welchem obige Art am nächsten zu kommen scheint, hat glashelle Flügel, die Cubital- und Discoidalader parallel, die hintere Querader in der Mitte des Flïgels gelegen und ein an der Spitze gelbes Schildchen.

\section{Agculocera grisea n. sp. ळ}

ơ Kopf genau halbrund, Augen nackt; Untergesicht breit, grau, weiss bestäubt, mit seichten Fïhlerlagern und ebenem Mundrande; die kurze schwarze Bewimperung bis zum ersten Drittel des Untergesichtes reichend und von einer einzehnen, längercn Borste (Mundborste) welche ober den Mundrande steht, überragt; die Backen schmal, an der Grenze der Augenleiste rothbraun, ganz weissgrau schimmernd und kurz borstlich; Stirne nicht vorstehend, zum Scheitel hin allmälig verschmälert und daselbst etwa den vierten Theil der Koptbreite eimmehmend, Mittelstrieme sammtschwarz; die Augenleisten am Untergesicht weiss, auf der Stirne wie der Scheitel mehr gelblichgrau, doch auch da in gewisser Richtung weisschimmernd, mit einer dichten, geordneten, zusammenneigenden, bis zur Fühlerbasis reichenden Borstenreihe besetzt; Hinterkopf aschgrau, kurzhaarig, am unteren Augenrande weisschimmernd; Riissel zuriickgezogen, brann, mit breiten, rostrothen Saugflächen; Taster schwarzbraun, kurz und dünn, fast fadenförmig; Fiihler auf der Mitte des Kopfes eingefügt, schwarz, von halber Untergesichtslänge, das dritte Glied etwa $2 \frac{1}{2} \mathrm{mal}$ so lang als das beborstete zweite,

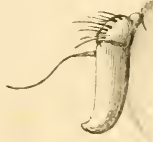
gerade, mit auffallend fast rechtwinkelig nagelartig vorstehender spitze, 
die Unterecke zugerundet; Fühlerborste schwarz, an Grunde verdickt, dann plötzlich haarfein. - Rï ckenschild schwarz glänzend, mit kurzer Beharung und längeren Borsten, aschgrau bestäubt, vorne mit den Anfängen vou vier Längslinien, deren mittlere einander genähert und nicht ganz bis zur Quermaht reichend; Schultern weiss bestäubt, Brustseiteı grauschimmernd. Schildchen wie der Rückenschild gefürbt und behaart, am Rande mit sechs symmetrisch gestellten langen Porsten. Hinterleib genau eförmig, nur am Bauche etwas abgeflacht, schwarz, überall mit aschgrauer Bestiiubung, welche die Grundfarbe an ersten Ringe, an den Ringrändern und auf der Mitte des zweiten und dritten Ringes schwach schillernd durchdringen lässt; überdiess ist der ganze Hinterleib mit schwarzen Punktwärzchen, auf welchen die kurze, niederliegende Behaarung steht, übersäet; ebensolche grössere Wärzchen sind an den Hinterrändern der einzelnen Ringe und tragen daselbst die Macrocheten, welche auch am ersten Ringe deutlich vorhanden sind. $\mathrm{schwinger}$ gelb; Schúppchen weiss und weissgerandet, das untere sehr gross. Flügel blassgraulich tingirt, zur Basis hin etwas gelblich, Discoidalader stumpfwinkelig abbengend und daun etwas bogig, der Cubitalader sehr nahe gerückt, kurz vor der Flïgelspitze mündend, die Hinterrandzelle oflen; die kleine Querader auf der Mitte der Discoidalzelle, die hintere Querader mehr bogig als geschwungen. Beine einfach, ziemlich kurz, schwarz und schwarzbeborstet; Beborstung gewölnilich: anf den vordersten Schenkeln oben und hinten, an den hinteren Paaren vorn und unten, an den schienen, besonders den hintersten, zerstreut, anf der Innenseite der Mittelschienen eine einzelne, abwärts geneigte Borsto auffallend; die vordersten Tarsen etwas länger, die hintersten dentlich kürzer als die entsprechenden Schienen. - Grösse $21 / 2$ ".

Q Fleicht im Allgeneinen dem Männchen, doch ist das Untergesicht reiner weiss und zarter bewimpert, die Stirne nimmt den dritten Theil der Kopfbreite ein, die Borsten daselbst ungeordnet; die Fühlerbasalglieder etwas grauschimmernd, das zweite Glied obeu an der Spitze gelb. Rïcken, Schildchen und IInterleib mehr weissgrau bcstäubt. Grösse stark :'“.

[ch sammelte diese Art in August 1866 bei Losoncz auf Wiesen; sie ist selten.

Die Gattungsdiagnose Macquart's passt aut die vorliegende Art; von A. nigra M cq. unterscheidet sie sich durch geringere Grösse, dichtere Bestaiubung, Fehlen der weissen Hinterleibsbinden, weisse Schïplehen und durch die höchstens bis zum ersten Drittel reichende Verdickung der Fühlerborste; von A. cineren Mik durch die Zeichnung des Riickenschildes, durch die Firbung der Fühler, Taster und Beine und durch das Flügrelgeäder.

Herausgegeben von der k. k. zool.-bot. Gesellschaft. - Druck von Carl Veberreuter (M. Silzer) in Wien. 


\section{Beitrag zur Dipteren-Fauna Ungarns.}

\section{Von \\ Ferdinand Kowarz.}

k. k. Telegraphen-Beamter in Asch.

(Aus den Verlındlungen d. k. k. zoolog.-botanischen Gesellschaft in Wien [Jahrgang 1869] besonders abgedruckt.)

Vorgelegt in der Sitzung vom 5. Mai 1869.

M einen dreijährigen Aufenthalt in Losoncz beniitzte ich - soviel es die sehr beschränkten dienstfreien Stunden meines Amtes gestatteten - zur sorgfältigen Durchforschung der dortigen Dipteren-Fauna. Obwohl ich meine Excursionen nur auf die allernäclıste Umgebung von losoncz ausdehnen konnte, so bot diese doch allen Bedingungen des Sammelns entsprechende Plätze, unter denen ich den Losonczer Wald, den sogenannten alten Graben, Losonc\%-Bad, Tugar-Bad und die nahe an Tugar an Wege mach Miksi gelegene Puszta besonders erwähne. Durch die gefälligeu Bemühungen des Herm Dr. Pantotschek in Zlatno und meines Freundes $\mathrm{Kunszt}$ in Losoncz erhielt ich so manche werthvolle Bereicherung.

Das nachstehende Verzeichniss ist weit entfernt, auch nur annähernd erschöpfend zu sein; demnoch finde ich mich zu dessen Verïfentlichuug veranlasst, theils um auf die Reichhaltigkeit und auf das Anziehende dieses Faunengebietes hinzuweisen, theils um eiuen kleinen Beitrag zur Verbreitung der Dipteren zu liefern.

Ich beginne mit den Dolichopoden, weil ich mit dieser Familie in Bestimmen zum Abschlusse gelangte; das Verzeichniss der Gattungen und Arten anderer Familien beabsichtigte ich in der Folge zu bringen.

Terzerirhniss der in der Lingebung ron Losoucz gesanmelten Dipleren.

\section{Die Dollehopodeu.}

\section{Dolichopus Ltr.}

1. D. campestris Mg. Juni-August. In einem Sumpti bei T'ugnr aut Wasserlinsen sehr häufig.

2. D. nubilus $\mathbf{M g}$. April-August. Ueberall häufig.

3. D. latelimbatus Macq. April-September. Ueberall sehr gemein und rorberrschend. 
4. D. excisus I, w. April-August. Hie und da, selten.

5. D. plumipes Scop. April-August. Ueberall häufig.

6. D. pennatus $\mathbf{M g}$. September. In Altgraben in der Nähe der Dampfmühle ein einziges Stïck gesammelt, scheint selten.

7. D. argyrotarsis IV a hlbg. Juni. Tugar-Bad, ziemlich selten.

8. D. longiconnis Staun. Juni-Angust. Sehr verbreitet, doch meist selten.

9. D. nitidus FH. Juni-August. Ueberall vereinzelt, häufiger in einem Buschwerk bei Tugar.

10. D. griseipenmis Stann. August-September. Bei Tugar, sehr vereinzelt.

11. D. signifer Hal. Mai. Im Altgraben, in der Nähe der Dampfmühle häufig, seltener auch in Gärten.

12. D. simplex $\mathrm{M}$ g. April-September. Ueberall gemein.

13. D. arbustorum Stann. Juni-Aug. Auf Buschwerk bei Tugar, selten.

14. D. festivus Hal. Juni-September. Selır verbreitet und häufig.

15. D. aeneus Deg. April-Jumi. In der Nähe der Pokorny-Puszta unter einer Briicke anf Schlamm in Mehrzahl, sonst aber nirgends getroffen.

\section{Gymnopternus L, w.}

16. G. nobilitatus L. Jumi-Juli. In Tugar-Bad längs der Wassergräben, häufig.

17. G. ducalis $\mathrm{L}, \mathrm{w} .(=$ ministerialis $\mathrm{K}$ ow. $)$ ). Juni. Mit der rorigen Art, doch viel seltener.

18. G. comitialis $\mathrm{K} \cap \mathrm{w}$. Juni. Fbenfalls mit $G$. nolilitatus, nicht selten.

19. G. regalis Mg. Juni-Juli. In Tugarbad und im Altgraben an schlammigen Stellen oft in Menge anzutreffen.

20. G. chrysozygus Wied. Juni-Aug. Teberall gemein und vorherrschend

21. G. celer. Mg. Mai. Aus Zlatno.

22. G. aerosus Fil. Juni. Bei Tugar-Bad nur stellenweise in Mehrzahl.

23. G. nanus Macq. Juni-Juli. Mit der vorigen Art; diirfte nicht selten sein; wegen seiner grossen Aehulichkeit mit $G$. aerosus übersehen.

\section{Tachytreohus Staun.}

24. $T$. ocior. Lw. Juni. In Altgraben ein einzelnes $\sigma$ gesammelt.

25. T. notatus Stann. Mai-September. Am Altgraben häufig.

26. T. ripicola L w. Mai-September. Mit den beiden vorigell Arten, nicht selten. Diese Art tritt hier als eine Varietät mit ockergelben $\sigma^{\star}$ oder gelblichgrauem $\$$ Untergesichte auf.

27. T. Kowarzii Mk. Maj-August. Ebenfalls an demselben Orte mit den vorbenannten Arten auf dem Sand und Gerölle des stellenweise aus-

*) Die gleichzeitig mit $\boldsymbol{G}$. ministerialis in den "Verhandlungen der zool.-bot. Gesellschan Jahrg 1868 pag. 217" von mir als $G$. civilis beschriebene Art hat sich nach Vergleich mil Iypischen Stücken unzweifelhaft als $\theta$. rrincipalis $\mathrm{L}$ w. ausgewiesen. 
getrockueten Baches, meist zur Zeit der grössten Somenhitze, oft in Melırahl ruckweise dahinschreitend; dieser eigenthümliche frang und die stark glänzenden Flïgel machen diesc Art schon in einiger Entfernumg kenntlich.

28. T. genualis Lw. Juli August. Im Altgraben häufig, mehr in der unmittelbaren Nähe des Wassers auf feuchtem Schlamme und auf Steinen ruhig sitzend.

\section{Sybistroma $\mathrm{Mg}$.}

29. S. nodicornis $\mathbf{M g}$. Mai. Bei Tugar auf Büschen in Mehrzahl.

30. S. setosø Schiu. Mai-Juni. Bei Tugar-Bad und nit der vorigen Art häutig.

\section{Heroostomus Lw.}

31. H. fulvicaudis $\mathbf{W}$ a $/ \mathrm{k}$. Juni-Juli. In Tugar-Bad, selten.

\section{Hypophyllus L w.}

32. H. obscurellus Fll. Juni-Juli. An der nassen Wand eines Sturzbaches im Losonczer Wald, selten.

33. H. sciophilus Lw. Juni. Mit der vorigen Art, sehr selten.

\section{Argyra M a c q.}

34. A. Hofmeisteri Lw. Mai. Im Losonczer Wald, sehr selteu.

35. A. diaphana F. Mai-Juni. An schattigen Bachufern iiberall häutig.

36. A. confonis Staeg. Juni. Im Losonezer Walde ein $\sigma$ gesammelt.

37. A. aryentina $M \mathrm{~g}$. Juni. In Tugar-Bad, sehr häufig.

3ъ. A. leucacephala Mg. Juni-September. Im Altgraben und Tugar-Bad, sehr häufig.

39. A. atriceps Lw. Mai-Juni. In Tugar-Bad, sehr selten.

40. A. grata Lw. Mai-August. In Tugar-Bad an Bachrändern und auf niederen P'flanzen häufig.

\section{Syntormon Lw.}

41. S. denticulatus $Z$ ett. März- $\Lambda$ pril. Bei Tugar auf Schlamm in bedeutender Menge. - Die Ausdehnung der schwarzbraunen Färbung der Beine variirt bei dieser Art sehr: meist sind dic Hinterschenkel an der Basis und Spitze, seltener mit Ausnahme der äussersten Spitze ganz volı dieser dunklen Färbung eingenommen; im letzteren Falle sind auch die vordersten Sehenkel bis nahe zur Spitze hin und die Mittelschenkel an der Basis breit schwarzbraun.

42. S. metathesis Lw. April. Mit der vorigen $\Lambda \mathrm{rt}$, äusserst selten.

43. S. pumilus Mg. Mai. In Tugar-batt auf niederen Sumpfpflanzen, selten. 


\section{Synarthrus Lw.}

4. S. pallipes F. Mai-Juni. Ueberall, ziemlich häufig. - Eine seltenere Varietät dieser Art hat einen ganz einfarbig metallischgrünen Hinterleib, vorherrschend braun gefärbte Metatarsen an den Vorderbeinel, an den Hinterbeinen das Spitzendrittel der Schenkel, die Spitzenhälfte der Schienen nud die Tarsen ganz schwarz. Bei einer anderen Varietät, die häufiger vorkommt, ist der zweite und dritte Hinterleibsring an der Bauchseite ganz gelb; diese Färbung erstreckt sich bei anderen Individuen mehr weniger anch auf dic Seiten der beiden Ringe; die Metatarsen der Vorderbeine sind nur an der Spitze braun, an den Hinterbeinen nur die äusserste Spitze der Schenkel und Schienen schwarzbraun, ihr Metatarsus an ter Basis gelbbraun.

45. S. subinemis Lw. Mai. In Tugar-Bad auf anderen Uferptlanzen, äusserst selten.

\section{Xiphandrium $\mathrm{L}$ w.}

46. X. caligninosum $\mathbf{M g}$. April-Juli. Ueberall in Auen häufig.

47. I. appendiculatum Zett. Mai-September. Mit der vorigen Art, sehr selten.

\section{Porphyrops $\mathbf{M}$.}

48. P. Schineri Mk. Mai-September. Im Altgrahen und Tugar-Bat an Bachuferu anf Steinen und Laub, selten.

49. P. spinionses Lw. April-Mai. In Iosonczer Wald und Tugar-Bal, häufig.

50. P. fasripes $\mathbf{M g}$. April-September. Im Fribjahre anf Sihlamm stellenwoise in Nenge, später soltener.

51. P. nemorum Mg. April-September. Velorall gemein und vorlierschend, auch b.i Salgó-Tarján.

52. I’. micans 11 g. April-Sept. Im Altgraben und Tugar-Bad, selten.

53. I'. nasulus Fll. April. In Tugar-Bad, selır selten.

54. I'. penicillatus L, W. Juni-Juli. Hie und da, selten.

\section{Nematoproctus I, w.}

35. N. distendens II g. Mai-September. I'm T'ugal-Barl anf l'apelstanden oft massenhaft, an anderen Orten mehr vereinzelt.

äb. V. prosectus 1, w. Juni. Im Mtgraben ein o’ gesammelt.

\section{Dlaphorus $\mathrm{MI}$.}

:7. D. disjunetus 1, w. Juli. Im. Ntgraben anf fenclitem lifersand, sehr selten.

38. D. tripilus L, Inni. In Tugar-Barl anf liuschwerk, äusserst selten. - Ein ó dieser Art hat nur je cin langes Borstenhazr aut der Innenseita der Vopilerschicuen. 


\section{Chrysotus $\mathrm{Mg}$.}

59. Ch. cupreus Macq. Mai-Juni. Auf Ufergebüschen, selten.

60. Ch. laesus Wied. Mai-Juli. Ueberall sehr gemein und vorherrschend.

61. Ch. gramineus FIl. Mai-September. In Auen überall häufig. - Im Altgraben kommt eine Varietät vor, hei weleher ausser den Schenkelringeu auch die Basis aller Schenkel, die der hintersten sogar bis zum ersten Viertheile und beim $\sigma^{\circ}$ auch die Basis der Hinterschie nen gelb gefärbt sind.

62. Ch. suavis Lw. Juni-September. Sehr vereinzelt, uur oे

63. Ch. cilipes $\mathbf{I I g}$. Juni. Mit Ch. yromineus in Altgraben ein $₹$ gesammelt.

6'. Ch. niger L, Juni. Im Losonczer Wald an einem schattigen feuchten Platze auf Eichenklötzen, sehr selten.

\section{Teuchophorus $\mathrm{L}, \mathrm{w}$.}

65. $\boldsymbol{T}$. calcaraus M a cq. Juni. An Sumpfrändern bei Tugar und l'ngarBad, häufig; $\$$ vorherrschend.

66. $\boldsymbol{T}$ pectinifer $\mathrm{K}$ ow. Juni. Mit der vorigen $\mathrm{Art}$, iusserst selten.

\section{Sympyenus $I, w$.}

67. S. neneicoxus Mg. August. Im Altgraben und hei Losoncz-Bad, selten.

68. S. annulipes $\mathbf{M g}$. Inni. Mit der vorigen Art, sehr selten.

(i9. S. spiculatus Gerst, Mai, Ein ơ aus Zilatıo.

70. S. elegans $M \mathrm{~g}$. Im Tugarer Sumpf, sehr selten

\section{Campricnemus $\mathrm{H}$ a 1 .}

71. C. pusillus $\mathbf{M g}$. März. Auf sandigem, feuchten Schlaum am Rande des Losonczer Waldes, sehr selten.

72. C: scambus Fll. August. Ceberall, meist vereinzelt.

73. C. curvipes F11. Februar - August. Sehr verbreitet und überall gencin.

74. C. umbripennis Lw. Fehruar-Juni. Auf Schlamm in der Nähe des I,osonczer Waldes, Tugar, nicht selten.

75. C. lumbatus 1,w. März. Auf Schlamm, stellenweise häufig; Tugar, Pokoruy-Pus\%ta.

76. C. maryinatus LW. Mal\%. Am Waldrande auf Schlamm cin finziges l'ärchen gefangen.

77. C. varipes 1,w. März-September. Im Altgrahen bis zur Dampfuible hiı, hänfiger au Losonczer Waldsaum.

\section{Hydrophorus $\mathrm{IV}$ a $h \mid \mathrm{l} g \mathrm{~g}$.}

78. II. inrequalipes Macq. Mai. Im Altgraben, selten.

79. H. Viforeus Fll. Mäı\%. In Wiesenbächen hie und da, meist rercinzelt.

sn. H. balticus $\mathbf{M g}$. Eebruar-October. Mit den vorhergehenden Arten. häufiger. 


\section{Medeterus $\mathrm{Mg}$.}

81. M. melanopleurus Lw. Juni. Im Losonczer Wald, an einer schattigen, massen Stelle auf moderndem Holz in Mehrzahl.

82. M. ambiguus $\mathrm{Z}$ ett.? Juni. Mit der vorigen gesellig. Die hier gemeinte Art ist vou der Zetterstedt'schen bestimmt verschieden: Der Thorax ist nicht braun, soudern weisslichgrau bestäubt, der Schwingerknopt vorherrschend gelb, die vordersteu Hüfteu glänzend schwarz; auch das Flügelgeäder und nawentlich die rom Flïgelrande etwas entferntere Stellung der hinteren Queraderu dürfte Unterschiede ergeben. Der diister-griine metallisch schimmernde Hinterleib des cinzigen mir vorliegenden ${ }^{*}$ ist so verschrumpft, dass sich die Gestalt des Hypopygiums und der bräunlichen Auhänge nicht mit Sicherbeit erkenneu lässt.

83. M. jaculus Fll. Juni-October. An Baumstämmen und auf Steinen, überall gemein.

84. M. truncorum $\mathbf{M g}$. Juni-August. Mit $\mathbf{M}$. jaculus, seltener.

83. M. diadema L. Juni. An Mauern, überall bäutig.

86. M. micaceus Lw. Juni. Im Losonczer Wald, in Altgraben auf Steinen, sehr selten.

87. M. muralis Mg. Juni. Iu Tugar-Bad an Baumstämnen, häutig.

20. Chrysotimus Lw.

88. Ch. molliculus. Fll. August. Im Altgraben, sehr selten.

\section{Xanthochlorus $\mathrm{Lw}$.}

89. I. tenellus Wied. Juni-September. In Auen, überall häutig.

\section{Saucropus Lw.}

90. S. quadrifasciatus F. Mai. Aus Zlatno, ein б.'

91. S. Erichsonii Zett. Juni. Die $\$$ \& sind nicht selten: ich traf sie im Losonczer Wald an laubreichen, schattigen Stellen, besonders auf niederen Pflanzen, dürren Aestchen und angeschwemmten Eichenklötzen oft in Mehrzahl. Die $\sigma^{7} 5$ jedoch seheinen weit seltener zu sein; ich erhaschte ein einziges Stück in Tugar-Bad, wo es einen am dortigen Sumpfrande stehenden Baum mehrmals von unten nach oben entlang flog, eine Eigenthüulichkeit, welche den $\sigma^{\circ} \sigma^{\prime \prime}$ dieser rattung im Allgemeinen zugehöreu dirrtte.

92. 5. pallidus Fll. Mai-Juni. Diese Art ist wieder im of Geschlechte vorwiegend, hat dasselbe Benehmen wie $S$. Erichsonii und ruht auch gerne an Baumstämmen oft in ansehulicher Anzahl aus; $f \uparrow$ habe ich nie getroffell. Tugar-Bad, Gärten.

\section{Psillopus $1 \mathrm{~g}$.}

93. I's. platypterus F. Mai-Juni. Im Altgraben, Losonczer Wald, in Auen, haiutig.

94. Ps. lnbipes II g. Juni. In Tugar-Bad, selten. 


\section{Beitrag zur Dipteren-Fauna Ungarns.}

Von

\section{Ferdinand Kowarz.}

K. k. Telegraphen-Beamter in Asch.

(Aus den Verhandlungen der k. k. zoologisch-botanischen Gesellschaft in Wien) [Jahrgang 1873] besonders abgedruckt.)

Mein diesmaliger Bericht umfasst die Aufzählung sämmtlicher während meiner in den Monaten Mai und Juni 1871 nach Herculesbad unternommenen Reise gesammelten Dipteren. Ausser Neusatz und Semlin sind die Umgebungen von Orsova und Herculesbad die von mir meist durchforschten Gebiete, welche einerseits im Donauthale die wundervollen Partien des Kasan (Plavischeviza) bis nach Turn-Severin mit Inbegriff des serbischen Ufers, und andererseits die Thäler der Czerna- und Béla-Reka nnd Mehadika bis nach Verendin hin umfassen. - Das sehr bescheidene Ergebniss dieser von mir mit vieler Vorliebe unternommenen Sammelreise würde gewiss weit reichhaltiger ausgefallen sein, wenn nicht die anhaltende Ungunst der Witterung fast das ganze Unternehmen vereitelt hätte; dessungeachtet entdeckte ich melirere sehr interessante neue und einige zwar bereits bekannte, jedoch in unserem Faunengebiete bisher noch nicht aufgefundene Arten. Die Sammelplätze in Rumänien und Serbien hieherzuziehen gestattet sowohl deren Nähe als auch deren nahezu gleichartige Beschaffenheit mit den diesseitigen Boden- und Vegetationsverhältnissen, unter welchen die Verbreitung der dortigen Dipteren sehr möglich ist.

Wie bereits bemerkt, ist die Ausdehnung des nachfolgenden DipterenVerzeichnisses verhältnissmässig sehr dürftig und lückenhaft; dennoch drängt es mich, den Herren Dipterologen das erwähnte an grossartigen Naturschönheiten so überaus reiche Gebiet, das zahllose entomologische Schätze birgt, zur eingehendsten Durchforschung ganz besonders zu empfehlen.

Die von mir aufgefundenen neuen Arten sind im Druck ausgezeichnet. Ihre Beschreibung findet sich im XVII. Bande der Berliner entomologischen Zeitschrift, Jahrgang 1873, pag. 33 unter dem Titel: "Diptera nova, in Pannonia inferiori et in confinibus Daciae regionibus a Ferd. Konvarzio capta. Descripsit H. Loew. 


\section{Verzeichniss der in den Umgebnngen ron Herenlesbad und Orsova gesammelten bipteren.}

A. Nemocert.

Lasioptera eryngii Gir. Sciura carbonaria Mg.?

- rufiventris Macq.

- humeralis Ztt.

- nocticolor Winn.

- brunnipes $\mathrm{Mg}$.

- insignis Winn.

- alpicola Winn.

- lugubris Winn.

- pauperata Winn.

Ditomyia fasciata Mg. Bolitophila cinerea $\mathrm{Mg}$. Macrocera fasciata $\mathrm{Mg}$.

- lutea Panz.

- stigma Curtis.

Platyura fasciata Mg.

- dorsalis Staeg.

Sciophila limbata Wim.

- pallens Lw. n. sp. Alpe Kernecska Csoka. Mit der vorigen sehr selten.

- nigriceps Lw.n.sp. Im Juni bei Hereulesbad auf Unbelliferen sehr selten.

Empheria lineola Mg. Polylepta splendidaWinn. Lasiosoma pilosa $\mathrm{Mg}$.

- rufia $\mathrm{Mg}$.

Boletinu scierinu Staeg. Gilaphyroptera fascipennis $\mathrm{Mg}$.

- borealis Winn.

Acnemia amoena Winn. Docosia valida Winn. Allodia crassicomis Stan. - ornaticollis $\mathrm{Mg}$.

Brachycampta amoena Winn.
Brachycampta griscicollis Staeg.

Phronia humeralis Winn.?

- signata Winn.

Mycetophila punctata Mg.

- biusta Mg.

- rufescens Z $\mathrm{Ztt}$.

Dynatosoma nobilis Lw. n. sp. Im Juni auf d. Alpe KernecskaCsoka in Schluchten ziemlich häufig.

Liponeura cinerascens Lw.

Blepharocera fasciata Westw.

Simulium reptans $\mathrm{L}$.

- latipes MIg.

- columbacense Schünb.

Scatopse recurva $\mathrm{Lw}$.

Dilophus vulgaris $\mathrm{Mg}$.

Bibio marci L.

- leortulanus L.

- venosus Mg.?

- reticulatus Lw.

- varipes Mg.

- macer Lw. n. sp. Im Mai bei Börsa im Hochgebirge an einer schattigen Waldstelle auf den Blättern einer Urtica, welche cinen Sturzbach säumte, in Mehrzahl aber nur $\sigma^{\pi} \sigma^{\pi}$ angetroffen.

IIesperimus imbccillus Lw. (7ivonomus nubeculosus. Mg. apud Schin.

- sculcuus Sclirk.

- plumosus L.

- ferrugineovittatus $\mathrm{Z}$.
Chironomus riparius $\mathrm{Mg}$.

- venustus Staeg.

- vilratorius $\mathrm{Mg}$.

- obscurus Mg.?

Tanypus nervosus $\mathrm{Mg}$.

- punctipennis $\mathrm{Mg}$.

- varius $\mathrm{F}$.

- carneus F.

- monitis $\mathrm{L}$.

Ceratopogon proeustus Lw.

Orphnephila testucea Ruthe.

Culex vexans $\mathrm{Mg}$.

- cantans $\mathrm{Mg}$.

- onnatus Mg.

- leucacanthus Lw. n. sp. Mit $C$. vexans selir selten.

Anopheles maculipennis $\mathrm{Mg}$.

- nigripes Staeg.

Corethra plumicomis F. Psychoda platuenoides L. Pericoma tristis $\mathrm{Mg}$.

- calccuta Mg.

- ocellaris $\mathrm{Mg}$.

Tipula gigrntea Schrk.

- truncorum $\mathrm{Mg}$.

- pabulina $\mathrm{Mg}$.

- heros Egg.

- hortulana $\mathrm{Mg}$.

- pictipennis Staeg.

- oleracea L.

- nolicornis $\mathrm{Mg}$.

- ochrucea $\mathrm{Mg}$.

- pannonia Lw.n.sp. Im Mai und Juni bei Herculesbad ziemlich häufig.

- peliostigma Schumm 
Tipula stigmatella

Schumm.?

- truncata Lw. n. sp. Im Mai und Jnni bei Herculesbad, Orsova nnd T. Severin ziemlich häufig.

- bispina Lw. n. sp. Im Mai bei Herculesbad sehr selten.

- helvola Lw. u. sp. In Mai und Juni bei Herculesbad im Sesseminthale und bei Plavischeviza anf der Wiese Krninamare sehr selten.

- variiconis Schumm. Pachyrthina imperialis 川g.

- lumeliconis Schumn.

- quedrifaria Mg.

- Mistrio $\mathrm{F}$.

- aculeata Lw.

Ctenophora bimaculata $\mathrm{L}$.

- atrata L.

- elegans $\mathrm{Mg}$.

Limnobia pannonica Kow.

- nebeculosa MIg.

- analis $\mathrm{Mg}$.

- xunthoptera Mg.

- tripunetata F.

- decem maculata Lw. n. sp. Im Juni auf der Alpe Kernecska-Csoka ziemlich selten.

- cleorea Mg.

- dumetorum $\mathrm{Mg}$.

- trinotata Mg.

- macrostigma Schum.

- morio F.

- pitipennis Egg.
Limnobre tristis Schumm. Elliptera omissa Egg.

Rlyphtolophus nodulosus Macq.

- pentagonulis Lw. n. sp. Im Mai und Juni bei Orsova in Grazkathale und bei Herculesbad im Sesseminthale in feuchten Schluchten auf niederen Laubpflanzen selten.

Erioptera maculata $\mathrm{Mg}$. - fuscipennis $\mathrm{Mg}$.

Molopteilus merinus $\mathrm{Mg}$. Symplecta stictica Mg.

- punctipennis $\mathrm{Mg}$.

Cladura fuscula Liw. n. sp. Im Juni bei Herculesbad an Wasserfüllen sehr selten.

Dicranota bimaculate Schumm.

Tricyphome immaculata $\mathrm{Mg}$.

Limnophite hospes Egg.

- nemorelis MIg.

- lucorrem Mg.

- discicollis Mg.

- ochracen Mg.

Epiphragma picta $\mathrm{F}$.

It liopter trimaculate $\mathrm{Ztt}$. Ephelire mundeta Lw.

Poecilostola pietipenuis $\mathrm{Mg}$.

Ductylolebis tergestina Egg.?

- Fruenfeldi Egg.

- grucitipes Lw.

Ptychopter praludose $\mathrm{Mg}$. Dixa maculate MIg.

\section{B. Brachycerc} orthorecther.

$\mathrm{X}$ ylopihegus ater $\mathrm{F}$.

Subula varia MIg.

Beris clavipes L.

- sexdentatu Ztt.

- geniculata Curtis.

- fuscipes $\mathrm{Mg}$.

Actina nitens Latr.

Sargus cuprarius L.

Chrysomyia speciosu Macq.

- formosa Scop.

Strationyia concinna $\mathrm{Ig}$.

- longicornis Scop.

Odontomyiu flavissima Rossi.

- periscelis Lw.n.sp. Im Mai bei Orsova am neutralen Grunde auf Euphorbia sehr selten.

Nemotelus pantherinus $\mathrm{L}$. Oxycera limbata Lw. Clitellaria Dahlii $\mathbf{M g}$.

Cyclogaster temuirostris Lw.

Pachygaster ater Panz.

Silvius vituli $\mathrm{F}$.

Tabamus pilosus Lw.

- corliger $\mathrm{Mg}$.

- spectubilis Lw.

- bovinus L.

- spodopterus $\mathrm{Mg}$.

- ferrugineus $\mathrm{Mg}$.

- infuscutus Lw.

IIaematopota italica $\mathrm{Mg}$. Chrysopila aurea $\mathrm{Mg}$.

- splendidu Mg.

- muerens Lw. n. sp. Im Mai und Juni in der Umgebung von Herculesbad nicht selten. 
Leptis maculata Deg.

- vitripennis $\mathrm{Mg}$.

- punctata Lw.

- tringaria L.

- conspicua Mg.

Atherix marginata $\mathrm{F}$.

- Tois F.

- melaena Mg.

- immaculata F.

Dasypogon teutonus L.

Stichopogon albofasciatus $\mathrm{Mg}$.

Dioctria aurifrons Mg.

- oelandica L.

- rufipes Deg.

- lincaris $\mathrm{F}$.

Leptogaster cylindricus

Deg.

- guttiventris Ztt.

Lasiopogon cinctus $\mathrm{F}$.

Cyptopogon lateralis Fll.

Dysmachus spiniger Zell.

- pracmorsus Lw.

— stylifer Lw.

- bifurcus Lw.

Machimus modestus Lw.

- cyanopus Lw.

Itamus socius Lw.

Tolmerus atripes Lw.

Asitus crabroniformis L.

Pamponerus germanicus $\mathrm{F}$.

Echthistus rufinervis Wiedem.

Laphria ephippium F.

- aurea Mg.

- dioctriiformis Mg.

Thereua arcuata Luw.

Pleycus dispar $\mathrm{Mg}$.

Scenopinus niger Deg.

- fenestralis L.

Bombylius ater Scop.

- medius $\mathrm{L}$.

- major L.
Bombylius fimbriatus $\mathrm{Mg}$.

- vulpinus Mg.

- cinerascens Mikan.

- fulvescens $\mathrm{Mg}$.

Dischistusminimus Schrk.

Lomatia Sabaea F.

Hemipenthes morio L.

Anthrax Ixion F.

Tomomyza europaca Lw.

Brachystoma vesiculosa $\mathrm{F}$.

Hybos fumipennis $\mathrm{Mg}$.

Trichina cluvipes $\mathrm{Mg}$.

Oedalea stigmatella Ztt.

- Holmgreni Ztt.

- infuscata Lw.

Ocydromia glabricula Fll.

Trichopeza longicornis $\mathrm{M} \mathrm{g}$.

Leptopeza favipes $\mathrm{Mg}$.

Empis stercorea $\mathrm{L}$.

- trigramma $\mathrm{Mg}$.

- lutea Mg.

- monogramma $\mathrm{Mg}$.

- meridionalis $\mathrm{Mg}$.

- confusa Lw.

- tessellata F.

- nepticula Lw.

- opaca F.

- livida L.

- procera Lw. n. sp. Im Mai in den Umgebungen von Herculesbad und Orsova längs den Ufern der Donau bis nach Pla. vischeviza auf Blüthen sehr häufig.

- jennipes $\mathrm{L}$.

- decora Mg. apud Schin.

- alampra Lw. n. sp. Im Juni auf der Alpe Kerneeska-Csoka auf Valeriana sehr selten.
Emp is nitidiventris Lw. n. sp. Mit der vorigen Art selir selten.

- tanysphyra Lw. 11. sp. Im Mai fast überall auf Saniculablüthen.

- plebeja Lw. n. sp. Mit der vorigen Art.

- melanotricha Lw. n. sp. Im Mai und Juni bei Herculesbad aufUmbelliferen ziemlich hänfig.

- pennaria Fll.

- filata Lw. n. sp. Im Mai bei Herculesbad und Plavischeviza ziemlich selten.

- setose Lw.

- pusio Egg.

- levis Lw. n. sp. Im Mai bei Herculesbad sehr selten.

- leиćopeza Lw.n.sp. Im Mai bei der Veteranilı̈hle in Kasan unter Baumkronen schwärmend $\sigma^{\top} \sigma^{\top}$ und auf Umbelliferen $\sigma^{\top}$ 오 ziemlich lüufig.

- nigritarsis Mg.

Pachymeria femorata F. Rhamphomyia spissirostris Fll.

- nigripes $\mathrm{F}$.

- stigmosa Macq.

- atra $\mathrm{Mg}$.

- umbripennis $\mathrm{Mg}$

- hybotina Ztt.

- sphenoptera Lw. n. sp. Im Mai und Juni bei Herculesbad und am serbischen 
Donaunfer mit den beiden letztern Arten. Ramphomyia eupterota Lw. n. sp. Im Mai bei Plavischeviza auf Sträuchern sehr selten.

- leptopus Lw. n.sp. Im Juni bei Herculesbad sehr selter.

Hilara cuneata Lw. n. sp. Im Juni bei Plavischeviza sehr selten.

- thoracica Macq.

- tetragramma Lw. n. sp. Im Mai in der Umgebung vonOrsova häufig.

- pubines Lw. n. sp. Im Mai im Kasan am serbischen Donauufer sehr selten.

- quadrivittata MIg.

- platyura Lw.n. sp. Mit der vorigen Art doch seltener u. auch auf Umbelliferen.

- ciliata MIg.?

- lurida Fll.

- maura F.

- lugubris Ztt.

- pilosa Ztt.

- scrobiculata Lw. n. sp. Im Mai bei Dubova und aul serbischen Donauufer mit H. quadrivittata häufig.

eumer a Lw. n. sp. Im Mai bei Verendin über Bächen schwärmend.
Hilara cornicula Lw. n. sp. Im Mai im Bachnathale sehr selten.

Cyrtoma nigrum $\mathrm{Mg}$. - simplicipes Ztt.

Hemerodromia precatoria Fll.

Tachypeza mubila Mg. - fuscipennis Fll.

Tachista anmulimana $\mathrm{Mg}$.

- longipennis Lw.

Tachydromia cursitans $\mathrm{F}$.

- major Ztt.

- agilis $\mathrm{Mg}$.

- anmulata Fll.

- minuta Mg.

- anmulipes IIg.

- bicolor F. Ardoptera guttata Hal. Clinocera lamellata $\mathrm{Lw}$.

- fallaciosa Lw. n. sp. Mit der vorigen Art und unter ähnlichen Verhältnissen auch bei Herculesbad, jedoch seltener.

- hygrobia Lw.

- tenella Wahlb.?

- Robertii Macq.

Dolichopiss campestris $\mathrm{Ig}$.

- nubilis Mg.

- latelimbatus Maca.

- excisus Lw.

- claviger Stann.

- plumipes Scop.

- pennatus Mg.

- griseipennis Staun.

- signifer Hal.

- simplex $\mathrm{Mg}$.

- arbustorium Stann.

- salictorem Lw.

- festivus Hal.

Gymnopternus regalis Ig.
Gymnopternus chrysozygus Wiedem.

- laevifrons Lw.

- nigriplantis Stann.

- atrovirens Lw.

- exarticulatus Lw.

- caudatus Lw.

- inornatus Lw.

- celer Mg.

- aerosus Fll.

Tachytrechus notatus Stann.

- ripicola Lw.

- genualis Lw.

Sybistroma nodicornis Mg.

- maerens Lw. n.sp. Im Juni bei Orsova im Grazkathale und bei Herculesbad an den Wasserfällen hinter dem Ferdinandshofe auf Steinen und auf Laub, stellenweise nicht selten.

Hercostomus cretifer Wlk.

- blepharopus Lw.

- longiventris Lw.

Hypophyllus discipes Ahrens.

- crinipes Staeg.

- sphenopterus Lw.

Argyria diaphana $\mathrm{F}$.

- confinis Staeg.

- argentina $\mathrm{Mg}$.

- leucocephala $\mathrm{Mg}$

- Hoffmeisteri Lw.

Syntormon spicatus Lw.

- biseriatus Lw.

Synarthrus monilis Wlk.

- pallipes $\mathrm{F}$.

- Zelleri Lw.

Xiphandrium caliginosum $\mathrm{Mg}$. 
Xiphandrium sagax Gst.

- monotrichum Lw.

- appendiculatum Ztt.

Porphyrops spinicoxus Lw.

- fascipes Mg.

- nemorum Mg.

- micans Mg.

- penicillatus Lw.

- praerosus Lw.

Nematoproctus distendens $\mathrm{Mg}$.

Lencostola vestita Wied. Diaphorus oculatus Fll.

- tripilus Lw.

- lugubris Lw.

- nigricans $\mathrm{Mg}$.

Chrysotus cupreus Macq. - suavis Lw.

Teuchophorus monacanthus Lw.

Sympycnus annulipes $\mathrm{Mg}$.

Campsicnemus curvipes Fll.

- umbripennis Lw.

- lumbatus Lw.

- varipes Lw.

Liancalus virens Scop.

Hydrophorus inaequalipes Macq.

- balticus Mg.

Medeterus melanoplewrus Lw.

- diadema L.

Saucropus pallidus Fll. - suturalis Fll.

Oncopygus distans Lw.

- magnificus Lw. n. sp. Mit der vorigen Art und auch an den Ufern der Czerna beim grossen Wasserfall, immer sehr selten. Ich konnte trotz grossem
Zeit- and Mülieanfwand nur wenige $\sigma^{x} \sigma^{x}$ dieser ungewöhnlich schünen, neuen Species erlangen; das $q$ blieb mir leider unbekannt.

Psilopus platypterus F.

- ludens Lw. n. sp. Im Juni bei Orsova inı Grazkathale auf Sumpfpflanzen, sehr selten.

- bellus Lw. n. sp. Im Mai und Juni bei Herculesbad, im Sesseminthale und auf der AlpeKernecska-Csoka selten.

Lonchoptera lutea Panz.

\section{Brachyceru cycloraphe.}

Callomyia aemoena $\mathrm{Mg}$.

- elegans Mg.

- antennata Ztt.

Platypcza atra Fll.

Pipunculus silvaticus $\mathrm{Mg}$.

- ruralis Mg.

Dalmania punctata F.

Myopa testacea L.

Oncomyia atra $\mathrm{F}$.

Zodion notatum Mg.

Ceria conopsoides L.

- tridens Lw. n. sp.

Im Jumi beim eisernen Thor auf Pyrcthrum sehr selten.

Callicera aenea $\mathrm{F}$.

Microdon mutabilis L.

- latifions Lw.

Psarus abdominalis $\mathrm{F}$.

Chrysotoxum intermedium Mg.
Chrysotoxumbicinctum L.

- festivum $\mathbf{L}$.

- vernale Lw.

- silvarum $\mathrm{Mg}$.

- elegans Lw.

Volucella pellucens L.

- inflata F.

- zonaria Poda.

Paragus tibialis Fll.

- albifrons Fll.

- bicolor F.

Triglyplus primus Lw.

Pipiza festiva $\mathrm{Mg}$.

Pipizella virens $\mathrm{F}$.

Orthoneura nobitis Fll.

Chrysogaster splendidus $\mathrm{Mg}$.

- coemeteriorm L.

- basalis Lw.

- splendens $\mathrm{Mg}$.

Chilosia nigra Lw.

- barbata Lw.

- variabilis Panz.

- melanopa Zitt.

- scutellata Fll.

- soror Ztt.

- means F.

- impressa Lw.

- albitarsis Mg.

- morio Ztt.

- mutabitis Fll.

- pygmaea Ztt.

- praecox Ztt.

Chrysochlamys cuprea Scop.

Metithreptus strigatus Staeg.

- scriptus L.

- dispar Lw.

Xanthogramma ornata $\mathrm{Mg}$.

Syrphus seleniticus $\mathrm{Mg}$.

- luniger Mg.

- corollue F. 
Syrphus lasiophthalmus Ztt.

- lunulatus Mg.

- topiarius Mg.

- decorus $\mathrm{Mg}$.

- bifusciatus $\mathrm{F}$.

- ribesii L.

- nitidicollis $\mathrm{Mg}$.

Melanostoma hyalinata Fll.

- ambigua Fll.

- mellina $\mathrm{L}$.

- gracilis $\mathrm{Mg}$.

Platychious albimames $\mathrm{F}$.

- scutatus Mg.

- ferrugineus Macq.

Buccha elongata F.

Sphegina clumipes Fll.

Myiolepta luteola Gmel. - vara Panz.

Rhingia rostrata $\mathrm{L}$.

Brachyopa arcuata Panz.

- Vicolor Fll.

Xylota segnis L.

- lenta Mg.

- ignava Panz.

- femorata L.

- rufipes Lw. n. sp. Im Juni bei Herculesbad und bei Orsova im Bachnathale auf Cormus selten:

- bifasciata Mg,

- nemorum $\mathrm{F}$. apud $\mathrm{Mg}$. Syritta pipiens I.

Brachypalpus euno$t u s$ Lw. n. sp. Im Mai auf einem Ausflug nach dem Meteriss ein 오.

- valgus Panz.

Mallota eristaloilles Lw. Criorrhina berberina $\mathrm{F}$.

- asilica Fll.
Criorhina oxyacanthue Mg.

Eumerus ovatus Lw.

- simuatus Lw.

- tricolor $\mathrm{F}$.

- basalis Lw.

- angustifions LW.

- pulchellus Lw.

Temnostoma speciosa Rossi.

- bombylans F.

- vespiformis L.

Helophitus florcus L.

- pendulus L.

- trivittutus F.

Eristalis sepulcralis L.

- tenax L.

- arbustorum L.

- horticola Deg.

Merodon equestris $\mathrm{F}$.

- clavipes $\mathrm{F}$.

- aberrans Egg.

- rufitilius Rond.

- spinipes $\mathrm{F}$.

- funestus $\mathrm{F}$.

- aeneus Mg.

- armipes Rond.

Prosena siberita F.

Dinera flaviconis $\mathrm{Mg}$.

- grisescens Fll.

Zeuxia cinerea $\mathrm{Mg}$.

Dexia carinifrons Fll.

- ferina Ell.

- rustice $\mathrm{F}$.

Phorostoma adelpha Lw. n. sp. Im Juni auf der Alpe Kernecska-Csoka und im Sesseminthale aut Umbelliferen ziemlich selten.

- triangulifera Ztt.

- microcera Rond.
Phorostoma macrophtham $u$ Lw. n. sp. Im Juni in der Nähe des eisernen Thores auf Pyrethrum sehr selten.

Mintho prueceps Scop.

Melania volvulus F.

Thelaira lencozona Panz. Melanophora rorulis L. Morinia nana $\mathrm{Mg}$. Rhinophora femoralis $\mathrm{Mg}$.

- inornata Lw. apud Schin.

- melania IIg.

Lencostoma simplex Fll.?

- analis $\mathrm{Mg}$.

- limbata $\mathrm{Mg}$.

Clista foeda Mg.?

Scopolia carbonaria Panz.

- succincta Mg.

- cunctans $\mathbf{M g}$.

- lugens Mg.

Hypostena medorina Schin.

Degeeria seria Mg.

Macquartia nitida Ztt.

- grisca Fll.

- chalybeata Mg.

- nigrita Fll.

- dispar Fll.

Loewia setibarba Egg. Clytia continua Panz. Siphona cristata F. - geniculata Deg.

Thryptocera crassicomis $\mathrm{Mg}$.

- latifrons Mg.

- cagnata Schin.

Myobia fenestrata (Mg.?) Śchin.

Leskia aurea Ell.

Redtenbucheria phaniaeformis Egg. 
Miltogramma oestracca Fil.

- pilimana Rond.

- conica Fll.

Macronychia agrestis Fll. - signata MIg.

Metopia leucocephala Rossi.

- campestris Fll.

- argyrocephala Mg.

Baumhaueria goniaeformis $\mathrm{Mg}$.

Phorocera concinnata Mg.

- caesifrons Macq.

- cilipeda Rond.

Ctenocnemis*) flavoscutellata Ztt.

- major Macq.

Masicera pratensis $\mathrm{Mg}$.

Tachina rustica Mg.

Meigeniamajuscula Rond.

- bisignata Mg.

Exorista festinans $\mathrm{Mg}$.

- gnava Mg.

- lucorum Mg.

- vetula Mg.

- affinis Fll.

- fimbriata Mg.

Nemoraea amoena $\mathrm{Mg}$.

- notabilis Mg.

Cnephalia bucephale $\mathrm{Mg}$. Gonia ornata $\mathrm{Mg}$.

- hebes Fll.

Plagia ruralis Fll.

- trepida Mg.

- nigripalpis Rond.

- ambigua Fll.

Zophomyia temula Scop. Micropalpus fulgens $\mathrm{Mg}$.
Echinomyia Brunneri Lw. n. sp. Im Juni in der Nähe des eisernen Thores auf Pyrethrum macrophyllum sehr selten.

- tessellata F.

- magnicornis Ztt.

- lurida F.

Uromyia curvicauda Fll. Ocyptera bicolor Enc. Gymnosoma rotundata L. Strongygaster pannonius Lw. n. sp. Im Mai und Juni bei Herculesbad und Plavischeviza auf Dolden sehr selten.

Xysta cana Mg. Phasia analis F. Alophora hemiptera $\mathrm{F}$.

- subcoleoptrata L.

- pusilla Mg.

- cinerea $\mathrm{F}$.

- muscaria Fll.

Sarcophaga haematodes $\mathrm{Mg}$.

- haemorrhoa Mg.

Sarcophila Meigenii Schin.

Theria muscaria Mg.

MLusca domestica L.

- corvina F.

- vitripennis Mg.

Pollenia vespillo $\mathrm{F}$.

- rudis $\mathbf{F}$.

Myospila meditabunda $\mathrm{F}$.

Morellia simplex Lw.

- hortorum Fll.

Cyrtoneura stabulans Fll.
Cyrtoneura pabulorum Fll.

- pascuartm Mg.

- caesia Mg.

Pyrellia serena Mg.

- aenea $\mathrm{Ztt}$.

- cadaverina L.

Lucilia regina $\mathrm{Mg}$.

- nobilis $\mathrm{Mg}$.

- caesar L.

- cornicina F.

Dasyphora pratorum $\mathrm{Mg}$. Calliphora erythrocephale $\mathrm{Mg}$.

Mesembrina meridiana L.

Rhynchomyia cyanescens Lw.

- columbina Mg.

Idia lunata $\mathrm{F}$.

Stomoxys calcitrans L.

Chirosia fallax Lw. n. sp. Im Mai bei Orsova am neutralen Grund im Grase sehr selten.

Anthomyia pluvialis L.

- albicincta Fll.

- diaphana Wiedem.

- socia Fll.

- lactucae Bouché.

- pratensis Mg.?

- schisticolor Ztt.

- radicam $\mathrm{L}$.

- floralis Fll.

- pusilla Mg.?

- villipes Ztt.

- brunnescens Ztt.

- paralleliventris Ztt.

- triplex Lw. n. sp.

*) Diese und ăhuliche Arten sind von Robinoan-Desvoidy zur Gattung Sturmia vereinigt worden, welcher Name wegen mehrfacher früherer Anwendung auf Pflanzengattungen verworfen werden muss, und für den später Rondani den übel gebildeten Namen Blepharipa gewählt hat. 
Im Mai im Kasan sehr selten.

AnthomyiacilicruraRond. - corvina Lw. n. sp. Im Mai bei Orsova im Grazkathale sehr selten.

Pegomyia vittigera Ztt.

- hyoscyami Reaumur.

- mitis Mg.?

- bicolor Wiedem.

Azelia Staegeri Ztt.

- cilipes Hal.

- Zetterstedtii Rond.

- aterrima Mg.

Homalomyia pardalina Rond.

- canicularis L.

- obesa Lw. n. sp. Im Juni bei Orsova und Herculesbad auf Laub ziemlich selten.

- monitis Hal.

- scalaris F.

- coracina Lw. n. sp. Im Juni bei Herculesbad sehr selten.

- incisurata Ztt.

- armata Mg.

- cothurnata Lw. n. sp. Im Juni im Sesseminthale selten.
Homalomyia lepida

Wieden.

- serena Ztt.

-- herniosa Rond.

- aerer Mg.

- fasciculata Lw.

n. sp. Im Junibei Herculesbad sehr selten.

Eustalomyia*) hilaris Fll. Hylemyia variata Fll.

- strigosa F.

- nigrimana IIg.

- conica Wiedem.

- maculata Macq. Spilogaster duplicatus $\mathrm{Mg}$.

- uliginosus Fll.

- consimilis Fll.

- pertusus Mg.

- vespertinus Fll.

- quadrimaculatus Fll. Aricia lucorum Fll.

- lardaria F.

- marmorata Ztt.

- carbo Schin.

- umbratica Mg.

- pura Lw. n. sp. Im Juni bei Herculesbad sehr selten.

- laeta Fll.

- trimaculata Bouché.

- erratica Fll.
Aricia pagana F.

- angelicae Scop.

- urbana $\mathrm{Mg}$.

- aculeata Lw. n. sp. Im Juli bei Herculesbad sehr selten.

- pallida $\mathrm{F}$.

- populi $\mathrm{Mg}$.

- variegata Mg.

- fuscata Fll,

- trigonalis $\mathrm{Mg}$.

Lasiops semicinerea Wiedem.

- cincta Z Ztt.

Hydrotaea occulta Mg.

- silvicola Lw.

- dentipes $\mathrm{F}$.

- dentimana Mg.

- armipes Fll.

- meteorica L.

- amoena Lw. n. sp.

In Mai und Juni im

Kasan ziemlich selten.

- cinerea R. D.

Ophyra leucostoma Wied.

Dialyta atriceps Lw.

Limnophora riparia Fll.

- pulchriceps Lw.

- triangula Fll.

Brontaca**) polystigma

Mg.

*) Herr Dr. Löw hat in seiner Sammlung diejenigen Hylemyia-Arten, denen die Krenzborsten der Stirn fehlen und deren Männchen eine breitere Stirn haben, unter dem Namen Eustalomyia generisch abgesondert.

**) Meigens Anthomyia polystigma passt in keine der bisher erichteten Anthomyiden-Gattungen; Herr Dr. Löw hat sie in seiner Sammlung mit A. tonitrui Wiedem. und anderen dieser verwandten Arten $\mathrm{znr}$ Gattung Brontaea vereinigt. 
Lispe simplicissima Lw.

- tentaculata Deg.

Myopina reflexa R. D.

Syllegoptera ocyptcrata

$\mathrm{Mg}$.

Atherigona varia Mg.

Mycophaga fungorum

Deg.

Coenosia inornata

Lw. n. sp. Im Mai

bei Semlin in Auen auf niederen Laubpflauzen häufig.

- tigrina F.

- alma Mg.

- globuliventris Ztt.

- mollicula Fll.

- tricolor Ztt.

- nana Ztt.

- pedella Fll.

Chelisia monitis $\mathrm{Mg}$. Cordylura ciliata Mg.

- albilabris F.

- albipes Fll.

- glaucescens Lw.

Norellia spinipes Mg.

- spinimana Mg.

Scatophaga inquinata Mg.

- stercoraria L.

- squalida Mg.

Helomyza affinis $\mathrm{Mg}$.

- similis Mg.

- ustulata Mg.

- olens Mg.

- univittata v. Roser.

Eccoptomera emarginata Lw.
Eccoptomera pallescens Mg.

Oecothea fenestralis Fll. Blepharoptera modesta $\mathbf{M}$.

- serrata L.

- brachypterna Lw.

n. sp. Im Juni bei Mehadia an Baumstämmen sehr selten.

- caesia Mg.

Teplnochlamys rufiven$t v$ is $\mathrm{Mg}$.

- laeta $\mathrm{Mg}$.

Diyomyza anilis Fll. Lncina fasciata $\mathrm{Mg}$. Pelidnoptera nigripennis $\mathrm{F}$.

Sciomyza cinerella Fll.

- dubia Fll.

Tetanocera elata F.

- ferruginea Fll.

- punetulata Scop.

- Chaerophylli F.

Limnia marginata $\mathrm{F}$.

- unguicornis Scop.

Psila fimetaria $\mathrm{L}$.

Psila rosae F.

- nigricornis $\mathrm{Mg}$.

Chyliza atriseta $\mathrm{Mg}$.

- annulipes Macq.

- leptogaster Panz.

- vittata $\mathrm{Mg}$.

Calobata calceata Fll.

- ephippinm $\mathrm{E}$.

- adusta Liw.

- trivialis Lw.
Micropeza corvigiolata $\mathrm{L}$.

- angustipennis Lw.

Pteropoecila lamed Schrk.

Ptilonota centralis F.

Ortalis ruficeps $\mathrm{F}$.

- levigat a Lw. n. sp. Mit der vorigen Art selten.

- Kowarzii Lw. n.sp. Im Mai bei Orsova sehr selten.

Platystoma tegularia Lw.

- biseta Lw.

Seoptera vibrans L.

Acidia Heraclei L.

- Lychnidis E.

Rhagoletis Cerasi L.

Trypeta falcata Scop.

Urophora terebrans Lw.

Carphotricha guttularis

$\mathrm{Mg}$.

Oxyphora Sehneideri

LW.

Oxyna parietina I. Tephritis cineta Lw.

- postiea $\mathrm{Lw}$.

Palloptera ustulata Fll.

Lonchaee dasyops $\mathrm{Mg}$.

- Deutschii Ztt.

- chorea F.

- inaequalis Lw. n. sp. Im Mai nnd Juni bei Herculesbad und Plavischeviza hänfig.

- flavidipennis Ztt.

Sapromyza longipennis $\mathbf{F}$.

- lupulina $\mathrm{F}$. 
Sapromyza flaviventris Costa.

- fasciata Fll.

- plumicornis Fll.

- pallidiventris Fll.

- rorida Fll.

- pracusta Fll.

- bivmbrata Lw.

- decempunctata Fll.

- tetrachaeta Lw.

n. sp. Im Juni im Kasan sehr selten.

Larxania aenea Fll.

OpomyzagerminationisL.

Balioptera tripunctata Fll.

Scyphelle lutea Fll.

- flava L.

- latifrons Lw. n.sp.

Mit den beiden vori-

gen Arten selten.

Sepsis cynipsea $\mathrm{L}$.

- punctum F.

Nemopoda cylindrice $\mathrm{F}$. - stercoraria R. D.

Piophila nigriceps $\mathrm{Mg}$.

- nigrimana $\mathrm{Mg}$.

- casei L.

Saltella chaerophylli

Schrk.

Madiza glabra Fll.

Notiphila riparia $\mathrm{Mg}$.

- cinerea Fll.

- dorsata Stenh.

- nigricornis Stenh.

Discocerina obscurella

Ig.
Discocerina nigrina $\mathrm{Mg}$.

- pulicaria Hal.

Gymnopa subsultans $\mathrm{F}$. Athyroglossa glabra Mg.

- nudiuscula Lw. n. sp. Herculesbad. Mit der vorigen Art sehr selten.

Hydrellia griseole Fll.

- fulviceps Stenh.

- nigricans Stenh.

- modesta Lw.

Parydra pusilla $\mathrm{Mg}$.

- fossarum Hal.

- aquila Fll.

- cognata Lw.

- coarctata Fll.

- quadripunctata Mg.

- littoralis Mg.

Ephydra riparia Fll.

Scatella sorbillens Hal.

- stagnalis Fll.

Diestata inornata Lw.

Stegana curvipennis Fll. Amiota variegata Fll.

Scaptomyza graminum Fll.

Drosophila maculata Duf.

- transversa Fll.

- tristis Fll.

- obscura Fll.

- rufifrons Lw. n. sp. Mit Dr. tristis sehr selten.

- ampelophila Lw.

Drosophila funebris $\mathbf{F}$. Dicraeus obscurus
Lw. n. sp. Im Mai ausOrsova sehr selten. Oscinis quinquangula Lw. n. sp. Im Mai um Orsova sehr selten.

- cbdominalis Ztt.

Centor Cercris Fll.

Diplotoxa messoria Fll. Chlorops taeniopus Mg.

- minuta Lw.

- serena Lw.

Chloropisca ornata $\mathbf{M g .}$ Crassiseta cornuta Fll. Ochthiphila juncorum Fll. Lobioptera speciosa Mg. - ludens Wahlb.

Desmometopa atrum Mg. Agromyza obscurella Fll.

- abiens Ztt.

- geniculata Fll.

- reptans Fll.

- errans Mg.

- aeneiventris Fll.

- trivittata Lw.n.'sp. Im Mai bei Herculesbad sehr selten.

Ceratomyza denticomis Panz.

Napomyza lateralis Fll. Phytomyza affinis Fll.

- flavoscutellata Fll.

- albipennis Fll.

- obscurella Fll.

Borborus nitidus $\mathrm{Mg}$.

- niger Mg.

- suillorum Hal. 
Sphaeocera subsultans F. Limosina crassimana - pusilla Fll.

Limosina limosa Fll.

- pumilio Ztt.

- lutosa Stenh. Hal.

- coxata Stenh.

- geniculata Macq.

- ferruginata Stenh.
Phora florea $\mathrm{F}$.

- mordellaria Fll.

- rufipes $\mathrm{Mg}$.

- crassicornis $\mathrm{Mg}$.

Gymnophora arcuata Mg. 


\section{Die Dipteren-Gattung Chrysotus Meig.}

Von

\section{Ferdinand Kowarz,}

k. k. Telegraphen-Beamten in Asch.

(Hiezu Tafel XIII.)

(Vorgelegt in der Sitzung vom 7. October 1874.)

(Aus den Verhandlungen der k. k. zoologisch-botanischen Gesellschaft in Wien [Jahrgang 1874] besonders abgedruckt.)

Ausser mehreren Arten der Gattung Medeterus Fisch. sind in der Familie der Dolichopoden nur noch die Mehrzahl der in Europa einheimischen Arten der Gattuug Chrysotus Mg. bisher nicht genügend bekannt; die Ursache dürfte wohl in der Schwierigkeit - brauchbare Merkmale zur Unterscheidnng der einzelnen, meist kleinen Arten aufzufinden, - gelegen sein. In der nachfolgenden Arbeit, die durchaus nicht den Anspruch macht, erschöpfend zu sein, habe ich die Wahl relativer und subtiler Unterschiede der einzelnen Arten nicht umgehen können und daher durch ausführliche Beschreibungen derselben und Vergleichungen mit den nächststehenden ähnlichen Arten eine Erleichterung in sicheren Bestimmen angestrebt. Die hie und da ausgesprochenen Zweifel und Vermuthnngen zu berichtigen, muss ich denjenigen Herren Dipterologen überlassen, welehe Gelegenheit haben, die typischen Exemplare der Autoren genauer zu untersuchen.

Ehe ich zu der Untersuchung der Gattung Chrysotus schreite, drängt es mich, dem Herrn Dr. H. Loew in Guben, der mich mit den werthvollsten Rathschlägen und mit seiner reichhaltigen Chrysoten-Sammlung unterstützte, dem Herrn A. Rogenhofer, der nir die Chrysotus-Arten der Winthem'schen, Egger'schen und Sehiner'schen Sammlung aus dem k. k. Hof-Naturaliencabinet in Wien zur Benützung übersendete, und den Herren J. Mik und J. v. Bergenstamm in Wien, Dr. Kriechbaumer und A. Hiendlmayr in München und Herru Dr. Grzegorzek in Podegrodzie, welche mir ihr gesammtes ChrysotenMaterial zur Verfügung stellten, in der verbindlichsten Weise zu danken.

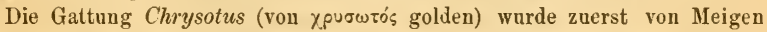
im IV. Bande seiner ${ }_{n}$ systematischen Beschreibung der bekannten europäischen, zweiflügeligen Insecten " errichtet und von Herrn Dr. H. Loew, nach Ausscheidung einiger, insbesonders schon von Meigen (Chr. distendens Mg. und Chr. laetus Mg. = molliculus Fll.) und nach ihm von Zetterstedt (Chr. pumilus Mg., Chr. molliculus Fll. und Chr. concinnus Ztt.) dahin gebrachten, aber in andere Dolichopoden-Gattungen gehörigen Arten (vide ${ }_{n} N_{\text {Neue Beiträge }}{ }^{\mathrm{V}} \mathrm{V}$. 1857) in den ${ }_{n}$ Neuen Beiträgen" VIII. 1861 und in den ${ }_{n}$ Monographs of the Diptera of 
North Amerika“, Part. II. 1874. 171, schärfer begrenzt. Nach Voraussetzung des allgemeinen Dolichopoden-Charakters würde es zur Charakterisirung der Gattung Chrysotus genügen, blos die an den beiden letzterwähnten Stellen gegebenen Gattungsdiagnosen zu wiederholen; doch halte ich es mit Rücksicht auf die unten folgenden Beschreibungen, welche nur europäische Arten behandeln, für geboten, noch diejenigen Merkmale in die Gattungscharakteristik aufzunehmen, welche ich ausser den gedachten als allen Arten gemeinsam gefunden habe, um dadurch die noch engere Begrenzung der Gattung Chrysotus in meiner Auffassung $\mathrm{zu}$ rechtfertigen; es sind folgende:

Stirn breit, zum Scheitel hin allmälig erweitert, jederseits mit einer nach vorwärts gebogenen Scheitelborste am Augenrande und einem nach rückwärts gerichteten Borstenpaar zwischen den Ocellen. Augen kurzhaarig - im lebenden Zustande prachtvoll grün oder rothgolden - bei den Männchen der meisten Arten auf der Mitte des Gesichtes einander so genähert, dass sie sich fast berühren und dass das unter den Fühlern mit einer spitzwinkligen Furche versehene Gesicht ein kleines Dreieck bildet, welches sich als feine Linie bis zum Mundrande fortsetzt; sind die Augen bei den Männchen auffallend getrennt, so ist das Gesicht zum Mundrande hin wenigstens etwas verschmälert; in weiblichen Geschlechte ist dasselbe stets breit, unterhalb der Mitte, nahe am Angenrande etwas höckerig erhoben und mit einer weisslichgrau schimmernden Bestäubung bedeckt. Hinterkopf von Cilien umrahmt, welche in der Nähe des Scheitels schwarz, am Augenrande aber weiss und mehr oder weniger dicht sind. Fühler kurz, meistens schwarz, das erste Glied dümu, uubelıart; das zweite transvers, kurz beborstet; das dritte von verschiedener Grösse, nierenförmig, dicht behaart, mit subapicaler, pubescenter Borste. Dic Taster, den kurzen Rüssel seitlich deckend, sind flach, bei den Männchen meist sehr klein, selten durch mässige Länge und Breite auffallend, gelb schimmernd, bei den Weibchen immer breit und so wie das Gesicht grau schimmernd. - Thorax metallisch glänzend, an den Seiten grauschinmernd, vor dem Schildchen ohne Eindruck, ausser der Beborstung an Scitenrande, anf dem Rücken mit vier Reihen schwarzer Borsten und zwischen den mittleren Reihen fast bei allen Arten mit einer Doppelreihe kurzer, steifer Härchen auf der Mittellinie. Schildehen metalliseh glänzend, unbehaart, mit je einer grösseren und einer kleineren Borste an Seitenrande. - Flügel in Unrisse elliptisch oder oval, ziemlich kurz, leblaft irisirend; vierte Längsader einfach, bei den meisten Arten unmittelbar hinter der hinteren Querader etwas ausgebogen, aber in weiteren Verlaufe gerade und mit der dritten Längsader parallel, an der Flügelspitze oder nahe vor derselben mündend, sechste Längsader vorlıandeı, die hintere Querader weit von Flügelrande entfernt. - Schüppchen klein, am Rande gewimpert; Schwinger unbedeckt, bei allen Arten hellgelb. - Hüften mit grauer, an den vordersten oft auffallend weissgrau schimmernder Bestäubung bedeckt, die vorderen Hüften überdiess mit mehr oder weniger borstenartiger Behaarung und die Hinterhüften auf der Aussenseite, nahe an der Basis, mit einer abstehenden, schwarzen Borste bekleidet. - Beine ziemlich kurz und einfach, aber verhältnissmässig kräftig 
gebaut; die Schenkel besonders auf der Vorderseite mit borstenartiger, nach abwärts gerichteter Behaarung; alle Schienen an der Spitze beborstet; Vorderschienen auf der Oberseite in der Nähe der Basis meistens mit einem kurzen Borstchen, oder nebst diesem mit einem zweiten noch zarteren Borstchen hinter der Mitte, oder - ausser an der Spitze - ganz unbeborstet; nur selten sind die Vorderschienen etwas auffallender als gewühnlich gewimpert; Mittelschienen auf der Unterseite unbeborstet, auf der Oberseite dagegen ausser zwei bis drei kleinen, meist unscheinbaren Nebenbörstchen in der Regel mit zwei auffallenden Borsten; die eine dieser zwei Borsten steht in der Nähe der Basis, die andere - bisweilen fehlend - steht hinter der Mitte der Schiene; selten nur fehlen diese beiden Borsten; Hinterschienen auf der Oberseite mit drei bis vier meist ungleichartigen Borstenpaaren, bei den Männchen mit mehr oder weniger auffallenden, dichten, kammartig gereihten Wimpern verziert, welche sich, allmälig kïrzer werdend, auch auf die Hintertarsen fortsetzen. Ausser an der Spitze der einzelnen Glieder sind die Tarsen aller Beine unbeborstet; der Metatarsus der vorderen Beine ist deutlich länger, der der Hinterbeine nur wenig länger als das zweite Tarsenglied. - Hinterleib ziemlich kurz, metallisch glänzend, mit kurzer, an den einzelnen Ringrändern etwas längerer und mehr borstlicher Behaarung; bei den Männchen am Ende anf der Unterseite mit einer Auskerbung, in welcher die nach vorn gekrümmiten inneren, die lamellenartigen, bewinperten änsseren Anhänge des kleinen, kurz behaarten, am Hinterleibsende nur wenig vorragenden Hypopygiuns und die nach abwärts gerichtete - im ansgestreckten Zustande aber nach rüchwärts gebogene - Scheide des sehr dünnen Penis meist ganz verborgen sind. Der Hinterleib des Weibchens, in lebenden Znstande eiförmig mit kaum merklich vorstehender Legeröhre, erscheint im getrockneten Zustande an Ende gerade abgestutzt und die Legeröhre ist meistens ganz zurïckgezogen.

Unter allen Dolichopoden-Gattungen sind Diaphorus Mg., Asyndetus Lw. und Nematoproctus Lw. von der Gattung Chrysotus am schwierigsten zu unterscheiden; es ist daher nothwendig, in Kürze ihre Differenzen zu erwähnen: Bei den genannten drei Gattungen hat die Fühlerborste eine dorsale Stellung, die Flügel sind länger und an der Basis wegen des mehr vortretenden Hinterwinkels breiter, die Beine sind schlanker und der Hinterleib gestreckter als diess bei Chrysotus der Fall ist. - Diaphorus und Asyndetus haben im männlichen Geschlechte stets auf dem Gesichte breit getrennte Augen, das Gesicht selbst ist eingesenkt, die Pulvillen der Vorderbeine sind meist verlängert, am Hypopygium finden sich vier steife. Borsten und oft auffallend entwickelte Analanhänge. Die Diaphorus-Männchen zeichnen sich überdiess durch, in der Regel auf der Stirne sich berührende Aingen und Asyndetus in beiden Geschlechtern durch die grosse Divergenz der dritten und vierten Längsader und durch das Aufhören dir Pandader an der Mündung der dritten Längsader aus. - Nematoproctus hat in beiden Geschlechtern anf der Unterseite der Mittelschienen eine abstehende Borste, im männlichen Geschlechte stets sehr deutlich getrennte Augen, ein gleichbreites Gesicht und meistens verlängerte Analanhänge. 
Ueber die Verwandlungsstadien der Chrysotus-Arten ist bis jetzt nichts bekannt geworden. Die entwickelten Fliegen erscheinen, je nach den klimatischen Verhältnissen der Gegend, im Mai oder Juni und treiben bis zum Spätherbste ihr munteres Spiel an windfreien Tagen unter dem hellen und warmen Einflusse der Sonne, meist in der Nähe vom Wasser auf Schlamm, auf dem Laube der Uferbüsche, wohl auch entfernt vom Wasser anf Wiesen und Brachfeldern, auf Feldwegen und Steinen; ihre Bewegungen sind rasch; ihr Gang - wobei die Flügel halb ausgespreitet getragen werden - geschieht ruckweise und wird oft durch Bücken nach Nahrung unterbrochen; ihr Flug ist kurz und mehr sprungartig.

Wie schon oben in der Einleitung hervorgehoben, sind die ChrysotusArten - besonders im trockenen Zustande - schwer zu bestimmen; beispielsweise wird bei denjenigen Arten, deren Männchen über dem Mundrande sehr genäherte Augen haben, je nach der Weise des Eintrocknens das Gesicht durch die Augen noch mehr verengt oder ganz verdrängt; sind die Hinterschienen der Männchen durch das Trockenwerden vou der natürlichen Gestalt abgewichen, so ist auch die Art der Wimperung derselben selten mit Sicherbeit zu erkennen. - Man berücksichtige daher ausser der allgemeinen Körperfärbung und Körpergrösse vorzugsweise die Gestalt des dritten Fühlergliedes, die Behaarung der vordersten Hüften und die Beborstung der vorderen Schienen. Man täusche sich nicht über die Farbe der Taster und über die Farbe der Wimpern der Deckschüppchen, welche - auch wenn sie dunkel sind - stets heller schimmern.

\section{Tabelle zum Bestimmen der männlichen Chrysotus.}

1. Schenkel vorherrschend gelb gefärbt . . . . . . . . . . 2 Schenkel vorherrschend schwarz gefärbt . . . . . . . . . 3

2. Hinterschenkel ganz gelb, Vorderhüften schwarz behaart, grosse Art

sp. 1. neglectus. Wied.

Hinterschenkel an der Spitze schwarz ${ }^{1}$, Vorderhüften gelb behaart, kleine Art . . . . . . . . . . . sp. 2. cilipes. Mg.

3. Schenkelknopf der Hinterhüften gelb . . . . . . . . . . 4 Schenkelknopf der Hinterhüften schwarz oder braun . . . . . . 5

4. Drittes Fühlerglied verhältnissmässig gruss, kleine Art. sp. 3. pulchell us. n. sp. Drittes Fühlerglied verhältnissmässig nicht gross, mittelgrosse Art

sp. 4. femoratus. Zitt.

5. Vorderschienen anf der Oberseite deutlicher als gewöhnlich gewimpert, grosse, düster gefürbte Art . . . . . sp. 5. blepharosceles. n. sp. Vorderschienen auf der Oberseite undentlich oder doch nicht auffallend gewimpert

1) Sollte bei diesem Merkmal ein Zweifel obwalten, so entscheidet die Körpergrő die Farbe der Bebaarung der Vorderbüften. 
6. Vorderbüften an der Spitze und meistens auch anf der Vorderseite blassgelb, grosse Art . . . . . . . . sp. 6. cupreus. Macq. Vorderhüften schwarz, höchstens an der Spitze in nur geringer Ansdehnung gelb, mittelgrosse oder kleine Art . . . . . . . . 7

7. Die weisse Behaarung der Vorderhüften sehr deutlich ${ }^{1}$ ), Taster verhältnissmässig gross . . . . . . . . . . . . . 8 Die weisse Behaarung der Vorderbüften undeutlicb, Taster meistens klein 10

8. Stirn weissschimmernd, Gesicht sehr schmal, Augen fast zusammenstossend . . . . . . . . . . . . sp. 7. suavis. Lw. Stirn nicht weiss schimmernd, Augen durch das Gesicht deutlich getrennt 9

9. Wimpern der Deckschüppchen weisslicb, Gesicht schmal, weiss bestäubt, lebhaft blaugrün gefärbte Art . . . . . sp. 8. albibarbus. Lw. Wimpern der Deckschüppehen schwärzlich, Gesicht verhältnissmässig breit, grau oder weisslich grau bestänbt, dunkel stahlblau oder violet gefärbte Art . . . . . . . . . . . sp. 9. laesus. Wied.

10. Drittes Fühlerglied verhältnissmässig gross, kleine Art . . . . . . 11

Drittes Fühlerglied verhältnissmässig nicht gross . . . . . . . . 12

11. Drittes Füblerglied querrundlich, alle Schienen schwarz, Mittelschienen auf der Oberseite wenigstens mit zwei Borsten. sp. 10. amplicornis. Ztt. Drittes Fühlerglied mit deutlicher Ficke am Ende, sammt dem zweiten Glied dreieckig erscheinend, vordere Schienen gelb, Nittelschienen anf der Oberseite mit nur einer Borste. . . sp. 11. monochretus. n. sp.

12. Hinterschienen ganz oder vorherrschend rostgelb . . . . . . . 13 Hintersehienen ganz oder vorherrschend schwarz . . . . . . . . 14

13. Drittes Fühlerglied verhältnissmässig sehr klein, Fühlerbasalglieder meistens roth . . . . . . . sp. 12 microcerus. n. sp. Drittes Füblerglied nur mässig klein, Fühler immer ganz schwarz

sp. 14, varians. n. sp.

14. Vordere Schienen schwarzbraun, Hinterschienen ausser ler gewöhnlichen Beborstung auf der Oberseite ohne dentliche Wimperung .

sp. 13. melampodius. Lw.

Vordere Schienen gelb oder rostgelb, höchstens die Mittelschienen dunkler, Hinterschienen dentlich gewimpert . . . . . . . . 15

15. Gesicht weiss schimmernd, Körperfärbung lebhaft blangrün oder goldgrün, Wimpern der Deckschüppchen meistens blassgelb. sp. 15. gra m ine us. F1l. Gesicht metallisch grün, Körperfarbe ziemlich dunkel erzgrün, Wimpern der Deckschüppchen meistens dunkel, goldgelb schimmernd . . . . 16

16. Das dritte Fühlerglied mit zugespitzter Ecke an Ende sp. 16. angulicornis. n. sp. Das dritte Fühlerglied an Ende stmupf . . . sp. 14. varians n. sp.

1) Man betrachte die Vorderhüften von der Saite; sind dieselhen an der Spitza arhwarx behaart, so gehört die Art nicht hieher, weun sich auch eiue theilweise weissliche Brhaarnng an den Vorderhüften zeigen sollte 


\section{Tabelle znm Bestimmen der weiblichen Chrysotus.}

1. Vorderhüften weiss behaart . . . . . . . . . . . . . 2

Vorderhüften schwarz - oder nur theilweise weiss behaart . . . . 4

2. Schenkel vorherrschend gelb gefärbt . . . . . sp. 2. cilipes. Mg. Schenkel vorherrschend schwarz gefärbt . . . . . . . . . . 3

3. Wimpern der Deckschüppchen weisslich . . . . sp. 7. suavis. Lw. Wimpern der Deckschüppchen schwärzlich . . sp. 9. la esus. Wied.

4. Schenkelknopf der Hinterhüften gelb . . . . . . . . . . . . 5

Schenkelknopf der Hinterhüften schwarz oder brann . . . . . . . 7

5. Drittes Fühlerglied verhältnissmässig gross, kleine Art

$$
\text { sp. 3. pulchellus. n. sp. }
$$

Drittes Fühlerglied verhältnissmässig nicht gross . . . . . . . . 6

6. Hinterschienen meistens ganz gelb, grosse Art. sp. 1. neglectus. Wiell. Hinterschienen an der Spitze schwarz oder braun, nittelgrosse Art

sp. 4. femoratus. Ztt.

7. Hinterschienen schwarz . . . . . . . . . . . . . 8

Hinterschienen gelb . . . . . . . . . . . . . 9

8. Schenkelkuopf der Vorderhüften nnd meistens auch die Vorderhüften wenigstens an der Spitze blassgelb, grosse Art sp. 6. cupreus. Macq. Schenkelknopf der Vorderhüften schwarz oder braun, Vorderhüften ganz schwarz, kleinere Art. . . . . . . . sp. 10. amplicornis. Ztt.

9. Das dritte Fühlerglied verhältnissmässig gross, Mittelschienen mit nur einer langen Borste anf der Oberseite. . sp. 11. monochaetus n. sp. Das dritte Fühlerglied klein oder ziemlich klein, Mittelschienen mit zwei langen Borsten auf der Oberseite . . . . . . . . . . . 10

10. Die gelbe Färbung an der Spitze der vorderen Schenkel nimmt etwas mehr als den vierten Theil des Schenkels ein, Fühlerbasalglieder meistens roth . . . . . . . . . . . sp. 12. microcerus. n. sp. Die gelbe Färbung an der Spitze der vorderen Schenkel nimmt kaum den vierten Theil des Schenkels ein, Fühler immer ganz schwarz . . 11

11. Wimpern der Deckschüppchen meistens blassgelb, Körperfärbung blangrïn oder goldgrün, Schienen ziemlich hellgelb. sp. 15. gramineus. Fll. Wimpern der Deckschüppchen dunkel, bräunlichgelb schimmernd, Körperfärbung mehr erzgrün, Schienen ziemlich rostgelb. sp. 14. varians $\mathrm{n}$. $\mathrm{sp}$.

\section{Beschreibung dor Arten.}

1. Chr. negleotus Wied. Laete viridis, antennarum nigrarum articulo tertio mediocri, tegulis pallide-ciliutis, trochanteribus tibiisque omnilnus flavis.

$\sigma^{7}$ Oculis fere contiguis, facie viridi, ex allidomicante, palpis parvis, flanis, femoribus fluvis, tibiis posticis confertim ciliatis. 
오 Facie lata, albo-cinere $\bar{a}$, palpis nigricantilus, femoribus aut totis fluvis, aut nigris, in basi et in apice angustius vel latius flavis, aut unterioribus in apice tantum flavis.

Long. corp. of 2.2-2.5, ㅇ 2.5-2.8 Mm. (Fig. 1-5).

Syn. Dolichopus neglectus. Wied. Zool. Mag. I. 74. 22. 1818.

- Dolichopus viridulus. Fll. Dol. 18. 23. 1823.

- Chrysotus neglectus. Mg. Syst. Beschr. IV. 41. 1. 1824.

- Chrysotus femoralis. Mg. Syst. Beschr. IV. 42. 5. 1824. ?.

- Chrysotus taeniomerus. Mg. Syst. Beschr. VI. 362. 10. 1830.

- Chrysotus viridulus. Ztt. Dipt. Scand. II. 482. 2. 1843.

- Chysotus taeniomerus. Ztt. Dipt. Scand. II. 485. 6. 1843. var. a.

- Chrysotus viridulus. Walk. Ins. Br. Dijt. I. 217. 3. 1851.

- Chrysotus neglectus. Lw. Neue Beitr. V. 48. 1857.

- Chrysotus neglectus. Schin. Fauna austr. I. 186. 1862.

$\sigma^{7}$. Stirn metallisch grün; Augen sich fast berührend; Gesicht metallisch grün, weisslich schimmernd; Fühler schwarz, drittes Fühlerglied mässig gross; T'aster gelb, klein. Rückenschild und Schildchen lebhaft metallisch grün oder blaugrün, sehr wenig bestäubt. Flügel glashell. Deckschüppchen gelb und gelb gewimpert. Vorderhüften ganz gelb, oder an der Basis in grösserer oder geringerer Ausdehuung verdunkelt, schwarz behaart; Mittel- und Hinterhüften schwarz; Schenkelknopf aller Hüften gelb. Beine gelb, nur die Tarsen gegen ihr Endglied hin braun; dunkle Stücke haben auf der Obcrseite der Hinterschenkel eine mehr oder weniger deutliche, dunkle Strieme, die sich in der Nähe der Spitze manchmal zu einem schwarzen, metallisch grün schimmernden Fleck erweitert; in letzterem Falle sind auch die Hinterschienen an der Spitze verdunkelt und die Hintertarsen vorherrschend schwarz gefärbt. Vorderschienen mit einem kurzen Borstchen in der Nähe der Basis und meistens einem zweiten, zarteren hinter der Mitte; Mittelschienun nit den gewühnlichen zwei Borsten und nicht selten mit drei deutlichen Nebenborsten versehen; Hinterschienen und auch das erste und zweite Tarsenglied der Hinterfüsse noch deutlich gewimpert. Hiuterleib metallisch grün oder blaugrün; die äusseren Analanhänge kaum vorragend, bräunlich.

․ Gesicht breit, sammt den scluwarzen Tastern weissgrau bestäubt. Vorderhüften ausgedehnter schwarz als beim Männchen. Schenkel meistens gell, die vorderen auf der Mitte, die hintersten in der Nähe der Spitzie breit schwarz; diese schwarze Färbung der Schenkel hat jedoch eine sehr verschiedene Ausdehnung: bei helleren Stücken beschränkt sie sich auf eine wischartige Strieme an den vorderen SchenkeIn und einen verwaschenen Fleck vor der Spitze der Hinterschenkel; bei dunkleren Stücken sind die Schenkel uit Ausnahme der Spitze der vorderen Schenkel ganz schwarz und die Hinterschienen au der Spitze etwas gebräunt; in seltenen Fällen kommen auch Stücke mit gauz gelb gefurbten Sehenkeln vor.

Vaterland: Oesterreich, Ungarn, Deutschland, Russland, Scandinavien und England. 
A nmerkung. Chr. neglectus ist besonders im weiblichen Geseblechte in der Färbung der Sehenkel eine überaus veränderliche Art und fast nur an der ziemlich constant erhebliehen Körpergrösse von den ihr ähnlichen Arten zu unterseheiden. - Die Angabe Meigen's, dass die Vordersehenkel des Weibehens an der Spitzenhälfte schwarz seien, dürfte wohl auf einen Schreibfehler zurüekzuführen sein. - Dass Chr. taeniomerus $Q \mathrm{Mg}$. wirklieh als synonym zu obiger Art gehört, kann ich nach einem typisehen Stücke Meigen's, welches sich in der Winthem'schen Sammlung befindet, bestätigen.

2. Chr. cilipes $\mathrm{Mg}$. Aureo-viridis, antennarum nigrarum articulo tertio majusculo, tegulis pallide-ciliatis, pedibus flavis, femorum posticorum apice nigro.

$\sigma^{\top}$ Oculis fere contiguis, facie viridi, palpis parvis, flavis, tibiis posticis confertim ciliatis.

ㅇ Facie latā, albo-cinereā, palpis nigricantibus, in apice plerumque pallescentibus.

Long. eorp. 1.8-2 Mm. (Fig. 18-20).

Syn. Chrysotus cilipes. Mg. Syst. Beselır. IV. 41. 3. 1824. o’'

- Chrysotus cilipes. Walk. Ins. Br. Dipt. I. 217. 4. 1851.

- Chrysotus cilipes. Ztt. Dipt. Scand. XII. 4620. 9-10. 1855. 오.

- Chrysotus cilipes. Lw. Neue Beitr. V. 48. 1857. $\sigma^{7}$.

- Chrysotus cilipes. Schin. Fauna austr. I. 186. 1862. $\sigma^{\top}$.

$\sigma^{7}$. Stirn und Gesicht metallisch grün; Augen fast zusammenstossend, Fühler schwarz, das dritte Fühlerglied ziemlieh gross; Taster klein, gelb. Rückenschild goldgrün, undeutlieh bestäubt; Schildehen blaugrün. Flügel blassgrau gefärbt; Deckschüppehen gelb und blassgelb gewimpert. Vorderhüften gelb, an der Basis bisweilen verdunkelt, gelblich behaart; Mittel- und Hinterhüften sehwarz; Schenkelknöpfe und Beine gelb, nur die Hintersehenkel und Hintersehienen an der Spitze sehwarz; Tarsen der vorderen Beine von der Spitze des Metatarsus an braun, die der Hinterbeine mit Ausnahme der gelben Basis des Metatarsus, sehwarz. An den Vorderschienen das Borstchen in der Nähe der Basis vorhandeu, an den Mittelschienen die gewöhnlichen zwei Borsten auffallend; Hintersehienen mit recht auffallender Wimperung, welehe sich auch deutlich noch auf die beiden ersten Tarsenglieder fortsetzt. Hinterleib goldgrüı oder blaugrün; dio inneren Analaihhänge nur wenig gebogen, ziemlich stumpf, sammt den bräunlich gefärbten äusseren verborgen.

\&. Gesicht breit; Taster sehwärzlich, an der Spitze meistens schmutzig gell, und wie das Gesicht weissgrau bestäubt. Vorderhüften an der Basis merklicher verdunkelt als beim Mänuchen; Hinterschienen ganz gelb oder an der Spitze in nur geringer Ausdehnung gebrïunt.

Vaterland. Oesterreich, Ungarn, Deutschland, Schweden und England.

Anmerkung. Die Art, welehe Zetterstedt l. c. beschreibt, wäre wenn er wirklich beide Geschlechter unterschieden hat - allerdings von $\mathrm{Chr}$. cilipes $\mathrm{Mg}$. verschieden; weil jedoch Zetterstedt von einem bestimmten Geschlechte nicht spricht, in der Diagnose seiner Art ein weissliches Gesicht zusehreibt und 
in einer Anmerkung, neben dem Citate Meigen's, über die Hinterschienen ausdräcklich sagt: "Tibiae posticae non nisi summo apice dilute fuscanae, et latere exteriori (in medio late) modice setulosue, earum basi apiceque submudis", so darf man wohl annehmen, dass er nur das Weibchen des Chr. citipes beschrieben hat.

3. Chr. pulchellus n. sp. Aeneo-viridis, antennarum nigrarum articulo tertio magno, tegulis pallide-ciliatis, trochanteribus flavis, femorilnus nigris, basi tamen posticorum tibiisque anterioribus totis flavis.

$\sigma$ Facie mire angusta, aeneo-viridi, palpis paris, pallide-flavis, tibiis posticis aut nigris, aut in basi angustius vel latius ferrugineis, ciliatis.

Q Facie latā, cinereā, palpis nigricantibus, tibiis posticis ferrugineis, in apice nigris.

Long. corp. $\sigma^{\pi} 1.5$, $1.8 \mathrm{Mm}$. (Fig. 15).

Syn.? Chr. taeniomerus. Ztt. Dipt. Scand. II. 486. 1843. Q var. b.

$\sigma^{7}$. Stirn und das über dem Mundrande sehr schmale Gesicht metallisch blaugrün; Fühler schwarz, das erste Fühlerglied schmal, stielartig, das dritte gross; Taster klein, blassgelb. Rückenschild erzgrün, vor dem Schildchen, wie dieses, mehr blaugrün, undeutlich bestänbt. Flügel blassgrau gefärbt: Deckschüppchen gelb und gelb gewimpert. Hüften schwarz, die vordersten mit schütterer, weisslich schimmernder Behaarung; Schenkelknopf aller Hüften gelb. Schenkel schwarz, die vorderen mit gelben Knieen, die hintersten an der Basis in grösserer oder geringerer Ausdehnung gelb; rordere Schienen gelb, Hinterschienen entweder ganz schwarz oder braun und auf der Oberseite von der Basis her rostgelb oder rostgelb und nur an der Spitze schwarz; der Metatarsus der vorderen Beine gelb, an der Spitze wie die folgenden Tarsenglieder braun: Tarsen der Hinterbe ine schwarz, höchstens der Metatarsus an der Basis gelb. An den Vorderschienen das Börstchen in der Nähe der Basis und an den Mittelschienen die gewöhnlichen zwei Borsten vorhanden; Hinterschienen und der Metatarsus der Hinterbeine deutlich gewimpert. Hinterleib metallisch grün oder blaungrün: Analanhänge verborgen.

․ Gesicht breit, wie die schwärzlichen Taster gran bestäubt; Hinterschienen gelb, höchstens an der Spitze gebräunt.

Vaterland: In Oesterreich, Ungarn und Deutschland sehr verbreitet, wahrscheinlich auch in Scandinavien. Diese Art scheint sich vorzugsweise an Teichufern auf Gräsern aufzuhalten.

Anmerkung. Die Zetterstedt'sche Varietät b von seinem Chr. taeniomerus dürfte wohl zu Chr. pulchellıs gehören; dafür spricht die Grössenangabe und Zetterstedt's eigene Vermnthung, dass diese kleine Varietät eine selbststäıdige Art sein könne; bedauerlicher Weise erwähnł Zetterstedt über das entscheidende Merkmal der Füllergrösse nichts.

4. Chr. femoratus Ztt. Aeneo-viridis, antennarum nigrarum articulo tertio mediocri, tegulis pallide-ciliatis, femoribus nigris, posticorum basi plenuque, trochanteribus omnibus tibiisque anterioribus flavis. 
$0^{\top}$ Oculis fere contiguis, facie viridi, palpis parvis, subfuscis in apice pallide-micantibus, tibiis posticis aut nigris, aut in basi angustius vel latius ferrugineis, confertim ciliatis.

O Facie latā, albo-cinereā, palpis nigricantibus, tibiis posticis flavis, in apice plerumque nigricantibus.

Long. corp. 2-2.2 $\mathrm{Mm}$. (Fig. 22).

Syn. Chrysotus femoratus. Ztt. Dipt. Scand. II. 483. 3. 1843. $\sigma^{7}$.

$\sigma^{7}$. Stirn und das über dem Mundrande sehr schmale Gesicht metallisch grün; Augen sich fast berührend; Fühler schwarz, das dritte Fühlerglied mässig gross; Taster klein, schwärzlich, gelb schimmernd. Rückenschild und Schildchen lebhaft metallisch grün oder blaugrïn, nur wenig grau bestänbt. Flïgel blassgrau gefürbt; Deckschüppchen gelb nnd gelb gewimpert. Hüften schwarz, die vordersten an der Spitze bisweilen gelb gefärbt und an der Vorderseite manchmal weisslich, sonst aber schwarz behaart; Schenkelknopf aller Hüften gelb. Schenkel schwarz, die vorderen an der Spitze und - besonders die Hinterschenkel - oft auch an der Basis gelb; vordere Schienen gelb oder rostgelb, die Mittelschienen wohl anch schwarzbraun; Hinterschienen entweder ganz schwarz oder schwarzbraun und anf der Oberseite von der Basis her in grösserer oder geringerer Ausdehnung rostgelb; Metatarsus aller Beine von der Farbe der Schiene, doch mindestens an der Spitze wie die iibrigen Tarsenglieder braum oder schwarz. An den Vorderschienen das Börstchen in der Nähe der Basis vorbanden, an den Mittelschienen die gewöhnlichen zwei Borsten auffallend, Hinterschienen mit anffallender, auch an den beiden ersten Tarsengliedern noch dentlicher Winperung. Hinterleib metallisch grün, goldgrün oder blangrün; die äusseren Analanhänge brännlich, meist verborgen.

Q. Gesicht breit, wie die schwärzlichen Taster gran bestänbt. Hinterschienen und der Metatarsus der Hinterbeine gelb, an der Spitze schwarz oder braun.

Vaterland: Dänemark; in Oesterreich bisher nur bei Gastein von meinem Freunde Mik und bei Asch nnd Innsbruck von mir selbst gefunden; Herr Professor Kriechbaumer und Herr Hiendlmayr haben obige Art bei München liäufig gefangen.

Anmerkung. Das Männchen des Chr. femoratus wird man an der Wimperung der Hinterschienen, welche ebenso auffallend wie bei $\mathrm{Chr}$. cilipes $\mathrm{Mg}$. ist, gewiss erkennen; weit schwieriger dagegen steht es mit der Unterscheidung des Weibchens von dem ihm schr ähnlichen Weibchen des Chr. neglcctus Wied. und zwar jener Varietät, welche mit Chr. femoratus in der Färbung der Schenkel übereinstimmt; hier ist nur die geringere Grösse das für Chr. femoratus einzig verlässliche und die Färbung der Hinterschienen das noch am meisten zutreffende Unterscheidungsmerkmal. - Die Angabe Zetterstedt's, dass das Gesicht des Weibchens von Chr. femoratus breiter als bei dem Weibchen von Chr. neglectus zn sein scheine, finde ich nicht bestätigt.

5. Chr. blepharoseeles n. sp. $\sigma^{7}$. Obscure viridis, antennarum nigranum articulo tertio minusculo, oculis fere contiguis, palpis parvis, fuscis, in 
apice flavo-micantibus, tegulis fusco-ciliatis, pedibus nigris, tibiis unterionum fusco-ferrugineis, anticorum distincte pubescentibus, posticorum cilia confcrta ferentibus.

Long. corp. 2:5 Mm. (Fig. 21).

ऽ. Stirn dunkel metallisch grün; Augen sich fast berührend; Fühler schwarı, das dritte Fühlerglied verhältnissmässig ziemlich klein, Taster sehr klein, schwärzlich, die noch sichtbare Spitze derselben gelb schimmernd. Rückenschild dunkel metallisch grün, undeutlich grau bestäubt; Schildchen lebhafter blaugrün. Flügel blassbräunlich gefärlt, am Vorderrande getrübt; Deckschüppchen rostgelb, mit schwärzlicher, bräunlichgelb schimmernder Wimperung. Hiiften schwarz und schwarz behaart; Schenkelknopf der vorderen Hüften bräunlichgelb, der Hinterhüften schwarzbraun. Beine schwarz und die vorderen Schienen und Metatarsen rostbraun. Vorderschienen insbesonders auf der Oberseite dentlicher als gewöhnlich gewimpert und ausser dem Börstchen in der Nähe der Basis mit einem zweiten zarteren, von der Wimperung kaum zu unterscheidenden Börstchen hinter der Mitte; Mittelschienen mit den gewöhnlichen zwei Borsten versehen; Hinterschienen sammt dem Metatarsus der Hinterbeine mit auffallender Wimperung. Hinterleib dunkel erzgrün; Analanhänge verborgen.

Vaterland: Das beschriebene Exemplar stammt aus der Gegend von Marktbreit, wo es an den Ufern des Main von Herrn Dr. H. Loew gefangen wurde. In der Winthem'schen Samulung befindet sich dieselbe Art mit der Vaterlandsangabe "Lyon".

Anmerkung. Die obige Art ist durch die auf der Oberseite der Vorderschienen deutlicher als gewöhulich auftretende Wimperung ausgezeichnet; sie unterscheidet sich von dem ihr an Grösse gleichkommenden Chr. cupreus Macq. ausser dem angegebenen Merkmale noch durch die ganz schwarzen Vorderhüften, durch die Beborstung der Vorderschienen und durch die auffallende Wimperung der Hinterschienen. - Die Beschreibung Meigen's von Chr. copiosus köunte man auf Chr. blepharosceles anwenden, letzterer fällt aber gerade durch sein dïster grünes Colorit auf.

6. Chr. cupreus Macq. Obscure viridis, antennarum nigrarum articulo tertio minusculo, tegulis fusco-ciliatis, pedibus nigris, coxarum anticarum apice pallido.

$\sigma^{\top}$ Oculis fere contiguis, palpis parvis, fuscis, in apice pullide-micantibus, tibiis intermediis plerumque set̄̄ tantum unicā instructis.

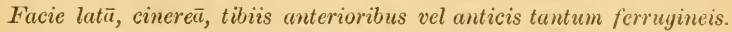
Long. corp. $25 \mathrm{Mm}$.

Syı. Chrysotus cupreus. Macq. Dipt. du Nord de Fr. 20. 5. 1827.

Chrysotus cupreus. Mg. Syst. Beschr. VII. 149. 12. 1838. б' u. q.

Chrysotus cupreus. Lw. Neue Beitr. V. 48. 1857. ơ u. Q.

Chrysotus cupreqs. Schin. Fauna austr. I. 185. 1862.

c`. Stirn und Gesicht dunkel metallisch blaugrün, Augen fast zusammenstussend; Fühler schwarz, das dritte Fühlerglied ziemlich klein; Taster klein, sehwärzlich, blissgelb schimmernd. Rückenschild dunkel metallisch blaugrün 
oder erzgrün, undeutlich gelbbräunlich bestäubt, Schildchen lebhafter blaugrün. Flügel grau gefärbt, an Vorderrande getrübt; Deckschüpjehen gelb, nit schwärzlichen, gelbbräunlich schimmernden Wimpern. Vorderhüften blassgelb, an der Basis schwarz gefärbt, weisslich bestäubt, ziemlich lebhaft weissgrau schimmend und schwarz behart; Mittel- und Hinterhüftelı ganz schwarz; Schenkelknopf der Vorderhüften blassgelb, der Mittel- und Hinterhüften schwarz. Beine schwarz, uur die Vorderschienen sammt Tarsen schwarzbraun; bei einzelnen Stücken ist auch die Basis der Vorderschenkel blassgelb und die Kniespitzen der Vorderbeine sind bräunlichgelb. Das Börstchen in der Nähe der Basis der Vorderschienen sehr zart nnd undentlich; Mittelschienen meistens mit nur ciner, selten mit zwei Borsten; Hinterschieneu spärlich beborstet, mit ziemlich kurzer Wimperung. Hinterleib dunkel metallisch grün; Analanhänge verborgen.

○. Gesicht breit, sammt den scliwarzen Tastern grau bestäubt. Rïckenschild mehr metallisch grün. Vorderhüften meist ansgebreiteter schwarı als beim Männchen, doch an der Spitze und der Schenkelknopf inmer blassgelb. Vordere Schienen an der Basis in grösserer oder geringerer Ausdehnung bräunlichgelb gefärbt und mit der gewöhnlichen Beborstung versehen.

Vaterland: In den südlicheren Gegenden von Oesterreich, Ungarn und Deutsehland, in Frankreich und Italien (von Bergenstamm).

Anmerkung. Obgleich das Weibchen des Chr. cupreus kaum zu verkemnen ist, so dürfte doch ein kurzer Vergleich desselben mit dem Weibchen des Diaphorus nigricans Mg. nicht ganz überflüssig sein, weil sich beide in Grösse und Färbung einander ziemlich näheru und weil die Gattungsmerkmale in Bezug auf die Kopfbildung, die Beschaffenheit des Flügelgeäders und die Beborstung der Beine nicht immer ausreichen, daher eine Täuschung leicht möglich wird: Die Grundfarbe des Rückenschildes ist bei ersterem stets lebhafter, als die mit ziemlich dichter Bestäubung bedeckte des letzteren; Chr. cupreus hat weissliche Cilien an hinteren Augenrande und die Spitze und der Schenkelknopf der Vorderhüften sind gelb, bei $D$. nigricans sind dagegen die gedachten Cilien und Hüftentheile stets schwarz. - Der Zetterstedt'sche $\mathrm{Chr}$. obscuripes seheint mir nichts weiter als Diaphorus nigricans $\mathbf{M g}$. zu sein.

7. Chr. suavis Lw. Antennarum nigrarum articulo tertio mediocri, tegulis albo-cilintis, femoribus nigris, coxis anticis albo-pilosis.

$\delta^{7}$ Cyaneus aut violacens, thorace albo-pollinoso, fronte praesertim in laieribus aryenteo-micante, facie mire angustü, aeneo-viridi, mope antennas albo-nicante, palpis majusculis, pallide-flavis, ciliis oculorum inferis confertis, pedibus pube exalbidê vestitis, tibiis anterioribus flavis, posticis nigris.

$f$ Aenco-viridis, llurace cinereo-pollinoso, fronte et facie latī sordidecinereis, palporum nigrorum apice plerumque pallescente, tibiis omnibus flavis. Long. corp. $0^{\top} 1 \cdot 8-2$, ㅇ 2-2.2 $\mathrm{Mm}$.

Syn. Chrysotus suavis. Liw. Neue Beitr. V. 49. 1857. 07:

Chrysotus suavis. Schin. Fauna austr. I. 186. 1862. 0".

万?. Stirn metallisch blaugrïn, aber besonders am Augenrande silberweiss sehimmernd; Gesicht sehr schmal, metallisch blaugrün, unter den Füllern in 
gewisser Richtung weisslich schimmernd; Fühler schwarz, das dritte Fühlerglied mässig gross, T'aster blassgelb, ziemlich gross, vorragend: Cilien an unteren Augenrande sehr dicht. Rückenschild und Sehildehen metallisch grünlichblau oder blauviolett, ziemlich dentlich weissgran bestäubt. Flïgel glashell, mit an der Flügelbasis gelben Adern; Dechschïppchen gelb, weisslich gewimpert. Alle Hüften schwarz, die vordersten weiss behaart; der Schenkelkuopf der vorderen Hüften gelb, der der Hinterhüften schwarzbraun. Alle Schenkel schwarz, nur die vorderen an der Spitze gelb; die vorderen Schieuen gelb, die Mittelschienen bisweilen an der Basis gebräunt, die Hinterschienen schwarzbraun; Tarsen mit Ausnahme der gelben Metatarsen der vorderen Beine schwärzlich. Die ganzen Beine mit zarter, weisslich schimmeruder Behaarung bekleidet; an den Vorderschienen das Börstchen in der Nähe der Basis äusserst zart oder fehlend; Mittelschienen meistens mit nur einer ziemlich langen Borste vor der Mitte; Hinterschienen mit deutlicher, aber ziemlich kurzer weisslicher Wimperung. Hinterleib metallisch blaugrün, dessen Behaarung weisslich; Analanhänge verborgen.

Q. Gesicht breit; Taster schwarz, an der Spitze manchmal gelb und wie das Gesicht und die Stirn schmutzig gran bestäubt. Rëckenschild und Schildehen erzgrün, gelblichgrau bestänbt. Schienen und Metatarseu aller Beine gelb, die der Hinterbeine an der Spitze meistens geschwärzt. An den Vordersehienen das Börstchen in der Nähe der Basis deutlicher als beim Männchen, Mittelschienen meistens mit den gewöhnlichen zwei Borsten versehen. Hinterleib erzgrün, bisweilen blaugrün, mit zwar vorherrschend schwarzer, doch an den Seiten und am Ende des Hinterleibes etwas weisslich schimnernder Behaarung bekleidet.

Vaterland: Chr. suavis ist in Oesterreich, Ungaru und Deutschland sehr verbreitet und nach meinen Beobachtungen in den südöstlichen Gegenden häufig; bei Seullin traf ich diese Art in Auen sehr zahlreich an.

A umerkung. Chr. suavis ist im männlichen Geschlechte durch die in der Regel lieblich blaue Körperfärbung, durch das sehr sehıale, unter den Fühlern weissliche Gesicht und die silberweiss schinmernde Stirn, durch die ziemlich grossen, vorragenden Taster, durch den dichten, weissen Backenbart und durch die weissliche Behaarung des Hinterleibes und der Beine sehr ausgezeichnet; beide Geschlechter wird man an der dichter als gewöhnlich auftretenden Bestäubung des Rüekenschildes, an den an der Flügelbasis gelben Adern, an der weissen Behaarung der Vorderhüften und an den weissen Wimpern der Deekschïppchen leicht erkennen.

S. Chr. albibarbus Lw. OT. Cyeneo-viridis, antennis nigris, facie angusta, alb $\bar{a}$, palpis majusculis fluvis, ciliis oculorum inferis confertis, tegulis pallide-ciliatis, pedibus nigris, anticorum eoxis albo-pilosis, anteriorum tibiis ferrugineis vel fuscis.

Long. corp. $2 \mathrm{Mm}$.

Syu. Chr. albiburbus. Lw. Neue Beitr. V. 50. 1857. $\sigma^{7}$. 
ర․ Stirn metallisch blaugrün; Gesicht schmal, weiss bestäubt, die Augen der ganzen Länge nach sehr deutlich trennend; Fühler schwarz; Taster gelb, ziemlich gross, vorragend; Cilien am unteren Augeurande dicht. Rückenschild und Schildchen metallisch grünlichblau, nur undeutlich bestäubt. Fllügel glashell; Deckschüppchen blassgelb, weisslich gewimpert. Hüften schwarz, die vordersten weiss behaart; Schenkelknopf der vorderen Hüften gelb, der hintersten schwarzbraun. Schenkel schwarz, nur die Kniee der vorderen gelb; Schienen und Metatarsen der vorderen Beine rostgelb oder braun, die übrigen Tarsenglieder und die Hinterschienen schwarzbraun. An deu Vorderschienen das Börstchen in der Nähe der Basis deutlich und an den Mittelschienen die gewöhnlichen zwei Borsten vorhanden, doch ist die zweite Borste hinter der Mitte erheblich kürzer als die erste; Hinterschienen mit nur kurzer Wimperung. Hinterleib grünlichblau; Analanhänge verborgen.

Vaterland: In Griechenland und Kleinasien von Herrn Dr. H. Loew entdeckt.

A nmerkung. Dem lier wach einem typischen Exemplare beschriebenen Chrysotus fehlte das dritte Fühlerglied; ich berufe mich daher auf die vom Herrn Dr. H. Loew l. c. gemachten Angaben, wonach das dritte Fühlerglied etwa die Grösse wie bei Chr. suavis Lw. hat. - Chr. albibarlus nähert sich dem Chr. suavis, mit dem der erstere auch die Beschaffenheit der Taster, den dichten weissen Backenbart und die deutlich weiss behaarten Vorderhüften gemein hat, unterscheidet sich jedoch von ihm im männlichen Geschlechte ausser durch die dunklere Behaarung der Beine, durch das dentlich breitere Gesicht, durch die metallisch blaugrüne, nicht weiss schimmernde Stirn und durch die viel geringere Bestäubung des Rückenschildes.

9. Chr. laesus Wied. Antennarum nigrarum articulo tertio palpisque magnis, facie latā, cinerēe, tegulis fusco-ciliutis, pedibus nigris, coxis unticorum albo-pilosis.

o' Chalybeus, genibus extremis sordide flavis.

o Virili-aenea, facie quam in mare etiam latiore, tibiis basim versus flaveseentibus.

Long. corp. 1.7-2.2 Mm. (Fig. 6-14).

Syn. Dolichopus lacsus. Wied. Zool. Mag. I. 75. 21. 1818.

Dolichopus laesus. Fll. Dol. 19. 25. 1823. \&.

Chrysotus laesus. Mg. Syst. Beschr. IV. 43. 7. 1824.

Chrysotus luesus. Ztt. Dipt. Scand. II. 458, 5. 1843.

Chrysotus laesus. Walk. Ins. Br. Dipt. I. 217. 2. 1851.

Chrysotus laesus. Lw. Neue Beitr. V. 50. 1857.

Chrysotus laesus. Schin. Fauna austr. I. 185, 1862.

Chrysotus nigripes E.? ap. Gerst. Stett. entom. Zeitsehr. XXV. 42. 3. 1864. \&.

$\sigma^{\top}$. Stirn dunkel metallisch grün, etwas grau bestäubt; Augen durch das verhältnissmässig breite Gesicht, dessen metallische Grundfarbe unter der grauen Bestäubung wenig durchschimmert, auffallend getrennt; Fühler schwarz, das dritte Fühlerglied verhältnissmässig gross und breit; 'Taster gross, hervorstehend, 
schwarz, gelblichgrau schimmernd. Rückenschild und Schildchen stahlblau, etwas gelblichgrau bestäubt, von voru gesehen meist mit grünlichen, von oben und hinten betrachtet mit violetten Reflexen; Mittelliuie des Thoraxrückens fast unbehaart. Flügel grau gefärbt, am Vorderrande getrübt; vierte Längsader von der hinteren Querader an bis zur Mündung vor der Flügelspitze fast ganz parallel mit der dritten Längsader verlaufend; Deckschüppchen bräunlichgelb mit schwärzlichen, gelbbräunlich schimmernden Wimpern. Alle Hüften schwarz, die vordersten an der Spitze bisweilen braun bis gelbbräunlich gefärbt und weiss behaart; der Schenkelknopf der vordersten Hüften gelbbräunlich, der der Mittel- und Hinterhüften schwärzlich. Beine schwarz, an den vorderen Beinen die äussersten Kniespitzen bräunlichgelb, die Schienen schwärzlichbraun. Die vordersten Schienen ohne dentliches Börstchen in der Nähe der Basis; Mittelschienen auf der Oberseite ohne, oder mit nur einem meist kleinen Börstchen; die Wimperung der Hinterschienen sehr kurz und undeutlich. Hinterleib oben stahlblau oder violett, an den Seiten mehr blangrün; Analanhänge klein, schwarz und kanm vorragend.

Q. Gesicht sehr breit, wie die Taster schmutzig grau bestäubt; Stirn, Rückenschild und Schildehen metallisch grün oder blangrün, ziemlich deutlich gelblichgran bestäubt. Die Kniespitzen an allen Beinen gelb, hüchstens die der hintersten dnnkler; Schienen rostgelb, an der Basis heller, an der Spitze allmälig dunkler gefärbt oder ganz schwarzbraun; Beburstung der vorderen Schienen in der Regel wie bei dem Männchen, doch ist an den Mittelschienen die Borste vor der Mitte deutlicher und manchmal auch das zweite Börstchen hinter der Mitte vorhanden.

Vaterland: Diese Art scheint über den grössten Theil von Europa verbreitet zu sein; mir ist dieselbe ausser aus Oesterreich, Ungarn und aus -verschiedenen Gegenden von Deutschland anch aus Frankreich, Scchweden und dem westlichen Russland bekannt geworden: Bonsdorf gibt ihr Vorkommen in Finland und Walker in England an.

Anmerkung. Chr. laesus zeichnet sich in beiden Geschlechtern durch die fast unbehaarte Mittellinie des Thoraxrückens, durch die schwärzlichen Wimpern der Deckschüppchen, durch die weisse Behaarung der Vorderhüften und durch die geringe Beborstung der Beine genügend ans; das Männchen ist an der stahlblauen, gewöhnlich in das Violette übergehenden Körperfarbe, an dem verhältnissmässig breiten Gesicht und an den grossen vorragenden Tastern kenntlich. - Das Weibchen des Chr. nigripes F.?, welches Herr Gerstäcker 1. c. beschreibt, scheint nichts weiter als das Weibchen von Chr. laesus zu sein.

10. Chr. amplicornis $\mathrm{Htt}$. Obscure viridis, antennarum nigrarum articulo tertio magno, tegalis fusco-cilintis, pedibus nigris, antcriorum genibus ferrugineis.

$\sigma^{\top}$ Facie angustissimu, obscure viridi, palpis parvis, fuscis, in apice flavo-micantibus.

우 Facie latā, albo-cinere $\bar{u}$.

Long. corp. 1.8-2 $\mathrm{Mm}$. 
Syn. Chrysotus amplicornis. Ztt. Dipt. Scand. VIII. 3064. 5-6. 1849. 오. 万. Stirn und Gesicht dunkel metallisch grün; Augen sich fast berührend; Fühler schwarz, das dritte Fühlerglied gross, querrundlich; Taster klein schwärzlich, an der Spitze gelb schimmernd; Cilien am unteren Augenrande blassgelb. Rückenschild ziemlich dunkel erzgrün, etwas grau bestäubt; Schildchen lebhafter blaugrün. Flügel grau gefärbt, an der Spitze merklich stumpfer als gewöhnlich; Deckschüppchen gelb, mit schwärzlichen, gelbbraun schimmernden Wimpern. Hüften schwarz, die vordersten schwarz behaart, doch ist diese Behaarung auf der Vorderseite dieser Hüften manchmal ziemlich hell. Schenkelknopf der vorderen Hüften braun, derjenige der Hinterhüften schwarz. Beine schwarz, nur die äussersten Kniespitzen der vorderen Beine bräunlichgelb. An den Vorderschienen das Börstchen in der Nähe der Basis und an den Mittelschienen ausser den gewöhnlichen zwei Borsten oft auch die Nebenbörstchen stark entwickelt; Hinterschienen nur mit kurzer Wimperung. Hinterleib dunkel blaugrïn oder erzgrün; Analanhänge verborgen.

ㅇ. Gesicht breit, weisslichgrau, die schwarzen Taster aschgrau bestäubt. Beine wic bei dem Männchen schwarz und nur an den äussersten Kniespitzen bräunlichgelb. Die Vorderschienen ausser dem Börstchen in der Nähe der Basis oft noch mit einem zweiten hinter der Mitte und die Mittelschienen nicht selten mit drei ansehnlichen Borsten auf der Oberseite.

Vaterland: Ich sammelte diese Art bei Asch auf Steinen, die einen kleinen Teich auf einer Moorwiese umgaben. Dänemark.

Anmerkung. Chr. amplicornis wird man in beiden Geschlechtern an dem verhältnissmässig grossen dritten Fühlerglied, welches fast ebenso wie bei Chr. laesus Wied. beschaffen ist, erkennen; von dem Männchen des Chr. laesus unterscheidet sich das Männchen der obigen Art durch das dunkel metallisch grüne Gesicht, anf dem sich die Augen fast berühren, durch die kleinen Taster und durch die dïster erzgrüne Körperfärbung; beide Geschlechter durch die Beborstung der vorderen Schienen. - Die Beschreibung, welche Zetterstedt von Chr. anplicornis gibt, passt bis auf die Angabe: "Genicula in summa fractura vix puncto testaceo" ganz gut auf die obige Art; berücksichtigt man aber, dass bei Chr. laesus die Kniespitzen der vorderen Beine ziemlich hell rostgelb, bei $C h r$. amplicornis dagegen bräunlichgelb, ja oft so dunkel sind, dass ihre Färbung von der übrigen der Beine nur bei genauer Betrachtung zu unterscheiden ist, so schwindet auch dieses Bedenken.

11. Chr. monochaetus n. sp. Aeneo-viridis, antennarum nigrarum articulo tertio magno, tegularum ciliis subfuscis, pallide micantibus, pedibus nigris, anteriorum trochanteribus, genibus et tibiis flavis, tibiis intermediis setā unic̄̄ instructis.

$0^{7}$ Oculis fere contiguis, palpis mediocribus, pallide flavis, tibiis posticis nigris. cis flavis.

ㅇ Facie latū, cinere $\bar{u}$, palpis nigricantibus, in apice flavis, tibiis postiLong. corp. $1.8 \mathrm{Mm}$. 
07. Stirn metallisch grün; Augen auf dem Gesichte fast zusammenstossend; Fühler sclıwarz, das dritte Fühlerglied gross, mit deutlicher Ecke am Ende, sammt dem zweiten Gliede dreieckig erscheinend, das erste Fühlerglier schmal, stielartig; Taster mittelmässig gross, blassgelb. Rïckenschild metallisch grün, nur wenig bestäubt; Schildehen blaugrün. Flügel blassgrau gefärbt; Deckschüppchen gelb, mit blassbräunlichen, hell schimmernden Wimpern. Hüften schwarz, die vordersten mit weisslicher, jedoch schütterer und undeutlicher Behaarung; Schenkelknopf der vorderen Hüften gelb, der Hinterhüften schwarz. Beine schwarz; die äussersten Kniespitzen, die Schienen und Metatarsen der vorderen Beine gelb, die übrigen Tarsenglieder derselben von der Spitze des Metatarsus an braun. Vorderschienen mit einem kurzen Börstchen in der Nähe der Basis, Mittelschienen mit nur einer auffallenden Borste vor der Mitte, Hinterschienen undeutlich gewimpert. Hinterleib dunkel metallisch grün; Analanhänge verborgen.

Q. Gesicht breit, so wie die schwärzlichen an der Spitze gelben Taster grau bestäubt. Schienen und Metatarsus der Hinterbeine gelb; Mittelschienen ebenfalls mit nur einer Borste.

Vaterland: Das Mänuchen in der Gegend von Alt-Sandez in Galizien von Herrn Dr. Grzegorzek und das Weibchen in der Ungebung von Görz. von Professor Mik entdeckt.

Anmerkung. Chr. monochaetus charakterisirt sich durch die einzelne Borste auf der Oberseite der Mittelschienen und durch die Form und Grösse des dritten Fühlergliedes; letzteres Merkmal erinnert an Chr. pulchellus m. dem Chr. monochactus - von der Färbung der Hinterbeine abgesehen - ïberhaupt sehr ähnlich ist; das dritte Fühlerglied ist jedoch bei letzterem etwas gestreckter und am Ende spitzer, die Taster sind grösser und die Wimpernng der Hinterschienen kürzer. - Da die schwarze Färbung der Hinterschienen auch in das Braune neigt, so ist es möglich, dass dieselben bei manchen Stücken heller sein könne; ich hatte leider nur zwei männliche Exemplare dieser ausgezeichneten Art zur Untersuchung. Das beschriebene Weibchen stimmt in den beiden Geschlechtern sonst gemeinsamen Merkmalen, insbesonders in der Grösse der Fühler - welche aber wie bei allen Chrysotus-Weibchen am Ende etwas stumpfer als bei den Männchen sind - und in der Beborstung der vorderen Schienen mit dem Männchen so gut überein, dass ich über die Zusammengehörigkeit beider Geschlechter sicher zu sein glaube.

12. Clir. microcerus. n. sp. Laete viridis, antennarum articulis basalibus plerumque rufis, terminali parvo, nigro, tegularum ciliis subfuscis, for ribus nigris, tibiis flavis.

$\sigma^{7}$ Oculis fere contiguis, facie viridi, palpis minutis micantilus, tibiis posticis in lasi et in apice plerumo."

오 facie latā, albo-cinereā, palpis nigririn apice late ferrugineis.

Long. corp. $\sigma^{7} 1 \cdot 8$. 오 $2 \mathrm{Mr}$ 
$\sigma^{7}$. Stirn und Gesicht metallisch grün: Augen fast znsammenstossend, die beiden Basalglieder der Fühler oder blos die Spitze des zweiten Gliedes meistens roth, das Endglied klein, schwarz; Taster sehr klein, die noch sichtbare Spitze derselben gelb schimmernd. Rückenschild und Schildchen lebhaft metallisch grün oder blaugrün, nur wenig weisslich grau bestäubt. Flügel blass grau gefärbt; Deckschüppchen gelb, mit bräunlichen, doch hell schimmernden Wimpern. Hüften schwarz, auf der Vorderseite undeutlich weisslich, sonst aber schwarz behaart; Schenkelknopf der vorderen Hüften rostgelb, der mittleren oft bräunlich, der hintersten braun oder schwarz. Schenkel schwarz, nur die Spitze der vorderen Schenkel, alle Schienen und Metatarsen gelb; Hinterschienen jedoch an der Basis und meistens auch an der Spitze braun oder schwärzlich; die Tarsen der Hinterbeine von der Spitze des Metatarsus an schwarzbraun. An den Vorderschienen das kurze Börstchen in der Nähe der Basis und an den Mittelschienen die gewöhnlichen zwei Borsten deutlich vorhanden: Hinterschienen mit ziemlich kurzer aber deutlicher Wimperung. Hinterleib metallisch grün oder blaugrün; die äusseren Analanhänge verborgen.

Q. Gesicht breit, weisslichgran bestänbt, Taster schwärzlich am Rande bisweilen gelblich, grau schimmernd. Rückenschild erzgrün oder blaugrün, wenig gelblichgrau bestäubt. Vorderer Schenkel an der Spitze breit gelb; Hinterschienen ganz gelb oder rostgelb. Der Metatarsus und oft anch das zweite Tarsenglied der Hinterbeine rostgelb, an der Spitze schwarz.

Vaterland: Ich sammelte diese Art hänfig bei Asch, Herr Dr. H. Loew in verschiedenen Gegenden von Deutschland und Herr Fedtschenko bei Warschau.

Anmerkung. Chr. microcerus unterscheidet sich im männlichen Geschlechte durch das verhältnissmässig kleine dritte Fühlerglied, welches entschieden kleiner als bei dem Männchen des Chr. gramincus Fll. ist, und durch die meistens entweder ganz oder theilweise roth gefärbten Fühlerbasalglieder von allen Chrysotus-Arten. Bei dem Weibchen dagegen ist dieser Unterschied in der Fühlerbildung nicht so auffallend wie bei dem Männchen; sind die Fühlerbasalglieder des Weibchens schwarz gefärbt, so ist dasselbe von dem Weibchen des Chr. gramineus schwer zu trennen; Chr. microcerus ist jedoch in der Regel kleiner und die gelbe Färbung an der Schenkelspitze der vorderen Beine nimmt meistens mehr als den vierten Theil der Schenkel ein. - Siehe Anmerkung bei $C h r$. varians $\mathrm{m}$.

13. Chr. melampodins. Lw. $\sigma^{7}$. Obscure viridis, antennarum nigrarum articulo tertio minusculo, oculis fere contiguis, facie mire angustü, prope antennas obscure viridi, palyis parvis, fuscis, in apice flavo-micantibus, tegulis fusen-cilialis, pedibus nigris, anteriorum genibus ferrugineis.

nrv. $1.8 \mathrm{Mm}$.

's melampodius. Lw. Neue Beitr. V. 49. 1857. ठ

'.nkel metallisch grün; Augen fast zusammenFühlerglied ziemlich klein; Taster klein, ^nd. Rückenschild ziemlich dunkel 
metallisch grün, undeutlich bestäubt, Schildchen blaugrün. Flügcl grau gefärbt, an der Spitze ziemlich stumpf; Deckschüppchen gelb, mit schwärzlichen, goldgelb schimmernden Wimpern. Hüften schwarz und schwarz beharrt; Schenkelknopf der Vorderhüften bräunlichgelb, der Mittel- und Hinterhüften schwarz Beine schwarz, nur die Kniee der vorderen rostgelb; Vorderschienen sehwarzbraun. Das Börstchen in der Nähe der Basis der Vorderschienen undeutlich, an den Mittelschienen die gewöhnlichen zwei Borsten vorhanden, an den Hinterschienen ausser der Beborstung keine deutliche Wimperung auf der Oberseite zu bemerken. Hinterleib dunkel blaugrün: Analanhänge kaum vorragend.

Vaterland: Von Herrn Prof. Zeller bei Syrakus entdeckt. Das typische Exemplar befindet sich in der Sammlung des Herrn Dr. H. Loew, welches mir freundlichst zur Ansicht mitgetheilt wurde.

Anmerkung. Chr. melampodius sieht in Grösse und Colorit dem Chr. amplicornis Ztt. ähnlich, unterseheidet sich aber von ihm sehr auffallend durch das erheblich kleinere dritte Fühlerglied.

14. Chr. varians n. sp. Aeneo-viridis, antennarum nigrarum articulo tertio minusculo, tegulis fusco-ciliatis femoribus nigris genibus et tibiis anterioribus flavis.

ठ Facie mire angustā, obscurc viridi, palpis parvis, fuscis, in upice flavo-micantibus; tibiis posticis aut omnino ferrngineis; aut ferruguineis, in basi et in apice angustius vel latius fuscis; aut nigris.

우 Facie lutū, albo cinerē̄, palpis nigricantibus, tibiis posticis ferrugineis, in apice plerumque nigricantibus.

Long. corp. 1.8-2 Mm.

Syn.? Chrysotus nigripes. F. ap. Mg. Syst. Besehr. IV. 42. 6. 1824.

6. Stirn und Gesicht dunkel metallisch grün; Augen sich fast berührend; Fühler schwarz, das dritte Fühlerglied ziemlich klein; Taster klein, schwärzlich, an der Spitze gelb schimmernd. Rïckenschild ziemlich dunkel erzgrün oder wie das Schildchen blaugrïn, undeutlich bestäubt. Flügel gran gefärbt, Deckschüppchen gelb, mit schwärzlichen, goldgelb schimmernden Wimperu. Hüften schwarz, die vordersten schwarz behaart; Schenkelknopf der Vorderhüften rostgelb, der Mittel- und Hinterhüften schwärzlich. Schenkel schwarz, die Kniee, Schienen und Mctatarsen der vorderen Beine gelb; bisweilen sind die vorderen Schienen an der Basis gebräunt und die Metatarsen wie die übrigen Tarsenglieder der vorderen Beine braun; Hinterschienen ganz rostgelb, oder nur an der Basis und Spitze in verschiedener Ausdehnung schwärzlich, oder ganz schwarz; der Metatarsus der Hinterbeine an der Basis gelb oder wie die übrigen 'T'arsenglieder ebenfalls ganz schwarz. An den Vorderschienen das Börstchen in der Nähe der Basis und an den Mittelschienen die gewöhnlichen zwei Borsten vorhanden; Hinterschienen ziemlich deutlich gewimpert. Hinterleib dunkel erzgrün; die äusseren Analanhänge kaum vorragend.

․ Gesicht breit, so wie die schwärzlichen Taster weissgrau bestäubt. Hinterschienen rostgelb, an der Basiş bisweilen, an der Spitze mcistens geschwärzt. 
Vaterland: Herr Dr. H. Loew sammelte diese Art in Galizien im TatraGebirge, ich selbst in der Ungebung von Aseh und Herr Hiendluayr bei München.

An inerkung. Das Männchen des Chr. varians hat - besonders wenn die Hintersehienen ganz oder vorherrsehend rostgelb gefärbt sind - ganz das Aussehen des Chr. microcerus m., unterscheidet sich jedoch von letaterem durch das erheblich grössere dritte Fühlerglied, welches fast noch etwas grösser als bei Chr. gramineus Fll. ist, durch stets ganz schwarze Fühler, neist dunkel erzgrüne Körperfärbung und - im lebenden Zustande - durch deutlicher getrennte Augen. Von Chr. melampolius Lw. unterscheidet sieh obige Art durch etwas kürzere, an der Spitze schmälere Flügel, durch die gelb gefärbten vordereu schienen und durch die noeh deutliche Wimperung der Hinterschienen. Das Weibchen des varians unterscheidet sich von dem Weibchen des Chr. microcerus dureh die an der Spitze in nur geringer Ausdehnung gelb gefärbten vorteren Sehenkel, von dem Weibchen des gramineus durch in der Regel dunklere Wimpern der Deckschüppehen und von beiden Arten durch mehr erzgrüne, als blaugrüne Körperfürbung, und durch die etwas mehr in das Rostgelbe neigende Färbung der Schienen. - Chr. nigripes F. bei Meigen scheint mir eine Misehart von Chr. microcerus m. und obigem varians zu sein; Meigen's Beschreibung wenigstens passt viel eher auf die beiden letztgenannten als auf irgend einc andere der bisher bekaunten Arten, besonders aber auf varians, wenn man die "metallisch grïne* Körperfärbung und die ,ziegelrothe oder rost$g_{\text {gelbe }}$ Färbung der Hinterbeine auf das Männchen desselben bezieht. Ich war desshalb im '/weifel, ob für varipes nicht der ältere Fabricius'sche Name zu wählen sei; da jedoch sowvhl die Benenumng als auch die Beschreibung Fabricius' ') höehstens auf Chr. laesus Wied. oder anf Chr. cmplicornis Ztt., uieht aber auf die von Meigen beschriebene Art hindeutet, und weil mir die Bestimmung Wiedemanu's nicht genügende Sicherheit bot, so entschied ich mich für einen neuen Namen.

15. Chr. gramineus Fll. Caeruleo-viridis, antennarum nigrarum articulo tertio minusculo, tegularum ciliis pallidis vel subfuscis, femoribus nigris, anteriorum genibus et tibiis flavis.

${ }^{-1}$ Oculis fere contiguis, facie mire angusta, viridi, albomicante, palpis parvis, finsis, in apice flavis, pallide-micantibus, tibiis posticis nigris, ciliutis.

O Facie latā, albo-cinereā, palpis nigricantibus, tibiis posticis flavis, in apice plerumque nigricantibus.

Long. corp. 1:8-2 Mm.

Syn. Dolichopus grumineus. Fll. Dol. 19. 24.1824.

Dolichopus laesus Fll. Dol. 19. 25. 1824 ठ․

1) Die Beschreibung vou M. nigripes F. in der Ent. syst. IV. 341. 122 lautet: "Mrusca nigripes M. antennis setariis aenea nitida antennis pedibusque atris, alis innautatis. Habitat in Gallia Mus. Dom. Bose.

Triplo minor M. ungulata, caput cum antennis nigrum, thorax et abdomen pilosa, aenea, sitida. Alae albae, immaeulatae. Pedes nigri." 
Syn. ? Chrysotus copiosus Mg. Syst. Beschr. IV. 41. 2. 1824.

Diuphorus minimus. Mg. Syst. Beschr. VI. 360. 6. 1830.

? Chrysotus gramineus. Mg. Syst. Beschr. VII. 149. 11. 1838.

Chrysotus gramineus. Ztt. Dipt. Scand. II. 483. 4. 1843.

Chrysotus nigripes. Walk. Ins. Br. Dipt. I. 217. 1. 1851.

Chrysotus gramineus. Lw. Nene Beitr. V. 48. 1857.

Chrysotus gromineus. Schin. Fauna austr. I. 186. 1862.

? Chrysotus nigripes F. ? (facialis) ap. Gerst. Stett. enton. Zeitschr. XXV. 42. 3. $1864 \cdot 0^{3}$.

07. Stirn metallisch blaugriin; Augen fast zusammenstossend; Gesicht im Grunde metallisch grïn, aber ein wenig bestäubt und daher besouders im todten Zustande in gewisser Richtung weiss schimmernd; Fühler schwarz; drittes Fühlerglied ziemlich klein; Taster klein, schwärzlich, an der Spitze gelb, blassgelb schimmernd. Rückenschild lebhaft metallisch blaugrün, oder goldgrün, etwas grau bereift. Fliigel blassgrau gefärbt; Deckschüppchen gelb, mit bräunlichen, meistens aber blassgelben Wimperı. Hüften schwarz, die vordersten mit schwärzlicher auf der Vorderseite heller, wenig deutlicher Behaarung und leblaft weissgrau schimmernder Bestäubung. Schenkelknopf der vorderen oder blos der vordersten Hüften gelb, Hinterhüften schwarz oder braun. Schenkel schwarz; die Kniee, Schienen und Metatarsen der vorderen Beine gelb, deren übrigen Tarsenglieder braun; Hinterschienen schwarz oder schwarzbraun, auf der Oberseite bisweilen rostgelb; Hintertarsen schwarz, oder nur die Basis des Metatarsus rostgelb. Vorderschienen sehr zart gewimpert, das Börstchen in der Nähe der Basis und an den Mittelschienen die gewöhnlichen zwei Borsten vorhanden; Hintersehienen deutlich gewimpert. Hinterleib metallisch blangrün; Analanhänge meistens verborgeu.

․ Gesicht breit, wie die schwärzlichen Taster weissgran bestäubt. Sehienen und Metatarsen der Hinterbeine gelb, an der Spitze meistens gebräunt.

Vaterland: Oesterreich, Ungarn, Deutschland, Scandinavien, Dänemark, Russland und England.

Anmerkung: Das Männchen des Chr. gramineus ist an der lebhaften, vorherrschend blangrünen Kürperfärbung, an den stalılblau schimmernden Flügeln, an dem sehr schmalen, weiss schimmeruden Gesieht, an den in der Regel ganz schwarzen Hinterbeinen und an den deutlich gewimperten Hinterschienen zu erkennen. Das Weibchen ist ebenfalls an der blaugrünen Körperfärbung, weiche aber auch in das Goldgrüne abändert, an den an der Spitze in nur geringer Ausdehnung gelb gefärbten Schenkeln und an den vorherrschend blass gelben Wimpern der Deckschïppchen kenntlich. Frisch entwickelte Exemplare dieser Art haben dunklere Wimpern an den Decksehüppchen. - Ich habe Chr. copiosus $\mathrm{Mg}$. als fragliches Synonymon zu gramineus gebracht, weil es auffallend ist, dass Mieigen seinen copiosus mit neglectus Wied. vergleicht, ihm die Grösse desselben nnd „röthliçhgelbe vorderste Schienen" zuschreibt; es möge hier an einen Vergleich der möglicherweise noch zu erlangenden Type von Chr. copiosus $\mathrm{Mg}$. mit blephurosceles in. erinnert werden. - Da Neigen's Chr. gramineus nur 
die "vordersten Sehienen und Füsse gelb" haben soll, so bezweifle ich noch die Identität dieser Art mit gramineus Fll. - Die Beschreibung, welehe Herr Gerstäcker von dem Männchen des Chr. nigripis F. ? gibt, scheint mir auf $C h r$. gramineus Fll. hinzuweisen. - Erwähnt sei noch, dass ich bei der Beschreibung des Chr. gramineus Fll. von Zetterstedt herrührende Typen besonders berücksichtiget habe.

16. Chr. angulicornis. n. sp. $\sigma^{7}$ Olscure viridis, antennarum nigrarum articulo tertio mediocri, apice acuto, facie mire angustū, obscure viridi, palpis parvis, fuscis, flavo-micantibus, tegulis fuscociliatis, pedibus nigris, antcriorum genibus et tibiis ferrugineis, tibiis posticis ciliatis.

Long. corp. $2 \mathrm{Mm}$. (Fig. 16.).

Stirn und das sehr schmale Gesicht dunkel metalliseh grün; Fühler schwarz, das dritte Fühlerglied mässig gross, dentlich behaart, mit verhältnissmässig seharfer Ecke am Ende; Taster selıwärzlich, gelb schimmernd. Rü̈ckensehild dunkel metalliseh grün, in der Nähe des Sehildchens so wie dieses melır blaugrün, unileutlieh bestänbt. Flügel blassgrau gefärbt: Deckschüppehen gelb, mit schwärzliehen, goldgelb sehimmernden Wimpern. Hüften schwarz und schwarz behaart, die vordersten lebhaft weissgrau schimmernd; Sehenkelknopf dur Vorderhüften bräunlichgelb, der Mittel- und Hinterhüften schwarz. Beine sehwarz, nur die äussersten Kniespitzen, Schienen und Metatarsen der vorderen Beine gelb, Mittelschienen von der Basis her gebräunt. Vorderschienen auf der Oberseite sehr kurz aber merklich gewimpert, mit je einem zarten Börstehen in der Nähe đer Basis und hinter der Mitte: Mittelsehieneu mit den gewöhnlichen zwei Borsten; Hinterschienen deutlich gewimpert. Hinterleib dunkel metallisch blaugrün; die änsseren Analanhänge schwarz.

Vaterland: Bei Salzburg von Hern von Bergenstanm, bei Innsbruck vou nir gefundeu.

A nmerkung. Von den ihn nächststehenden Cirr. melampodius Lw. und varians $\mathrm{m}$. unterseheidet sich anyulicornis besonders durch die Form des dritten Fühlergliedes, welehes nicht nur ein wenig grösser, sondern auch am Ende schärfer zugespitzt ist und durch die dentliche, etwa wie bei Chr. gramineus Fll. besehaffene Wimperung an den Hintersehienen. Viel ähnlicher sieht obige Art dem Chr. femorntus Ztt., für dessen Varietät ich sie zu halten versucht war; doch hat angulicornis ein dunkleres Colorit, entschieden kürzer bewimperte, stets ganz schwarze Hinterschienen und schwarze Sehenkelknöpfe an den Hinterhüften. - Chr. ungulicornis der dunklen Mittelschienen wegen für copiosus $\mathrm{Mg}$. oder gramineus $\mathrm{Mg}$. zu erklären, halte ich mit Rücksicht auf die Körperfürbung für gewagt.

\section{Anhang.}

Es erübrigt noch, auch diejenigen Arten, welche unter den Synonymen der oben beschriebenen nieht enthalten, sind, zum Zwecke künftiger Bestätigung oder Beriehtigung meiner hier folgenden Anschauungen zu bespreehen. 
1. Chrysotus elegaus ․ Mg. Syst. Beschr. VI. 362. 9. 1830. - Dass diese Art nicht zu Chrysotus, sondern zur Gattung Sympycnus Lw. gehört, habe ich bereits in den "Verhandl. der zool.-bot. Ges. zu Wien“, Jahrg. 1868 p. 219 , nachgewiesen.

2. Chrysotus rufipes $\sigma^{7}$. Mg. Syst. Beschr. VII. 150. 14. 1838. Schin. Fauna austr. I. 186. 1862. - Meigen gibt folgende Merkmale an: ,Glänzend schwarz, etwas metallisch, Untergesicht nur eine vertiefte Linie, Beine hell ziegelroth, Flügel etwas geschwärzt, Grösse 1".. - Aachener Gegend." Mir ist keine solche Art bekannt geworden; die dunkelsten Arten haben stets vorherrschend schwarz gefärbte Beine; bei dieser Analogie ist man versucht anzunehmen, dass Chr. rufipes kein Chrysotus sei. Sollte da nicht ein Campsicnemus untergelaufen sein?

3. Chrysotus bicolor $Q$. Macq. Dipt. du Nord de Fr. 21. 6. 1828. Mg. Syst. Beschr. VIl. 150. 14. 1838. - Die Beschreibung Macquart's lantet: "Thorax d'un bleu violet. Abdomen et cuisses d'un vert métallique; jambes fauves. Long. $2 / 3$ lin. - Femelle. Épistome et thorax d'un bleu violet, front, abdomen et cuisses d'un vert metallique. Second article des hanches fauve, ainsi que l'extrémité des cuisses et les jambes." Diese Beschreibung scheint sich viel eher auf eine Art aus der Gattung Thripticus Gerst. als auf einen Chrysotus zu beziehen, denn nach meinen Erfahrungen zeichnen sich die Weibchen sămmtlicher Chrysotus-Arten - auch solcher, deren Männchen eine stahlblaue, in das Violete übergehende Körperfarbe halen - gerade durch eine mehr oder weniger lebhaft gold- oder erzgrüne Körperfarbe aus und die weissliche Bestäubung des Untergesichtes ist bei allen Weibchen der mir bekannt gewordenen Chrysotus-Arten so dicht, dass die metallisehe Grumdfarbe desselben gar nicht oder höchstens nur wenig durchschimmert.

4. Chrysotus magnicornis $\sigma^{\top}$. Ztt. Dipt. Scand. II. 481. 1. 1843. Die Grösse, die Fühlerform, die Bildung der Analanhänge, der Verlauf der vierten Längsader und die Färbung der Beine, welche Zetterstedt seiner Art zuschreibt, veranlassen - wie schon Herr Dr. H. Loew ("Neue Beitr.“ V. p. 48) hervorhob - gerechte Zweifel, dieselbe als zur Gattung Chrysotus gehörend aufzufassen; die Angabe, dass die Angen bei magnicornis auf dem Gesichte fast zusammenstossen sollen, genügt den obigen Merkmalen gegenüber noch nicht, ihn für einen Chrysolus zu halten. Ich habe noch keine sichere Veranlassung, obige Art für synonym mit Porphyrops pectinatus Lw. zu erklïren, aber ich muss hier erwähnen, dass sich in meiner Sammlung unter $P$. pectinatus ein Exemplar befindet, dessen Augen durch das Einschrumpfen des Gesichtes sich berühren; vergleicht man die Beschreibung Zetterstedt's mit diesem Stïcke, so passt sie ganz gut darauf mit Ausnahme der Bemerkung, dass die Spitze des Hinterleibes etwas weiss schimmernd sei; $P$. pectinatus zeigt bekanntlich einen solchen weissen Schimmer auch an den Seiten des Hinterleibes.

5. Chrysotus rhaphioides Q. Zt.t. Dipt. Seand. II. 486. 7. 1843. Zetterstedt fragt am Schlusse seiner Beschreibung, ob die Art nicht vielleicht zu Dolichopus zu bringen sei. Die dunkle Färbang des Kärpers und der 
Flügel bei gelber Färbung der Beine, die Stellung der hinteren Querader und die Beborstung der Hintersclienen erwecken Zweifel, ob diese Art als ein Chrysotus interpretirt werden dürfe.

6. Chrysotus obscuripes ․ 7tt. Dipt. Scand. II. 487. 8. 1843. Ich halte diese Art, wie ich schon in einer Anmerkung bei Chr. cupreus Macq. hervorgehoben habe, für das Weibchen des Diaphorus obscurellus Ztt. = nigricans Mg.

7. Chrysotus signatus $\sigma^{7}$. Ztt. Dipt. Scand. VIII. 3065. 9-10.1849. Das was Zetterstedt bei dieser Art über die Flügel: „ad apicem nervi auxiliaris incipit lineola subcuneiformis, distincta, atra, quae sensim attenuata costam sequitur, ....." und über die Mittelschenkel: „subtus ad basin parce pilosula" sagt, genügt wohl, nachzuweisen, dass Chr. signatus in die Gattung Teuchophorus Lw. gehört.

8. Chrysotus niger. ठ․ Lw. Beschr. europ. Dipt. I. 298. 177. 1869. Chr. niger Lw. passt weder in die Gattung Chrysotus, wie ich dieselbe charakterisirt habe, noch in eine der Gattungen, die bisher errichtet sind. Das Definitive über seine systematische Stellung behalte ich mir einstweilen noch vor.

9. Chrysotus nigrieilius $\sigma^{\nearrow}$. Lw. Beschr. europ. Dipt. II. 297. 160. 1871. - Auch diese Art habe ich der Fühlerbildung, des concaven Gesichtes, der längeren Flügel und der Beborstung des Hypopygiums wegen in der Gattung Chrysotus, wie ich dieselbe anfgefasst habe, nicht unterzubringen vermocht. Obwohl der Verlauf der vierten Längsader und die nicht verlängerten Pulvillen der Vorderbeine des Chr. nigricilius eine Vereinigung mit Diaphorus Mg. bedenklich erscheinen lassen, so spricht doch die Form des Gesichtes und die Beborstung des Hypopygiums mehr für die Unterbringung in letzterer Gattung, wie Herr Dr. H. Loew in einer Anmerkung zu seiner Beschreibung dieser Art bereits anerkannt hat.

Herr von Roser beschreibt in ${ }_{n}$ Correspondenzblatt des $k$. würt. landw. Vereins", Jahrg. 1840. Bd. I. H. 1. p. 55 und 56 sechs neue ChrysotusArten; die Beschreibungen sind leider so kurz, dass dieselben für die vorstehende Arbeit nicht berücksichtiget werden konnten; ans densclben lässt sich vermuthen, dass nur Chr. viridifemoratus als Weibchen zu irgend einem Chrysotus gehören dürfte. - Der Vollständigkeit wegen reproducire ich die Beschreibungen der von Roser'schen Arten:

1. Chr. viridifemoratus, viridis, pedibus flavis, femoribus viridibus.

2. ก flaviventris, abdomine supra viridi, subtus pallide flano.

3. "nigrieosta, alis basi linea costali nigra.

4. " atripes, peditus atris, posticis incrassatis.

5. " flavipes, cilipedi affinis, pedibus totis flavis.

6. " virescens, thorace cinerascente, abdomine virescente, pedibus fuscis. 


\section{Arten- und Synonymen-Register.}

1. Chr, neglectus. Wied. Mg. Lw. Schin. p. 458.

viridulus. Fll. Ztt. Walk.

femoralis. Mg. $Q$.

taeniomerus. Mg. Ztt. (var. a.)

9. „illpes. Mg. Walk. Ztt. \&. Lw. Schin. p. 460.

3. n pulchellus. n. sp. p. 461.

taeniomerus. Ztt. (var. b.).

4. ” femoratus. Ztt. p. 461.

5. " blepharosceles. n. sp. p. 462.

6. $₫$ cupreus. Macq. Mig. Lw. Schin. p. 463.

7. $n$ suavis. Lw. Schin. p. 464.

8. $₫$ albibarbus. Lw. p. 465.

9. „ laesus. Wied. Fll. \&. Mg. Ztt. Walk. Lw. Schin. p. 466. nigripes F. ? (facialis) ap. Gerst. ‥?

10. \# amplicornis. Zitt. p. 467.

11. " mouochaetus. n. sp. p. 468.

12. " microcerus. n. sp. p. 469.

13. „ melampodius. Lw. p. 470.

14. $n$ varians. n. sp. p. 471. nigripes $\mathrm{F}$, ap. $\mathrm{Mg}$. ?.

15. ๓ gramineus. Fll. Mg. ?. Ztt. Lw. Schin. p. 472.

laesus. Fll. ơ.

copiosus. Mg. ?.

minimus. Mg.

nigripes. F. ap. Walk.

nigripes. F. ? (facialis) ap. Gerst. $\sigma^{7}$. ?.

16. " angulicornis. n. sp. p. 474.

elegans. Mg. p. 475.

rufipes. Mg. p. 475.

bicolor. Macq. p. 475.

maynicornis. Ztt. p. 475 .

rhuphioiles. Ztt. p. 475.

obscuripes. Ztt. p. 476.

signatus. Ztt. p. 476.

viridifemoratus. Roser. p. 476 .

flaviventris. Roser. p. 476.

nigricosta. Roser. p. 476.

atripes. Roser. p. 476.

flavipes. Roser. p. 476.

virescens. Roser. p. 476.

niger. Lw. p. 476.

nigricilius. Lw. p. 476. 


\section{Erklärung der Tafel XIII.}

Fig. 1. Chrysotus neglectus Wied. $0^{\lambda}$. sammt Grösse.

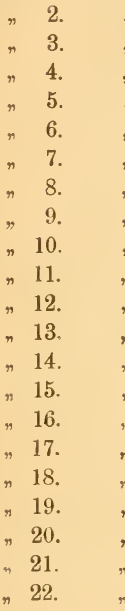

$$
\begin{aligned}
& n \quad n \text { Kopf voul vorn. } \\
& \eta \quad n \quad n \text { vou der Seite. } \\
& n \quad n \text { Fühler. } \\
& n \quad n \quad \text { Flügel. } \\
& \text { laesus } n, \quad \text { Kopf vou vorn. } \\
& n \quad n \quad n \text { ven der Seite. } \\
& n \text { n.. Fühler. } \\
& n \quad n \quad \text { Flügel. } \\
& n \pi n \text { Vorderschiene. } \\
& n \quad n \text { Hinterschiene sammt Tarsen. } \\
& n \quad n \text { ㅇ. Kopf von vorn. } \\
& n \quad n \quad n \text { vou der Seite. } \\
& n n \text { " Hinterleibsende von der Seite. } \\
& \text { pulchellus. m. ơ . Fühler. } \\
& \text { angulicornis. m. " Fühler. } \\
& \text { microscerus. m. " Fühler. } \\
& \text { cilipes. Mg. " Vorderschiene sammt Tarsen. } \\
& \text { "Mittelschiene , , } \\
& \text { n Hinterbein. }
\end{aligned}
$$

blepharosceles. m. $\sigma^{7}$. Vorderschiene.

femoratus. Ztt. or. Hinterleibsende mit ausgestrecktem $\mathrm{Hy}-$ popygium: a. Hypopygium, b. innere Analauhänge, c. äussere Analanlänge, ddd. Scheide, e. Penis.

"23. Nematoproctus distendens. Mg. $\sigma^{7}$. Kopf von vorn.

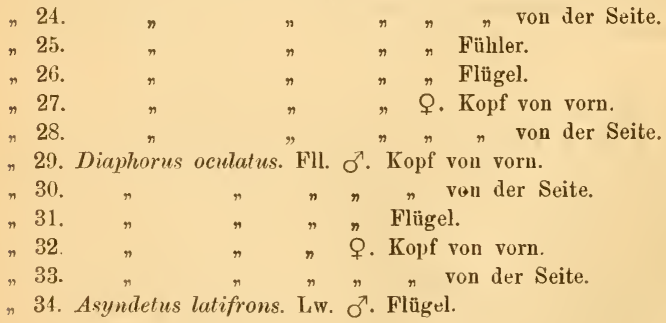



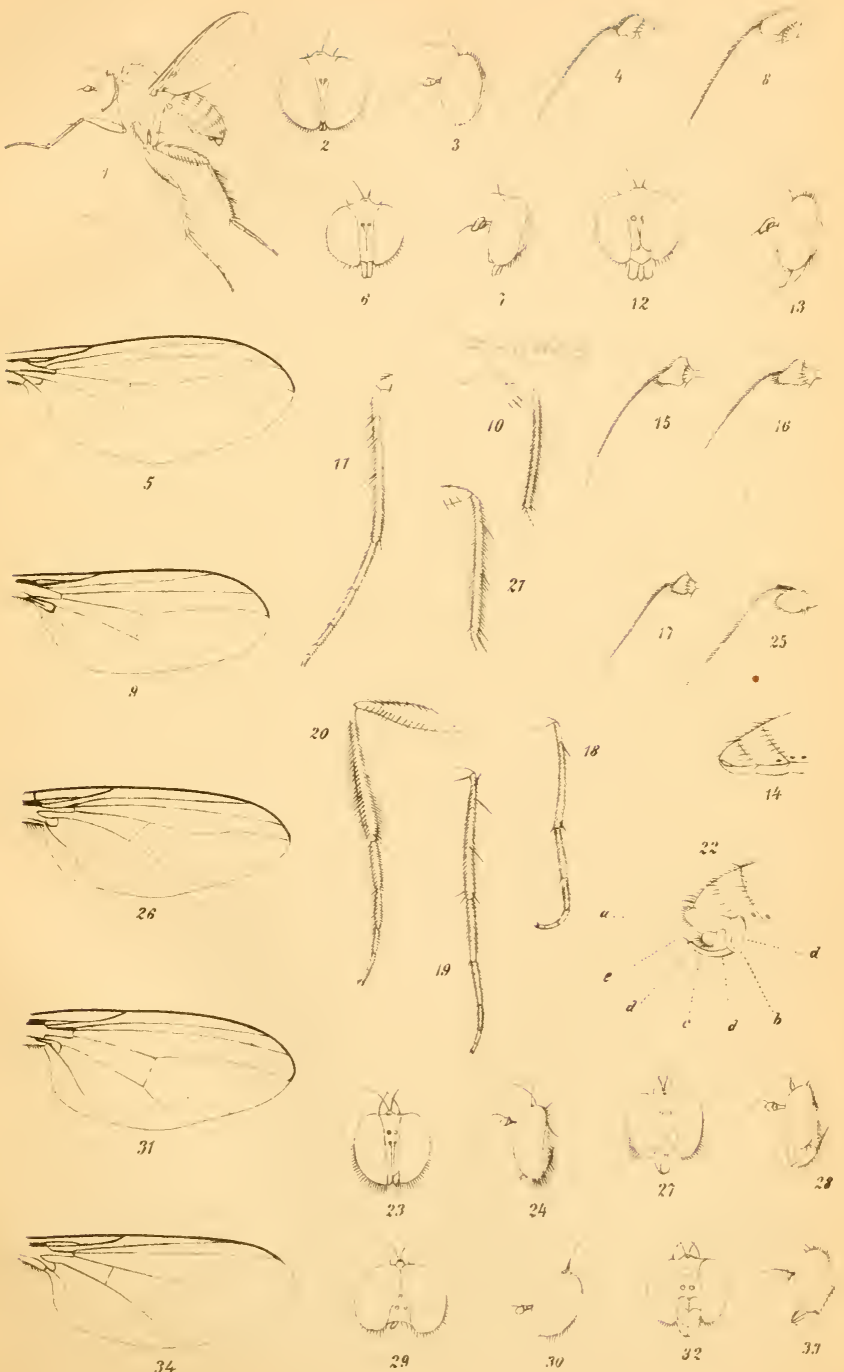


\section{Die Dipteren-Gattung Medeterns Fischer.}

Von

\section{Ferdinand Kowarz,}

k. k. Telegraphen-Beamten in Asch.

(Hiezu Tafel II.)

(Vorgelegt in der Versammlung am 7. Februar 1877.)

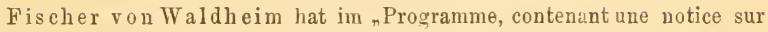
une mouche earnivore nomée Médétère; Moscou $1819^{\star}$ der Fab ricius schen Musca

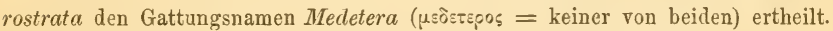
Fall én begründete im Jahre 1823 auf die Merkmale : ${ }_{n}$ Kurze Fühler mit geknieter zweigliedriger Borste und hintere Querader dem Flügelrande sehr genähert" die Gattung Hydrophorus und wahm Medetera rostrata F. in dieselbe auf; Hydrophorus Fll. enthielt der heutigen Systematik gemäss Arten aus den Gattungen Liancalus Lw., Hydrophorus Lw., Scellus Lw. und Medeterus Fisch. - Meigen hat - vielleicht ohne die Fallen'sche Publication über Hydrophorus bereits gekannt zu haben - im IV. Theile seiner $n$ systematischen Beschreibung der bekannten zweillügeligen Insecten 1824" den Fischer'schen Gattungsnamen zwar wieder angenommen, aber in Medeterus abgeäudert und die Gattung folgendermassen charakterisirt: „Fühler vorstehend, dreigliederig; das dritte Glied kurz, flach, fast eirund; auf denn Rücken ${ }^{1}$ ) mit zweigliederiger Borste. Augen getrennt. Hiuterleib des Männchens mit zwei Fäden. Beine verlängert, dünne. Flügel parallel anfliegend; nach jetziger Systematik enthält Medeterus Mg. ausser den nnter Hydrophorus Fll. begriffenen Gattungen auch Campsicnemus Wlk. und Xanthochlorus Lw.: hiezu kamen im VII. Theile seines citirten Werkes (1838), von den darin aufgenommeneu Macquart'sehen Arten abgesehen, noch die Gattungen Sympycnus Lw., Teuchophorus Lw., Anepsius Lw., Saucropus Lw. und muthmasslich Thrypticus Gerst. - Macquart schloss sicb in den "Insectes Dipteres du Nord de la France 1827" und in den "Suites à Buffon 1834" wesentlich den Anschauungen Meigen's an, zerlegte aber Medeterus Mg. in zwei Gattungen und wählte für die Arten mit apicaler

1) Meigen hatte bei Horstellnng der Gattungsdiagnose offenbar Med. regius F. besonders im Auge, da or sonst nicht übersehen haben würde, dass bei einigen seiner Medeterus-Arten die Fublerborste apical und nicht - wie er bei Afed. rostratus F. und bei Med. truncomem Mg. 8elbst erwähut - dorsal sei. 
Fühlerborste irrthümlich den Gattungsnamen Hydrophorus und für jene mit dorsaler Fühlerborste den Gattungsnamen Medeterus; Macquart scheint sich hiebei auf eine genaue Selbstkenntniss der Arten nicht gestützt zu haben, weil er einerseits seinem Hydrophorus nebulosus Fll. (non $\mathrm{Mg}$.), eine apicale und andererseits seinem Medeterus rostratus F. eine dorsale Fühlborste - im letzteren Falle wahrscheinlich durch $\mathrm{Me}$ igen's eigene Angaben irregeführt zuschreibt. - Z e t ter s te d t nahm in seinem Werke „Diptera Scandinaviae II. 1843“ die Fallén'sche Gattung Hydrophorus wieder auf und theilte sie in zwei Untergattungen; die Arten mit dorsaler Fühlerborste fasste er unter dem Namen Hydrophorus zusammen und die Arten mit apicaler Fühlerborste brachte er mit Recht zu Medeterus. - Walker führte im ersten Bande seiner "Diptera Britannica $1851^{4}$ die Gattung Medeterus als selbstständig, in beschränktem Umfange und mit Beibehaltung des von Meigen abgeänderten und seitdem allgemein eingebürgerten Namens wieder ein. - H. Loew entschied sich in den "Neuen Beiträgen V. 1857 “ für die Walker'sche Auffassung, begrenzte und sicherte in den "Neuen Beiträgen VIII. 1861" und in den "Monographs of the Diptera of North-Amerika Part. II. 1864" die Gattung Medeterus durch genaue Charakterisirung vollständig.

Der von Haliday im "Zoological Journal Vol. V. 1831" für Medeterus eingeführte Name Toechobates ist mit Rücksicht auf $\mathrm{F}$ ischer's Publication für jetzt nicht verwendbar; ${ }^{1}$ ) aus eben demselben Grunde muss auch der von Wa hlberg in ${ }_{n}$ Ofvers. Vet. Forh. $1844^{4}$ für Medeterus angewendete Name Orthobates ${ }^{2}$ ) vermieden werden. Anorthus - wie Loew in Stett. ent. Zeitg. XI. 1850, p. 117 und Rondani im „Prodr. I. 1856, p. $145^{4}$ obige Gattung nennt, scheint ein bis dahin unpublicirter und von Staeger nur in litteris gebrauchter Name zu sein, weil dieser Name auch in von Marschall's Nomenclator als fraglich von Staeger herrührend aufgefülurt ist ${ }^{3}$ ).

Die allgemeinen Merkmale der Gattung Medeterus sind folgende: Stirn und Gesicht beider Geschlechter breit, die Stirn gegen den Scheitel hin allmälig erweitert und daselbst mit den gewöhnlichen vier Scheitelborsten versehen; das Gesicht wird durch eine unterhalb seiner Mitte liegende Querleiste in das obere (facies superior) und in das untere Gesicht (facies inferior) getheilt; die Augen sind nackt, im Leben meist olivengrän mit rothbraunen Reflexen und bisweilen bandirt; Fühler kurz, das erste Glied derselben unbehaart, das zweite transvers und am Vorderrande kurz beborstet, das dritte rundlich oder oval, am Ende zugespitzt oder stumpf oder ausgekerbt, dicht behaart und mit einer apicalen oder subapicalen, verhältnissmässig langen, mikroskopisch haarigen oder nackten

1) Der If a liday'sche Name Toechobates wird jedoch dann zu berücksichtigen und wieder anfzunehmen sein, wenn die gegenwärtige Gattung Medeterus in zwei Gattnngen zerlegt werden sollte; er wird dann der kleineren Gattung gegeben werden müssen, zn welcher Mfed. rostratus F. nicht gehört.

$\left.{ }^{2}\right)$ W a hlberg und Ron dan i haben den Namen Medeterus für die Gattung Campsicnemus Wlk. beibehalten, was sich gar nicht recbtfertigen lässt.

3) In dem erwähnten Nomenclator steht statt Anorthus ${ }_{\text {Anorthrus }}$ (Staeger ?) Rond. 
Borste versehen; Taster breit, aus der Mundöffnung hervortretend und dem in der Regel sackartig hervorragenden, meist grossen Rüssel aufliegend; Cilien am hinteren Augenrande etwas schütter, das dem Mundrande nächststehende Borstchen ziemlich lang. - Thorax und Schildchen metallisch gefärbt und mit einer mehr oder weniger dichten grauen oder braunen Bestäubung bedeckt; die längere Beborstung des Thoraxrückens und des Schildchens stets schwarz; die Mittellinie des ersteren von einer bis zu dem Eindrucke vor dem Schildchen reichenden Doppelreihe kurzer steifer Härchen (setulae in thoracis dorso lineam mediam includentes) eingefasst, welche mehr oder weniger deutlich sind oder ganz zu fehlen scheinen; die gewöhnlichen beiden Borstenreihen des Rückens entweder von nur wenigen langen und ziemlich gleichartigen oder von zahlreichen am vorderen Theile des Rï̈ckens kurzen und auf dem hinteren Theile desselben allmälig längeren Borsten gebildet; am Prothorax über den Vorderhüften zwei bis sechs übereinander stehende Haarborsten (prothoracis setae); Schildchen unbehaart und am Rande jederseits mit je einer einzigen langen oder wie bei den meisten Arten mit je einer längeren und einer kürzeren Borste versehen. - Flügel im Umrisse länglich elliptisch oder oval; die Randader bis zur Mündung der einfachen vierten Längsader reichend; der letzte Abschnitt dieser ist völlig gerade, oder bildet einen sanften, mit seiner convexen Seite der dritten Längsader zugekehrten Bogen, mit welcher er stets deutlich convergirt und an der Flügelspitze mündet; die sechste Längsader unvollständig und verblasst; die hintere Querader dem Flügelrande sehr genähert oder höchstens um das doppelte ihrer eigenen Länge von demselben entfernt. - Deckschüppchen klein, am Rande gewimpert; Schwinger unbedeckt. - Die Hüften mehr oder weniger deutlich behaart, die hinteren überdiess auf der Aussenseite mit je einer abstehenden Borste bewehrt. Beine ziemlich schlank, mit kurzer anliegender Behaarung bekleidet nnd nur sparsam beborstet; Schenkel ohne Präapicalborste, ${ }^{1}$ ) aber auf der Hinterseite der Vorderschenkel nnd auf der Vorderseite der hinteren Schenkel mit nach abwärts gerichteter zarter, bisweilen steifer oder ziemlich langer Behaarnng, bei manchen Arten auch die Hinterschenkel in der Nähe der Basis oberseits mit aufgerichteter wimperartiger Behaarung versehen; die Vorderschienen ausser dem Borstchen auf der Unterseite der Spitze stets borstenlos, die hinteren Schienen ausser dem Borstchen auf der Unterseite der Spitze meist mit ein oder zwei Börstchen auf der Oberseite in der Nähe der Basis (setae subbasales, und die Männchen überdiess auf der Oberseite der Hinterschienen mit einem Borstchen in der Nähe der Spitze; die Tarsen der vorderen Beine einfach, der Metatarsus der Hinterbeine unbeborstet, kürzer als das folgende Tarsenglied und bei deın Männchen mehrerer Arten an der Basis ein wenig ausgekerbt und daselbst mit bei stärkerer Vergrösserung wahrnehmbaren Dörnchen oder Knötchen verziert. - Hinterleib ziemlich kurz, mehr oder weniger kegelfürmig, bisweilen flach gedrückt, metallisch gefärbt, selten lebhaft glänzend, mit kurzer, an den Seiten des ersten Hinterleibsringes längerer Behaarung; das unsymmetrische

1) Eine nahe vor der Spitze der Schenkel stehende Borste.

Z. B. Ges, B. XXVII. $\Lambda \mathrm{bh}$. 
Hypopygium frei, glänzend schwarz und aus drei mit einander verwachsenen Theilen bestehend, von welchen der erste oder Basaltheil der kleinste ist und die Verbindung des Hypopygiums mit dem letzten Hinterleibsringe herstellt, der zweite meist grösste Theil bildet einen unregelmässig runden oder länglichen Körper und hat auf seiner linken Seite eine behaarte, gewöhnlich grau schimmernde Stelle; der dritte länglich kegelförmige oder fast herzfürmige Theil trägt die gewöhnlicben vier $\left.{ }^{1}\right)$ Analanhänge, von denen die äusseren meist kurz, blättchenartig und gewimpert, die imneren aber ziemlich lang und an der Spitze gespalten sind und entweder griffelartig vorragen oder zangenartig zusammenneigen. Die Legeröhre des Weibchens ist in der Regel zurückgezogen. Die Gattung Medeterus unterscheidet sich von allen übrigen DolichopodenGattungen ${ }^{2}$ ) hauptsächlich durch die nackten Augen und durch die Beschaffenheit des letzten Abschnittes der vierten Längsader, welcher mit der abwärts gebogenen dritten Längsader stets convergirt und gerade oder gebogen - ohne geschwungen, gebrochen oder wellenartig über die Flügelfläche erhoben zu sein - zur Flügelspitze lauft.

Die bis jetzt noch unbekannten Larven einiger durch Zucht hervorgegangener Medeterus-Arten scheinen unter Fichtenrinde zu leben; die orthoraphen Puppen einer Art wurden in den Gängen von Bostrychen in einem feinen Gespinnste gelegen angetroffen. ${ }^{3}$ ) Die entwickelten Fliegen halten sich vom Frühjahr bis zum Herbste an aufrecht stehenden Baumstämmen, Felsenwänden, Mauern, Planken, auf Steinen und nur selten an Pflanzen auf; sie lauern oft stundenlang auf ihre, aus winzig kleinen Insecten bestehende Beute, ohne sich zu regen, den Kopf nach oben gerichtet und die Brust auf die aufgerichteten Vorderbeine gestemmt; beunruligt bewegen sie sich rasch nach seitwärts, oder fliegen wie im Sprunge nach einem höher gelegenen Punkte ihres Aufenthaltsortes.

Es sei hier noch hervorgehoben, dass die Färbung der Beine und - mit Ausnahme der Borsten am Thoraxrücken und am Schildchen - selbst die Farbe der Behaarung bei mehreren Medeterus-Arten sehr veränderlich ist; dass

1) Das Hypopygium hut bekanntlich vier Paare Analanhänge, hier sind nur die an der Spitze des Hypopygiums stehenden zwei Paare gemeint.

$\left.{ }^{2}\right)$ Die Gattung Thrypticus Gerst., von der mir nur eine Art und zwar Thr. bcllus Lw. bekannt ist, hat mit Medeterus die meiste habituelle Aehnlichkeit; sie nnterscheidet sich von diesem durch den parallelen Verlauf der dritten und vierten Längsader. (Fig. 2⿺).

3) Rudolf Damianitsch hat die Puppe von Medeterus iristis Ztt.? in den Verh. d. zool. bot. Ges. XV. 237 (1865) zuerst beschrieben und abgebildet. - Herr Prof. Kriechbaumer in München theilto mir mit, dass Bed. signaticornis Lw. aus Pupyen schlüpfte, welche Herr Ritter von Posehinger im bairischen Walde mit einer Masse Larven und Puppen von Borkenkafern und solehen selbst gefuuden und an das Münchener Museum zur Untersuchung eingesendet hatte. Herr Ritter von Posehinger hatte die Güte auch mir eine Partie Fichtenrinde, welche mit Sciara- und Bostrychus-Larven reich besetzt war und aus welcher ich Med, pinicola m. erzog, zuzaschicken; die zur Untersuchung abgesonderten, für Medeterus gehaltenen Larven gingen mir leider sämmtlich zu Grunde. Med. pallipes Ztt. erzog ich ebenfulls aus mit Borkenkäfern besetzter Fichtenrinde. - Erwähnt sei noch, dass schon Ratzeburg in seinem Werke „die Waldverderber p. 68 (1860) das Vorkommen von Dipterenlarven ueben Borkenkäfera constatirt. 
durch die zwischen der vierten und fünften Längsader gelegenen Flügelfalte je nach deren Tiefe die hintere Querader mehr oder weniger verkürzt und daher das Längenverhältniss zwischen der hinteren Querader und zwischen dem letzten Abschnitte der fünften Längsader schwankend erscheint und dass auch die Beborstung des Thoraxrückens bisweilen unbeständig ist; man verwende daher zum Bestimmen der Arten vollkommen entwickelte und gut conservirte Stücke, welche insbesonders die Beborstung des Thorax, des Schildchens und der Beine möglichst vollständig zeigen.

\section{Tabelle zum Bestimmen der männlichen und weiblichen Meileterus.}

1. Schildchen jederseits mit nur einer langen Borste. . . . . . . . 2 Schildchen jederseits mit je einer längeren und einer kürzeren Borste 6

2. Das ganze Gesicht mit dichter weisslicher Bestäubung bedeckt . . . 3 Das Gesicht nur über der Querleiste grau oder braun bestäubt, unter der Querleiste mehr oder weniger metallisch glänzend . . . . . . 4

3. Vorderhüften und Beine lehmgelb . . . . . sp. 1. plumbellus Mg. Vorderhüften und Beine schwarz . . . . . sp. 2. seniculus n. sp.

4. Die Haarborsten am Prothorax weisslich . . . sp. 3. micaceus Lw. Die Haarborsten am Prothorax schwarz . . . . . . . . . . . 5

5. Schenkel ganz gelb . . . . . sp. 4. chrysotimiformis Kow. Schenkel von der Basis her bis über die Mitte hinaus schwarz

sp. 5. dichaetus n. sp.

6. Mittelschienen mit keinem Borstchen in der Nähe der Basis . . . . 7 Mittelschienen mit einem Borstchen in der Nähe der Basis . . . . 8

7. Cilien am hinteren Augenrande schwarz, meistens aber rostgelb schimmernd, Brustseiten von oben gesehen schwärzlich . . . sp. 6. muralis $\mathrm{Mg}$. Cilien am hinteren Augenrande weiss, Brustseiten meist wie der Thoraxrücken grau . . . . . . . . . . sp. 7. glaucellus n. sp.

8. Die kurze Behaarung, welche die Mittellinie des Thoraxrückens einschliesst, deutlich $\left.{ }^{1}\right)$

Die knrze Behaarung, welche die Mittellinie des Thoraxrückens einschliesst, äusserst kurz und undeutlich . . . . . . . . . . 18

1) Dieses Merkmal kann bei Med. ambiguts Ztt. und infumatus Lw, zweifelhaft erscheinen, weil bei diesen beiden schwarzbeinigen Arten die gedachte Behaarnng bald mehr bald weniger dentlich ist: Mled. ambiguus ist wegen seiner dunkel metallisch glānzenden Stirn und silberweissschimmernden Vorderhüften nicht zn verkennen; Med. infumatus kennzeichnet sich durch das schwarze, über der Querleiste - so wie die Stirn - braun oder grau bestänbte Gesicht. Bei den bieher gehörigen Arten bestehen die beider gewöhnlichen Borstenreiheu des Thoraxrūckens ausser aus 2-6 lāngeren Borsten noch ans meist zahlreichen am vorderen Theile des Thoraxrüekens befindlichen kurzen Börstchen; wăhrend bei den Arten, welche die Mittellinie mit keiner oder mit undentlicher Behaarung eingefasst haben, diese Borstenreihen nur aus 3-6, in der Regel schon anf dem vorderen Theile des Rückens befindlichen, lingen Borsten bestohen. 
9. Der letzte Abschnitt der fünften Längsader mindestens anderthalb Mal so lang als die hintere Querader ${ }^{1}$ ) . . . . . . . . . . . . . 10 Der letzte Abschnitt der fünften Längsader nicht anderthalb Mal so lang als die hintere Querader . . . . . . . . . . . . . . 13

10. Das Gesicht über der Querleiste gran, unter derselben metallisch schwarz. sp. 8. glaucus Lw.

Das ganze Gesicht metallisch glänzend .

11. Schwingerknopf wenigstens auf der Oberseite schwärzlich.

sp. 9. tristis Ztt.

Schwingerknopf ganz gelb

12. Mittelgrosse Art Kleine Art .

13. Das ganze Gesicht grau bestäubt .

Das ganze Gesicht metallisch glänzend, höchstens an der Querleiste grau. 14

14. Hinterleib lebhaft metallisch grün oder blau . . sp. 13. nitidus Macq. Hinterleib metallisch schwarz, düster grün oder grau schimmernd . 15

15. Schwingerknopf schwarz . . . . . sp. 14. signaticornis Lw. Schwingerknopf weisslich oder gelblich . . . . . . . . . . 16

16. Hüften und Hinterleib beider Geschlechter schwarz und glänzend, Fühler des Männchens an der Spitze ausgekerbt. sp. 15. dichrocerus n. sp. Hüften schwarz, grau bestäubt, Hinterleib des Männchens metallisch schwarz, der des Weibchens grau oder grün schimmernd . . . . 17

17. Hypopygium gross und dick, Hinterleib des Weibchens besonders an den Seiten und am Bauche grau ... . . . . sp. 16. obscurus Ztt. Hypopyginm schmal, Hinterleib des Weibchens auch am Bauche dunkel metallisch grün .......... sp. 17. pinic ola n. sp.

18. Beine gelb, höchstens die Schenkel an der Basis schwarz oder braun 19 Beine schwarz, höchstens die Kniee gelb .

19. Gesicht lebhaft metallisch glänzend, nur an der Querleiste grau. sp. 18. diadema L.

Das ganze Gesicht weisslich bestäubt .

20. Die Bestäubung des Gesichtes dünn, Taster schwarz sp. 19. flavipes $\mathrm{Mg}$. Die Bestäubung des Gesichtes dicht, Taster metallisch grün.

sp. 20. lamprostomus Lw.

21. Beine ganz schwarz . . . . . . . . . . . . . . . 22

Beine schwarz, mit gelben Knieen . . . . . . . . . . . 23

22. Stirn und das ganze Gesicht lebhaft glänzend, Vorderhüften mit silberweissem Schimmer .. . . . . . sp. 21. ambiguus Ztt. Stirn und das Gesicht über der Querleiste braun oder grau bestãubt, Vorderhüften ohne silberweissen Schimmer. . . sp. 22. infumatus Lw.

1) In zweifelhaftem Falle berücksichtige man die Beschreibungen von Med. glaucus Lw. und Med. pinicola. m. 
23. Das ganze Gesicht mit dünner grauer Bestäubung bedeckt.

sp. 23. jaculus Mg.

Das Gesicht mindestens unter der Querleiste unbestäubt und metallisch glänzend . . . . . . . . . . . . . . . . . . . . . 24

24. Der letzte Abschnitt der fünften Längsader länger als die hintere Querader ${ }^{1}$ ); Hypopygium ziemlich klein . . . sp. 24. truncorum Mg.

Der letzte Abschnitt der fünften Längsader so lang oder kürzer als die hintere Querader . . . . . . . . . . . . . 25

25. Thorax dicht bestäubt, matt, am Rücken meist ungestriemt ${ }^{2}$ ), Hypopygium schmal . . . . . . . . . . . . sp. 25. tenuicauda Lw.

Thoraxrücken gestriemt, Hypopygium gross . . . . . . . . 26

26. Der erste und zweite Abschnitt der vierten Längsader nahezu gleich lang; ziemlich kleine Art . . . . . sp. 26. dendrobaenus n. sp.

Der erste Abschnitt der vierten Längsader auffallend länger als der zweite; ziemlich grosse Art . . . . . . sp. 27. petrophilus n. sp.

\section{Beschreibung der Arten.}

\section{Scutellum utrinque setā singula instructum, tibiae inter- mediae prope basim setam distinctam ferentes.}

1. Med. plumbellus $\mathrm{Mg}$. $\sigma^{\top}$ 오. Facie albo-pollinosa, coxis anticis pedibusque flavis.

Long. corp. $2-2.5 \mathrm{~mm}$.

Syn. Hydrophorus jaculus. Fll. Dol. 5. 7. 1823. ㅇ․ var. $\gamma$.

- Medeterus plumbellus. Mg. Syst. Beschr. IV. 69. 20. 1824. О'ㅇ.

- Hydrophorus minutus. Ztt. Dipt. Scand. II. 456. 17. 1843. ․

- Medeterus plumbellus. Lw. Neue Beitr. V. 54. 1857. రㅇ․

- Medeterus plumbellus. Schin. Fauna austr. I. 237. 1862.

Stirn nnd Gesicht dicht weiss oder gelblichweiss bestäubt, Fühler schwarz, Taster weiss behaart und weiss schimmernd; Rüssel verhältnissmässig gross, Cilien am hinteren Augenrande weisslich. Thoraxrücken und das mit zwei langen Borsten versehene Schildchen mit dichter gelblichgrauer Bestäubung bedeckt, welche auf der Mittellinie des Rückens und oft auch neben den beiden von je drei gleichmässig langen Borsten gebildeten Borstenreihen striemenartig gelbbraun erscheint; Brustseiten grau bestäubt; Prothorax mit zwei oder drei

1) Med. dendrobaenus m. kann mit Mred. truncorum verwechselt werden, wenn bej jenem die hintere Qnerader durch die zwischen der vierten und fünften Längsader gelegene Flügelfalte erheblich verkūrzt erscheint.

$\left.{ }^{2}\right)$ Der Thoraxrücken des Mánnchens ron Jied. petrophilus $\mathrm{m}$. ist wohl anch ziemlich dicht bestāubt nnd häufig ohne dentliche Striemen; in diesem Falle entrcheidet die Gestalt des Hypopygiums. 
weisslichen Haarborsten. Flügel bräunlichgelb gefärbt, mit schwarzbraunen an der Flügelbasis gelben Adern; dritte Längsader mit dem fast geraden letzten Abschnitte der vierten Längsader wenig convergirend; der letzte Abschnitt der fünften Längsader so lang oder etwas kürzer als die hintere Querader. Deckschüppchen and Schwinger gelblich, erstere blassgelb gewimpert. Vorderhüften lehmgelb, an der Basis bisweilen gebräunt, die hinteren Hüften schwarz, grau bestäubt; die Behaarung der Vorderhüften und die Börstchen an den hinteren Hüften weisslich; Beine lehmgelb, nur die äussersten Spitzen der Schienen und der vier ersten Tarsenglieder und das letzte Tarsenglied schwärzlich; oft sind aber auch die Schenkel an der Basis und die Tarsen von der Spitze des ersten Gliedes an verdunkelt; die nach abwärts gerichtete Behaarung auf der Vorderseite der Hinterschenkel weisslich und zart, die Borste in der Nähe der Basis der Mittelschienen deutlich; Metatarsus der Hinterbeine beim Männchen an der Basis ausgekerbt. Hinterleib erzgrün, fahlgelb behaart und wenig glänzend; bei trächtigen Weibchen ist der Vorderrand der Hinterleibsringe schwärzlich: Hypopygium verhältnissmässig gross und dick, die äusseren Anhänge schmal dreieckig, braun, an der Basis schmutziggelb, die inneren Anhänge lineal, etwas länger als die äusseren und schwarzbraun.

Vaterland: Mir ist diese Art in Oesterreich bisher nur aus Altsandec in Galizien durch Herrn Dr. Grzegorzek bekannt geworden; in Deutschland ist sie sehr verbreitet: Herr Dr. A. Raddatz erwähnt in seiner "Uebersicht der in Mecklenburg bis jetzt beobachteten Insecten 1873. 62", dass Med. plumbellus Mg. von Ende Juni bis Mitte Angust auf trockenem, sterilen Boden zwischen den spärlichen Pflanzen nicht selten sei; Herr Dr. A. Gerstaecker gibt in der „Uebersicht der in der Umgegend Berlins bis jetzt beobachteten Dolichopoden (Stettiner entom. Zeitng. 1864. 41.6)" das Vorkommen obiger Art auf Baumstümpfen an. Schweden (Zetterstedt).

Anmerkung. In der Sammlung des Herrn Dr. H. Loew befinden sicb drei aus der Umgebung von Berlin stammende und von Meigen selbst bestimmte Exemplare obiger Art; auch in der Winthem'schen Sammlung ist noch das Stück vorhanden, welches Meigen l. c. beschrieben hat. - In der Zetterstedt'schen Beschreibung von Hydr. minutus finde ich Nichts, was der Annahme, dass minutus Ztt. mit plumbellus Mg. identisch sei, widerspräche.

2. Med. seniculus n. sp. $\sigma^{7}$. Facie albo-pollinosa, coxis anticis pedibusque nigris.

Long. corp. 2. mm.

Stirn, Gesicht und Taster dicht weiss bestäubt, Fühler schwarz, Rüssel von mittler Grösse, Cilien am hinteren Augenrande weiss. Thoraxrücken und das mit zwei langen Borsten versehene Schildchen dicht gelblichgrau bestäubt, auf der Mittellinie des Rückens und neben den beiden von je drei gleichmässig langen Borsten gebildeten Borstenreihen striemeuartig braun; Brustseiten 
weisslichgrau; Prothorax mit zwei weisslichen Haarborsten. Flügel bräunlich gefärbt, mit schwarzbraunen Adern; dritte Längsader mit dem fast geraden letzten Abschnitte der vierten Längsader wenig convergirend; der letzte Abschnitt der fünften Längsader etwa ein und einviertel Mal so lang, als die hintere Querader. Deckschüppchen und Schwinger gelblich, erstere sehr sclimal braun gerandet und blassgelb gewimpert. Hüften schwarz, grau schimmernd, die Behaarung der Vorderhüften und die Börstchen der hinteren Hüften weiss; Beine schwarz, nur die äussersten Kniespitzen rostgelb und die Hinterschienen an der Basis dunkelbraun; die abwärts gerichtete Behaarung anf der Vorderseite der Hinterschenkel weisslich und ziemlich undeutlich, die Borste in der Nähe der Basis der Mittelschienen auffallend; der Metatarsus der Hinterbeine an der Basis ausgekerbt. Hinterleib metallisch dunkelgrün, fahlgelb behaart und nur wenig glänzend; Hypopygium verhältnissmässig gross, die äusseren Analanhänge dreieckig, gelbbraun, am Rande schwarz, die etwas längeren, linealen, gegen die Spitze hin allmälig und schwach erweiterten inneren Anbänge ganz schwarz.

Vaterland: Die Art, welche sich in der Sammlung des Herrn Dr. H. Loew befindet, stammt aus dem südwestlichen Polen und wurde im Juli gefangen.

Anmerkung. Med. seniculus unterscheidet sich von Med. plumbellus $\mathbf{M g}$. von der Farbe der Vorderhüften und Beine abgesehen durch sein deutlich schmäleres Gesicht und durch die braun gerandeten Deckschüppchen.

3. Heal. micaceus Lw. O'․ Fucie superiore ochraceo-pollinosa, inferiore obscure viridi aut aeneo-nitida aut cinereo-micante, prothoracis setis albicantibus.

Loug. corp. 1:8-2 mm. (Fig. 19, 20).

Syn. Hydrophorus jaculus Fll. Dol. 5. 7. 1823. бㅇ. var. $\beta$.

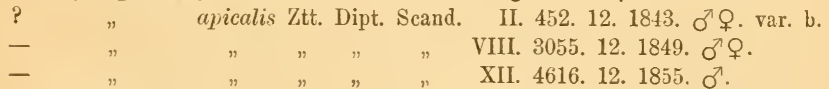

- Medeterus micaceus Lw. Neue Beitr. V. 55. 1857.

- $\quad \quad$ Schin. Fauna austr. I. 238. 1862.

Stirn und das Gesicht über der Querleiste braun oder bräunlichgrau bestäubt, das Gesicht unter der Querleiste schwarzgrün metallisch glänzend, in Folge einer dünnen Bestänbung bisweilen bräunlichgrau schimmernd; Fühler und Taster schwarz, Rüssel mässig gross; Cilien am hinteren Augenrande weisslich. Thoraxrücken and das mit zwei langen Borsten versehene Schildchen dicht gelblichgrau bestäubt, auf der Mittellinie des Rückens und neben den beiden von je drei gleichıässig langeu Borsten gebildeten Borstenreihen mit mebr oder weniger deutlichen, braunen, manchmal dunkel eingefassten, Striemen; Brustseiten grau; Prothorax mit zwei bis dré weisslichen Haarborsten. Flügel bräunlich oder grau gefärbt, mit schwarzen Adern; dritte Längsader mit dem fast geraden letzten Aischnitte der vierten Längsader wenig convergirend, 
der letzte Abschnitt der fünften Längsader ein und einviertel Mal so lang, als die hintere Querader. Deckschüppchen und Schwinger gelb, erstere fallgelb gewimpert. Hüften schwarz, grau schimmernd, die Behaarung der vordersten und die Börstchen der hinteren Hüften weisslich. Gewöhnlich sind die Schenkel von der Basis her bis über die Mitte binaus schwarz, an der Spitze so wie die Schienen und die Basis der Metatarsen aller Beine heller oder dunkler rostgelb, die Spitzen der Vorder- und Hinterschienen und die Tarsen aller Beine von der Spitze des ersten Gliedes an braun; bisweilen aber sind ausser den Knieen nur die hinteren Schienen auf der Mitte rostgelb, oder die Beine sind ganz schwarz; die abwärts gerichtete Behaarung auf der Vorderseite der Hinterschenkel weisslich oder fahlgelb und zart, die Borste in der Nähe der Basis der Mittelschienen auffallend; Metatarsus der Hinterbeine beim Männchen an der Basis ausgekerbt. Hinterlcib metallisch blaugrün oder düster erzgrün, fahlgelb behaart und wenig glänzend; Hypopygium ziemlich gross, die äusseren Analanhänge dreieckig und wie die schmal linealen und etwas längeren inneren Anhänge gelb oder braun.

Vaterland: Die Art scheint über ganz Europa verbreitet zu sein; Zetterstedt hat sie in Schweden, Herr Prof. Zeller in Sicilien gefunden; mir ist sie ausser aus Oesterreich, Ungarn und Deutschland auch aus Russland bekannt geworden; man findet sie besonders in Waldgegenden während der Monate Juni, Juli und August, meistens auf Steinen und an Felsenwänden.

Anmerkung. Ich habe sowohl die Type des Herrn Dr. H. Loew, als auch ein Zetterstedt'sches aus Esperöd stammendes und von ihm als $H y d r$. apicalis var. b. bezetteltes Exemplar untersucht.

4. Mea. chrysotimiformis Kow. $\sigma^{\top}$. . Facie superiore cinereopollinosa, inferiore aeneo-viridi et nitida, prothoracis setis nigris, femoribus flavis.

Long. corp. $1 \cdot 8-2 \cdot 2 \mathrm{~mm}$.

Syn. Medeterus chrysotimiformis Kow. Verh. d. zool.-bot. Ges. XVIII. 220. 9. 1868 ㅇ..

Stirn und das Gesicht über der Querleiste weisslichgrau bestäubt, das Gesicht unter der Querleiste dunkelgrün, metallisch glänzend, Fühler und Taster schwarz, Rüssel ziemlich gross, Cilien am hinteren Augenrande weisslich, die der Mundöffinung nächststehenden zwei Börstchen schwarz. Thorax und das mit zwei Borsten versehene Schildehen metallischgrün, jedoch in Folge einer gelblichgrauen, mässig dichten Bestäubung grünlichgrau erscheinend; die beiden Borstenreihen von je drei gleichmässig langen Borsten gebildet; Prothorax mit zwei bis drei schwarzen Haarborsten. Flügel blass bräunlichgelb gefärbt, mit bräunlichen, an der Flügelbasis gelben Adern; dritte Längsader mit dem fast geraden letzten Abschnitte der vierten Längsader wenig convergirend; der letzte Abschnitt der fünften Längsader ein und einviertel Mal so lang als die hintere Querader. Deckschüppchen und Schwinger gelb, erstere blassgelb gewimpert. Hüften 
schwarz, etwas grauschimmernd, die Behaarung derselben schwarz; Beine gelb, nur die äusserste Spitze der Schienen und die vier ersten Tarsen und das ganze letzte Tarsenglied schwarz; bisweilen ist - besonders bei den Männchen die Unterseite der Schenkel an der Basis geschwärzt; die nach abwärts gerichtete Behaarung auf der Vorderseite der Hinterschenkel fahlgelb und zart, die Borste in der Nähe der Basis der Mittelschienen deutlich; der Metatarsus der Hinterbeine beim Männchen an der Basis nicht ausgekerbt. Hinterleib metallischgrün, gelblich behaart und wenig glänzend; Hypopygium ziemlich klein, nit schwarzbraunen Analanhängen.

Vaterland: Herr von Frivaldszky entdeckte diese Art bei Ofen; Herr Prof. Mik traf sie Anfangs Juli auf der Türkenschanze bei Wien zahlreich auf niedrigen Pflanzen, zumeist auf Papilionaceen (Onobrychis, Lotus, Medicago) an.

Anmerkung. Ausser durch die lebhaft gelbe Färbung der Beine unterscheidet sich obige Art von Med. micaceus Lw. durch die etwas hellere und minder dichte Bestäubung des Thorax, hauptsächlich aber durch die schwarzen Haarborsten am Prothorax und an den hinteren Hüften und im männlichen Geschlechte durch keine vemerkbare Auskerbung des Metatarsus der Hinterbeine und durch das auffallend schmälere Hypopygium. - Das 1. c. beschriebene Exemplar war nicht vollkommen entwickelt und daher erschien die Farbe der Fliigeladern und der Beine bleicher, und da das Gesicht über der Querleiste durch Eintrocknen verschrunıft war, schien auch die Bestäubung desselben dunkler zu sein.

5. Med. dichaetus n. sp. $\sigma^{7}$. Fucie superiore cinereo-pollinosa, inferiore obscure aenea, prothoracis setis nigris, femoribus inde a basi ultra medium nigris in apice flavis.

Long. corp. $2-2.5 \mathrm{~mm}$.

Stirn und das Gesicht über der Querleiste gelblichgrau bestäubt, das Gesicht nnter der Querleiste schwarz oder schwarzgrün, metallisch glänzend, Fühler und Taster schwarz, Rüssel ziemlich gross; Cilien am hinteren Augenrande fahlgelb, die der Mundöffuung nächststehende Borste jedoch schwarz. Thorax und das mit zwei Borsten, versehene Schildchen metallischgrün, aber in Folge einer mässig dichton, gelblichgrauen Bestäubung grünlichgrau erscheinend; die beiden Borstenreihen von je drei gleichmässig langen Borsten gebildet; Prothorax mit zwei schwarzen Haarborsten. Flügel blass bräunlichgelb gefärbt, mit braunen an der Flügelbasis gelben Adern; dritte Längsader mit dem fast geraden letzten Abschnitt der vierten Längsader wenig convergirend; der letzte Abschnitt der fünften Längsader fast anderthalb Mal so lang als die hintere Querader. Deckschüppchen und Schwinger gelb, erstere gelb gewimpert. Hüften schwarz und schwarz behaart; Beine gelb, nur die Schenkel von der Basis her bis über die Mitte hinaus, die äusserste Spitze der Schienen und der drei ersten Tarsenglieder und das ganze vierte und fünfte Tarsenglied schwarz;

Z. B. Ges. B. XXVII. Abh. 
die nach abwärts gerichtete Behaarung auf der Vorderseite der Hinterschenkel fahlgelb und zart, aber deutlich, die Borste in der Nähe der Basis der Mittelschienen auffallend; der Metatarsus der Hinterbeine an der Basis nicht ausgekerbt. Hinterleib metallisch grün, gelblich behaart und wenig glänzend; Hypopygium gross, mit schwarzbraunen, an der Basis bräunlichgelben Analanhängen.

Vaterland: Herr Prof. Nowicki besitzt dic Art aus Galizien, Scholtz sammelte sie bei Breslau und Herr Prof. Kriechbaumer in der Umgebung von München.

Anmerkung. Die beschriebene Art hat ganz das Aussehen wie Med. chrysotimiformis m., von dem sie sich durch die Färbung der Beine und durch das grosse Hypopygium unterscheidet; mit Med. micaceus Lw. kann sie wegen der etwas geringeren Bestäubung des Thorax und wegen der schwarzen Farbe der Haarborsten am Prothorax nicht verwechselt werden.

\section{Scutellum utrinque setis binis instructum.}

\section{A) Tibiae intermediae seta subbasali destitutae.}

6. Med. muralis $\mathrm{Mg} . \sigma^{\top}$ ㅇ. Thoracis dorso cinereo-pollinoso, glauco, pleuris nigricantibus, ciliis posticis oculorum fuscis, rufo-micantibus.

Long. corp. 1·כ̌-2 mm. (Fig. 21).

Syn. Medeterus muralis Mg. Syst. Beschr. IV. 62. 5. 1824.

? Hydrophorus muralis Ztt. Dipt. Scand. II. 455. 16. 1843. ‥ var. c.

- Medeterus melanopleurus Lw. Neue Beitr. V. 52. 1857.

Stirn und das Gesicht über der Querleiste grau bestäubt, das Gesicht unter der Querleiste schwarz und entweder glänzend oder etwas gran schimmernd, Fühler und Taster schwarz, Rüssel klein, in die Mundöffnung oft ganz zurückgezogen; Cilien am hinteren Augenrande dunkel, rostgelb schimmernd, die der Mundöffunng nächsten Börstchen meistens schwarz. Thoraxrücken und das mit vier Borsten versehene Schildchen metallisch blau oder blaugrün, weisslichgrau bestäubt, die Bestäubung der Brustseiten duukelbraun, der Rücken daher bläalichgran, die Brustseiten - besonders von oben her betrachtet - schwarz erscheinend; von den die beiden Borstenreihen bildenden, am vorderen Theile des Rückens kurzen, gegen das Schildchen hin allmälig längeren Borsten sind nur die je zwei hintersten am auffallendsten; Prothorax mit zwei bis drei dunklen, rostgelb schimmernden Haarbörstchen. Flügel blassgrau gefärbt, mit schwarzbraunen Adern; die dritte Längsader mit dem nur wenig gebogenen letzten Abschnitte der vierten Längsader convergirend; der letzte Abschnitt der fünften Längsader anderthalb Mal so lang als die hintere Querader. Deckschüppchen und Schwinger gelblich oder bräunlich, erstere schwarz gerandet, mit bräunlichen, blassgelb schimmernden Wimpern, letztere mit auf der Oberseite schwärzlichem Knopfe. Hüften schwarz, grau schimmernd, mit bisweilen 
rostgelbem Schenkelknopfe; die Behaarung der Hüften schwärzlich. Beine entweder ganz schwarz, oder die Schienen und Tarsen braun und nur der Metatarsus der Hinterbeine an der Basis gelb, oder auch die äussersten Kniespitzen, die Schienen - besonders die der Hinterbeine - an der Spitze in grösserer oder geringerer Ansdehnung und die vier ersten Tarsenglieder gelb; immer aber zeigen vorzugsweise die Schienen und Tarsen in Folge einer kurzen, fahlen Behaarung einen gelblichen oder weisslichen Schimmer; die nach abwärts gerichtete Behaarung auf der Vorderseite der Hinterschenkel kurz und undeutlich, die Mittelschienen ohne Borstchen in der Nähe der Basis und der Metatarsus der Hinterbeine beim Männchen an der Basis ohne bemerkbare Auskerbung. Hinterleib metallisch schwarzgrün oder dunkelblaugrün, etwas glänzend; die Behaarung desselben dunkel, fahl schimmernd; Hypopygium von mittler Grösse, die äusseren Anhänge desselben dreieckig und rostgelb, die inneren, fast doppelt längeren, blassgelb, an der Basis schwarz.

Vaterland: In Oesterreich und Ungarn, besonders in Gebirgsgegenden auf Steinen, an Felsenwänden und an Manern vom Mai bis August; Herr Prof. Mik fand die Art bei Hammern in Oberösterreich häufig; Herr Scherfling in Oberitalien; Schlesien (Scholtz), Mecklenburg (Raddatz), Hamburg (Winthem), Schweiz (Zeller) und wahrscheinlich auch Scandinavien (Zetterstedt).

Anmerkung. Ich habe das in der Winthem'schen Sammlung befindliche typische Exemplar, welches Meigen als Med. muralis und die Type, welche Herr Dr. H. Loew als Med. melanopleurus beschrieben hat, untersucht und mich daher von der Identität beider überzeugen können.

7. Med. glaucellus n. sp. $\sigma^{7}$. Thorace glauco-cinereo, pleuris concoloribus, ciliis posticis oculorum albis.

Long. corp. $2-2 \cdot 2 \mathrm{~mm}$.

Stirn und das Gesicht über der Querleiste grau bestäubt, das Gesicht unter der Querleiste schwarz und entweder glänzend oder etwas grau schimmernd; Fühler und Taster schwarz, Rüssel klein, Cilien am hinteren Augenrande weiss. Thorax und das mit vier Borsten versehene Schildchen metallisch blau, in Folge der weisslichgrauen Bestäubung auf der Oberseite und an den Brustseiten blänlichgran erscheinend; von den die beiden Borstenreihen bildenden, am vorderen Theile des Rückens kurzen, gegen das Schildchen hin allmälig längeren Borsten sind nur die je zwei hintersten am auffallendsten; Prothorax mit zwei weissen Haarbörstchen. Flügel blassgrau gefärbt, mit schwarzbraunen Adern; dritte Längsader mit dem fast geraden letzten Abschnitte der vierten Längsader convergirend; der letzte Abschnitt der fünften Längsader nabezu anderthalb Mal so lang, als die hintere Querader. Deckschüppchen und Schwinger bräunlichgelb, erstere schwarz gerandet und mit bräunlichen, blassgelb schimmernden Wimpern versehen, letztere mit auf der Oberseite schwärzlichem Knopfe. Hüften schwarz, grau schimmernd; die Behaarung der Vorderhüften und die Börstchen an den hinteren Hüften weiss; Beine schwarz, höchstens an den hinteren Beinen die Basis der Metatarsen rostbraun; die kurze anliegende 
Behaarnng der Beine weisslich, die nach abwärts gerichtete Behaarung auf der Vorderseite der Hinterschenkel sehr kurz und undeutlich; Mittelschienen ohne Borstchen in der Nähe der Basis; der Metatarsus der Hinterbeine beim Männchen an der Basis nicht ausgekerbt. Hinterleib metallisch dunkelblau oder dunkelgrün, etwas glänzend, die Behaarung desselben hell schimmernd; Hypopygium verhältnissmässig gross, mit rostgelben äusseren und schwarzbraunen inneren Analanhängen.

Vaterland: Herr Prof. Mik entdeckte diese Art in Görz, wo sie schon Mitte April vorkommt, sammelte sie aber auch in Krain, Salzburg und Oberösterreich während der Monate Mai und Juni; ich fing sie im Kasan bei Orsova an Felsenwänden.

Anmerkung. Med. glaucellus gleicht dem Med. muralis Mg. sehr, unterscheidet sich jedoch von diesem durch die reinweissen Cilien am hinteren Augenrande, durch die weissen Haarbörstchen am Prothorax und an den hinteren Hüften und durch die graue Bestäubung der Brustseiten, im männlichen Geschlechte durch sein verhältnissmässig grosses Hypopygium. ${ }^{1}$ )

\section{B) Tibiae intermediae seta subbasali instructae.}

a) Setulae in thoracis dorso lineam mediam includentes distinctae.

a) Segmentum ultimum nervi longitudinalis quinti longitudinem nervi transversalis posterioris sesquialteram attingens.

8. Med. glaucus Lw. ㅇ. Facie superiore cinereo-pollinosa, inferiore aeneo-nigra.

Long. corp. $2.5 \mathrm{~mm}$.

Syn. Medeterus glaucus Lw. Beschr. europ. Dipt. I. 301. 179. 1869. ㅇ.

Stirn und das Gesicht über der Querleiste grau bestäubt, das Gesicht unter der Querleiste metallisch schwarz, mässig glänzend; Cilien am hinteren Augenrande weiss oder weiss und nur das dem Mundrande nächststehende Borstchen schwärzlich; Fühler und Taster schwarz; Rüssel von mittler Grösse. Thorax und das mit vier Borsten versehene Schildchen metallisch blaugrün, mit mässig dichter, hellgrauer Bestäubung bedeckt und daher bläulichgrau oder grünlichgrau erscheinend; die beiden Borstenreihen auf der Oberseite des Rückens von je fünf Borsten gebildet, von denen die vordersten kurz, die übrigen allmälig länger sind; die Behaarung, welche die Mittellinie einschliesst, schütter aber sehr deutlich; Prothorax mit zwei weisslichen oder bräunlichen Haarborsten. Flügel fast glashell, mit schwarzen, an der Flügelbasis bisweilen braunen Adern; dritte Längsader mit dem gebogenen letzten Abschnitte der vierten Längsader ziemlich stark convergirend; der letzte Abschnitt der fünften

1) Nach Prof. Mik sind die Augen von M. glaucellus im Leben unten zn zwei Dritttheilen schön metallischgrün, daselbst mit grösseren Façetten, am obersten Drittel rothbraun, sehr fein façettirt; bei $M$. muralis $\mathrm{Mg}$. durchaus dunkelrothbraun, zuweilen nach unten zu mit olivengrünlichem Schimmer, mit nicht auffallend verschiedener Façettirung. 
Längsader etwa anderthalb Mal so lang als die hintere Querader. Deckschüppchen und Schwinger blassgelb, erstere schwarz gerandet, mit braunen, fahlgelb schimmernden Wimpern. Hüften schwarz, etwas grau schimmernd, die Behaarung der vordersten und die Börstchen der hinteren schwarz; Beine schwarz, nur die äussersten Kniespitzen gelb; die kurze, anliegende Bebaarung der Beine bleich, die nach abwärts gerichtete Behaarung auf der Vorderseite der Hinterschenkel schwarz und zart, das Borstchen in der Nähe der Basis der Mittelschienen vorlıanden. Hinterleib dunkel metallisch blaugrün, fahl behaart und ziemlich glänzend.

Vaterland: Herr Prof. Zeller entdeckte die Art am 5. Juli 1867 in Kärnthen.

A nmerkung. Ich habe die Art nach typischen Exemplaren, welche sich in der Sammlung des Herrn Dr. H. Loew befinden, beschrieben; sie gleicht im Colorit dem Med. muralis Mg. und noch mehr dem Med. glaucellus m., unterscheidet sich aber von diesen beiden genannten Arten hauptsächlich durch das Vorhandensein des Borstchens in der Nähe der Basis der Mittelschienen.

9. Med. tristis Ztt. $\sigma^{\top}$ ㅇ. Facie superiore aeneo-viridi, inferiore nigra et nitida, halterum clava superne fusca.

Long. corp. $2 \cdot 5-2 \cdot 7 \mathrm{~mm}$.

Syn. Hydrophorus tristis Ztt. Ins. Lapp. 702. 9. 1840. $0^{7}$ ‥

- Medeterus tristis Lw. Neue Beitr. V. 53. 1857.

$\begin{array}{lll}- & \quad & \quad \text { Schin. Fauna austr. I. 238. } 1862 . \\ \text { ? } & \quad \text { Damianitsch Verh. d. zool.-bot. Ges. XV. 238. } 1865 .\end{array}$

Stirn bräunlichgrau bestäubt, Gesicht metallischgrün, unter der Querleiste fast schwarz und glänzend; Cilien am hinteren Augenrande, Fühler nnd Taster schwarz; Rüssel von mittler Grösse. Thorax und das mit vier Borsten versehene Schildchen metallisch schwarz, auf dem Rücken nur wenig bräunlichgran, auf dem Eindrucke vor dem Schildchen und an den Brustseiten gran bestäubt; die beiden Borstenreihen auf dem vorderen Theile des Rückens von mehreren kurzen, auf dem hinteren Theile desselben von je vier allmälig längeren Borsten gebildet; die kurze Behaarung, welche die Mittellinie einschliesst, deutlich; Prothorax mit zwei bis drei schwarzen, kurzen Haarbörstchen. Flügel blass bräunlich oder grau gefärbt, mit braunen oder schwarzen Adern; dritte Längsader mit dem gebogenen letzten Abschnitte der vierten Längsader stark convergirend; der letzte Abschnitt der fünften Längsader anderthalb Nal so lang als die hintere Querader; Deckschüppchen gelb, schwarz gerandet, mit bräunlichen oder schwärzlichen Wimpern; Schwinger gelblich, mit auf der Oberseite schwarzem Knopfe. Hïften schwarz, etwas glânzend; die Behaarung der vordersten und die Börstchen der binteren schwarz; Beine ganz schwarz, die äussersten Kniespitzen bisweilen rostbraun; die nach abwärts gerichtete Behaarung auf der Vorderseite der Hinterschenkel schwarz und fast borsten- 
artig, das Borstchen in der Nähe der Basis der Mittelschienen deutlich; Metatarsus der Hinterbeine beim Männchen ohne Auskerbung an der Basis. Hinterleib metallisch schwarz, mit schwachem blauen oder grünen Schimmer, schwarz behaart und mässig glänzend; Hypopygium ziemlich lang und schmal mit schwarzen oder braunen Analanhängen, die äusseren derselben - im trockenen Zustande - kurz und mit häkchenartigen Börstchen geziert; die inneren, mehr als doppelt länger und fadenförmig, sind zangenartig zusammengeneigt.

Vaterland: Ich sammelte die Art von Mai bis Juli bei Asch, Carlsbad und München an Baumstämmen, Herr Dr. H. Loew besitzt sie aus Schlesien und Zetterstedt erwähnt ihr Vorkommen noch während des August in Scandinavien. R. Damianitsch erwähnt 1. c., dass er Med. tristis aus Puppen, welche er unter Fichtenrinde gefunden hat, gezogen habe.

Anmerkung. Ich hatte wohl Gelegenheit ein typisches weibliches Stück von Med. tristis Ztt. zu sehen, dasselbe war aber so schadhaft, dass es sich für eine genaue Untersuchung nicht mehr eignete; ich habe daher meiner Auffassung die vollständig zutreffende Beschreibung Zetterstedt's zu Grunde legen müssen.

10. Med. apicalis Ztt. Q. Facie aenea, superiore viridi, inferiore nigricante, halteribus flavis, magnitudine corporis mediocri.

Long. corp. $3 \cdot 2-3.5 \mathrm{~mm}$.

Syn. Hydrophorus apicalis Ztt. Dipt. Scand. II. 452. 12. 1843. ㅇ.

- Medeterus apicalis Lw. Neue Beitr. V. 53. 1857.

Stirn grau bestäubt, Gesicht metallisch grün, unter der Querleiste dunkler und glänzender als über derselben; Cilien am hinteren Augenrande entweder braun und rostgelb schimmernd, oder fahlgelb, Fühler und Taster schwarz, Rüssel von mittler Grösse. Thorax und das mit vier Borsten versehene Schildchen dunkel metallischgrün, nur wenig bräunlichgrau bestäubt; die beiden Borstenreihen auf dem vorderen Theile des Rückens von mehreren kurzen, auf dem hinteren Theile desselben von je drei oder vier allmälig längeren Borsten gebildet; die kurze Behaarung, welche die Mittellinie einschliesst, deutlich; Prothorax mit zwei bis drei schwarzbraunen oder fahlgelben, kurzen Haarbörstchen. Flügel blass bräunlichgrau gefärbt, mit schwarzbraunen, an der Basis bisweilen hellbraunen Adern; dritte Längsader mit dem gebogenen letzten Abschnitte der vierten Längsader stark convergirend; der letzte Abschnitt der fünften Längsader anderthalb Mal so lang als die hintere Querader. Deckschüppchen und Schwinger rostgelb, erstere schwarz gerandet, mit bräunlichen, fahlgelb schimmernden Wimpern. Hüften schwarz und schwarz behaart; Beine schwarz mit rostgelben Knieen; die Färbung an den Kuieen jedoch bisweilen so ausgedehnt, dass die Beine auch rostgelb, mit brauner Schenkelbasis und braunen Schienenspitzen bezeichnet werden können; die kurze anliegende Behaarung der Beine fahl schimmernd; die nach abwärts gerichtete Behaarung auf der Vorder- 
seite der Hinterschenkel schwarz, das Borstchen in der Nähe der Basis der Mittelschienen deutlich. Hinterleib metallisch schwarzgrün, schwarz oder fablgelb behaart und ziemlich glänzend.

Vaterland: Vom Juni bis September in Oesterreich, Deutschland, Dänemark und Schweden an Baumstämmen ziemlich selten.

Anmerkung. Ob Med. apicalis Ztt. - wie ich vermuthe - nur eine Varietät von Med. tristis Ztt. sei, kann erst durch das Bekanntwerden des Männchens nachgewiesen werden; die Männchen, welche Zetterstedt im VIII. und XII. Bande seiner Dipt. Scand. erwähnt, gehören - wie ich mich theilweise überzeugen konnte - nicht zu Med. apicalis, sondern zu Med. micaceus Lw.; nach meinen Untersuchungen unterscheidet sich der in der Färbung der Beine sehr veränderliche $M c d$. apicalis von tristis durch die Körpergrösse, durch die im Allgemeinen hellere Körperfärbung und durch die einfärbig gelben Schwinger. - Bei obiger Beschreibung habe ich auch ein Staeger'sches aus Kopenhagen stammendes Exemplar von Med. apicalis, welches sich in der Sammlung des Herrn Dr. H. Loew befindet, benützt.

11. Med. pallipes Zett. $\sigma^{\top}$ ㅇ. Facie aeneo-viridi, halteribus flavis, magnitudine corporis parva.

Long. corp. $2 \mathrm{~mm}$. (Fig. 17).

Syn. Hydrophorus jaculus Ztt. Ins. Lapp. 702. 7. 1840. ㅇ. var. b. pallipes Ztt. Dipt. Scand. II. 453. 13. 1843. రㅇ.

- Medeterus muralis Lw. Nene Beitr. V. 55. 1857.

Schin. Fauna austr. I. 238. 1862.

Stirn weisslichgrau bestäubt; Gesicht metallischgrän, unter der Querleiste dunkler und glänzender als über derselben; Cilien am hinteren Augenrande weisslich; Fühler und Taster schwarz, Rüssel ziemlich klein. Thorax und das mit vier Borsten versehene Schildchen metallischgrün oder blaugrün, mässig dicht gelblichgran bestäubt und daher graugrün oder graublau erscheinend; die beiden Borstenreihen auf dem vorderen Theile des Rückens von einigen kurzen, auf dem hinteren Theile von je vier allmälig längeren Borsten gebildet; die kurze Behaarung, welche die Mittellinie einschliesst, noch ziemlich deutlich; Prothorax mit zwei kurzen, fahlgelben Haarbörstchen. Flügel blass gelblichgrau gefärbt, mit braunen, an der Flügelbasis meist gelben Adern; die dritte Längsader mit dem gebogenen letzten Abschnitte der vierten Längsader stark convergirend; der letzte Abschnitt der fünften Längsader reichlich anderthalb Mal so lang als die hintere Querader. Schwinger und die blassgelb gewimperten und bisweilen braun gerandeten Deckschüppchen gelblich. Hüften glänzend schwarz, die Behaarung der vordersten und die Börstchen der hinteren fahlgelb; Schenkel schwarz, an der Spitze sowie die Schienen und die ersten vier Tarsenglieder gelb, die äusserste Spitze der Schienen und das letzte Tarsenglied schwarzbraun; bisweilen sind auch die Schienen und Tarsen in grösserer oder geringerer Ausdehnung braun oder schwarz; die kurze anliegende 
Behaarung der Beine und die nach abwärts gerichtete fast borstenartige $\mathrm{Be}$ haarung auf der Vorderseite der Hinterschenkel fahlgelb; das Borstchen in der Nähe der Basis der Mittelschienen deutlich; der Metatarsus der Hinterbeine beim Männchen ohne Auskerbung. Hinterleib metallischgrün, oder blaugrün, seltener schwarzgrün und trotz der meistens fahlgelben Behaarung ziemlich lebhaft glänzend; Hypopygium lang und schmal mit rostgelben oder braunen Analanhängen.

Vaterland: In Oesterreich, Ungarn, Deutschland, Dänemark und Schweden vom Mai bis September an Baumstämmen, seltener an Steinen; ich zog die Art Ende Juni 1867 aus Fichtenrinde, welche mir Herr Förster Czech in Moskau gefälligst zugeschickt hatte.

Anmerkung. Med. pallipes ist an der geringen Grösse, an dem meist ziemlich lebhaft metallisch grün glänzenden und fahlgelb behaarten Hinterleib, der gewöhnlich durch Eintrocknen auffallend kurz und breit erscheint, an dem Flügelgeäder und an der fast borstenartigen Behaarung auf der Vorderseite der Hinterschenkel trotz der Veräuderlichkeit in der Färbung der Beine gut zu erkennen. - Die Zetterstedt'sche Beschreibung gibt für die richtige Deutung obiger Art wohl zu keinem Zweifel Veranlassung. Das von Herrn Dr. H. Loew 1. c. ausgesprochene Bedenken gegen die Synonymie seines muralis Mg. mit pallipes Ztt. beruht auf einem Merkmale, welches Zetterstedt nicht von pallipes - wie Herr Dr. H. Loew irrthümlich voraussetat - sondern von albipes Ztt. angibt. Erwähnt sei noch, dass sich diese Art auch in der Wiedemann'schen Sammlung mit der Bezeichnung "dendrophilus miti" ohne Vaterlandsangabe befindet.

ß) Segmentum ultimum nervi longitudinalis quinti longitudinem nervi transversalis posterioris sesquialteram non attingens.

12. Med. obesu's n. sp. ․ Facie cinereo-pollinosa.

Long. corp. $4 \mathrm{~mm}$.

Stirn und das ganze Gesicht weisslichgrau bestäubt, Cilien am hinteren Augenrande weiss, Fühler und die lebhaft glänzenden Taster schwarz; Rüssel ziemlich gross. Die Bestäubung des Thorax und des mit vier Borsten versehenen Schildchens grau, auf der Mitte des Räckens jedoch und neben den beiden gewöhnlichen Borstenreihen braun; die Härchen, welche die Mittellinie einschliessen, deutlich; die beiden gewöhnlichen Borstenreihen auf dem vorderen Theile des Rückens von mehreren kurzen, auf dem hinteren Theile desselben von je vier ziemlich langen Borsten gebildet; der vordere Theil des Rückens ist auch neben den beiden Borstenreihen deutlich und verhältnissmässig dicht mit kurzen borstenartigen Härchen besetzt; Prothorax mit vier bräunlichen, weiss schimmernden Haarborsten. Flügel blassgrau, gegen die Flügelspitze hin längs den schwarzbraunen Adern etwas dunkler gefärbt; die dritte Längsader mit dem gebogenen letzten Abschnitte der vierten Längsader stark convergirend; der letate Abschnitt der fünften Längsader etwas kürzer als die hintere Querader. Deckschüppchen und Schwinger blassgelb, erstere schwarz gerandet 
und fablgelb gewimpert; der Knopf der letzteren anf der Oberseite mit einem bräunlichen Fleckchen. Hüften schwarz, grau bestäubt und weiss behaart; Beine schwarz; die nach abwärts gerichtete weisse Behaarung auf der Vorderseite der hinteren Schenkel deutlich, an den Mittelschenkeln besonders anffallend; das Borstchen in der Nähe der Basis der Mittelschienen vorhanden. Hinterleib metallisch schwarzgrün, schwarz behaart und ziemlich glänzend, am Vorderrande der Ringe breit gran schimmernd.

Vaterland: Ich fing ein einziges Weibchen dieser Art im Juni 1873 bei Bozen auf Steinen.

A nmerkung. Med. obesus hat ganz den Habitus wie Med. obscurus Ztt., unterscheidet sich jedoch von diesem durch die weisslichgraue Bestäubung des ganzen Gesichtes.

13. Med. nitidus Macq. $\sigma^{\top}$ ․ Facie et abdomine aeneo-viridibus et nitidis.

Long. corp. $3.5-4 \mathrm{~mm}$.

Syn. Hydrophorus nitidus Macq. Snit. à Buff. I. 446. 4. 1834. 오.

- Medeterus nitidus Mg. Syst. Beschr. VII. 156. 28. 1838. $\$$.

Stirn gran bestänbt, Gesicht metallischgrün oder blaugrün, unter der Querleiste dunkler und glänzender als über derselben; Cilien am hinteren Augenrande weisslich; Fühler schwarz, das erste Glied derselben rothgelb; Taster schwarz, Rüssel ziemlich gross. Thorax und das mit vier Borsten versehene Schildchen dunkel metallischgrün, mässig grau bestäubt und daber etwas glänzend; die kurze Behaarung, welche die Mittellinie des Thoraxrückens einschliesst, deutlich; die beiden Borstenreihen auf dem vorderen Theile des Rückens von zahlreichen kurzen, auf dem hinteren Theile desselben von je fünf bis sechs allmälig längeren Borsten gebildet; der vordere Theil des Rückens ist überdiess ziemlich dicht mit kurzer steifer Behaarung bekleidet; Prothorax mit vier bis fünf schwarzen Haarborsten. Flügel blass gelbbräunlich gefärbt, mit braunen, an der Flügelbasis gelben Adern; die dritte Längsader mit dem gebogenen letzten Abschnitte der vierten Längsader stark convergirend; der letzte Abschnitt der fünften Längsader und die hintere Querader fast gleich lang. Deckschüppchen und Schwinger gelb, crstere schmal braun gesäumt und gelb gewimpert. Hüften schwarz, grau bestänbt, die Behaarung der vordersten und die Börstchen der hinteren dunkel, fahlgelb schimmernd; Beine schwarz, höchstens die Kniegelenke rostgelb; die Behaarung auf der Vorderseite der hinteren Schenkel, so wie die auf der Hinterseite der Vorderschenkel zart, aber verhältnissmässig lang und schwarz; die Borste in der Nähe der Basis der Mittelschienen deutlich; die äusserste Basis des Metatarsus der Hinterbeine beim Männchen verdünnt. Hinterleib kurz, metallischgrün oder blaugrün, lebhaft glänzend und schwarz behaart, der erste und zweite Hinterleibsring etwas grau schimmernd; Hypopygium ziemlich klein, nit rostgelben Analanhängen.

Z. B. Ges. B. XXVII. Abl. 
Vaterland: Herr Prof. J. Mik erhielt die Art aus Aachen; auch befindet sich ein Pärchen derselben in der Sammlung des k. k. Hofmuseums zu Wien; Frankreich (Macquart).

A nmerkung. Med. nitidus ist ebenfalls mit Med. obscurus Ztt. verwandt und diesem sehr ähnlich; nitidus hat jedoch besonders am Hinterleibe ein viel lebhafteres Colorit. - M acquart's Originalbeschreibung von Med. nitidus lautet: "Long. 2 lin. - D'un vert foncé, brillant. Les deux premiers articles des autennes testacés. Partie postérieure du thorax à sillon dorsal et duvet gris. Pieds noires. Ailes à bord exterieur des nervures d'un jaune pale ; Meigen übersetzt 1. c. die Ausdrücke "sillon dorsal " mit "Längsfurche und nduvet gris" mit "graue Flaumhaare"; ich glaube aber, Macquart habe unter sillon den Eindruck vor dem Schildchen und unter duvet die Bestäubung dieses Eindruckes gemeint; das Wort duvet wendet Macquart in dem interpretirten Sinne z. B. auch bei Diaphorus Hoffmannseggii und Psilopus platypterus an.

14. Med. signaticornis Lw. $\sigma^{7}$ ㅇ. Facie obscure aenea et nitida, halterum clava et abdomine nigris.

Long. corp. $3 \mathrm{~mm}$.

Syn. Medeterus signaticornis Lw. Neue Beitr. V. 51. 1857.

Stirn ein wenig grau bestäubt und daher etwas glänzend, Gesicht dunkel metallischgrün, unter der Querleiste fast schwarz; das erste oder das erste und zweite Fühlerglied rothgelb, das dritte schwarz und verhältnissmässig klein; Taster schwarz, Rüssel ziemlich gross; Cilien am hinteren Augenrand, fahlgelb, braun oder schwarz. Thorax und das mit vier Borsten versehene Schildchen metallisch schwarz, etwas bräunlichgrau bestäubt; die Behaarung, welche die Mittellinie des Thoraxrückens einschliesst, deutlich; die beiden Borstenreihen auf dem vorderen Theile des Rückens von einigen kurzen, auf dem hinteren Theile desselben von je vier oder fünf allmälig längeren Borsten gebildet; Prothorax mit drei bis vier schwarzen Haarborsten, von denen bisweilen eine fahlgelb ist. Flügel blassgrau gefärbt, mit schwarzbraunen Adern; die dritte Längsader mit dem gebogenen letzten Abschnitte der vierten Längsader convergirend; der letzte Abschnitt der fünften Längsader fast so lang als die hintere Querader. Deckschüppchen schmutzig fahlgelb, schwarz gerandet, mit braunen, fahlgelb schimmernden Wimpern; Schwinger schwarz, höchstens die Unterseite des Knopfes und der Stiel schmutzig fahlgelb. Hüften und Beine schwarz und schwarz behaart, die Hüften kaum etwas bränulich bereift und daher ziemlich glänzend; die nach abwärts gerichtete Behaarung auf der Vorderseite der hinteren Schenkel und das Borstchen in der Nähe der Basis der Mittelschienen zart, aber deutlich vorhanden. Hinterleib verhältnissmässig kurz, in beiden Geschlechtern metallischschwarz, schwarz behaart und glänzend; Hypopygium kaum von mittler Grösse mit schwarzen Analanhängen.

Vaterland: Herr Dr. H. Loew entdeckte die Art bei Meseritz, ich fing sie bei Asch im Juni an Baumstämmen; Herr Dr. Kriechbaumer zog die 
Art aus Larven, welche mit den Larven des Borkenkäfers im bairischen Walde unter Fichtenrinde gefunden wurden.

Anmerkung. Mled. signaticornis erinnert, obwohl weniger robust, an dunkel gefärbte Exemplare von Med. obscurus Ztt., unterscheidet sich aber von diesem durch die Form der Fühler, durch die Farbe der Schwinger, durch die schwarzen und mehr glänzenden Hüften, durch den in beiden Geschlechtern glänzend schwarzen Hinterleib und im männlichen Geschlechte durch das kleinere Hypopygium.

15. Med. dichrocerus n. sp. $\sigma^{\prime}$ ㅇ․ Facie obscure aenea, halteribus pallidis, coxis et abdomine nigris et nitidis.

○. Antennarum articulo tertio in apice emarginato.

Long. corp. $4 \mathrm{~mm}$. (Fig. 12, 13).

Stirn etwas bräunlichgrau bestäubt, Gesicht dunkel metallischgrün, glänzend, unter der Querleiste fast schwarz; Cilien am hinteren Augenrande entweder schwarz oder braun und fahl schimmernd; Taster schwarz; das erste Fühlerglied rothgelb, das zweite und dritte schwarz, letzteres beim Männchen fast eiförmig mit einer kleinen Auskerbung am Ende, in welcher die Fühlerborste steht; Rüssel ziemlich gross. Thorax und das mit vier Borsten versehene Schildchen metallisch schwarz, nur wenig bräunlichgrau bestäubt; die beiden gewöhnlichen Borstenreihen auf dem vorderen Theile des Rückens von zahlreichen kurzen, auf dem hinteren Theile von je vier oder fünf allmälig längeren Borsten gebildet; die Behaarung, welche die Mittellinie einschliesst, deutlich; Prothorax mit vier schwarzen Haarborsten. Flügel fast glashell, mit schwarzbraunen an der Flügelbasis rostgelben Adern; dritte Längsader mit dem gebogenen letzten Abschnitte der vierten Längsader stark convergirend; der letzte Abschnitt der fünften Längsader fast ebenso lang als die hintere Querader. Deckschüppchen schmutzig gelb, schwarzbraun gerandet, mit bräunlichen, gelblich schimmernden Wimpern; Schwinger weisslich oder gelblich. Hüften nnd Beine schwarz und schwarz behaart, erstere ziemlich glänzend und nur sehr wenig bräunlich schimmernd; die Behaarung auf der Vorderseite der Hinterschenkel kurz und undeutlich; das Borstchen in der Nähe der Basis der Mittelschienen verhältnissmässig zart; das Männchen hat auch auf der Mitte der Mittelschienen ein eben solches Borstchen. Hinterleib in beiden Geschlechtern metallisch schwarz, schwarz behaart und glänzend; Hypopygium von nur mittler Grösse, dessen Basaltheil und der letzte Hinterleibsring auf der Bauchseite mit ziemlich anffallender wimperartiger Behaarung geziert; die inneren Analanhänge rostbraun, die äusseren schwarz.

Vaterland: Ich habe diese hübsche Art bisher nur in Asch im Mai und Juni an Banmstämmen jedoch stets selten angetroffen.

Anmerkung. Med. dichrocerus sieht dem Med. signaticornis Lw. sehr ähnlich, von dem er sich durch die geringere Bestänbung des.Thorax, durch die weisslichen Schwinger und durch die kurze Behaarung auf der Vorderseite 
der Hinterschenkel unterscheidet, ist aber besonders im männlichen Geschlechte durch die Form der Fühler, durch die Börstehen an den Mittelschienen und durch die Behaarung am Basaltheile des Hypopygiums ganz besonders ausgezeichnet.

16. Med. obscurus Ztt. $\sigma^{7}$ ㅇ. Facie aeneo-viridi, halteribus pallidis, coxis cinereo-pollinosis.

$\sigma^{\top}$. Abdomine nigro et nitido, hypopygio crasso.

오. $\quad$ praesertim in lateribus et in ventre cinerascente.

Long. corp. $3 \cdot 2-4 \cdot 5 \mathrm{~mm}$. (Fig. 22, 23).

Syn. Hydrophorus obscurus Ztt. Ins. Lapp. 701. 6. 1840. ㅇ. .
"

\section{$n$}
Dipt. Scand. II. 449. 8. 1843. $\sigma^{\top}$ ㅇ․
- Medeterus robustus ${ }^{1}$ ) Lw. Neue Beitr. V. 51. 1857.

\section{$"$ obscurus Schin. Fauna anstr. I. 237. 1862.}

Stirn grau bestäubt, Gesicht metallisch grün, unter der oft grau schimmernden Querleiste glänzender als über derselben; Cilien am hinteren Augenrande entweder weisslich, oder weisslich und nur das dem Mundrande nächststehende Borstchen schwarz, oder alle Cilien braun oder schwarz; Fühler entweder ganz schwarz, oder das erste Glied derselben ganz oder theilweise rothgelb; Taster schwarz, Rüssel gross. ${ }^{2}$ ) Thorax und das mit vier Borsten versehene Schildchen metallisch schwarz, mässig grau oder braun bestäubt; ist die Bestäubung des Rückens grau, so erscheinen auf der Mitte und neben den beiden gewöhnlichen Borstenreihen desselben oft braune Striemen; die beiden Borstenreihen auf dem vorderen Theile des Rückens von zahlreichen kurzen, auf dem hinteren Theile desselben von je fünf bis sechs allmälig längeren Borsten gebildet; die Behaarung, welche die Mittellinie einschliesst, sehr deutlich; der vordere Theil des Rückens überdiess verhältnissmässig dicht mit kurzen Börstchen besetzt; Prothorax mit vier bis fünf schwarzen Haarborsten. Flügel glashell oder blassbräunlich gefärbt, mit schwarzen, an der Flügelbasis manchmal gelbbraunen Adern; die dritte Längsader mit dem gebogenen letzten Abschnitte der vierten Längsader stark convergirend; der letzte Abschnitt der fünften Längsader etwas kürzer als die auswärts gebogene hintere Querader. Deckschüppchen und Schwinger gelblich, erstere braun gerandet und fahlgelb gewimpert. Hüften schwarz, jedoch mit einer ziemlich dichten, grauen oder bräunlichgrauen Bestäubung bedeckt und schwarz behaart; Beine schwarz, die Kniegelenke manchmal rostgelb; die nach abwärts gerichtete Behaarung auf der Vorderseite der hinteren Schenkel zart, aber verhältnissmässig lang und schwarz; die Borste in der Nähe der Basis der Mittelschienen deutlich; die Hinterschienen auf der Oberseite gegen die Spitze hin gewimpert. Hinterleib des Männchens metallisch schwarz, glänzend und schwarz behaart, der des Weibchens besonders an den Seiten und am Bauche grau; Hypopygium gross

1) Schreibfehler für obscurus $Z$ tt.

3) Es sei hier Zetterstedt's Bemerkung über die Augen angeführt: „oculi in vivo aenescentes, macula in cantho superiori violacea*. 
und dick, mit rostgelben oder braunen Analanhängen; der Basaltheil des Hypopygiums und der letzte Hinterleibsring auf der Bauchseite schwarz behaart.

Vaterland: Herr Dr. H. Loew hat die Art im Tatragebirge angetroffen; ich fing sie bei Asch; in Deutschland ist sie weit verbreitet und im ersten Frübjahre an Klafterholz und an Baumstämmen oft sehr zahlreich zu finden; in Scandinavien im August (Zetterstedt).

17. Med. pinicola n. sp. $\sigma^{\top}$ ㅇ. Facie aeneo-viridi, halteribus pallidis, coxis cinereo-pollinosis, abdomine et in ventre obscure aeneo, nitido.

ऽ. Hypopygio minusculo.

Long. corp. $3 \mathrm{~mm}$.

Stirn grau bestäubt, das Gesicht metallisch grün, unter der gran schimmernden Querleiste dunkler und glänzender als über derselben; Cilien am hinteren Augenrande fahlgelb oder weisslich; das erste Füblerglied ganz oder theilweise rothgelb, das dritte Glied und die Taster schwarz; Rüssel von mittler Grösse. Thorax und das mit vier Borsten versehene Schildchen dunkel metallisch grün, etwas grau bestäubt; die beiden Borstenreihen auf dem vorderen Theile des Rückens von mehreren kurzen, auf dem hinteren Theile von je fünf allmälig längeren Borsten gebildet; die Behaarung, welche die Mittellinie einschliesst, deutlich; Prothorax mit vier fahlgelben oder braunen Haarborsten. Flügel glashell, mit schwarzbraunen, an der Flügelbasis bisweilen braunen oder lehmgelben Adern; die dritte Längsader mit dem gebogenen letzten Abschnitte der vierten Längsader stark convergirend; der letzte Abschnitt der fünften Längsader etwas länger als die hintere auswärts gebogene Querader. Deckschüppchen und Schwinger gelblich, erstere braun gerandet, mit bräunlichen, fahlgelb schimmernden Wimpern. Hüften schwarz, grau bestäubt; die Behaarung der vordersten und die Börstchen der hinteren fahlgelb oder schwarz; Beine schwarz, die äussersten Kniespitzen rostgelb; auch die vier ersten Tarsenglieder der Mittelbeine mit Ausnahme ihrer schwarzen Spitzen bisweilen dunkel rostgelb; die kurze anliegende Behaarung der Beine fahlgelb, die nach abwärts gerichtete Behaarung auf der Vorderseite der hinteren Schenkel weisslich und zart, aber noch deutlich; das Borstchen in der Nähe der Basis der Mittelschienen vorhanden; die Hinterschienen auf der Oberseite gegen die Spitze hin gewimpert. Hinterleib dunkel metallisch grün und glänzend, beim Weibchen an den Seiten etwas grau schinmernd, am Bauche wie auf der Oberseite gefärbt; Hypopygium ziemlich klein und schmal, am Basaltheile desselben und auf der Bauchseite des letzten Hinterleibsringes einige ziemlich lange lockenartige Wimperhaare; Analanhänge rostbraun.

Vaterland: Herr von Bergensta mm erbeutete die Art im Juni 1866 in der Ramsau bei Hainfeld V. O. W. W.; Herr Senator von Heyden in Frankfurt am Main erzog sie im Mai angeblich aus faulem Holze; ich selbst erzog die Art Mitte Juni aus Fichtenrinde, welche mir Herr Ritter von Poschinger in Frauenau aus dem bairischen Walde gefälligst zugesendet hatte. 
Anmerkung. Med. pinicola gehört auch zu den Verwandten des Med. obscurus Ztt.; das Männchen unterscheidet sich von diesem leicht durch das viel kleinere Hypopygium; beim Weibchen, das mit kleinen Exemplaren von obscurus verwechselt werden könnte, achte man auf die minder dichte $\mathrm{Be}$ stäubung der Hüften und auf die Farbe des Hinterleibes, der auf der Bauchseite ebenso wie anf der Oberseite dunkel metallisch grün und glänzend ist und nur an den Seiten sehr wenig grau schimmert; beide Geschlechter zeichnen sich auch noch dadurch ans, dass die Entfernung der hinteren Querader vom Flügelrande eine verbältnissmässig grössere ist, als bei den ihnen nächst verwandten Arten. Von dunkelbeinigen Varietäten des Med. apicalis Ztt., dessen Verhältniss zwischen der hinteren Querader und dem letzten Abschnitte der fünften Längsader pinicola nicht erreicht, unterscheidet sich dieser ausser durch andere Merkmale im Flügelgeäder, in der Behaarung des Thorax und der Beine durch die Farbe der Fühler.

b) Setulae in thoracis dorso lineam mediam includentes indistinctae.

18. Med. diadema L. $\sigma^{\top}$ ․ Facie aeneo-viridi et nitidissima, pedibus sordide flavis, femoribus plerumque piceis.

Long corp. 4.2-4.5 mm. (Fig. 14-16).

Syn. Musca diadema L. Syst. nat. XII. 982. 19. 1767.

rostrata F. Spec. ins. II. 448. 68. 1781.

- Medetera carnivora Fischer Progr. Moscou. 1819, p. 11.

- Hydrophorus rostratus Fll. Dol. 4. 6. 1823. o오.

- Medeterus rostratus Mg. Syst. Beschr. IV. 61. 3. 1824. cum. syn.

- Hydrophorus aeneivittatus Macq. Dipt. du Nord de Fr. 38. 2. 1827. o’ O.

- Medeterus rostratus Macq. Dipt. du Nord de Fr. 42. 2. 1827. $\sigma^{7}$.

- Medetera carnivora Fisch. WIdh. Oryctogr. d. Gouv. Moscou pl. d'hist. nat.

T. XV, f. 1. (Geäder und Genitalien falsch) 1830.

Medeterus aeneivittatus Mg. Syst. Beschr. VII. 156. 27. 1838. $\sigma^{\top}$ ㅇ․

- Hydrophorus rostratus Ztt. Dipt. Scand. II. 449. 9. 1843. ठㅇ․ var. a. u. b.

- Medeterus diadema Walk. Ins. Br. Dipt. I. 219. 1. 1851.

$\begin{array}{lll}- & \quad & \text { Lw. Neue Beitr. V. 54. } 1857 . \\ - & \quad & \text { Schin. Fauna austr. I. 237. } 1862 .\end{array}$

Gesicht lebhaft metallisch grün oder blangrün, glänzend, nur an der Querleiste und die Stirn grau bestäubt; Cilien am hinteren Augenrande weisslich, verhältnissmässig lang und dicht; Rüssel sehr gross, Fübler und Taster schwarz. Thorax und das mit vier Borsten versehene Schildchen erzgrün oder metallisch blaugrün, wenig grau bestäubt; Thoraxrücken auf der äusserst kurz behaarten Mittellinie und neben den beiden gewöhnlichen Borstenreihen striemenartig broncebraun; die beiden Borstenreihen des Rückens von je zwei kürzeren und je zwei längeren Borsten gebildet, das vorderste der kürzeren Börstchen bisweilen undeutlich; Prothorax mit drei bis fünf weisslichen Haarborsten. Flügel glashell, mit schwärzlichen, an der Flügelbasis lehmgelben Adern; die 
dritte Längsader mit dem geraden oder fast geraden letzten Abschnitte der vierten Längsader convergirend; der letzte Abschnitt der fünften Längsader halb so lang als die hintere Querader. Deckschüppchen fahlgelb, weisslich gewimpert; Schwinger gelb. Vorderbüften gelbbraun oder wie die hinteren Hüften schwarzbraun, grau schimmernd; die kurze Behaarung der vordersten und die Borsten an den hinteren Hüften weisslich; Beine meistens vorherrschend lehmgelb gefärbt, die Vorderschenkel entweder allein, oder die Vorder- und Hinterschenkel, oder alle Schenkel von der Basis her bis in die Nähe der Mitte oder über die Mitte hinaus verwaschen braun oder schwarzbraun; ebenso die äusserste Spitze der Schienen und der vier ersten Tarsenglieder gefärbt, das letzte Tarsenglied ganz schwarz; bei dunkelbeinigen Stücken sind auch die Schienen an der Spitze und die vier ersten Tarsenglieder in ausgedehnter Weise verwaschen braun; die nach abwärts gerichtete Behaarung auf der Vorderseite der Hinterschenkel kurz und undeutlich, dagegen die aufgerichtete, wimperartige, fahlgelbe $\mathrm{Be}-$ haarung in der Nähe der Basis dieser Schenkel auffallend; das Borstchen in der Nähe der Basis der Mittelschienen vorhanden; der Metatarsus der Hinterbeine beim Männchen an der Basis ausgekerbt. Hinterleib erzgrün oder inetallisch bliaugrün, fahlgelb behaart und nur mässig glänzend; Hypopygium ziemlich gross, mit rostgelben Analanhängen.

Vaterland: Med. diadema ist über ganz Europa verbreitet und kommt auch in Kleinasien vor; je nach der klimatischen Beschaffenheit der Gegend findet er sich vom Juni bis September all Mauern, Planken und Baumstämmen stellenweise sehr häufig.

Anmerkung. Die Einführung des Linnéschen Namens diadema für rostratus F. berulit auf der Untersuchung des typischen Excmplares der Linnéschen Sammlung durch Haliday (Stett. entom. Zeitschr. XII. 138. 1851); die Beschreibung, welche Macquart 1. c. von Med. rostratus gibt, ist lediglich eine Uebersetzung der Meigen'schen (Lw. l. c.).

19. Med. flavipes Mg. $\sigma^{7}$ ㅇ. Facie albo-pollinosa, palpis nigris, pedibus flavis.

Long. corp. $3-4 \mathrm{~mm}$.

Syn. Medeterus flavipes Mig. Syst. Beschr. IV. 61. 4. 1824. ठ'.

Lw. Neue Beitr. V. 54. 1857.

Stirn und das im Grunde metallisch grüne Gesicht weisslichgrau bestäubt, Cilien am hinteren Augenrande weisslich; Fühler und Taster schwarz, Rüssel gross. Thorax und das mit vier Borsten versehene Schildchen erzgrün, etwas grau bestäubt, neben den beiden Borstenreihen des Rückens und bisweilen auch auf der Mittellinie desselben striemenartig broncebraun; die beiden Borstenreihen von je vier ziemlich gleichartig langen Borsten gebildet; die Behaarung, welche die Mittellinie einschliesst, äusserst kurz; Prothorax mit vier weisslichen Haarborsten. Flügel fast glashell oder blass gelblichgrau gefärbt, mit schwarzbraunen, an der Flügelbasis gelben Adern; die dritte Längsader mit dem fast geraden letzten Abschnitte der vierten Längsader wenig convergirend, der 
letzte Abschnitt der fünften Längsader etwa halb so lang als die hintere Querader. Das fahlgelb gewimperte Deckschüppchen und die Schwinger blassgelb. Vorderhüften nnd alle Beine gelb, nur die äusserste Spitze der Schienen und der vier ersten Tarsenglieder braun, die hinteren Hüften und das letzte Tarsenglied aller Beine schwarz; die Behaarung der Hüften and Beine weisslich; die nach abwärts gerichtete Behaarung auf der Vorderseite der Hinterschenkel und die aufgerichteten Wimpern in der Nähe der Basis derselben Schenkel deutlich; das Borstchen in der Nähe der Basis der Mittelschienen vorhanden; der Metatarsus der Hinterbeine beim Männchen an der Basis ein wenig ausgekerbt. Hinterleib metallisch grün, weisslich behaart und wenig glänzend; Hypopygium gross, mit braunen äusseren und gelben inneren Analanhängen.

Vaterland: Die Art scheint nur im südlichen Europa und in Kleinasien einheimisch zu sein; Herr Dr. H. Loew fing sie bei Constantinopel, Herr von Roder besitzt sie ans Barcelona und die Exemplare in der Winthem'schen Sammlung stammen aus Lyon: nach Roser käme sie auch in Würtemberg vor.

A nmerkung. Med. flavipes Mg. ist von Med. jaculus Fll. nur durch die Farbe der Beine verschieden; ich vermuthe, dass jener nur eine Varietät von jaculus sein dürfte.

20. Merl. lamprostomus Lw. O' O. Facie albo-pollinosa, palpis aeneoviridibus, pedibus pavis femoribus in basi nigris.

Long. corp. $3.2 \mathrm{~mm}$.

Syn. Medeterus lamprostomus Lw. Beschr. europ. Dipt. 'II. 303. 165. 1871. o'

Stirn und das ganze Gesicht dicht weisslich bestäubt, Cilien am hinteren Augenrande weisslich; Fühler schwarz, Taster metallisch grün, lebhaft glänzend, am Rande weisslich behaart; Rüssel zienulich gross. Thorax und das mit vier Börstchen versehene Schildchen mit weịsslich grauer Bestäubung ziemlich dicht bedeckt, auf dem Rücken grünlichgrau, an den Brustseiten weisslichgrau erscheinend, neben den beiden von je vier gleichartig langen Borsten gebildeten Borstenreihen striemenartig bräunlich; die Behaarung, welche die Mittellinie des Thoraxrückens einschliesst, sehr undeutlich; Prothorax mit drei oder vier weisslichen Haarborsten. Flügel glashell, mit braunen, an der Flügelbasis gelblichen Adern; die dritte Längsader mit dem nur wenig gebogenen letzten $\mathrm{Ab}$ schnitte der vierten Längsader convergirend; der letzte Abschnitt der fünften Längsader entschieden kürzer als die hintere Querader. Deckschüppchen und Schwinger blassgelb, erstere weisslich gewimpert. Alle Hüften schwarz, weisslich behaart und grau schimmernd; Beine gelb, die Schenkel von der Basis her bis nahe zur Mitte hin schwarz, die äusserste Spitze der Schienen und der vier ersten Tarsenglieder braun, das letzte Tarsenglied aller Beine ganz schwarz; die kurze anliegende Behaarung der Beine und die aufgerichteten Wimpern in der Nähe der Basis der Hinterschenkel fahlgelb, die nach abwärts gerichtete Behaarung auf der Vorderseite der Hinterschenkel undeutlich; das Borstchen in der Nähe der Basis der Mittelschienen vorhanden; Metatarsus der Hinterbeine beim Männchen an der Basis ausgekerbt. Hinterleib metallisch grün, in 
Folge seiner weisslichen Behaarung von der Farbe des Thorax wenig verschieden und kaum etwas glänzend; Hypopygium ziemlich gross, Analanhänge rostgelb, an der Spitze geschwärzt.

Vaterland: Fedtschenko entdeckte die Art im Sarawschan-Thale.

Anmerkung. Ich habe bei obiger Beschreibung die in der Sammlung des Herrn Dr. H. Loew befindliche Type benutzt.

21. Med. ambiguus 7tt. $\sigma^{\top}$ ㅇ․ Fronte et facie aeneis ct nitidis, coxis anticis argenteo-micantibus, pedibus nigris.

Long. corp. $3 \cdot 2-3.7 \mathrm{~mm}$.

Syn. Hydrophorus ambiguus Ztt. Dipt. Scand. II. 456. 18. 1843. $\sigma^{7}$.

- Medeterus ambiguus Lw. Neue Beitr. V. 51. 1857.

- $" \quad$ Schin. Fauna austr. I. 237. 1862.

Stirn und das ganze Gesicht metallisch blaugrün, glänzend, unter der Querleiste dunkler oder mit violettem Schimmer; Augen im Leben blaugrün, mit purpurnem Querbande; Cilien am hinteren Angenrande weiss; Taster und die beim Männchen etwas schlanken Fühler schwarz; Rüssel gross. Thorax und das mit vier Borsten versehene Schildchen metallisch schwarz, bisweilen mit grünlichem Schimmer, auf der Oberseite sehr wenig bestäubt und daher ziemlich glänzend; Brustseiten blaugrün, weissgrau schimmernd; die beiden Borstenreihen des Thoraxrücken vorn von einigen sehr kurzen, hinten von je vier allmälig längeren Borsten gebildet; die Behaarung, welche die Mittellinie einschliesst, kurz und meist undeutlich; Prothorax mit drei bis vier weisslichen Haarborsten. Flügel fast glashell oder bräunlichgrau gefärbt, mit schwarzen, an der Flügelbasis bräunlichen Adern; dritte Längsader mit dem geraden oder nur wenig gebogenen letzten Abschnitt der vierten Längsader convergirend; der letzte Abschnitt der fünften Längsader so lang als die hintere Querader. Deckschüppchen schmutzig gelb, schwarz gerandet, mit bräunlichen, gelb schimmernden Wimpern; Schwinger bräunlich, mit auf der Oberseite schwärzlichem Knopfe. Hüften und Beine schwarz, die Vorderhüften auf der Vorderseite auffallend silberweiss schimmernd; die Börstchen der hinteren Hüften weiss; die Behaarung auf der Vorderseite der Hinterschenkel kurz und undeutlich, dagegen die aufgerichtete wimperartige Behaarung in der Nähe der Basis der Hinterschenkel und das Borstchen in der Nähe der Basis der Mittelschienen ziemlich auffallend; der Metatarsus der Hinterbeine beim Männchen an der Basis nur wenig ausgekerbt. Hinterleib metallisch schwarz, mit grünlichem oder blauem Schimmer, schwarz behaart und ziemlich glänzend; Hypopygium gross, mit schwarzbraunen Analanbängen.

Vaterland: Die Art ist in Oesterreich bisher noch selten gefunden worden; Herr Dr. H. Loew fing sie im Tatragebirge, Herr Prof. Mik bei Zettwing in Böhmen und bei Linz, ich selbst bei Asch; in Deutschland scheint sie hänfiger zu sein, insbesonders in den Umgebungen von Berlin (Gerstäcker), München (Kriechbaumer) und an mehreren Orten in Schlesien, Russland nnd

Z. B. Ges. B. XXVII Abh. 
Schweden (Zetterstedt); sie kommt im Juli und August an Baumstämmen und an Klafterholz vor.

Anmerkung. Ich habe Med. ambiguns Ztt. auch nach Exemplaren beschrieben, welche Herr Dr. H. Loew mit einer Zetterstedt'schen Type genau verglichen hat. - Die Beschreibung des Männchens, welche Zetterstedt im XII. Bande seiner Dipt. Scand. 4616. 18 nachbringt, passt weder auf die obige Art, noch überhaupt auf einen Medeterus; denn das Merkmal „femora postica ad apicem unisetosa" kommt der Gattung Medeterus gar nicht zu.

22. Med. infumatus Lw. $\sigma^{\top}$. . Fronte et facie superiore fusco-vel cinereo-pollinosis et opacis, facie inferiore nigra et nitida, coxis pedibusque nigris.

Long. corp. 2-2.2 $\mathrm{mm}$.

Syn. Hydrophorus muralis Ztt. Dipt. Scand. II. 455. 16. 1843. var. a u. b $\sigma^{\top}$.

- Medeterus infumatus Lw. Neue Beitr. V. 52. 1857. ㅇ․

\section{- $\quad n \quad$ Schin. Fauna austr. I. 238. 1862.}

Stirn und das Gesicht über der Querleiste braun oder grau bestäubt, das Gesicht unter der Querleiste schwarz und glänzend; Cilien am hinteren Augenrande weisslich, das dem Mundrande nächststehende Borstchen jedoch in der Regel schwarz; Fühler und Taster schwarz, Rüssel ziemlich gross. Thorax und das mit vier Borsten versehene Schildchen metallisch schwarz; der Rücken entweder braun, oder so wie der Eindruck vor dem Schildchen und die Brustseiten grau bestäubt; die Behaarung, welche die Mittellinie des Thoraxrückens einschliesst, meist sehr kurz und undeutlich; die beiden gewöhnlichen Borstenreihen auf dem vorderen Theile des Rückens von einigen kurzen, auf dem hinteren Theile von je zwei langen Borsten gebildet; sind jedoch die Börstchen auf dem vorderen Theile des Rückens etwas länger, dann pflegen auch die Härchen der Mittellinie etwas deutlicher zu sein; Prothorax mit zwei bis drei schwarzen Haarborsten. Flügel bräunlich oder blassgran gefärbt, mit schwarzen Adern; dritte Längsader mit dem fast geraden letzten Abschnitte der vierten Längsader convergiŕend; der letzte Abschnitt der fünften Längsader so lang oder nur wenig länger als die hintere Querader. Deckschüppchen schmutzig gelb, schwarz gerandet, mit bräunlichen, hell schimmernden Wimpern; Schwinger bräunlich oder gelblich, meistens mit auf der Oberseite schwarzem Knopfe. Hüften und Beine schwarz und schwarz behaart; die ersteren nur wenig bräunlich oder graulich bestäubt; die nach abwärts gerichtete Behaarung auf der Vorderseite der Hinterschenkel kurz, zart und undeutlich, das Borstchen in der Nähe der Basis der Mittelschienen vorhanden; der Metatarsus der Hinterbeine beim Männchen an der Basis ein wenig ausgekerbt. Hinterleib schwarz, schwarz behaart und ziemlich glänzend; Hypopygium gross, mit schwarzbraunen oder rostbraunen Analanhängen.

Vaterland: Oesterreich, Deutschland, Russland und Scandinavien rom Mai bis September (Zetterstedt) auf Steinen und an Baumstämmen, nach meinen Beobachtungen meistens nahe dem Erdboden. 
Anmerkung. Med. infumatus sieht dem tristis Ztt. sehr ähnlich, unterscheidet sich aber von diesem durch das Flügelgeäder, durch das Fehlen einer borstenartigen Behaarung auf der Vorderseite der Hinterschenkel und durch die Bestäubung des Gesichtes über der Querleiste, im männlichen Geschlechte überdiess durch das anffallend grosse Hypopygium. Die Varietät von Med. infumatus 우 mit gauz und gar grau bestäubtem Thorax könnte nur mit glaucus Lw. verwechselt werden, insbesonders wenn bei jenem auch die Behaarung der Mittellinie etwas deutlicher als gewöhnlich ist; glaucus ist zwar nicht erheblich grösser, aber verhältnissmässig etwas kräftiger gebaut als infumatus, mehr blaugrau gefärbt und durch die Beschaffenheit der Behaarung des Thoraxrückens und durch das Flügelgeäder von diesem auffallend verschieden. - Ich habe Med. infumatus mit dem typischen Exemplare des Herrn Dr. H. Loew genau verglichen und auch zwei von Zetterstedt mit der Bezeichnung "Ostrogothia Hydr. muralis var. b $Q^{\prime}$ und "Lapponia Hydr. muralis var. a $\sigma^{\text {" }}$ stammende Stücke untersucht, die obige Synonymie daher vollkommen sicherzustellen vermocht.

23. Med. jaculus Mg. $\sigma^{7}$ ㅇ. Facie cinereo-pollinosa, pedibus nigris, genibus ferrugineis.

Long. corp. $3.5-4 \mathrm{~mm}$. (Fig. 1-11).

Syn. Hydrophorus Jaculus Fll. Dol. 5. 7. 1823. $\sigma^{7}$ 오 var. $\alpha$.

- Medeterus Jaculus Mg. Syst. Beschr. IV. 66. 14. 1824.

n nigricans Mg. Syst. Beschr. IV. 67. 16. 1824. $\sigma^{7}$

- Hydrophorus jaculus Macq. Dipt. du Nord de Fr. 37. 1. 1827. ठ

- $\quad{ }^{2} \quad$ truncorum Ztt. Ins. Lapp. 702. 8. 1840. $\sigma^{\top}$ \&.

- jaculus Ztt. Dipt. Scand. II. 450. 10.1843. $\sigma^{7}$ ㅇ. var. a. b. c.

- Medeterus jaculus Wlk. Ins. Br. Dipt. I. 219. 2. 1851.

$\begin{array}{llll}- & n & n & \text { Lw. Neue Beitr. V. 53. } 1857 . \\ - & n & n & \text { Schin. Fanna austr. I. 238. } 1862 .\end{array}$

Stirn und das ganze Gesicht mit dünner grauer Bestäubung bedeckt, Cilien am hinteren Augenrande weisslich, Fühler und Taster schwarz, Rüssel ziemlich gross. Thorax und das mit vier Borsten versehene Schildchen metallisch blaugrün oder erzgrün, etwas grau bestäubt, auf der Mitte und neben den beiden gewöhnlichen Borstenreihen des Rückens mehr oder weniger deutlich striemenartig broncebraun; die Behaarung, welche die Mittellinie des Thoraxrückens einschliesst, äusserst kurz; die beiden gewöhnlichen Borstenreihen von je vier gleichmässig langen Borsten, vor welchen meistens noch ein oder zwei etwas kürzere Börstchen stehen, gebildet; Prothorax mit drei oder vier weisslichen Haarborsten. Flügel blassgrau gefärbt, mit schwarzbraunen, an der Flügelbasis lehmgelben Adern; die dritte Längsader mit dem wenig gebogenen letzten $\mathrm{Ab}$ schnitte der vierten Längsader wenig convergirend; der letzte Abschnitt der fünften Längsader fast nur halb so lang, als die hintere Querader, welche mit dem ersten Abschnitte der fünften Längsader einen spitzen inneren Winkel 
bildet. Deckschüppchen und Schwinger gelblich, erstere blassgelb gewimpert. Hüften schwarz, die Behaarung der vordersten und die Börstchen der hinteren weisslich; Beine schwarz, nur die Kniee gelb; die Behaarung der Beine ebenfalls weisslich; die nach abwärts gerichtete Behaarung auf der Vorderseite der Hinterschenkel und das Borstchen in der Nähe der Basis der Mittelschienen deutlich; beim Männchen sind die Hinterschienen auf der Oberseite dẹr Länge nach kurz gewimpert und der Metatarsus der Hinterbeine ist an der Basis ein wenig ausgekerbt. Hinterleib metallisch blaugrün oder düstergrün, weisslich behaart und etwas glänzend; Hypopygium gross, mit rostgelben oder braunen Analanbängen.

Vaterland: Med. jaculus kommt in ganz Europa vom Juni bis October an Baumstämmen, Planken und Mauern sehr häufig vor.

Anmerkung. Fallén hat unter Hydr. Jaculus offenbar mehrere Arten vermengt; Meigen hat den Fallén'schen Namen auf gegenwärtige, der Fallén'schen var. $\alpha$. entsprechenden Art fixirt; ich glaube sie desshalb correcter als Med. jaculus Mg. statt als Med. jaculus Fll. bezeichnet zu haben. - In der Wiedemann'schen Sammlung des Wiener k. k. Hofmuseums befindet sich das von Meigen 1. c. erwähnte und mit „Wiedm. Type“ und „nigricans M. Kiel“ bezeichnete Männchen, welches aber nur ein fett gewordener Med. jaculus ist und in diesem Zustande der Meigen'schen Beschreibung vollkommen entspricht. - Ich habe auch von Zetterstedt und Stäger herrührende Typen des Med. jaculus untersucht.

24. Med. truncomum Mg. $\sigma^{7}$ Q. Facie inferiore aeneo-viridi et nitida, segmento ultimo nervi longitudinalis quinti quam nervus transversalis posterior longiore, pedilus nigris, genibus ferrugineis.

万. Hypopygio mediocri.

Long. corp. 2-2.5 mm.

Syn. Medeterus truncorum Mg. Syst. Beschr. IV. 67. 15. 1824. б'.

- Hydrophorus truncorum Macq. Dipt. du Nord de Fr. 39. 4. 1827. ठ'.

?

?

Ztt. Dipt. Scand. II. 452, 11. 1843. $0^{7}$ ㅇ․

$"$

Medeterus truncorum Walk. Ins. Br. Dipt. I. 219. 3. 1851.
$n \quad$ Lw. Neue Beitr. V. 54. 1857.

Schin. Fauna austr. I. 238. 1862.

Gesicht metallisch grün, glänzend, auf der Querleiste weisslichgrau, neben dem Augenrande' über der Querleiste und unter den Fühlern, sowie die Stirn bräunlichgrau bestäubt; Cilien am hinteren Augenrande weisslich, Fühler und Taster schwarz, Rüssel verhältnissmässig zieınlich gross. Thorax und das mit vier Borsten versehene Schildchen metallisch blaugrün, mit dünner Bestäubung bedeckt, auf der Mittellinie und neben beiden gewöhnlichen Borstenreihen des Rückens striemenartig broncebraun und etwas glänzend; die Behaarung, welche die Mittellinie des Thoraxrückens einschliesst, äusserst kurz und undeutlich; die beiden gewöbnlichen Borstenreihen von je vier gleichmässig langen Borsten 
gebildet; Prothorax mit zwei oder drei weisslichen oder bräunlichen Haarborsten. Flügel blass bräunlichgrau gefärbt, mit schwarzbraunen, an der Flügelbasis lehmgelben Adern; die dritte Längsader mit dem fast geraden letzten Abschnitte der vierten Längsader nur wenig convergirend; der letzte Abschnitt der fünften Längsader etwas länger als die hintere Querader. Deckschüppchen und Schwinger gelblich, erstere blassgelb gewimpert. Hüften schwarz, grau bestänbt und weisslich behaart, die Börstchen der hinteren Hüften bisweilen verdunkelt; Beine schwarz, nur die Kniee gelb; die nach abwärts gerichtete Behaarung auf der Vorderseite der Hinterschenkel weisslich, ziemlich kurz und nicht sehr deutlich; das Borstchen in der Nähe der Basis der Mittelschienen vorhanden; Metatarsus der Hinterbeine beim Männchen an der Basis ein wenig ausgekerbt. Hinterleib dunkel metallisch grün, fahlgelb behaart und ziemlich glänzend; Hypopygium von nur mittler Grösse mit schwarzbraunen Analanhängen.

Vaterland: Med.truncorum ist mir aus Oesterreich, Ungarn, Deutschland, Frankreich, Russland und Sicilien bekannt geworden und kommt vom Juni bis October an Baumstämmen vor; wenn obige Synonymie richtig, so wäre er auch in Schweden und Dänemark (Zetterstedt) und in England (Walker) einheimisch.

Anmerkung. Med. truncorum macht sich schon durch seine geringe Grösse den verwandten Arten gegenüber kenntlich und unterscheidet sich ausserdem von dem ihm ähnlichen Med. jaculus $\mathbf{M g}$. durch die Farbe des Gesichtes, durch die Stellung der hinteren Querader und im männlichen Geschlechte ganz auffallend durch das viel kleinere Hypopygium. - Bei obiger Beschreibung wurde auf die iu der Winthem'schen Sammlnng befindlichen Stücke, welche Meigen erwähnt, Rücksicht genommen. - Macquart bezeichnet in seiner Beschreibung 1. c. die Kniee des Hydr. truncorum "noirs", was wohl mit Rücksicht auf seine Diagnose, wo dieselben njaunes" genannt werden, auf einen Schreibfehler Macquart's zurückzuführen sein wird.

25. Med. tenuicauda Lw. $\sigma^{\nearrow}$ Q. Facie inferiore aeneo-viridi et nitida, thorace confertim pollinoso, opaco, in dorso plerumque non vittato, segmento ultimo nervi longitudinalis quinti quam nervus transversalis posterior breviore, pedibus nigris, genibus ferrugineis.

$0^{\top}$. Hypopygio elongato.

Long. corp. $3-4 \mathrm{~mm}$.

Syn. Medeterus tenuicauda Lw. Neue Beitr. V. 53. 1857.

Gesicht metallisch grün, lebhaft glänzend, auf der Querleiste weisslichgrau, neben dem Augenrande über der Querleiste und unter den Fühlern so wie die Stirn brännlichgran bestäubt; Cilien am hinteren Augenrande weisslich, Fühler nnd Taster schwarz, Rüssel von mittler Grösse. Thorax und das mit vier Borsten versehene Schildchen mit dichter weisslichgrauer oder gelblichgrauer Bestänbung bedeckt, daher matt und nur selten mit einer Spur bräunlicher Striemen am Rücken; die beiden gewöhnlichen Borstenreihen von je 
vier gleichmässig langen Borsten gebildet; die Härchen, welche die Mittellinie des Thoraxrückens einschliessen, äusserst kurz, weisslich und in der Regel schwer wahrnehmbar; Prothorax mit drei bis vier weisslichen Haarborsten. Flügel blass gelblichgrau gefärbt, mit schwarzbraunen, an der Flügelbasis lehmgelben Adern; dritte Längsader mit dem fast geraden letzten Abschnitte der vierten Längsader wenig convergirend; der letzte Abschnitt der fünften Längsader nahezu nur halb so lang als die hintere Querader. Deckschüppchen und Schwinger gelblich, erstere blassgelb gewimpert. Hüften schwarz, etwas grau bestäubt; Beine schwarz, nur die Kniee gelb; die Behaarung der Hüften und Beine weisslich; die nach abwärts gerichtete Behaarung auf der Vorderseite der Hinterschenkel und das Borstchen in der Nähe der Basis der Mittelschienen deutlich; der Metatarsus der Hinterbeine beim Männchen an der Basis ein wenig aúsgekerbt. Hinterleib erzgrün oder blaugrün, weisslich behaart und fast matt; Hypopygium verhältnissmässig lang und schmal mit schwarzbraunen Analanhängen.

Vaterland: Die Art wurde bisher in Oesterreich nur im Prater bei Wien und in Ungarn an Neusiedler-See gefangen; in Deutschland sammelte sie Herr Dr. H. Loew bei Dürrenberg häufig, Frankfurt a. O.; Russland, die Winthem'sche Sammlung enthält mehrere Stücke aus Frankreich; Med. tenuicauda kommt im Juli und August vor.

Anmerkung. Ich habe bei obiger Beschreibung typische Exemplare aus der Sammlung des Herrn Dr. H. Loew benützt.

26. Med. dendrobaenus n. sp. $\sigma^{7}$ ․ . Facie inferiore aeneo-viridi et nitida, thoracis dorso trivittaio, segmento ultimo nervi longitudinalis quinti quam nervus transversalis posterior breviore, pedibus nigris, genibus ferrugineis, magnitudine corporis minuscula.

\section{万. Hypopygio magno.}

Long. corp. $25-3 \mathrm{~mm}$.

Gesicht metallisch grün, glänzend, auf der Querleiste weisslichgrau, neben dem Augenrande über der Querleiste und unter den Fühlern sowie die Stirn grau bestäubt; Cilien am hinteren Augenrande weisslich, die der Mundöffnung nächststehende Borste bisweilen verdunkelt; Fühler und Taster schwarz, Rüssel ziemlich gross. Thorax und das mit vier Borsten versehene Schildchen dunkel metallischgrün, mit dünner grauer Bestäubung bedeckt, auf der Mitte des Rückens und neben den beiden gewöhnlichen Borstenreihen jedoch striemenartig broncebraun oder erzgrün und glänzend; die beiden gewöhnlichen Borstenreihen von je vier gleichmässig langen Borsten, vor welchen bisweilen noch je eine etwas kürzere Borste steht, gebildet; die Behaarung, welche die Mittellinie des Rückens einschliesst, änsserst kurz und undeutlich; Prothorax mit zwei bis vier weisslichen Haarborsten. Flügel blass bräunlichgrau gefärbt, mit schwarzbrannen Adern; die dritte Längsader mit dem fast geraden letzten $\mathrm{Ab}$ schnitte der vierten Längsader meist stark convergirend; der letzte Abschnitt 
der fünften Längsader kürzer als die hintere Querader. Deckschüppchen schmutzig gelb, meistens schwarzbraun gerandet und fahlgelb gewimpert; Schwinger blassgelb. Hüften schwarz, etwas grau bestäubt; die kurze Behaarung der Vorderhüften und die Börstchen der hinteren Hüften weisslich oder bräunlich; Beine schwarz, nur die Kniee gelb; die Behaarung der Beine weisslich, die nach abwärts gerichtete Behaarung auf der Vorderseite der Hinterschenkel ziemlich kurz und meist undeutlich, das Borstchen in der Nähe der Basis der Mittelschienen vorhanden; der Metatarsus der Hinterbeine beim Männchen an der Basis ausgekerbt. Hinterleib dunkel metallisch grün, fahlgelb behaart und ziemlich glänzend; Hypopygium gross, mit schwarzbraunen Analanbängen.

Vaterland: In Oesterreich und Deutschland vom Juli bis October in Gebirgsgegenden an Baumstämmen häufig.

Anmerkung. Med. dendrobaenus kann im weiblichen Geschlechte mit dem ihm sehr ähnlichen und auch in der Körpergrösse übereinstimmenden $M e d$. truncorum Mg. leicht verwechselt werden, besonders wenn - wie schon früher hervorgehoben - die hintere Querader durch die zwischen der vierten und fünften Längsader liegende Längsfalte erheblich verkürzt erscheint und dadurch das Längenverhältniss zwischen der hinteren Querader und dem letzten $\mathrm{Ab}$ schnitte der fünften Längsader schwankend wird; die Männchen der beiden genannten Arten unterscheiden sich dagegen leicht durch die verschiedene Grösse des Hypopygiums. Von dem nächstfolgenden Med. petrophitus m. unterscheidet sich dendrobaenus hauptsächlich durch die geringere Körpergrösse und durch die Beschaffenheit der Flügel.

27. Merl. petrophilus $\sigma^{7}$ ‥ n. sp. Facie inferiore aeneo-viridi et nitida, segmento ultimo nervi longitudinalis quinti quam nervus transversalis posterior breviore, pedibus nigris genibus ferrugineis, magnitudine corporis majuscula. pygio magno.

$\sigma^{\top}$. Thoracis dorso confertim pollinoso, plerumque unicolore, hypo-

‥ Thoracis dorso trivittato.

Long. corp. 35-4 mm. (Fig. 18).

Gesicht metallisch grün, glänzend, auf der Querleiste weisslichgrau, neben dem Augenrande über der Querleiste und unter den Fühlern, sowie die Stirn grau bestäubt;1) Cilien am hinteren Augenrande weisslicl, Fühler und Taster schwarz, Rüssel ziemlich gross. Thorax und das mit vier Borsten versehene Schildchen ziemlich dicht grau bestäubt, auf der Mitte und neben den beiden gewöhnlichen Borstenreihen des Rückens mit broncebraunen Striemen, welche jedoch bei dem Männchen in der Regel nicht auffallend sind; die gewöhnlichen beiden Borstenreihen des Rückens von je vier gleichmässig langen Borsten, vor welchen bisweilen noch je eine kürzere Borste steht, gebildet; die Behaarung,

1) Die Angen des $\sigma^{\nearrow}$ im Leben prächtig blangrün (teste Mik). 
welche die Mittellinie einschliesst, äusserst kurz und undeutlich; Prothorax mit drei bis vier weisslichen Haarborsten. Flügel - an der Spitze verhältnissmässig stumpfer und breiter als gewöhnlich - fast glashell, mit braunen, an der Flügelbasis helleren Adern; die dritte Längsader mit dem fast geraden letzten Abschnitte der vierten Längsader nur wenig convergirend; dieser letzte Abschnitt der vierten Längsader auffallend kürzer als der erste Abschnitt derselben Ader; der meist stark nach abwärts gebogene letzte Abschnitt der fünften Längsader deutlich kürzer als die meist etwas nach auswärts gebogene hintere Querader. Deckschüppchen und Schwinger blassgelb, erstere fahlgelb gewimpert und bisweilen braun gerandet. Hüften schwarz, grau bestäubt und weisslich behaart, die Börstchen der hinteren Hüften fahlgelb oder brann; Beine schwarz mit gelben Knieen und weisslich behaart; die nach abwärts gerichtete Behaarung auf der Vorderseite der Hinterschenkel, sowie die aufgerichtete wimperartige Behaarung in der Nähe der Basis derselben Schenkel deutlich; das Borstchen in der Nähe der Basis der Mittelschienen vorhanden, die Hinterschienen des Männchens auf der Oberseite der Länge nach kurz gewimpert, der Metatarsus der Hinterbeine beim Männchen an der Basis ausgekerbt. Hinterleib dunkel metallisch grün, fahlgelb behaart und etwas glänzend; Hypopygium gross, mit schwarzbraunen Analanhängen.

Vaterland: Herr Prof. Zeller entdeckte die Art am.3. Juli 1867 in Kärnten; Herr Prof. Mik, der sie im August desselben Jahres bei Gastein fand, theilte mir mit, dass sie auf Steinen und an Felsenwändeu vorkomme; Herr $\mathrm{Scherfling} \mathrm{fing} \mathrm{sie} \mathrm{in} \mathrm{Ober-Italien.}$

Anmerkung. Med. petrophilus hat viele Aehnlichkeit mit Med. jaculus Mg., dem jener in der Körpergrösse, in der allgemeinen Körperfärbung und im männlichen Geschlechte auch in der Grösse des Hypopygiums gleicht; petrophitus hat aber ein mindestens unter der Querleiste glänzendes Gesicht und einen dichter bestäubten Thorax, unterscheidet sich aber auch noch wesentlich durch die Stellung der hinteren Querader, welche - meist ein wenig nach auswärts gebogen - mit dem ersten Abschnitte der fünften Längsader einen stets rechten - und nicht wie bei jaculus einen spitzen - inneren Winkel bildet. Von tenuicauda Lw. unterscheidet sich obige Art durch einen minder lebhaften Glanz des Gesichtes und im männlichen Geschlechte durch die Grösse des Hypopygiums, von truncorum $\mathrm{Mg}$. und dendrobaenus $\mathrm{m}$. durch erheblichere Körpergrösse und durch die Kürze des letzten Abschnittes der vierten Längsader, von truncorum überdiess durch die geringere Entfernung der hinteren Querader vom Flügelrande und im männlichen Geschlechte durch das viel grössere Hypopygium und endlich von allen den genannten Arten durch die stumpfere Form der Flügelspitze. 


\section{A n h a $\mathbf{n}$ g.}

Ueber die von den Autoren bisher zur Gattung Medeterus gebrachten und in den obigen Beschreibungen nicht erwähnten Arten sei Folgendes bemerkt:

1. Merl. albiceps ㅇ. MIg. Syst. Beschr. IV. 68. 17. 1824. - Das typische Stück der Wiedemann'schen Sammlung bezeichnet mit "Holsatia" ist wie schon aus der Beschreibung Meigens selbst hervorgeht, eine Hydrellia und zwar $H$. Ranunculi Hal.

2. Med. gratiosus ơ $\sigma^{7}$. Mg. Syst. Beschr. VII. 158. 35. 1838. Die Beschreibnng Meigens lautet: „Untergesicht des Männchens silberweiss, des Weibchens grauweiss; Stirn stablblau. Fühler schwarz. Rückenschild glänzend schwarzgrün; Hinterleib metallischgrün. Schwinger und Beine blassgelb. Flügel etwas gravlich. - Aus Baiern. - $2 / 3$ Lin." Da Meigen das Gesicht silberweiss resp. grauweiss und zugleich die Stirn stahlblan bezeichnet, welche beide Merkmale nach meiner Erfahrung bei Medeterus niemals vereint vorkommen, so vermuthe ich, dass obige Art nicht zu Medeterus, vielleicht aber zu Teuchophorus Lw., gehören dürfte.

3. Med. neneus ㅇ․ Mg. Syst. Beschr. VII. 159. 37. 1838. - Die Angabe Meigen's ngiānzend goldgrün; Kopf, Fühler und Brust schwarz. Beine rothgelb; Schenkel schwarz, mit rothgelber Spitze. Schwinger weiss; Flïgel fast glashell. - Stark 1 Lin." scheint - wenn nicht auf Med. pallipes Ztt. auf einen Verwandten des Thrypticus bellus Lw. hinzudeuten.

4. Med. bicolor ‥ Mg. Syst. Beschr. VII. 159. 38. 1838. - Meigen beschreibt die Art wie folgt: ${ }_{n}$ Stirn schwärzlich, Mittelleib ganz glänzend schwarz. Hinterleib grünlichgrau. Beine schwärzlich. Schwinger weiss. - Flügel glashelle. - 11/3 Lin." Mir ist keine Art bekannt geworden, anf welche diese Beschreibung bezogen werden köunte; wenn der Glanz des Thorax nicht von einer etwaigen Verfettung - wie diess bei MIed. nigricans MIg. der Fall ist herrührt, würde ich die Art überhaupt für keinen Medeterus halten, weil ein „glänzender Thoras“ und gleichzeitig ein "grünlichgrauer Hinterleib“ bei Medeterus meines Wissens nicht vorkommit.

5. Hydrophorus albipes 9. Ztt. Dipt. Scand. II. 454. 14. 1843. Zetterstedt bemerkt über die Beschaffenheit der dritten und vierten Längsader Folgendes: ,alarum nervis longitudinalibus 3 et 4 usque ad apicem exacte parallelis"; ans dem Gesagten folgt, dass diese Art nicht zu Medeterus gehöre; da diese Art sich überdiess durch Präapicalborsten an den Schenkeln und durch mehr dorsale Stellung der Fühlerborste auszeichnet, so dürfte sie in der Gattung Sympycnus Lw. vorläufig besser untergebracht erscheinen.

6. Medeterus chloropus v. Roser. Correspondenzblatt des k. würt. landw. Vereins 1840. I. 56. gehört offenbar zur Gattung Hydrophorus Whlbg. and ist wahrscheinlich mit Hydr. balticus $\mathrm{Mg}$. identisch, was die nachfolgende Beschreibung vermuthen lässt: „thorace flaveseente-viridi, hypostomate supra pedilusque viridibus, femoribus anticis incrassatis, spinosis".

z. B. Ges. B. XXVII. Abh. 
7. Med. Mnipunctatus v. Roser. 1. c. kann ebensowobl zur Gattung Campsicnemus Wlk, als zur Gattung Hydrophorus Whlbg. gehören, wie aus "alis fuscescentibus, puncto 1 fusco in nervo longitudinali quarto" zu schliessen ist.

8. Med. anuulitarsus v. Roser. 1. c. „virescens, pedibus rufis, femoribus fuscis; tarsis posticis nigro annulatis; alis basi flavescentibus" und

9. Med. minutus v. Roser 1. c. "virescens, pedibus ferrugineis; $1 / 2$ "1. werden ohne Autopsie der typischen Exemplare wohl niemals mit Sicherheit erkannt werden.

10. Med. MTorio Fischer de Waldh. Oryctographie d. Gouv. d. Moscou 1830. pl. hist. nat. Tab. XV. f. 2 ohne Beschreibung. Die Abbildung, welche ein $f$ im vergr. Massstabe darstellt, ist bestimmt unrichtig; der GesammtHabitus und die Stellung der hinteren Querader lassen ohne Zweifel auf einen Medeterus schliessen - entweder auf $M$. infumatus Lw. oder auf M. tristis Ztt., auf letzteren jedoch wegen der Stellung der hinteren Querader minder als auf ersteren; - während der Kopf und die Schwingung des letzten Abschnittes der vierten Längsader auf ein Acalypteron hindeuten.

11. Dolichopus minutus F. Syst. Antl. 270. 19. 1805. Meigen bemerkt in VII. B. seiner syst. Beschr., p. 70, in einer Anmerkung, dass Dol. minutus F. wahrscheinlich auch in die Gattung Medeterus (ap. Mg.) gehöre; dass diese Art jedoch in der Fabricins'schen Sammlung gefehlt habe und zu kurz beschrieben sei, um die Art zu bestimmen. - Auch mir ist es nicht gelungen, die Fabricius'sche Beschreibung auf eine Art der Gattung Medeterus im engeren Sinne oder auf eine Art der übrigen DolichopodenGattungen zurückzuführen. Der Vollständigkeit wegen, sei jedoch die erwähnte Besolhreibung hier reproducirt: „D. thorace atro, abdomine cinerascente immaculato. Habitat in Gallia muris, capta d. XIII. Jun. Minutus. Caputobscurum, orecrassoprominulo atro. Oculimagni, globosi, prominuli. Antennaebreves, atrae, apice seta elongata, obscura. Thorax pilosus, ater. Abdomen subconicum, cinereum, immaculatum. Alac hyalinae. Halteres nivei. Pedes nigri.

\section{Arten- und Synonymen-Register.}

1. Medeterus plumbellus Mg. Lw. Schin.

jaculus Fll. (var. $\gamma$ ).

minutus Ztt.

2. - seniculus n. sp. .

3. - micaceus Lw. Schiu.

jaculus Fll. (var. $\beta$ ).

apicalis Ztt. (var. b)?

4. - chrysotimiformis Kow.

5. - dichaetus n. sp. 
Seite

6. Medeterus muralis Mg. Ztt. (var. c)?

melanopleurus Lw.

$\begin{array}{ll}\text { 7. } & - \\ 8 . & - \\ 9 & -\end{array}$

10.

11. glaucellus n. sp. glaucus Lw. tristis Ztt. Lw. Schin. apicalis Ztt. Lw. pallipes Ztt. jaculus Ztt. (var. b). muralis Lw. Schin.

12. - obesus n. sp. 56

13.

14.

15. nitidus Macq. Mg. signaticornis Lw. 57 58

16. dichrocerus n. sp. obscurus Ztt. (robustus) Lw. Sichiv. . . . . . . 60

17. pinicola n. sp.

diadema L. Walk. Lw. Schin.

18. rostratus F. Mg. Macq. Ztt. aeneivittatus Macq. Mg.

carnivorus Fischer.

19. - flavipes Mg. Lw.

$20 . \quad-$ lamprostomus Lw.

21. -

22. ambiguus Ztt. Lw. Schin. infumatus Lw. Schin. . muralis Ztt. (var. a. b).

23. jaculus Mg. Fll. (var. $\alpha$ ). Macq. Ztt. Walk. Lw. S'chin. nigricans $\mathrm{Mg}$.

truncorum Ztt.

24. truncor $u$ m Mg. Macq. Ztt.? Walk.? Lw. Schin. 68 tenu iсаu da Lw. .

$25 . \quad-$ cendrobaenus n. sp. 70

26. 27.

\section{A $\mathrm{n}$ h a $\mid 1 \mathrm{~g}$.}

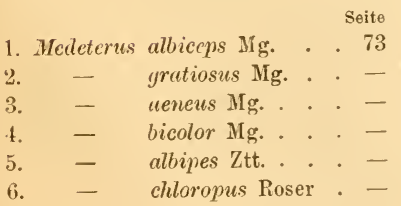

Einer socben eingetroffenen Zuschrift Herrn Rondani's zufolge, ist der Name Anorthus von Staeger nur in Briefen an Herrn Pondani zuerst vorgeschlagen worden. 


\section{Erklärung der Tafel.}

Fig. 1. Medeterus jaculus Mg. $\sigma^{7}$. sammt Grösse.

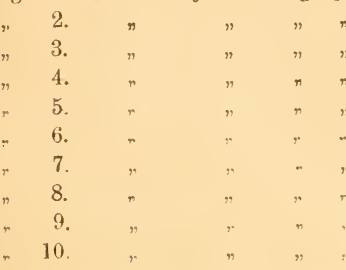

Kopf von vorn.

Kopf von der Seite.

Fühler.

Flügel.

- Hypopygium.

Analanbänge des Hypopygiums.

Spitze der inneren Analanhänge.

Metatarsus der Hinterbeine.

Thorax und das vierborstige Schildchen von oben. (Die Punkte bezeichnen die Stellung der Borsten, aus welchen die beiden gewöhnlichen Borstenreihen bestehen.)

" $\quad "$ Eine der beiden gewöhnlichen Borstenreihen des Thoraxrückens und die Beborstung des Schildchens von der Seite.

" $12 . \quad$ dichrocerus m. $\sigma^{7}$. Fühler.

. $13 . \quad$ ",$\quad$ Flügel.

$\pi 14 . \quad " \quad$ diadema L. O. Fühler.

15. $" \#$, Eine der beiden gewöhnlichen Borstenreihen des Thoraxrückens und die Beborstung des Schildchens von der Seite.

16. $" \#, \quad$ Hinterleibsende von der Seite.

17. $n$ pallipes Ztt. $\sigma^{\top}$. Flügel.

$" 18 . \quad n$ petrophilus m. $\mathrm{O}^{7}$. Flügel.

19. Mclcterus micaceus Lw. $\sigma^{7}$. Thorax und das zweiborstige Schildcheu von oben.

20. " $" n$ Eine der beiden gewöbnlichen Borstenreihen des Thoraxrückens und die $\mathrm{Be}$ borstung des Schildchens von der Seite.

21. $n$ muralis Mg. $\sigma^{7}$. Hypopygium.

n 22. " obscurus Ztt. ㅇ. . Eine der beiden gewöhnlichen Borstenreihen des Thoraxrückens und die $\mathrm{Be}$ borstung des Schildchens von der Seite.

"23. $n \pi n$ " Hypopygium.

"24. Thrypticus bellus Lw. $\sigma^{\top}$. Flügel. 
Verhundl. d.k.k.zool.bot ties Band XXVII, $18 \% \%$.
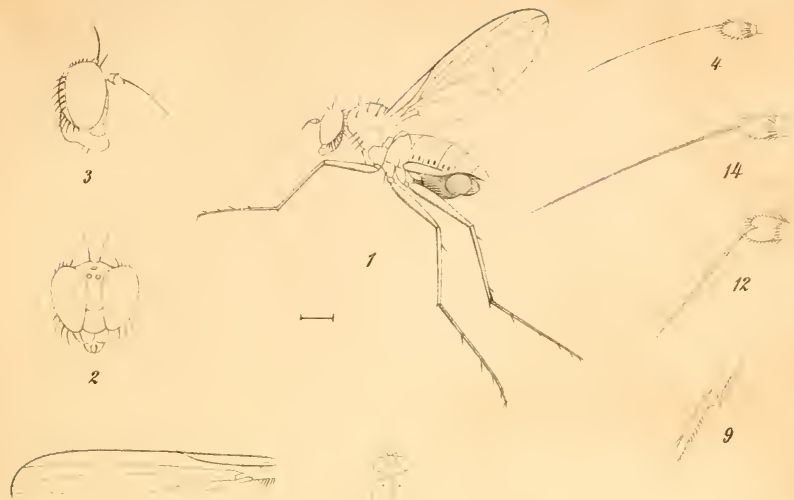

5
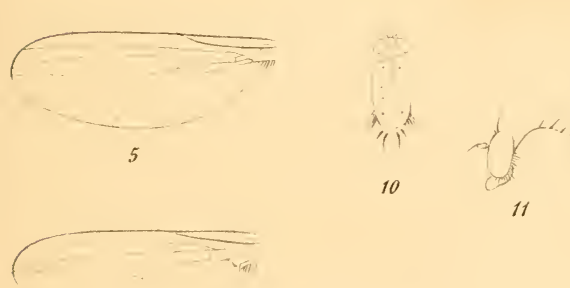

17

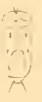

19

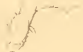

20

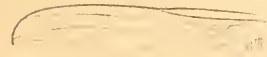

13

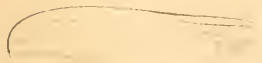

18

\section{4}

F Kowarz ad nat.del. M Streicher bith.
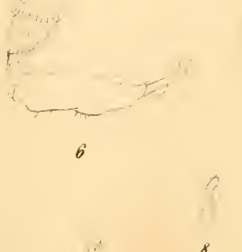

23

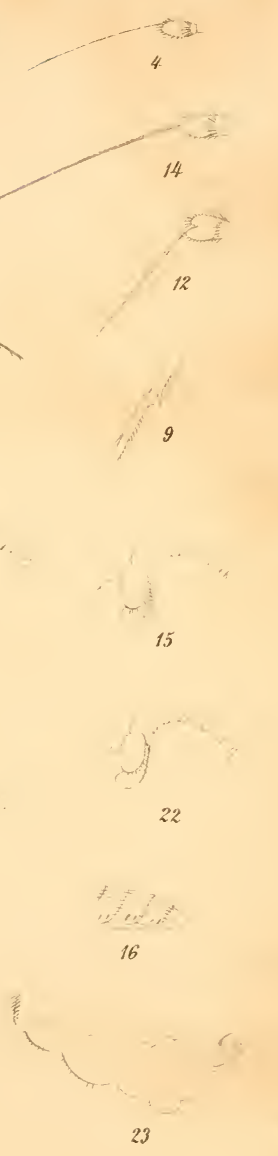

1.5

16

\section{3}





\title{
Die Dipteren-Gattungen
}

\section{Argyra Macq, und Leucostola Lw.}

Von

\section{Ferdinand Kowarz,}

k. k. Telegraphen-Peamter in $\Lambda$ sch.

\begin{abstract}
(Aus den Verhandlangen der k. k. zoologisch-botanischen Gesellschaft in Wien [Jahrgang 1878] besonders abgedruckt.)
\end{abstract}

\author{
Mit einer Tafel.
}

\section{WIEN, 1879.}

D r u e von $A$ dolf II olzhansen. 



\title{
Die Dipteren-Gattungen
}

\section{Argyra Macq, und Leucostola Lw.}

Von

\author{
Ferdinand Kowarz, \\ k. k. Telegraphen-Beamter in Asch.
}

\begin{abstract}
(Aus den Verhandlnngen der k. k. zoologisch-botanischen Gesellschaft in Wien [Jahrgang 1878] besonders abgedruckt.)
\end{abstract}

Mit einer Tafel.

\section{WIEN, 1879.}

Druck von Adolf II olzhausen. 

Diejenigen Porphyrops-Arten, welche Meigen inı IV. Bande seiner "Systematischen Beschreibung der bekannten europäischen zweiflügeligen Insecten“ 1824. 46 unter der Abtheilung A „Fühlerborste vor der Spitze eingefügt" von seineu übrigen Porphyrops-Arten mit apicaler und dorsaler Fühlerborste abgesondert hatte, erhob Marquart in den "Suites à Buffon" 1834. 456 zu einer selbstständigen Gattung unter dem Namen Argyra (von äpүupos = silbern). Zur Bildung dieses Gattungsnamens hat Macquart den Meigenschen Artnamen von Porph. argyrius verwendet und diese Art Arg. argentatu genannt. Meigen billigte diesen Vorgang, weil er - nach Ausscheidung des Porph. crassipes Mg. aus der Gattung Argyra - nicht nur den von Macquart verwendeten Gattungsnamen, sondern auch den von Letzterem substituirten Artnamen im VII. Bande seines oben citirten Werkes 1838, 153 und 154, beibehalten hat. - Zetterstedt vereinigte zwar im II. Bande der „Diptera Skandinaviae" 1843. 498 und 587 die Gattung Argyra init der Gattung Dolichopus Latr., trennte aber schon die Arten, welche zur Gattung Argyra im Sinne der späteren Systematik gehörten, in einer eigenen Phalanx von Meigen's Arg. culica und quadrifasciata. $\left.{ }^{1}\right)-$ Walker führte in I. Bande der "Insecta Britannica. Diptera" 1851. 207 den Gattungsnamen Argyra für die in Grossbritannien einheimischen Arten der erwähnten Zetterstedt'schen Phalanx wieder ein. - Die aus den noch übrigen Meigen'schen und aus den von Macquart und von Z ettersted t beschriebenen neuen Arten bestehende Gattung Argyra zerlegto H. Loew in den „Neuen Beiträgen" V. 1857. 38 in drei Gattungen und zwar zählte er diejenigen Arten, deren „erstes Fühlerglied auf der Oberseite behaart" ist, zur Gattung Argyra, und jelle, deren -erstes Fühlerglied auf der Oberseite nackt“ ist, zur Gattung Leucostolu, wenn "die äusseren Analanhänge

1) Porph. suturalis Fll. erscheint bei $\mathrm{M}$ eigen im VII. Fande nicht mehr nnter den Arten der Gattnng Argyra, obgleich er die Art im VI. Bande als zur "Ahtheilung A* geliörend bezeichnet. 
des Hypopygiums nicht lang und niclit fadenförmig" sind und zur Gattung Nematoproctus, wemn diese Anhänge "lang und fadenförmig“ sind.') - M. J. B igot hat in den "Annales de la Société entomol. de France" VII. 218. 1859 die Gattungen Leucostola und Nematoproctus eingezogen und mit Argyra im Sinne Macquart's wieder vereinigt. - - In der Begrenzung von Argyra und Leucostola entschied ich mich für die Anschanungen Loew's and bespreche hier die europäischen Arten dieser beiden Gattungen.

\section{Argyra.}

Stirn breit, beim Männchen zum Scheitel hin allmälig erweitert, beim Weibchen fast gleichbreit; die gewöhnlichen vier Scheitelborsten vorhanden, doch die am Augenrande stehenden bei dem Männchen anffallend kürzer, als die zwischen den Ocellen; Gesicht die untere Angenecke nicht erreichend, bei dem Männchen schmäler, als bei dem Weibchen, dessen Gesicht so wie die Stirn weiss bestänbt ist; die Augen behaart, im Leben purpurroth; Fühler kurz oder verlängert, schwarz, das dritte Glied beim Männchen oft braun; das erste Glied auf der Oberseite behaart, das zweite transvers, am Vorderrande beborstet; das dritte dreieckig zngespitzt und äusserst kurz behaart; die Fühlerborste nahe vor der Spitze des dritten Fühlergliedes eingefügt, zweigliedrig und pubescent oder nackt; Taster schwarz, an Rande behaart, die des Männchen ziemlich schnal und sammt dem Rüssel nur wenig aus der Mundöffnung vorragend, die des Weibchens breit, weiss oder grau schimmernd und den dicken Rüssel von oben her bedeckend; Cilien am hinteren Augenrande dicht, bei dem W cibchen stets weiss. - Thorax und Schildchen metallisch grün oder blangrün, bei den Männchen mehrerer Arten silberschimmernd; Thoraxrücken ohne Eindruck vor dem Schildchen, auf der Mitte mit einer weit vor dem Schildchen aufhörenden, doppelten Längsreihe aufgerichteter Haare nud mit je eiuer einfachen Reihe langer, anfgerichteter Bursten zwischen der Mitte und dem Seitenrande; Schildchen mit zwei längeren und zwei kürzeren Randborsten, auf der Oberseite entweder nackt oder behaart; in letzterem Falle pflegt auch der Raun zwischeu je einer der genannten einfachen Borstenreihen und den Borsten am Seitenrande des Thoraxrückens deutlich behaart zu sein; Brustseiten grau oder silberschimmernd, der Prothorax über den Vorderhüften meistens mit zwei oder mehreren nach abwärts gerichteten Borsten. - Flügel im Umrisse elliptisch oder länglich eiförmig, mit ziemlich breiter Basis; die Randader reicht bis zur Mündungsstelle der einfachen vierten Längsader, deren letzter Abschnitt anf oder in der Nähe seiner Mitte nach vorn geschwungen ist und dann mit der dritten Längsader parallel verläuft; erste Längsader meistens nahe vor der Mitte des Vorderrandes in diesen mündend; sechste Längsader nahe vor dem Flügelrande verblassend. Deckschüppehen mässig klein, mit langen Wimper-

1) Das vou der Form der ăusseren Analanhange hergenommene Merkmal der Gattungen Nematoproctus geü̈gt seit dem Bekinntwerden des Nem. praesectus Lw. (Beschr. europ. Dipt. 1869. 292. 172) nicht mehr; ich verweise hier auf das zur Unterscheidung der Gattungen Leucustula and Nematoproctus Ge'sigte. 
baaren versehen und entweder ganz schwarz, oder gelb mit schwarzem Rande; Schwinger gelb. - Die vorderen Hüften auf der Vorderseite borstenartig behaart, die Hinterhüften auf der Aussenseite mit zwei ') oder melireren, übereinander gereihten, abstehenden Haarborsten, von denen die tieferstehenden zarter und kürzer, als die höherstehenden sind. - Beine einfach, ziemlich schlank; Schenkel mit einer Präapicalborste, welche jedoch bei den Männchen unter der nach abwärts gerichteten Behaarung auf der Hinterseite der Vorderschenkel und auf der Vorderseite der hinteren Schenkel verschwindet, wenn diese Behaarung lang und dicht ist; alle Schienen auf der Oberseite mehr oder weniger reich beborstet, die Mittelschienen überdiess auf der Unterseite mit zwei oder mehreren einzelnen oder paarigen Borsten, der Metatarsus der Vorderbeine auf der Unterseite mehr oder weniger deutlich beborstet; der Metatarsus der Hinterbeine auf der Oberseite nicht beborstet; ${ }^{2}$ ) Pulvillen klein. - Hinterleib länglich, kegelförmig, metallisch gefärbt, häufig mit gelben, durchscheinenden Flecken an den Seiten der vorderen Ringe ${ }^{3}$ ) und bei der Mehrzahl der Arten im männlichen Geschlechte mit silberweissem Schimmer bedeckt; das Hypopygium ist verhältnissmässig klein, rundlich und sitzend, glänzend schwarz, theilweise grau schimmernd und entweder nur mit kurzen, steifen Härchen, oder ausser diesen noch mit zwei bis vier längeren, abstehenden Borsten besetzt; die äusseren Analanhänge sind ziemlich klein, gewöhnlich schmal, selten breit, dreieckig zugespitat und stets behaart; die inneren Anbänge, kaum länger als die äusseren, sind in der Regel länglich ovale oder zugespitzte, schuppenartige, stets unbehaarte, glatte Lamellen, welche die tiefer liegenden, nur wenig vortretenden und mannigfaltig gebildeten Copulationsorgane einschliessen. Legeröhre des Weibchens zurückgezogen oder nur kurz vorstehend.

Die Gattung Argyra unterscheidet sich durch die Behaarung auf der Ober'seite des ersten Fühlergliedes, durch die subapicale Stellung der Fühlerborste und durch das Vorhandensein von wenigstens zwei abstehenden Haarborsten auf der Aussenseite der Hinterhüften hinreichend von allen übrigen, europäischen Dolichopoden-Gattungen, von der ihr nächst verwandten Gattung Nematoproctus Lw. ausser durch obige Merkmale noch durch die schwarzen oder doch schwarz gerandeten Deckschüppchen und von Leucostola Lw. nur durch die Behaarung auf der Oberseite des ersten Fühlergliedes und durch die Beborstung auf der Unterseite der Mittelschienen.

Die Argyren, deren erste Entwicklungsstadien noch unbekannt sind, halten sich rom Mai bis September an warmen, sonnigen Tagen mit Vorliebe in der Nähe von Gewässern buschreicher Auen oft in Nehrzahl auf; sie schwärmen an solchen Stellen im Kreisfluge, oder ruhen auf den Blïttern

1) Bei Arg. grata Lw. ist die nntere, zweite Borste auf der Auseenseite der Hinterhúften bisweilen so zart, dass sio leicht übersehen werden kann.

2) Der Metatarsus der Hinterbeine des Männchens von Arg. confinis Ztt. ist anf der Hinterseite beborstet, auf der Verder- nnd Unterseite mit je einer Reilie längerer Haare bekleidet.

s) Weun von gelben Flecken an den Seiten des Hinterleibes die Kede ist, so wird darunter die fahlgelbe Farbe der Bindehaut zwischen der Ober- und Bauchseite der Ringe uicht gemeint. 
niederer Büsche und Sumpfpflanzen, wohl auch am Boden, auf Schlamm und auf Steinen aus und erfreuen den Beobachter durch ihr munteres Treiben und durch ihr prächtiges, meist silberschimmerndes Kleid.

\section{Tabelle zum Bestimmen der männlichen Argyra.}

1. Schildchen auf der Oberseite behaart Schildchen auf der Oberseite nicht behaart

2. Fühlerborste so lang oder länger als die Fühler Fühlerborste kürzer als die Fühler

3. Thoraxrücken mit Silberschimmer . . . . . sp. 2. setimana Lw. Thoraxrïcken ohne Silberschimmer

4. Hinterleib an den Seiten des zweiten Ringes mit gelbell, durchscheinenden Flecken

Hinterleib an den Seiten des zweiten Ringes ohne gelbe durchscheinende Flecken

5. Schenkel schwarz .

Schenkel theilweise gelb

6. Thoraxrücken mit deutlichem Silberschimmer . Thoraxrücken ohne deutlichen Silberschimmer

7. Fühler kürzer als der Kopf ${ }^{1}$ ). sp. 3. diaphana F. Fühler so lang oder länger als der Kopf

8. Fühlerborste so lang oder länger als die Fühler Fühlerborste kürzer als die Fühler ${ }^{2}$ )

sp. 4. Hoffmeisteri Lw. sp. 5. Loewii n. sp.

9. Metatarsus der Hinterbeine länger als das folgende Tarsenglied . . 10

Metatarsus der Hinterbeine so lang oder kürzer als das folgende Tarsenglied $\left.^{3}\right)$.

10. Hinterleib mit auffallendem Silberschimmer ${ }^{4}$. . . . . . . . 11

Hinterleib ohne auffallenden Silberschimmer . . . . . . . . . . 12

11. Metatarsus der Hinterbeine mit verhältnissmässig langer Behaarung.

sp. 9. confinis Ztt.

Metatarsus der Hinterbeine ohne lange Behaarung .

sp. 10. auricollis $\mathrm{Mg}$.

12. Gesicht schwarz Gesicht weiss - sp. 11. atriceps Lw. sp. 12. spoliata n. sp.

1) Um das Verhāltniss zwischen der Lānge der Fühler und der des Kopfes richtig zu beurtheilen, denke man sich die Lăngsachse der Fühler als gerade Linie senkrecht durch den Kopf der zu untersuchenden Art fortgesetzt; dieses Längenverhältniss zwischen den Fühlern und dem Kopfe, sowie das der einzelnen Fühlerglieder untereinander ist bei den Argyra-Arten kein streng constantes und kann daher nur schätzungsweise angegeben werden.

2) Im zweifelbaften Falle entscheidet die Länge der Fühler; bei Arg. argentina sind die Fūhler auffallend länger als der Kopf, bei Arg, argyria dagegen nur so lang, oder doch nur wenig lănger als der Kopf.

3) Kommt man hier auf eine Art mit silberschimmerndem Hinterleib, so vergleiche man sie mit Leucostola vestita Wied.

4) Man betrachte den Hinterleib von vorn. 
13. Hinterschienen auf der Oberseite der ganzen Länge nach auf fallend beborstet. Hinterschienen auf der Oberseite nicht auffallend beborstet.

sp. 13. elongata Ztt.

sp. 14. grata Lw.

\section{Tabelle zum Bestimmen der weiblichen Argyra.}

1. Schildchen auf der Oberseite behaart

Schildchen auf der Oberseite nicht behaart

2. Vorderhüften ganz schwarz

Vorderhüften an der Spitze gelb

3. Hinterschenkel schwarz

Hinterschenkel theilweise gelb

4. Fühler länger als der Kopf .

Fühler so lang oder kürzer als der Kopf . . . . . . . . . . . 5

5. Metatarsus der Hinterbeine länger als das folgende Tarsenglied . . . 6

Metatarsus der Hinterbeine so lang oder kürzer als das folgende Tarsenglied

6. Hinterhüften ganz schwarz

Hinterhüften ganz oder theilweise gelb. . . . sp. 9. confinis Ztt.

7. Die vier vorderen Hinterleibsringe an den Seiten und am Bauche mit gelben Flecken

Hinterleib ohne, oder blos an den Seiten und am Bauche des zweiten und dritten Ringes mit gelben Flecken

8. Hinterhüften an der Spitze gelb

Hinterhüften ganz schwarz

sp. 8. argentina Mg.

9. Hinterleib an den Seiten des zweiten Ringes mit gelbem Flecke.

sp. 6. leucocephala $\mathrm{Mg}$.

Hiuterleib an den Seiten des zweiten Ringes ohne gelben Fleck. ${ }^{1}$ )

sp. 7. argyria $\mathrm{Mg}$.

\section{Beschreibung der Arten.}

\section{Scutellum supra pilosum.}

1. Arg. magnicornis Ztt. $\circlearrowleft$. Coxis anticis in apice flavis.

万. Seta antennis breviore.

Long. corp. $5.5 \mathrm{~mm}$. (Fig. 15-18).

Syn. Dolichopus magnicornis Ztt. Ins. Lapp. 712. 19. 1840. б’.

- $\quad \Rightarrow \quad$ Dipt. Scand. II. 593. 81. 1843. $\sigma^{\prime}$.

- Argyra aristata Gerst. Stett. entom. Zeitschr. 31. 4. 1864. $0^{7}$.

1) Hat man eine Art vor sich, deren erstes Fühlerglied anf der Oberseite nnbehaart ist, so vergleiche man sie mit Leucostola vestita Wied. Die Weibchen von Arg. leucocephala, argyria nnd argentina sind sehr schwer von einander zn unterscheiden, um möglichst sicher zu urtheilen, berūcksichtige man die Anmerkungen bei den Beschreibungen der genannten Arten. 
ơ. Stirn und Gesicht weiss; Fühler reichlich ein- und einhalbmal so lang als der Kopf, das erste Glied so lang als die Hälfte der beiden Endglieder zusammengenommen, Fühlerborste kürzer als die Fühler und mässig dick; Cilien am hinteren Augenrande weiss. Thoraxrücken und Schildchen metallisch grün, ersterer längs der gewöhnlichen beiden Borstenreihen striemenartig grau bereift, an den Schultern weissschimmernd, die Behaarung auf der Oberseite des Schildchens kurz, die Borsten am Prothorax schwarz und lang. Flügel blassbräunlichgrau gefärbt, die erste Längsader vor der Mitte der Randader mündend; Deckschüppchen gelb, mit schwarzem Oberrande und braunen fahlgelb schimmernden Wimpern. Vorderhüften an der Spitze und Hinterseite gelb, sonst so wie die hinteren Hüften schwarz, grau schimmernd. Beine gelb, nur die Spitze der Hinterschenkel und Hinterschienen, die vorderen Tarsen von der Spitze des ersten Gliedes an und die Hintertarsen schwarz oder schwarzbraun; die Behaarung der vorderen Schenkel mässig lang und ziemlich schütter, die der Hinterschenkel zwar kürzer aber etwas dichter; die Präapicalborste an den hinteren Schenkeln deutlich; die vorderen Schienen auf der Oberseite mit drei oder vier, die Hinterschienen ebenda mit fünf oder sieben Borstenparen, die Mittelschienen überdiess auf der Unterseite mit drei bis vier, die Hinterschienen daselbst mit fünf oder sechs Borstenpaaren; die Vorderschienen und der Metatarsus der Vorderbeine auf der Unterseite der ganzen Länge nach mit zarten Börstchen bekleidet; der Metatarsus der Hinterbeine kaum länger als das folgende Tarsenglied. Hinterleib dunkel metallisch grün, am Bauche und an den Seiten des zweiten, oder des zweiten und dritten Ringes durchscheinend gelb; die äusseren Analanhänge des Hypopygiums schwarzbraun, klein und schmal.

Q. Fühler reichlich so lang als der Kopf, das erste Glied fast so lang als die beiden Endglieder zusammengenommen, Fühlerborste länger als die Fühler; Hinterleib metallisch blaugrün, an den Seiten der einzelnen Ringe mit dreieckigen, weisslich schimmernden Vorderrandsflecken, welche sich am letzten Ringe bindenartig vereinigen.

Vaterland: Herr 0. Scherfling fing diese noch seltene Art im Juli bei Ebensee und Hallstadt, Herr Dr. A. Gerstäcker Ende Mai in der Umgebung von Berlin. Dänemark, Scandinavien (Zetterstedt).

Anmerkung. Der Kopf des Männchens von Arg. magnicornis ist im Vergleiche zu dem Kopfe anderer Argyra-Arten verhältnissmässig kleiner und das Gesichtsprofil weniger gewölbt. - Um die obige Synonymie zu rechtfertigen, sei erwähnt, dass die dunkle oder helle Farbe der Wimpern an den Deckschüppchen bei obiger Art eine sehr variable ist und entweder von der Betrachtungsweise im reflectirten Lichte oder von der grösseren oder geringeren Ausdehnung des schwarzen Randes am Deckschïppchen abhängt, dass die dunkelgrün $\theta$ Grundfarbe des Hinterleibes bei den von mir untersuchten Männchen auf der Mitte der vorderen Ringe einen broncegelben, auf der Mitte der hinteren Ringe einen bronzebraunen, fast violetten Ton zeigt und dass Zetterstedt das 
Abdomen des Männchens 1. c. „obscure aeneum, postice certo situ violaceomicans" beschreibt.

\section{Arg. setimana Lw. $\sigma^{\nearrow}$. Thoracis dorso argenteo-induto.}

Long. corp. 7. $\mathrm{mm}$.

Syn. Argyra setimana Lw. Neue Beitr. VI. 20. 1. 1859. ठ'.

Schin. Fauna austr. I. 190. 1862.

ণ. Gesicht und Stirn weiss; Fühler etwas länger als der Kopf, das erste Glied etwas länger als die Hälfte der beiden Endglieder zusammengenommen, Fühlerborste ein wenig länger als die Fühler; Cilien am hinteren Augenrande weiss. Thoraxrücken und Schildchen metallisch grün oder blangrün, silberschimmerad, ersterer zwischen der Mittellinie und den gewöhnlichen Borstenreihen mit den Anfängen je einer dunklen Längsstrieme; die Behaarung zwischen den erwähnten Borstenreihen und dem Seitenrande, so wie die des Schildchens deutlich; die Borsten am Prothorax schwarz und lang. Flügel blassbräunlicb gefärbt, die erste Längsader nahe vor der Mitte der Randader mündend; Deckschüppchen gelb, mit breit schwarzem Oberrande und braunen oder schwarzen Wimpern. Hüften schwarz, grau schimmernd; Beine vorherrschend gelb, doch die Vorderschenkel von der Basis bis fast zur Spitze hin, oder wie die Mittelschenkel nur auf der Ober- und Hinterseite, die Spitze der Hinterschenkel und der Hinterschienen, die vorderen Tarsen von der Spitze des ersten Gliedes an und die Hintertarsen schwarz oder braun; die Behaarung der Vorderschenkel mässig lang und mässig dicht, die der Mittelschenkel lang aber schütter, die der Hinterschenkel ziemlich kurz; Vorderschienen und der Metatarsus der Vorderbeine auf der Unterseite der ganzen Länge nach zart aber deutlich beborstet; die Mittelschienen ausser den Borsten auf der Oberseite noch mit zwei bis vier kürzeren Börstchen auf der Unterseite; die Hinterschienen auf der Oberseite zerstrent beborstet, auf der Hinterseite der ganzen Länge nach gewimpert, Metatarsus der Hinterbeine etwas länger als das folgende Tarsenglied. Hinterleib silberschimmernd, an den Seiten des zweiten und dritten, bisweilen auch des vierten Ringes durchscheinend gelb; die äusseren Analanhänge des Hypopygiums schwarzbraun, schmal und ziemlich kurz, die inneren gelb, zugespitzt und breiter als die äusseren.

Vaterland: Herr Dr. H. Loew entdeckte die Art im Juli in der Nähe von Neuwaldegg bei Wien, Herr Dr. Grzegorzek sammelte sie bei Alt-Sandec in Galizien, ich selbst im Mai bei Mährisch-Schönberg auf einer Waldwiese, Herr Dr. Kriechbaumer bei Rosenheim in Baiern.

Anmerkung. Ich habe die obige Art mit dem typischen Exemplare in der Sammlung des Herrn Dr. H. Loew verglichen.

3. Arg. diaphana F. $\sigma^{\top}$. Seta antennis longiore, coxis nigris.

$\sigma^{7}$. Thoracis dorso aeneo-viridi, abdomine in lateribus segmenti secundi macula flava notato.

ㅇ. Femoribus posticis flavis, in apice nigris.

Long. corp. 5.5-7.5 mm. (Fig. 1-12). 
Syn. Musca diaphana F. Spec. ins. II. 448. 70. 1781.

- $\quad$ \# Ent. Syst. suppl. 564. 126. 1798.

Dolichopus diaphanus F. Syst. Antl. 270. 18, 1805.

pellucens Fll. Dol. 17. 20. 1823. O'

- Porphyrops diaphanus Mg. Syst. Beschr. IV. 46. 1. 1824. б’.

" versicolor Mg. Syst. Beschr. IV. 50. 9. 1824. ․

" diaphanus Macq. Dipt. du Nord de Fr. 29. 1. 1827. $0^{\text {T. }}$

, versicolor Macq. Dipt. du Nord de Fr. 31. 5. 1827. ㅇ.

- Argyra diaphana Macq. Suit. à Buff. I. 456. 1. 1834. రㅇ․

- Dolichopus diaphanus Ztt. Dipt. Scand. II. 587. 76. 1843. O’

- Argyra diaphana Wlk. Ins. Br. Dipt. I. 208. 2. 1851. бㅇ.

- Porphyrops hirtipes Curtis. Brit. Entom. 541. 1a. 1862 . б’.

- Argyra diaphana Schin. Fauna austr. I. 190. 1862. రㅇ․

రౌ. Gesicht und Stirn schwarz, bräunlichgrau schimmernd; Fühler etwas länger als der Kopf, das erste Glied etwa halb so lang als die beiden Endglieder zusammengenommen; Fühlerborste länger als die Fühler; Cilien am hinteren Augenrande schwarz, bisweilen fahlgelb oder weisslich schimmernd. Thoraxrücken und Schildchen dunkel metallisch grün oder blaugrün; ersterer an den Schultern weiss schimmernd, zwischen der Mittellinie und den gewöhnlichen Borstenreihen mit den Anfängen je einer dunklen Längsstrieme; zwischen je einer dieser beiden gewöhnlichen Borstenreihen und dem Seitenrande, so wie die Oberseite des Schildchens auffallend behaart; die Borsten am Prothorax schwarz und lang. Flügel glashell oder blassbräunlich gefärbt, erste Längsader kurz vor oder auf der Mitte der Randader mündend; Deckschüppchen gelb, mit breit schwarzem Rande und schwarzen Wimpern. Hüften schwarz, grau schimmernd; Schenkel schwarz, die Spitze der vorderen Schenkel, bisweilen auch die Basis der Hinterschenkel, die Schienen und die Metatarsen der vorderen Beine rostgelb, die Basis und Spitze der Hinterschienen, die Tarsen der vorderen Beine von der Spitze des ersten Gliedes an und die Tarsen der Hinterbeine schwarz oder braun; die Behaarung der Schenkel lang und dicht; die Schienen auf der Oberseite mit vier bis sechs stärkeren, die Mittelschienen überdiess auf der Unterseite mit drei bis vier schwächeren Borstenpaaren; die Wimperung der vorderen Schienen auf der Unterseite und der Hinterschienen auf der Vorder- und Hinterseite ziemlich deutlich; der Metatarsus der Vorderbeine auf der Unterseite der ganzen Länge nach beborstet; der Metatarsus der Hinterbeine etwas länger als das folgende Tarsenglied. Hinterleib dunkel metallischgrün, vom Hinterrande des ersten Ringes an silberschimmernd, an den Seiten des zweiten, oder des zweiten und dritten Ruinges mit gelben, durchscheinenden Flecken; die äusseren Analanhänge des Hypopygiums schwarzbraun, mässig lang und schmal, die inneren braun oder gelb, länglich oval.

Q. Fühler kürzer als der Kopf, das erste Glied fast so lang, als die beiden Endglieder zusammengenommen. Der vordere Theil des Thoraxrückens an den Seiten grau bereift, auf der Mitte striemenartig metallisch glänzend; die Behaarung neben den gewöhnlichen Borstenreihen und dem Seitenrande, 
so wie die auf der Oberseite des Schildehens ziemlich kurz, aber deutlich. Beine gelb, nur die Vorderschenkel auf der Oberseite von der Basis her oft bis in die Nähe der Spitze und die Hinterschenkel au der Spitze schwarz; häufig sind auch die Mittelschenkel an der Basis verdunkelt. Hinterleib am Vorderrande der Ringe mit weisslichem Schimmer, welcher an den Seiten des zweiten bis vierten und am fünften Ringe deutlicher erscheint; der zweite Ring an den Seiten ohne gelbe Flecken.

Vaterland: Ganz Europa vom Mai bis August häufig.

4. Arg. Hoffimeisteri Lw. $\sigma^{\nearrow}$ ㅇ. Seta antennis parum longiore, coxis femoribusque nigris.

б. Thoracis dorso aeneo-viridi, abdomine in lateribus segmenti secundi immaculato.

Long. corp. 6-8 mm. (Fig. 13).

Syn. Rhaphium Hoffimeisteri Lw. Stett. entom. Zeitschr. 92. 1. 1850. ठ'.

- Argyra Hoffmeisteri Lw. Neue Beitr. V. 38. 1857. ㅇ.

" $\quad$ Schin. Fauna austr. I. 189. 1862. రㅇ.

\%". Gesicht "und Stirn schwarz, bräunlichgrau schimmernd; Fühler etwas länger als der Kopf, das erste Glied etwas länger als die Hälfte der beiden Endglieder zusammengenommen, Fühlerborste etwas länger oder nur so lang als die Fühler; Cilien am hinteren Augenrande schwarz, braun schimmernd. Thoraxrücken und Schildchen dunkel metallisch grün, blaugrün oder blau; ersterer an den Schultern weiss schimmernd, zwischen der Mittellinie und den beiden gewöhnlichen Borstenreihen mit den Anfängen je einer duuklen Längsstrieme; zwischen je einer dieser beiden gewöhnlichen Borstenreihen und dem Seitenrande so wie die Oberseite des Schildchens auffallend behaart; die Borsten am Prothorax schwarz und lang. Flügel blassbräunlich gefärbt; erste Längsader auf oder nahe vor der Mitte der Randader mündend; Deckschüppehen gelb, breit schwarz gerandet und schwarz gewimpert. Hüften schwarz, grau schimmernd; Schenkel schwarz, die Spitze der vorderen Schenkel, die Schienen und die Metatarsen der vor-leren Beine gelb, die Basis und Spitze der hinteren Schienen, die Tarsen der vorderen Beine von der Spitze des ersten Gliedes an und die Tarsen der Hinterbeine schwarz oder braun; bisweilen sind auch die Mittelschienen und Tarsen ganz schwarzbraun, die Behaarung der Schenkel lang und dicht; ausser der Beborstung der Schienen auf der Oberseite sind auch die Vorderschienen so wie der Metatarsus der Vorderbeine auf der Unterseite der ganzen Länge nach wimperartig beborstet, die Mittelschienen ebenda mit drei oder vier schwachen Borstenpaaren versehen und die Hinterschienen längs der Vorder- und Hinterseite gewimpert; Metatarsus der Hinterbeine etwas länger als das folgende Tarsenglied. Hinterleib dunkel metallischgrün oder blau, vom Hinterrande des ersten Ringes an silberschimmernd; die äusseren Analanhänge des Hypopygiums schwarz und länglich, die inneren schwarz oder braun und zugespitzt.

ㅇ․ Fühler kürzer als der Kopf, das erste Glied fast so lang, als die beiden Endglieder zusammengenommen. Der vordere Theil des Thoraxrückens 
weisslich bestäubt, auf der Mitte und läugs den beiden gewöhnlichen Borste nreihen striemenartig metallisch glänzend; die Behaarung zwischen den gewöhnlichen Borstenreihen und dem Seitenrande, so wie die des Schildchens kurz aber deutlich. Hinterleib metallisch grün oder bronzegelb, am Vorderrande der Ringe mit weisslichem Schimmer, der an den Seiten der vorderen und am letzten Ringe deutlicher erscheint.

Vaterland: Dornbach bei Wien (Schiner); Alt-Sandec (Grzegorzek) und das südöstliche Galizien (Nowicki), Görz in österr. Küstenlande im Mai (Mik). Ich sammelte die Art bei Losoncz und Herkulesbad in Ungarn, bei Bad Liebenstein in Thüringen und bei Hoym im Herzogthum Anhalt im Mai und Juni häufig. Cassel (Loew).

Anmerkung. Arg. Hoffimeisteri gleicht der Arg. diaphana sehr, unterscheidet sich aber von dieser im männlichen Geschlechte durch die wimperartige Beborstung auf der Unterseite der Vorderschienen, durch das Fehlen der gelben Flecke an den Seiten des zweiten Hinterleibsringes und durch die Gestalt der inneren Analanhänge; ich habe sie mit dem typischen Exemplare verglichen.

5. Arg. Loewii n. sp. $\sigma^{7}$. Seta antennis longiore, thoracis dorso aeneo-viridi, femoribus posticis flavis in apice nigris, abdomine in lateribus segmenti secundi immaculato.

Long. corp. $65-7 \mathrm{~mm}$. (Fig. 14).

ऽ. Stirn und das verhältnissmässig breite Gesicht weisslichgrau; Fühler fast so lang als der Kopf, das erste Glied etwas länger als die Hälfte der beiden Endglieder zusammengenommen, Fühlerborste länger als die Fühler. Taster verhältnissmässig gross, grau schimmernd; Cilien am hinteren Augenrande weisslich. Thoraxrücken und Schildchen metallischgrün, ersterer an den Schultern weiss schimmernd, am vorderen Theile zwischen der Mittellinie und den beiden gewöhnlichen Borstenreihen mit den Anfängen je einer dunklen Längsstrieme, zwischen je einer dieser Borstenreihen und dem Seitenrande mit kurzer, die Oberseite des Schildchens mit etwas längerer Behaarung; Borsten am Prothorax schwarz und lang. Flügel blassbräunlich gefärbt; erste Längsader auf oder nahe vor der Mitte der Randader mündend; Deckschüppchen gelb, breit schwarz gerandet und schwarz gewimpert. Hüften schwarz, weisslichgrau schimmernd; Beine gelb, nur die Vorderschenkel mit Ausnahme der Spitze, die Mittelschenkel besonders auf der Oberseite von der Basis her oft bis in die Nähe der Spitze die Hinterschenkel an der Spitze und die Tarsen der Hinterbeine schwarz, die Hinterschienen an der Basis und Spitze und die Tarsen der vorderen Beine von der Spitze des ersten Gliedes an braun; die Behaarung der Schenkel verhältnissmässig kurz; ausser der Beborstung auf der Oberseite sind die Vorderschienen auf der Unterseite mit wimperartigen kurzen Börstchen, die Mittelschienen ebenda mit drei oder vier ziemlich kurzen Borstenpaaren versehen, und die Hinterschienen auf der Vorder- und Hinterseite der ganzen Länge nach kurz gewimpert; der Metatarsus der Vorderbeine längs der Unterseite wimperartig beborstet, Metatarsus der Hinterbeine wenig länger als das folgende Tarsenglied. Hinterleib metallischgrïn, bronzegelb oder bronzebraun; die ersten 
vier Ringe weisslich bereift, der fünfte und sechste Ring silberschimmernd; die äusseren Analanhänge des Hypopygiums schwarz und schmal, die inneren gelbbraun und länglich oval.

Vaterland: Die Art kommt im Juni und Juli bei Egex und Komotau in Böhmen vor, wo ich sie nicht selten traf.

Anmerknng. Arg. Loewii sieht in der allgemeinen Körperfärbung dem Weibchen von Arg. diaphana F. nicht unähnlich, woran sie auch der breiten, grau schimmernden Taster wegen gemahnt; sie bildet mit Arg. setimana Lw., diaphana F. und Hoffmeisteri Lw. eine eigene Verwandtschaftsgrnppe, zu welcher man auch Arg. magnicornis Ztt. bringen kann, wenn man auf die Behaarung des Schildchens nnd anf die langel schwarzen Borsten am Prothorax Rücksicht nimint. - Ich widme diese sehr interessante nene Art meinem Meister und Gönner Herrn Professor Dr. H. Loew als ein Zeichen meiner Achtung und Dankbarkeit.

\section{Scutellum supra non pilosum.}

6. Arg. Leucocephala Mg. $\sigma^{7}$ ㅇ․ Antennis capite brevioribus, coxis posticis nigris, metatarso postico quam articulus secundus plerumque breviore.

o. Thoracis dorso argenteo induto.

․ Abdomine in lateribus segmenti secundi flavo maculato.

Long. corp. $4.5-8.5 \mathrm{~mm}$.

Syn. Dolichopus diaphanus Fll. Dol. 16. 19. 1823. ठౌ. p.

- Porphyrops diaphanus Mg. Syst. Beschr. IV. 46. 1. 1824. 오.

- $\quad$ leucocephahus Mg. Syst. Beschr. IV. 49. 8. 1824. ‥

- $\quad$ diaphanus Macq. Dipt. du Nord de Fr. 29. 1. 1827. 오.

- $\quad$ fulgens Hal. Zool. Journ. V. 354. 9. 1835. ठ".

- Dolichopus pellucens Ztt. Ins. Lapp. 712. 18. 1840.

- $\quad$ leucocephalus Ztt. Dipt. Scand. II. 589. 77. 1843. $\sigma^{\top}$ 오.

- Argyra leucocephala Wlk. Ins. Br. Dipt. I. 208. 3. 1851. ठㅇ․

- $" \quad$ Schin. Fauna austr. I. 191. 1862. $\sigma^{\top} Q$.

c". Gesicht "und Stirn schwarz, weisslich schimmernd; Fühler kürzer als der Kopf, das erste Glied kürzer als die beiden Endglieder zusammengenommen, Füblerborste wenigstens doppelt so lang als die Fübler; Cilien am hinteren Augenrànde weisslich. Thoraxrücken und Schildchen metallischgrün, ersterer am vorderen Theile bis über die Mitte hinaus silberschimmernd, zwischen der Mittellinie und den beiden gewöhnlichen Borstenreihen mit den Anfängen je einer mehr oder weniger deutlichen Längsstrieme; die Behaarung der Mittellinie lang, die Oberseite des Schildchens unbehaart; die Börstchen am Prothorax haarartig, ziemlich lang und weisslich. Flügel blass bräunlichgelb gefärbt, erste Längsader fast auf der Mitte der Randader mündend; Deckschüppchen gelb, schwarz gerandet, und schwarz gewimpert. Hüften entweder ganz schwarz, oder nur die Vorderhüften an der Spitze und Hinterseite mehr oder weniger ausgebreitet gelb und so wie die hinteren Hüften weisslichgrau schimmernd; Beine 
entweder vorherrschend gelb und nur die vorderen Schenkel an der Basis, die Hinterschenkel und Hinterschienen an der Spitze, die Tarsen der vorderen Beine von der Spitze des ersten Gliedes an und die Hintertarsen schwarz oder auch die Schenkel schwarz und nur die vorderen an der Spitze gelb; die Beharrung der Schenkel ziemlich lang und mässig dicht; ausser der Beborstung auf der Oberseite der Schienen sind die Mittelschienen auf der Unterseite mit drei oder vier Borstenpaaren versehen und die Hinterschienen anf der Ober- und Unterseite ziemlich dentlich gewimpert; die Börstchen längs der Unterseite des Metatarsus der Vorderbeine äusserst kurz, der Metatarsus der Hinterbeine nur wenig kürzer als das folgende Tarsenglied. Hinterleib vom Hinterrande des ersten Ringes an silberschimmernd, die Seiten des zweiten, dritten und oft auch des vierten Ringes durchscheinend gelb, die äusseren Analanhänge des Hypopygiums sehr klein, braun oder schwärzlich, die inneren gelblich, länglich und am Ende zugerundet.

Q. Fühler fast nur halb so lang, als der Kopf, das erste Glied nur wenig kürzer als die beiden Endglieder zusammengenommen. Der vordere Theil des Theraxrückens mit Ausnabme der Mitte dünn weisslich bereift; Wimpern der Deckschüppchen schwarz, braun schimmernd. Vorderhüften und Schenkel in der Regel ganz gelb, nur bisweilen die Spitze der Hinterschenkel schwarz oder braun. Hinterleib metallischgrün oder bronzebraun, weisslichgrau schimmernd, an den Seiten des zweiten, bisweilen auch des dritten Ringes mit je einem mehr oder weniger deutlichen gelben Flecke, der auch die Bauchseite dieser Ringe einzunehmen pflegt.

Vaterland: Ganz Europa vom Mai bis September häufig.

A nmerkung. Um das Weibchen der Arg. lencocephala von dem ihm sehr ähnlichen Weibchen der Arg. argyria Mg. zu unterscheiden, lese man das in der Anmerkung der folgenden Art Gesagte. - Das typische Weibchen von Arg. leucocephala in der Winthem'schen Sammlung (auch mit Porph. eximius bezeichnet) entspricht der hier gegebenen Beschreibung; die unter demselben Namen vorkommenden Weibchen in der Wiedemann'schen Sammlung dagegen gehören wahrscheinlich zu Arg. argyria.

7. Arg. aryyria Mg. $\sigma^{\top} Q$. Coxis posticis nigris, metatarso postico quam articulus secundus breviore.

5. Anternis saltem longitudine capitis, seta antennis plerumque longiore, thoracis dorso argenteo induto.

‥ Antennis capite brevioribus, abdomine in lateribus segmenti secundi plerumque immaculato.

Long. corp. $45-6 \mathrm{~mm}$.

Syn. Dolichopus diaphanus Fll. Dol. 16. 19. 1823. o'. p.

- Porphyrops argyrius Mg. Syst. Beschr. IV. 46. 2. 1824. ठ".

? Dolichopus vividus Mg. Syst. Beschr. IV. 100. 48. 1824. 우

- Porphyrops argyrius Macq. Dipt. du Nord de Fr. 29. 2. 1827. 万’.

- Argyra argentata Macq. Suit. à Buff. I. 457. 2. 1834. $\sigma^{7}$.

- Dolichopus argentatus Ztt. Dipt. Scand. II. 590. 78. 1843. $\sigma^{7}$. 
Syn. Dolichopus argentellus 7tt. Dipt. Scand. H. 592. 80. 1843. ठౌ.

- Argyra argentata Wlk. Ins. Br. Dipt. I. 209. 4. 1851. б'.

- Dolichopus argentatus Ztt. Dipt. Scand. XI. 4297. 78. 1852. ㅇ․

- Argyra argentata Lw. Nene Beitr. VI. 20. 2. 1859.

Schin. Fauna austr. I. 191. 1862. $\sigma^{\top}$

$\sigma^{\prime \prime}$. Gesicht" und Stirn weiss; Fühler so lang oder nur wenig länger als der Kopf, das erste Glied etwa halb so lang als die beiden Endglieder zusammongenommen, Füllerborste so lang, meistens aber länger als die Fühler; Cilien am hinteren Augenrande weisslich. Thoraxrücken und Schildchen metallisclıgrün, ersterer mit Ausuahme des Raumes unuittelbar vor dem Schildchen silberschimmernd, zwischen der Mittellinie und den beiden gewöhnlichen Borstenreihen mit den Anfängen je einer mehr oder weniger deutlichen dunklen Längsstrieme; die Behaarung der Mittellinie lang; Schildehen auf der Oberseite unbehaart; die Börstchen am Prothorax weisslich, ziemlich kurz und haarartig. Flügel blass gelbbräunlich gefärbt, die erste Längsader auf oder ganz nahe vor dex Mitte der Randader mündend; Deckschïppchen gelb, schwarz gerandet und unit schwarzen oder brauuen, bisweilen fahlgelb schimmerndon Wimperı. Hüften schwarz, grau schimmernd, die Vorderhüften an der Spitze und Hinterseite oft gelb; Beine gelb und entweder nur die Spitze der Hintersclienkel und der Hinterschienen, die Tarsen der vorderen Beine von der Spitze des ersten oder zweiten Gliedes an und die Tarsen der. Hinterbeine schwarz oder braun, oder es sind auch die vorderen Schenkel besenders auf der Oberseite von der Basis her bis in die Nähe der Spitze und die Hinterschenkel von dieser dunkeln Farbe; die Behaarung der vorderen Schenkel mässig dicht aber ziemlich lang, die der Hinterschenkel verhältnissmässig kurz; ausser der Beborstung auf der Oberseite der Schienen sind die Mittelschienen auf der Unterseite mit zwei oder drei einfachen oder parigen Borsten versehen; die Wimperung der Hinterschienen nicht auffallend, die Börstchen auf der Unterseite des Metatarsus der Vorderbeine äusserst kurz; Metatarsus der Hinterbeine fast so lang als das folgende Tarsenglied. Hiuterleib vom Hinterrande des ersten Ringes an silberschimmernd, an den Seiten des zweiten und dritten, oft auch des vierten Ringes mit gelben durchscheinenden Flecken; Hypopygium und die Analanhänge sehr klein, die äusseren braun, die inneren meist verborgen, gelb oder braun und stumpf.

f. Fühler kürzer als der Kopf, das erste Glied wenig kürzer als die beiden Endglieder zusammengenommen. Der vordere Theil des Thoraxrïckens längs den beiden gewöhnlichen Borstenreihen weisslich bereift. Wimpern der Deckschüppchen branı oder fahlgelb. Vorderhüften entweder gelb und nur an der Basis schwarz oder fast ganz schwarz; Beine gelb, nur die Spitze der Hiuterschenkel meistens schwarz oder braun. Hinterleib metallischgrün oder bronzebraun, weisslichgrau sclimmernd, an den Seiten und am Bauche des zweiten Ringes meistens ohne gelben Fleck.

Vaterland: Ganz Furopa, vom Mai bis August: die Art ist häufig.

A nmerkung. Arg. argyria unterscheidet sich vou der vorigen Art im männlichen Geschlechte leicht durch die Fühler, welche mindestens so lang 
als der Kopf sind, und durch das lebhaft weisse Gesicht; schwieriger steht es mit der Unterscheidung der Weibchen beider Arten, die sich ausserordentlich ähnlich sehen; das Weibchen der ersteren erkennt man hauptsächlich an den in der Regel hellen Wimpern der Deckschüppchen, ferner auch an der meist schwarzen Spitze der Hinterschenkel und an dem hänfigen Mangel der gelben Flecke an den Seiten des zweiten Hinterleibsringes; auch pflegt bei ihm die Bereifung des Thoraxrückens eine dichtere zu sein, als diess bei Arg. leucoeephala der Fall ist; bei denjenigen Weibchen der Arg. argyria mit gauz gelben Hinterschenkeln ist ausser der hellen Farbe der Wimper'n an den Deckschüppchen die nur geringe Ausdehnung der meist undeutlichen gelben Flecke an den Seiten des zweiten Hinterleibsringes das noch am sichersten zutreffende Unterscheidungsmerkmal. - Ich halte die Wiedereinführung des älteren M eige nschen Namens anstatt des neueren Macqart'schen für berechtigt. - Die Beschreibung, welche Meigen l. c. von Dol. vividus gibt, passt zwar vollständig auf das Weibchen von Arg. argyria, ob jedoch die hieraus gefolgerte Synonymie richtig ist, muss erst die Type Meigen's beweisen. - Schiner hat meines Erachtens Arg. argentella Ztt. irrthümlich als Synonym zu Arg. argentina Mg. gestellt, denn Zetterstedt sagt 1. c. in der Diagnose bei Dol. argentellus: "antennis longitudine capitis transversi $\left(\sigma^{\top}\right)$, seta antenua nonnihil longiore" und bei Dol argentinus: "Antennis capite transverso dimidio longioribus ( $\left.\sigma^{\top}\right)$ ". Ich war in meinem Entschlusse, die Artrechte von Arg. argentella Ztt. anzuerkennen, lange schwankend gewesen, zumal die Mehrzahl der Exemplare, die ich besitze, sich durch verhältnissmässig kürzere Fühler und längere Fühlerborste (argentella Ztt.) ziemlich auffallend von jenen mit längeren Fühlern und kürzerer Fühlerborste (argentata ap. Ztt.) unterscheidet; da ich jedoch in die Lage kam, anch die Uebergänge von der einen Form zur auderen constatiren zu können, so nehme ich keinen Anstand mehr, die erstere Form nur als eine Varietät der letzteren anzusehen. - Das Weibchen, welches Macquart als Porph. argyrius beschreibt, gehört sehr wahrscheinlich nicht zu dieser Art.

8. Arg. argentina Mg. $\sigma^{\top} \bigcirc$. Metatarso postico quam articulus seeundus plerumque breviore.

$\sigma^{\top}$. Antennis capite longioribus, seta antennis breviore, thoracis dorso argenteo-induto.

․ Antennis capite brevioribus, coxis posticis saltem in apice flavis, abdomine in lateribus segmenti secundi semper flavo-maeulato.

Long. corp. $4-5 \mathrm{~mm}$.

Syn. ? Musca semiargentata $\left.{ }^{1}\right)$ Don. Nat. history of Brit. Ins. IV. 92. 1794. O'. pl. 142. f. 2. und 3.

- Dolichopus diaphanus Fll. Dol. 16. 19. 1823. o7. p.

- Porphyrops argentinus Mg. Syst. Beschr. IV. 47. 3. 1824. $\sigma^{-7}$.

— ? " geniculatus Schumm. Arb. und Veränd. d. schles. Ges. 86. 4. 1836. $\sigma^{\prime}$. 
Syn. Dolichopus argentinus Ztt. Dipt. Scaud. II. 591. 79. 1843. $\sigma^{\top} \mathrm{Q}$.

- Argyra argentina Wlk. Ins. Br. Dipt. I. 209. 5. 1851. ठ'

Schin. Fauna austr. I. 190. 1862. $\sigma^{\top}$ ㅇ.

$\sigma$. Gesicht und Stirn weiss; Fühler auffallend länger als der Kopf, das erste Glied etwa halb so lang als die beiden Endglieder zusammengenommen, Fühlerborste kürzer als die Fühler; Cilien am hinteren Augenrande weiss. Thoraxrücken silberschimmernd, nur der Raum unmittelbar vor dem Schildchen und dieses selbst metallischgrün; die Behaarung der Mittellinie mässig lang; Oberseite des Schildchens unbehaart; die Börstchen am Prothorax weisslich, ziemlich kurz und haarartig. Flügel blassbräunlich gefärbt, die erste Längsader nahe vor der Mitte der Randader mündend; Deckschüppchen gelb, mit schmalem schwarzem Rande und meist fahlgelben Wimpern. Vorderhüften gelb, an der Basis bisweilen schwärzlich, die hinteren Hüften schwarz, doch an der Spitze in grösserer oder geringerer Ausdehnung gelb; Beine gelb, höchstens die Spitze der Hinterschenkel und der Hinterschienen, die Tarsen der vorderen Beine von der Spitze des ersten oder zweiten Gliedes an und die Tarsen der Hinterbeine braun oder schwarz; die Behaarung der vorderen Schenkel mässig lang und schütter, die der Hinterschenkel kürzer und etwas dichter; ausser der Beborstung auf der Oberseite der Schienen sind die Mittelschienen auf der Unterseite meist mit drei längeren und zwei kürzeren, einzelnen oder paarigen Borsten versehen, die Wimperung der Hinterschienen nicht auffallend; die Börstchen auf der Unterseite des Metatarsus der Vorderbeine äusserst kurz, der Metatarsus der Hinterbeine so lang oder nur wenig kürzer als das folgende Tarsenglied. Hinterleib vom Hinterrande des ersten Ringes an silberschimmernd, an den Seiten des zweiten und dritten, oft auch des vierten Ringes mit gelben, durchscheinenden Flecken; die äusseren Analanhänge des Hypopygiums klein, schwarz oder braun, die inneren bräunlichgelb und stumpf.

$\sigma^{7}$. Fühler fast so lang als der Kopf, das erste Glied etwas kürzer als die beiden Endglieder zusammengenommen, Borste länger als die Fühler. Der vordere Theil des Thoraxrückens längs den beiden gewöhnlichen Borstenreiken weisslich bereift. Hinterleib metallischgrün, weisslich schimmernd, an den Seiten und an Bauche des zweiten, bisweilen auch des dritten Ringes gelb.

Vaterland: Oesterreich-Ungarn, Deutschland, Niederlande (Van der Wulp), Dänemark, Scandinavien und England.

Anmerkung: Arg. argentina ist constant kleiner als jede der beiden vorhergehenden Arten und unterscheidet sich von diesen im männlichen Geschlechte durch die erheblich längeren Fühler und durch die kürzere Fühlerborste; das Weibchen unterscheidet sich von dem Weibchen der Arg. leucocephala durch helle Wimpern an den Deckschüppchen und durch mindest an der Spitze gelbe Hinterhüften und von dem Weibchen der Arg. argyria ausser durch das letztgenannte Merkmal noch durch die wenigstens an den Seiten des zweiten Hinterleibsringes befindlichen gelben Flecken und durch die in der Regel ganz gelben Hinterschenkel. - Ich habe Walker folgend Musca semiargentata Don. als synonym zu Arg. argentina gestellt, ob mit Recht lässt 
sich aus der Donovan'schen Beschreibung allein nicht nachweisen; diese Beschreibung, welche ich der Gefälligkeit des Herrn Dr. Alb. G ü n ther, Director an britischen Museum in London, verdanke, lautet: "Musca semiargentata. Eyes brown. Thorax green; changeable to silver. Abdomen silvery, with shades of bright jellow, and grey, and some transverse streaks of black, very changeable.

9. Arg. confinis Ztt. $\sigma^{\top} \uparrow$. Thorace aeneo-viridi, metatarso postico quam articulus secundus longiore.

5. Metatarso postico pilis longis instructo, abdomine argenteo induto.

9. Antennis capite brevioribus, coxis posticis saltem in apice flavis.

Long. corp. 4-6.5 mm. (Fig. 19).

Syn.? Porphyrops flaviventris Macq. Dipt du Nord de Fr. 32. 7. 1827. ㅇ.

— ? Argyra flaviventris Macq. Suit. à Buff. I. 458. 6. 1834. ㅇ.

- Dolichopus confinis Ztt. Dipt. Scand. VIII. 3090. 77-78. 1819. O’ $Q$.

- Argyra confinis Wlk. Ins. Br. Dipt. I. 208. 1. 1851. бㅇ.

- $" \quad$ Schin. Fauna austr. I. 190. 1862. O’ 9 .

$0^{7}$. Gesicht und Stirn schwarz, in schiefer Richtung besehen weiss schimmernd; Fühler etwas länger als der Kopf, das erste Glied etwa laalb so lang als die beiden Endglieder zusammengenommen; Fühlerborste länger als die Fühler; Cilien am hinteren Augenrande braun; fahlgelb oder weiss. Thoraxrücken und Schildchen metallischgrün oder blaugrün, Schultern und Seitenrand des ersteren weiss schimmernd; die Behaarung der Mittellinie mässig lang, die Oberseite des Schildchens unbehart; die Börstchen am Prothorax undeutlich. Flügel blass bräunlichgelb gefärbt, die erste Längsader auf der Mitte der Randader mündend; Deckschüppchen gelb, mit schmalem schwarzem Rande und mit schwarzen oder braunen, fahlgelb schimmernden Wimpern. Hüften schwarz, an der Spitze gelb, grau schimmernd; Beine gelb, die Hinterschenkel und Hinterschienen an der Spitze, die vorderen Schenkel bisweilen unten an der Basis schwarz oder braun; dic Tarsen der vorderen Beine gelb und nur das Endglied schwarz, oder schon von der Spitze des zweiten Gliedes an allmälig verdunkelt; die Tarsen der Hinterbeine entweder ganz schwarz oder braun und an der Basis in grösserer oder geringerer Ausdelınung gelb; die Behaarung der Schenkel ziemlich lang und ziemlich dicht, gegen die Spitze der Hinterschenkel hin fast borstenartig; ausser der Beborstung der Schienen auf der Oberseite sind die Vorderschienen auf der Unterseite änsserst kurz gewimpert, die Mittelschienen ebenda mit drei bis vier bisweilen parigen Borsten und die Hinterschienen der ganzen Länge nach mit auffallender Wimperung versehen, welche auf der Oberseite aus einer kurzen und steifen, auf der Unterseite aber aus einer etwas längeren, weicheren und mehr geordneten Beharung besteht; Metatarsus der Vorderbeine längs der Unterseite dentlich beborstet, der Metatarsus der Hinterbeine fast doppelt so lang als das folgende Tarsenglied, auf der Vorder- und Unterseite mit verhältnissmässig langen, auf der Hinterseite mit kürzeren aber mehr borstenartigen Haaren der Länge nach bekleidet und überdiess unterseits an der Basis mit einer auffullend langen aufgerichteten 
Haarborste versehen; die ïbrigen Tarsenglieder der Hinterbeine sind längs der Vorderseite, das zweite Glied auch noch längs der Hinterseite kurz gewimpert. Hinterleib vom Hinterrande des ersten Ringes an silberschimmernd, an den Seiten des zweiten, oft auch des ersten und dritten Ringes durchscheinend gelb; die äusseren Analanhänge des Hypnpygiums bräunlichgelb, von mässiger Länge und schmal.

Q. Fiihler etwas kuirzer als der Kopf, das erste Glied so lang als die beiden Endglieder zusammengenommen. Der Metathorax von der Basis der Hinterhüften bis zur Basis des Hinterleibes, die Vorder- und Hinterhüften und die Beine gelb, Metatarsus der Hinterbeine ohne anffallende Behaarung. Hinterleib metallischgrïn, weisslichgrau schimmernd, an den Seiten und am Bauche des ersten, zweiten und bisweilen auch des dritten Ringes gelb.

Vaterland: Arg. confinis ist in Oesterreich-Ungarn, Dentschland, Dänemark, England, Italien und der Schweiz zwar sehr verbreitet, aber bisher nicht häufig angetroffen worden; sie fliegt während der Zeit vom Juni bis August.

Anmerkung. Z etterstedt und W alker bezeichnen die Deckschüppchen "ganz gelb“, was bei den von mir untersuchten Exemplaren nicht der Fall ist.

10. Arg. auricollis Mg. $\sigma^{\top} 0$. Thoracis dorso aeneo-viridi, coxis posticis nigris, metatarso postico quam articulus secundus longiore et pilis longis destituto.

ธ. Abdomine argenteo induto.

ㅇ. Antennis capite fere brevioribus.

Long. corp. $5-5.5 \mathrm{~mm}$.

Syn. Porphyrops auricollis Mg. Syst. Beschr. IV. 47. 4. 1824. $\sigma^{7}$.

- Dolichopus auricollis Ztt. Dipt. Scand. II. 596. 84. 1843. б' $\sigma^{\top}$.

- Argyra auricollis Schin. Fauna austr. I. 191. 1862. O’.

$\sigma^{7}$. Gesicht und Stirn schwarz, in schiefer Richtung besehen weiss schimmernd; Fühler fast ein und einhalbmal so lang als der Kopf, das erste Glied etrwas länger als die Hälfte der beiden Endglieder zusammengenommen, Fühlerborste kürzer als die Fühler; Cilien am hinteren Augenrande schwarz. Thoraxrücken und Schildchen metallischgrün oder blaugrün, die Schultern und der Seitenrand des ersteren weisslich schimmernd; die Behaarung der Mittellinie lang, die Oberseite des Schildchens unbehaart; die Börstchen am Protherax undeutlich. Flügel braun, die Randzelle intensiver gefärbt, die erste Längsader nahe vor der Mitte der Randader mündend; Deckschüppchen ganz schwarz oder gelb mit breitem schwarzem Rande und schwarzen Wimpern. Hüften schwarz, grau schimmernd; Beine schwarz, die Spitze der vorderen Schenkel, die vorderen Schienen und die Basis der vorderen Metatarsen gelb; die Behaarung der Schenkel lang und ziemlich dicht; ansser der Beborstung der Schienen auf der Oberseite sind die Mittelsehienen auch auf der Unterseite mit drei bis vier einzelnen oder paarigen Borsten versehen und die Hinterschienen der ganzen Länge nach gewimpert; diese Wimperung besteht auf der Oberseite aus mässig langer, ziemlich schiitterer, fast borstenartiger, auf der Unterseite aus kürzerer, zarterer und ziemlich dicht gereihter Behaarung; der Metatarsus der Vorderbeine 
längs der Unterseite fein aber deutlich beborstet, der Metatarsus der Hinterbeine auffallend länger als das folgende Tarsenglied und längs seiner Hinterseite mit kurzer Wimperung bekleidet. Hinterleib dunkel metallischgrün oder blangrün, vom Hinterrande des ersten Ringes an silberschimmernd; die Analanhänge des Hypopygiums schwarz, die äusseren schmal, die inneren am Ende abgerundet.

ㅇ. Fühler kürzer als der Kopf, das erste Glied so lang als die beiden Endglieder zusammengenommen, Fühlerborste länger als die Fühler. Die Spitze der Vorderhüften zuweilen gelb; auch die Beine gelb, nur die Spitze der Hinterschenkel und Hinterscbienen schwarz, nicht selten auf der Oberseite der vorderen Schenkel nahe vor der Spitze ein brauner verwasehener Fleck. Hinterleib dunkel erzgrün, besonders an den Seiten weisslichgrau schimmernd.

Vaterland: Oesterreich, Dentschland, Scandinavien und Italien im Juli und Angust stellenweise bäufig.

11. Arg. atriceps Lw. $\sigma^{7}$. Facie nigra, thoracis dorso et abdomine aeneo-viridibus, hoc parum exalbido micante, metatarso postico quam articulus secundus longiore.

Long. corp. $5 \mathrm{~mm}$.

Syn. Argyra atriceps Lw. Nene Beitr. V. 38. 1857. $0^{\pi}$

” incompta Gerst. Stett. entom. Zeitschr. 145. 1. 1864. $\sigma^{7}$.

б. Gesicht und Stirn schwarz, in schräger Richtung besehen grau schimmernd; Fühler etwas länger als der Kopf, das erste Glied etwa so lang als die Hälfte der beiden Endglieder zusammengenommen, Fühlerborste nur wenig länger als die Fühler; Cilien am hinteren Angenrande weisslich oder braun, in der Nähe des Mundrandes meistens schwarz. Thoraxrücken und Schildchen metallischgrün oder dunkelblaugrün, wohl auch bronzebraun, ersterer an den Schultern und am Seitenrande weiss schimmernd; die Behaarung der Mittellinie lang, die Börstchen am Prothorax undeutlich, die Oberseite des Schildchens unbehaart. Flügel sehr blass bräunlichgran gefärbt; die erste Längsader nahe vor der Mitte der Randader mündend; Deckschüppchen gelb, mit schmalem schwarzem Rande und braunen oder schwarzen Wimpern. Hüften schwarz, grau schimmernd, die vorderen an der Spitze bisweilen gelb; Beine gelb, die vorderen Schenkel jedoch von der Basis her bis in die Nähe der Spitze, die Hinterschenkel und Hinterschienen an der Spitze schwarz; die Tarsen der vorderen Beine gelb und nur das Endglied schwarz, oder von der Spitze des ersten Gliedes an braun, die Hintertarsen ganz schwarz; die Behaarung der Schenkel verhältnissmässig lang und an den vorderen Schenkeln ziemlich dicht; ausser der Beborstung der Schienen auf der Oberseite sind die Mittelschienen auf der. Unterseite mit zwei oder drei einzelnen oder paarigen Borsten versehen und die Hinterschienen auf der Ober- und Unterseite der ganzen Länge nach auffallend gewimpert, der Metatarsus der Vorderbeine längs der Unterseite zart aber deutlich beborstet, der Metatarsus der Hinterbeine länger als das folgende Tarsenglied und sammt den folgenden Tarsengliedern längs der Vorder- und Hinterseite mit kurzer Wimperung bekleidet, welche jedoch auf der Hinterseite von der Spitze des zweiten Gliedes an undeutlich erscheint. Hinterleib dunkel 
metallischgrün, ohne eigentlichen Silberschimmer, aber mit einem dünnen weisslichen Reife überzogen, der die Grundfarbe auf der Mitte des Hinterleibes nur als eine schmale Längsstrieme freilässt und bei sehr schräger Betrachtungsweise einen weisslichgrauen Schimmer zeigt, Hypopygium ausser der gewöhnlichen'Behaarung mit zwei längeren Börstchen versehen ; die äusseren Analanhänge braun, kurz und schmal.

Vaterland: Die Art ist bisher nur selten gefunden worden; Herr Dr. Grzegorzek fing sie in der Gegend von Alt-Sandec in Galizien, Professor Mik bei Linz in Oberösterreich, ich selbst bei Bozen in Tirol, bei Losoncz in Ungarn und im Harze; Herr Dr. A. Gerstäcker bei Reuth in Baiern; sie fliegt vom Mai bis August.

Amerkung. Ich habe Arg. atriceps mit dem typischen Exemplare in der Sammlung des Herrn Dr. H. Loew verglichen.

12. Arg. spoliata n. sp. ㅇ. Facie alba, thoracis dorso et abdomine aeneo-viridibus, metatarso postico quam articulus secundus longiore.

Long. corp. $5 \mathrm{~mm}$.

6. Gesicht und Stirn weiss; Fühler kaum so lang als der Kopf, das erste Glied etwa halb so lang als die beiden Endglieder zusammengenommen, Fühlerborste nahezu doppelt so lang als die Fühler; Cilien am hinteren Augenrande weiss. Thoraxrücken und Schildchen metallischgrün, ersterer zwischen je einer der gewöhnlichen Borstenreihen und dem Seitenrande ein wenig grau bereift, an den Schultern weisslich schimmernd; die Behaarung der Mittellinio mässig lang, die Börstchen am Prothorax undeutlich, die Oberseite des Schildchens unbehaart. Flügel blass bräunlichgelb gefärbt, die erste Längsader vor der Mitte der Randader mündend; Deckschüppchen gelb, mit schwarzem Rande und braunen, fahlgelb schimmernden Wimpern. Die Vorderhüften gelb, die hinteren schwarz, an der Spitze gelb, alle grau schimmernd; Beine gelb, nur die Tarsen von der Spitze des ersten Gliedes an braun; die Behaarung der vorderen Schenkel mässig lang und ziemlich schütter, die der Hinterschenkel kurz und nur gegen die S'chenkelspitze hin allmälig etwas länger; die Schienen auf der Oberseite mit drei bis vier Borstenpaaren, die Mittelschienen überdiess auf der Unterseite mit drei einzelnen Börstchen; die Vorderschienen und der Metatarsus der Vorderbeine auf der Unterseite, die Hinterschienen auf der Ober- und Hinterseite der ganzen Länge nach, jedoch keineswegs auffallend gewimpert; der Metatarsus der Hinterbeine deutlich länger als das folgende Tarsenglied und sammt diesem längs der Hinterseite kurz gewimpert. Hinterleib dunkel metallischgrün, sehr dünn weisslichgrau bereift und an den Seiten des zweiten und dritten Ringes mit gelben Flecken; die äusseren Analanhänge des Hypopygiums klein und schmal, an der Basis gelb, gegen die Spitze hin schwarz; der noch vorstehende Theil der inneren Anhänge gelb und rundlich.

Vaterland: Ich entdeckte diese sehr seltene Art am 28. Juni 1869 bei Marienbad in Böhmen in der sogenannten Waldschlucht. 
Anmerkung. Arg. spoliata bildet mit Arg. confinis, auricollis und atriceps eine eigene Verwandtschaftsgruppe, die sich einerseits wegen des Mangels einer Behaarung auf der Oberseite des Schildchens and andererseits wegen der Länge des Metatarsus der Hinterbeine gut begrenzen liesse; von Arg. atriceps, der die obige Art am nächsten steht, unterscheidet sie sich durch die Kürze der Fühler, welche fast so wie bei dem Männchen von Arg. leucocephala gestaltet sind, durch das weisse Gesicht und durch die beinahe ganz gelben Beine; ein weiterer Unterschied liegt anch in der Form der Vorderrandzelle, welche bei Arg. spoliata von der Randader gerade, bei Arg. tariceps dagegen bogig abgeschlossen erscheint.

13. Arg. elongatia Ztt. $\sigma^{\top}$ ㅇ. Antennis capite longioribus, thoracis dorso et abdomine aeneo-viridibus, metatarso postico quam articulus secundus breviore.

\section{○. Tibiis posticis distincte setosis.}

Long. corp. 4-4.5 mm. (Fig. 20, 21).

Syn. Dolichopus elongatus Ztt. Dipt. Scand. II. 594. 82. 1843. $\sigma^{\top}$ O

- Argyra elongata Wlk. Ins. Br. Dipt. I. 209. 7. 1851. $0^{\top}$. .

6. Gesicht und Stirn weiss, letztere metallisch schimmernd; Fühler fast doppelt so lang als der Kopf, das erste Glied so lang als die beiden Endglieder zusammengenommen, Fühlerborste kürzer als die Fühler; Cilien am hinteren Augenrande weiss. Thoraxrücken und Schildchen metallischgrün, blaugrün oder bronzebraun, ersterer an den Schultern weisslich schimmernd, die Behaarung der Mittellinie mässig lang; die Börstehen am Prothorax zart, die Oberseite des Schildchens unbehaart. Flügel blassbräunlich gefärbt, die erste Längsader weit vor der Mitte der Randader mündend, der letzte Abschnitt der vierten Längsader sehr wenig geschwungen; Deckschüppchen gelb, mit schmalem schwarzem Rande und schwarzen Wimpern. Hüften und Beine gelb, die Mittel- und oft auch die Hinterhüften an der Basis mehr oder weniger ausgebreitet grau, die Hinterschienen an der Spitze schwarz, bisweilen auch die Spitze der Hinterschenkel obenauf in nur geringer Ausdehnung, dann die Tarsen der vorderen Beine von der Spitze des ersten Gliedes an und die Tarsen der Hinterbeine schwarz oder braun; die Behaarung der Schenkel weder besonders lang noch dicht und höchstens an den Mittelschenkeln und in der Nähe der Spitze der Hinterschenkel auffallend, die Präapicalborste der hinteren Schenkel deutlich; ausser der Beborstung auf der Oberseite der vorderen Schienen befinden sich auf der Unterseite der Vorderschienen ein bis zwei einfache, auf der der Mittelschienen zwei bis drei einfache oder paarige, auf der der Hinterschienen vier bis sechs einzelne Börstchen; die Beborstung auf der Oberseite der Hinterschienen besteht in der Regel aus fünf verhältnissmässig kräftigen Borstenpaaren; der Metatarsus der Vorderbeine längs der Unterseite mit kurzen, zarten Börstchen versehen; der Metatarsus der Hinterbeine etwas kürzer als das folgende Tarsenglied und sammt diesen wie die Hinterschienen längs der Hinterseite kurz gewimpert. Hinterleib dunkel metallischgrün, äusserst dünn bereift und nur am Vorderrande der Ringe sehr schmal weisslich schimmernd, an den Seiten und am Bauche 
des zweiten oder des zweiten und dritten Ringes mit gelben, durchscheinenden, in ihrer Ausdehnung sehr verschiedenen Vorderrandsflecken oder Binden; Hypopygium mit vier ziemlich langen Borsten, die äussereu Analanhänge schwarzbraun, klein und schmal, die inneren kürzer und breiter.

ㅇ. Fühler ein wenig länger als der Kopf, das erste Glied nahezu so lang als die beiden Eudglieder zusammengenommen, Fühlerborste kaum länger als die Fühler. Hinterleib an den Seiten und am Bauche des zweiten Ringes mit oder ohne gelbe Flecke.

Vaterland: Ich traf die Art bei Asch und Komotau in Böhmen vom Mai bis Juli auf Buschwerk häufig; Scandinavien (Zetterstett) und England (Walker).

Anmerkung. Arg. elongata steht einigermassen fremdartig in der Gattung Argyra und hat in mancher Beziehung eine gewisse Aehulichkeit mit Arg. magnicornis Ztt., insbesonders in der Form der Fühler, unterscheidet sich aber von dieser durch geringere Grösse, durch einen verhältnissmässig noch kleineren Kopf, durch das auf seiner Oberseite unbehaarte Schildchen, durch die Kürze der ersten und geringe Schwingung der vierten Längsader und durch die auffallende Beborstung der Schienen und des Hypopygiums.

14. Arg. greata $\sigma^{\top}$ ㅇ. Thoracis dorso et abdomine aeneo-viridibus metatarso postico quam articulus secundus breviore.

ర. Tibiis posticis confertim ciliatis.

ㅇ. Antennis capite brevioribus, abdomine in lateribus et in ventre segmentorum quatuor anticorum flavo.

Long. corp. 5-5.5 mm. (Fig. 22-25).

Syn.? Medeterus fulviventris Macq. Dipt. du Nord de Fr. 48. 11. 1827. ㅇ.

- $\quad " \quad$ Suit. à Buff. I. 454. 12. 1834. \&.

- Argyra grata Lw. Neue Beitr. V. 39. 1857. $0^{7}$.

- $\quad " \quad$ Schin. Fauna austr. I. 189. 1862. бㅇ.

ऽ". Gesicht und Stirn weiss; Fühler so lang als der Kopf, das erste Glied auf der Oberseite zart behaart, verhältnissmässig dünn, und etwas länger als die Hälfte der beiden Endglieder zusammengenommen, Fühlerborste wenig länger als die Fühler, diese meistens braun, das dritte Glied gelbbraun; Cilien am hinteren Augenrande weiss. Thoraxrücken und Schildchen metallischgrün, ersterer ein wenig grau bereift, an den Schultern weiss schimmernd; die Behaarung der Nlittellinie mässig lang, die Börstchen am Prothorax zart, die Oberseite des Schildchens unbehaart. Flügel blass bräunlichgelb gefärbt, die erste Längsader vor der Mitte der Randader mündend, vierte Längsader wenig geschwungen; Deckschüppchen gelb, mit schwarzem Rande und schwarzen oder braunen, fahlgelb schimmernden Wimpern, Hüften und Beine gelb, die Tarseu von der Spitze des ersten oder zweiten Gliedes an braun, die Behaarung der vorderen Schenkel weder besonders lang noch dicht, dagegen befindet sich auf der Vorderseite der Hinterschenkel eine schüttere Reihe von borstenartigeu Haaren, worunter einige durch ihre Länge ganz besouders auffallend sind; die Börstchen auf der Oberseite der Vorder- und Hinterschienen und auf der 
Unterseite der Mittelschienen zart, die Hinterschienen auf der Aussen-, Hinterund Unterseite der ganzen Länge nach dicht gewimpert; von diesen Wimperreihen ist die der Aussenseite die anffallendere: der Metatarsus der Vorderbeine auf der Unterseite kurz und zart beborstet, der Metatarsus der Hinterbeine nnd das nächste Tarsenglied nahezu von gleicher Länge. Hinterleib dunkel metallischgrün, mit dünnem weisslichem Reife überzogen, an den Seiten des zweiten, dritten und sehr oft auch noch des ersten und vierten Ringes mit gelben, durchscbeinenden Vorderrandsflecken, welche auch die Bauchseite dieser Ringe einnehmen; Hypopyginm mit zwei mässig langen Borsten; die äusseren Analanhänge breit, dreieckig, gelblich, die inneren schwärzlich griffelartig, gegen das Ende hin ein wenig erweitert.

‥ Fühler meist schwarz, kürzer als der Kopf, das erste Glied so lang als die beiden Endglieder zusammengenommen, die Fühlerborste viel länger als die Fühler. Hinterleib ohne dentlichen weissen Schimmer, an den Seiten des ersten bis vierten Ringes mit gelben Vorderrandsflecken, der Bauch mit Ausnahme des letzten Ringes gelb.

Vaterland: Oesterreich-Ungarn, Deutschland und, wenn obige Synonymie richtig ist, auch Frankreich vom Mai bis August im Allgemeinen ziemlich selten.

Anmerkung. Arg. grata habe ich mit dem typischen Exemplare verglichen. - Von Arg. elongata Ztt. unterscheidet sich Arg. grata in beiden Geschlechtern durch die kürzeren Fühler; im männlichen Geschlechte durch die langen Borstenhaare an den Hinterschenkeln, durch die viel zartere Beborstung der Schienen, durch die. Wimperung der Hinterschienen und durch die Form der äusseren Analanhänge; das Weibchen unterscheidet sich von allen Arten leicht durch den gelben und nur am letzten Hinterleibsringe schwarzen Bauch.

\section{Leucostola.}

Die Merkmale der Gattung Leucostola Lw. stimmen im Allgemeinen mit denjenigen der Gattung Argyra überein; sie unterscheidet sich von dieser durch das auf seiner Oberseite unbehaarte erste Fühlerglied und durch das Vorhandensein von nur einer einzelnen oder höchstens einem Borstenpaare auf der Unterseite in der Nähe der Spitze der Mittelschienen. Die Beschreibung der einzigen bis jetzt bekannten emropäischen Art lautet:

1. L. vestita Wied. $\sigma^{\top}$. . Antennarum articulo primo superne nudo, thoracis dorso aeneo-viridi, metatarso postico quam articulus secundus breviore.

$0^{T}$. Abdomine argenteo-induto.

ㅇ. Antennis capite brevioribus, coxis posticis nigris, abdomine obscure aeneo, immaculato.

Long. corp. 4-4.5 mm. (Fig. 26).

Syn. Dolichopus vestitus Wied. Zool. Mag. I. 75. 24. 1818. $\sigma^{7}$.

Fll. Dol. 17. 21. 1823. ठ".

- Porphyrops vestitus Mg. Syst. Beschr. IV. 48. 5. 1824. $\sigma^{7}$.

- $" \quad$ Meq. Dipt. du Nord de Fr. 30. 3. 1827. ठ". 
Syn. Argyra vestita Macq. Suit. à Buff. I. 457. 3. 1834. O".

- Dolichopus vestitus Ztt. Ins. Lapp. 713. 20.1840. O' .

- Argyra vestita "Wlk. Ins. Br. Dipt. 209. 6. 1851. $\sigma^{\top}$ \%

- Leucostola vestita Lw. Neue Beitr. V. 39. 1857. ठㅇ.

- Argyra vestita Schin. Fauna austr. I. 189. 1862. $\sigma^{\top}$ ㅇ.

$\sigma^{7}$. Gesicht und Stirn weiss; Fühler nahezu ein- und einhalbmal so lang às der Kopf, das erste Glied fast dreimal kürzer als die beiden Endglieder zusammengenommen, das dritte Glied verhältnissmässig gross; die Fühlerborste kürzer als die Fühler; Cilien am hinteren Augenrande weiss. Thoraxrücken und Schildchen metallischgrün; Schultern und Brustseiten weiss schimmernd; die.Behaarung der Mittellinie mässig lang, die Börstchen am Prothorax zart, die Oberseite des Schildchens unbehaart. Flügel glashell, die erste Längsader nahe vor oder auf der Mitte der Randader mündend; Deckschüppchen gelb, mit schwarzem Rande und schwarzen oder braunen, hellschimmernden Wimpern. Hüften schwarz, grau schimmernd, die Vorderhüften an der Spitze bisweilen gelb; Beine entweder gauz gelb oder - was meistens der Fall ist - die Vorderschenkel von der Basis her gegen die Spitze hin in grösserer, die Mittelschienen ebenda in geringerer Ausdehnung, die Hinterschenkel und Hinterschienen an der Spitze, die vorderen Tarsen von der Spitze des ersten Gliedes an und die Hintertarsen meist ganz schwarz oder braun; bisweilen sind auch die Vorderschienen an der Spitze und die Hinterschienen fast ganz braun; die Behaarung der Schenkel mässig dicht, die der hinteren Schenkel in der Nähe der Spitze ziemlich lang und borstenartig die Vorderschienen auf der Oberseite in der Regel nur mit je einem Börstehen in der Nähe der Basis und der Spitze, die Mittelschienen ausser den Borsten auf der Oberseite nur mit einem einzelnen Börstchen oder einem Borstenpaar auf der Unterseite in der Nähe der Spitze, die Hinterschienen ausser den Borsten auf der Oberseite längs der Vorderseite deutlich, längs der Hinterseite minder deutlich gewimpert; die Börstchen auf der Unterseite des Metatarsus der Vorderbeine äusserst kurz, der Metatarsus der Hinterbeine kürzer als das folgende Tarsenglied. Hinterleib ziemlich flach, am ersten Ringe dunkel metallischgrün, am zweiten bis fünften Ringe silberschimmernd, der letzte Ring schwarz; Hypopygiun meist mit vier längeren Börstchen, die äusseren Analanhänge schwarz, kurz und rundlich, die inneren etwas länger, bräunlich und griffelartig erscheinend; hänfig treten auch die tiefer gelegenen Copulationsorgane hervor.

․ Gesicht und Stirn weiss, letztere gegen den Scheitel hin bisweilen metallischgrün schimmernd; Fühler kürzer als der Kopf, das erste Glied kürzer als die beiden Endglieder zusammengenommen, Fühlerborste viel länger als die Fühler. Die Vorderhüften an der Spitze, die vorderen Schenkel und Hinterschienen meistens ganz gelb. Hinterleib dunkel metallischgrün oder bronzebraun, ohne deutlichen weisslichen Schimmer.

Vaterland: Oesterreich-Ungaru, Deutschland, Dänemark, Scandinavien, England and Frankreich vom Juli bis August stelleuweise häufig. 
Anmerkung. Porph. vestitus der Wiedemann'schen und der Winthemschen, desgleichell eine Meigen'sche Type der Sturm'schen Sammlung, welche sich gegenwärtig im Besitze des Herrn von Röder in Hoym befindet, stimmen mit obiger Beschreibung überein.

\section{A $\mathrm{n}$ h a $\mathrm{n}$ g.}

1. Porph. fulvipes Q. Macq. Dipt. du Nord de Fr. 31: 6. 1827. Macquart beschreibt die Art wie folgt: „Femelle: d'un vert doré. Trompe et palpes noirs. Partie inférieure de l'épistome grise, convexe; partie supérieure bronzée. Front d'un bleu d'acier. Antennes noires; style biarticule. Pieds fauves; derniers articles des tarses obscurs, Balanciers fauves. Ailes obscures, surtont au bord extérieur. Long. 2 1." Die Angabe, dass die Stirn stahlblau sei, lässt mich unter Porph. fulvipes keine Argyra vermuthen.

2. Porph. spinipes q. Mg. Syst. Beschr. VI. 363. 31. 1830. - Nach der Beschreibung Meigen's hat diese Art eine glänzend schwarze Stirn; dieses Merkmal macht es zweifelhaft, ob Porph. spinipes zu Argyra gehört; die Meigen'sche Beschreibung lautet: „Dunkel metallischgrün; Schildchen gleichfarbig; Stirne und Beine schwarz. Weibchen: Fühler schwarz, so lang als der Kopf; Borste dicht vor der Spitze eingesetzt; Taster schwarz; Untergesicht breit, weiss; Stirne glänzend schwarz. Brustseiten blaulichgrau; Hinterleib mit weissschillernden Seiten. Schwinger weiss; Flügel graulich. Beine schwarz, die-Schienen schimmeru ins Röthliche und sind mit langen Seitenborsten besetzt. - $2 \frac{1}{4}$ Linien".

3. Porph. scutellatus Q. Mg. Syst. Beschr. VI. 364. 33. 1830. - Ich halte diese Art für das Weibchen von Meigen's Raphium longicorne.

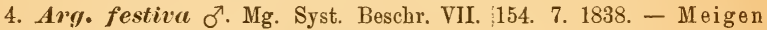
beschreibt die Art folgenderweise: "Männchen: Untergesicht und Stirne schwarz. Rückenschild und Schildchen glänzend metallischschwarz. Die vier vorderen Ringe des Hinterleibes silberblau, ohne durchscheinende Flecken, von der Seite gesehen blaulichgrau, am Vorderrande des dritten und vierten Ringes ein weisses Bändchen; die übrigen Ringe schwärzlich. Beine gelb; Flügel glashell. Baiern. - 2 Linien“. In der Diagnose bezeichnet Meigen den "Hinterleib silberglänzend mit schwarzem After". Mir ist keine Art bekannt, auf welche diese Beschreibung bezogen werden könnte; unter den Arten mit schwarzem Gesicht, mit metallisch glänzendem Thoraxrücken, mit vorherrschend gelb gefärbten Beinen und ungefleckten Hinterleib wäre nur Arg. atriceps Lw. diejenige, welche Meigen gemeint haben könnte; dieser Annahme widerspricht aber die metallischgrüne Färbung des Thoraxrückens, die schwarze Spitze der Hinterschenkel und der durchaus nicht "silberglänzende" oder "silberblaue" sondern metallischgrïne und nur weisslichgran bereifte Hinterleib von Arg. atriceps. Arg. festiva ist meines Wissens nicht wieder aufgefunden worden. 


\section{Arten- und Synonymen-Register.}

1. Argyra magnicornis Ztt. .

Seite aristata Gerst.

2. - setimana Lw. Schin. . . . . . . . . . . . . . . 443

3. - diaphana F. Mg. Macq. Ztt. Wlk. Schin. pellucens Fll.

versicolor Mg. Macq.

hirtipes Curtis.

4. - Hoffmeisteri Lw. Schin. . . . . . . . . . . 445

5. - Loewii n. sp. . . . . . . . . . . . . . . . 446

6. - leucocephala Mg. Ztt. Wlk. Schin. . . . . . . . 447 diaphana Fll. p. Mg. Macq.

fulgens Hal.

pellucens Ztt.

7. - argyria Mg. Macq. . . . . . . . . . . . . . . 448 diaphana Fll. p.

vivida Mg. ?

argentata Macq. Ztt. WIk. Lw. Schin.

argentella $\mathrm{Ztt}$.

8. - argentina Mg. Ztt. Wlk. Schin. . . . . . . . . 450 semiargentata (semiargentella) Don. ?

diaphana Fll. p.

geniculata Schumm. ?

9. - confinis Ztt. Wlk. Schin. . . . . . . . . . . 452 flaviventris Macq. ?

10. - auricollis Mg. Ztt. Schin. . . . . . . . . . . 453

11. - atriceps Lw.. . . . . . . . . . . . . . . . . 454

incompta Gerst.

12. - spoliata n. sp................ 455

13. - elongata Ztt. Wlk. . . . . . . . . . . 456

14. -- grata Lw. Schin. . . . . . . . . . . . . . 457

fulviventris Macq. ?

1. Leucostola vestita Wied. Fll. Mg. Macq. Ztt. Wlk. Lw. Schin. .

458

\section{A n h a n g.}

1. Porphyrops fulvipes Nacq.

2. - spinipes $\mathrm{Mg}$.

3. - scutellatus Mg.

4. Argyra festiva $\mathrm{Mg}$. 


\section{Erklärung der Tafel.}

Fig. 1. Argyra diaphana F. ठ․ sammt Grösse.

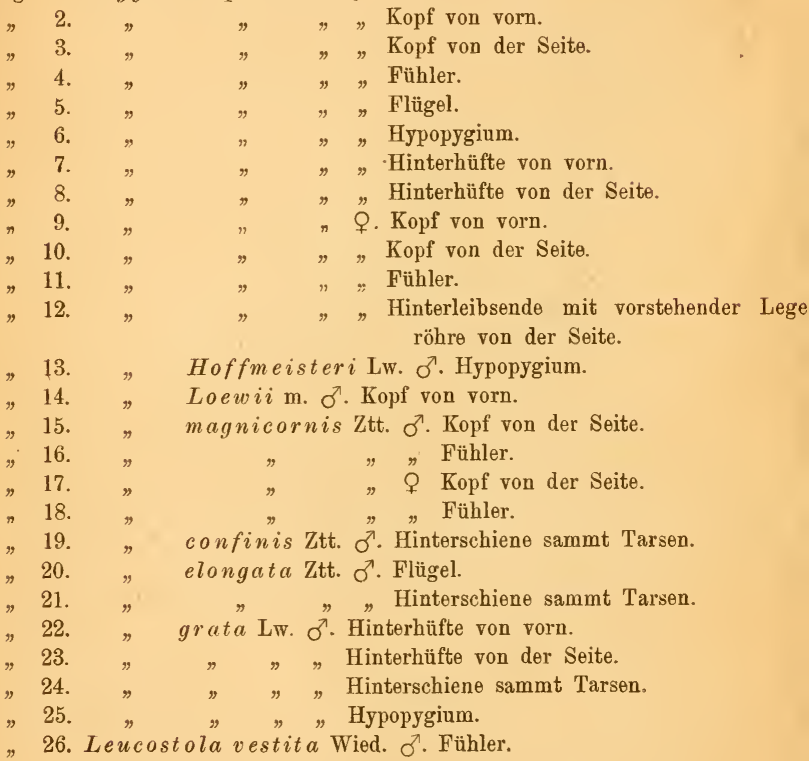


Verhardl.d.k.k:zool.bot.Ges.

Band XXITI 1878.
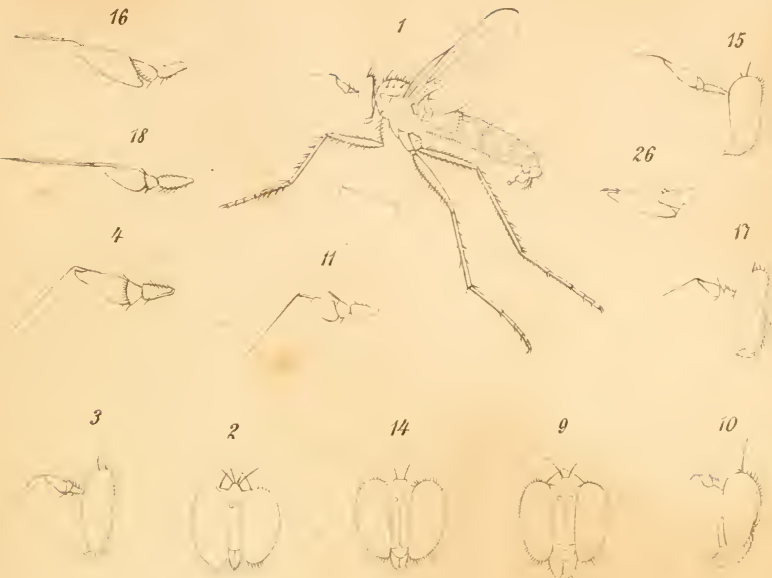

14
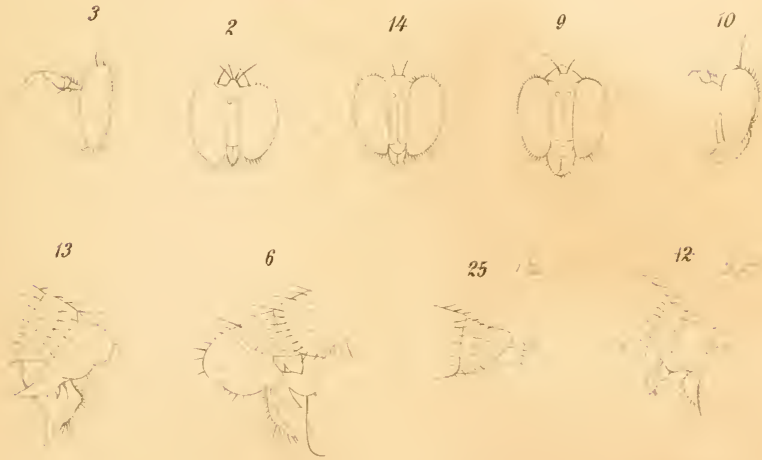

12.

5

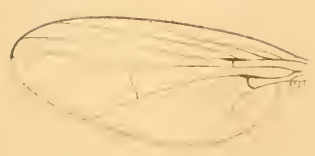

20

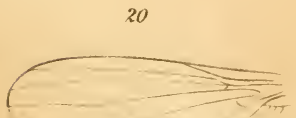





QL Kowarz, Ferdinand.

531 Papers on Diptera

K89

Ent.

cL

531

K89

Ent. 


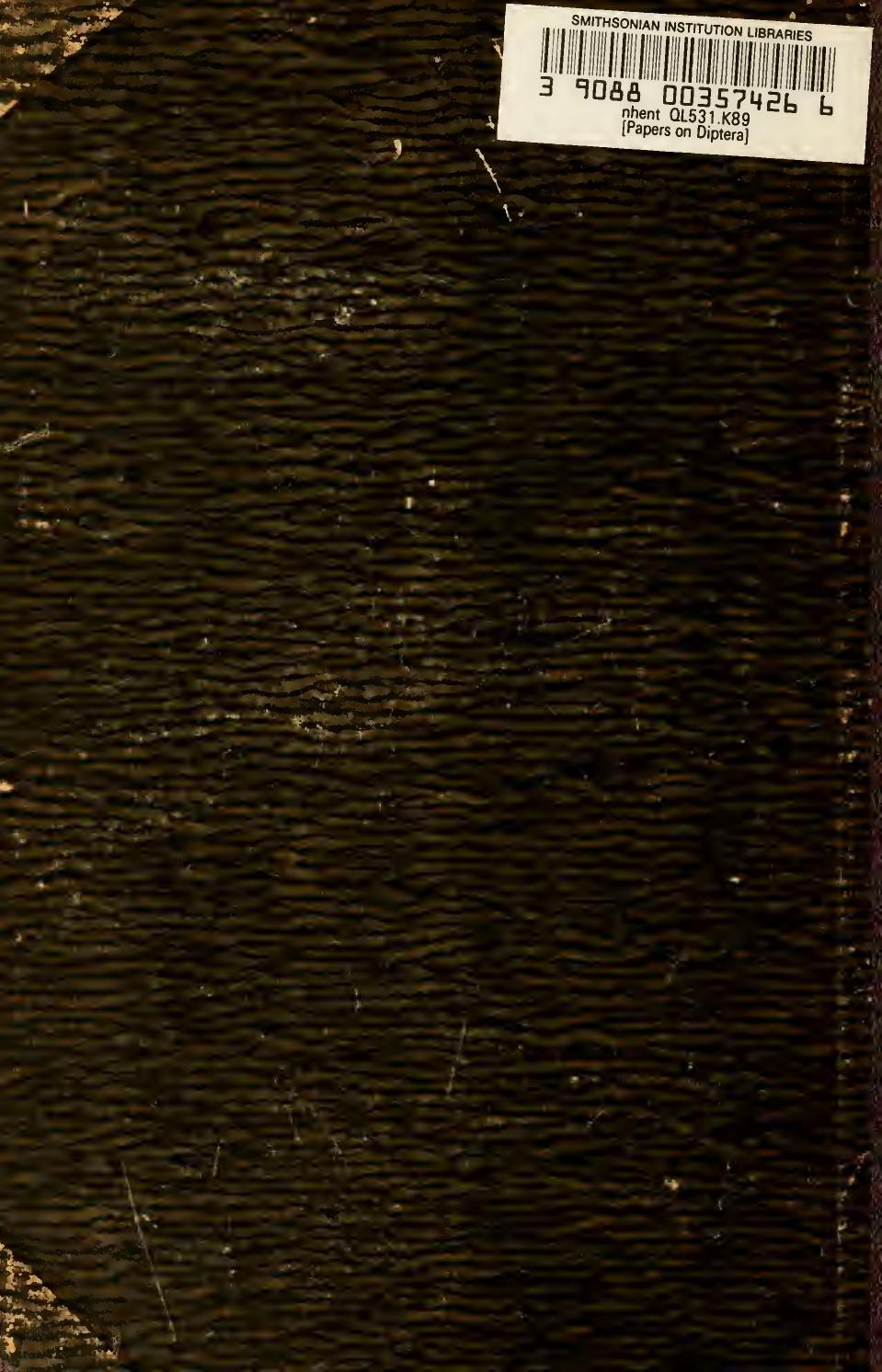

